\title{
MODELING CONVECTION IN THE GREENLAND SEA
}

by

\section{Vikas Bhushan}

M.Sc. University of British Columbia, Vancouver, Canada

(1995)

B.Sc. University of Toronto, Toronto, Canada

(1992)

Submitted in partial fulfillment of the

requirements for the degree of

Master of Science

at the

MASSACHUSETTS INSTITUTE OF TECHNOLOGY

and the

\section{WOODS HOLE OCEANOGRAPHIC INSTITUTION}

September 1998

(C) Vikas Bhushan 1998

The author hereby grants to MIT and to WHOI permission to reproduce and to distribute copies of this thesis document in whole or in part.

Signature of Author

Joint Program in Physical Oceanography

Massachusetts Institute of Technology

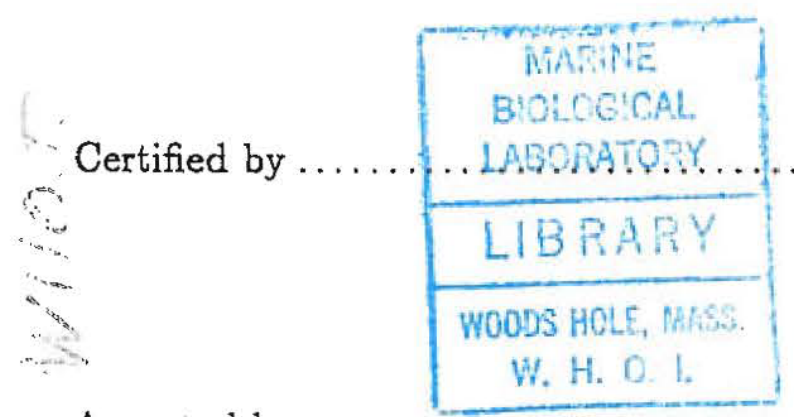

Woods Hole Oceanographic Institution

Angust 6. 1998

Accepted by

Jochem Marotzke

Associate Professor of Physical Oceanography

Thesis Supervisor

W. Brechner Owens

Chairman, Joint Committee for Physical Oceanography

Massachusetts Institute of Technology

Woods Hole Oceanographic Institution 


\title{
MODELING CONVECTION IN THE GREENLAND SEA.
}

\author{
by \\ Vikas Bhushan \\ Submitted in partial fulfillment of the requirements for the degree of \\ Master of Science at the Massachusetts Institute of Technology \\ and the Woods Hole Oceanographic Institution \\ August 6, 1998
}

\begin{abstract}
A detailed examination of the development of a deep convection event observed in the Greenland Sea in 1988-89 is carried out through a combination of modeling, scale estimates, and data analysis. We develop a prognostic one-dimensional mixed layer model which is coupled to a thermodynamic ice model. Our model contains a representation of the lowest order boundary layer dynamics and adjustable coupling strengths between the mixed layer, ice, and atmosphere. We find that the model evolution is not very sensitive to the strength of the coupling between the ice and the mixed layer sufficiently far away from the limits of zero and infinite coupling; we interpret this result in physical terms. Further, we derive an analytical expression which provides a scale estimate of the rate of salinification of the mixed layer during the ice-covered preconditioning period as a function of the rate of ice advection. We also derive an estimate for the rate of the mixed layer deepening which includes ice effects. Based on these scale estimates and model simulations, we confirm that brine rejection and advection of ice out of the convection area were essential ingredients during the preconditioning process. We also demonstrate that an observed rise in the air temperature starting in late December 1988 followed by a period of moderately cold $\approx-10^{\circ} \mathrm{C}$ temperatures was key to the development of the observed convection event. Finally, we show that haline driven deep convection underneath an ice cover is possible, but unlikely to occur in the Greenland Sea. On the basis of these results, we develop a coherent picture of the evolution of the convection process which is more detailed than that presented in any previous work. We also comment on the likelihood that deep convection occurred in the Greenland Sea in the past two decades from an examination of historical data, and relate these findings to what is known about the inter-annual variability of convective activity in the Greenland Sea.
\end{abstract}

Thesis Supervisor: Jochem Marotzke,

Title: Associate Professor of Physical Oceanography 


\section{Acknowledgements}

I would like to thank my advisor, Jochem Marotzke, for his patience, guidance and support, and for the opportunity to work on this project. I am also thankful to Jim Price, Breck Owens, and Dave Chapman, the other members of my thesis defense committee, for their helpful advice and support, and for taking the time to read my thesis.

Thanks are due to Charmaine King for kindly extracting NCEP data for me, and to Rich Pawlowicz for generously making available the results of his tomographic inversion and for providing me with hydrographic data.

A special word of thanks goes out to my peers in P.O. I would like to thank in particular: Misha, the other regular on the nightshift, for many interesting discussions and for helping me with some of the finer points of LaTeX and Maple; Christophe for the food for thought and constant encouragement that he gave me; Brian, for being a willing listener when I wanted to think out loud; and my officemate Alex for always being willing to lend a helping hand.

I would also like to thank Rachel for cheering me on to help me get through those moments when the task ahead seemed like nothing less than a job for Hercules.

I am especially grateful to my Mom and Dad, and my brother, for their constant and unfailing support and encouragement. I love you all very dearly.

I received financial support during the course of this work from the MIT Joint Program on the Science and Policy of Global Change through a Global Change Joint Program Fellowship. 


\section{Contents}

$\begin{array}{ll}\text { Abstract } & 3\end{array}$

$\begin{array}{lr}\text { Acknowledgements } & 4\end{array}$

1 Introduction $\quad 16$

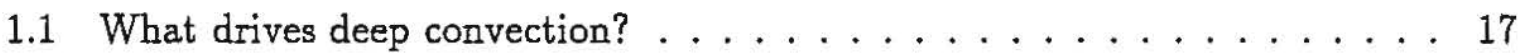

1.2 Characteristics of the Greenland Sea Gyre . . . . . . . . . . . . . 22

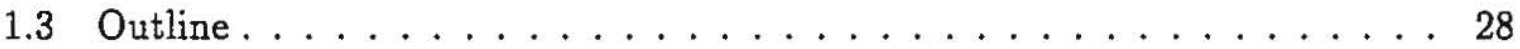

2 Greenland Sea Observations $\quad 30$

2.1 Tomographic Temperature Data . . . . . . . . . . . . . . . . . . 30

2.2 Other Data Used . . . . . . . . . . . . . . . . . . . . 35

3 Mixed Layer Model Formulation, Sensitivity, and Predictions 39

3.1 Model Formulation . . . . . . . . . . . . . . . . . 39

3.1 .1 Parameterizations . . . . . . . . . . . . . . . . . . . 42

3.1 .2 Model Equations . . . . . . . . . . . . . . . . 44

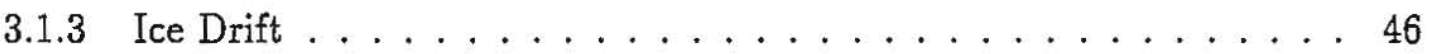


3.1.4 Surface Thermal Forcing . . . . . . . . . . . . 48

3.2 Baseline Run . . . . . . . . . . . . . . . . . . 49

3.2 .1 Model Configuration . . . . . . . . . . . . . . . . 49

3.2 .2 Results . . . . . . . . . . . . . . . . 51

3.2.3 Comparison with Tomographic Observations . . . . . . . . . 54

3.3 Limiting Cases and Model Sensitivity . . . . . . . . . . . . 57

3.3.1 Atmosphere - Ice Coupling . . . . . . . . . . . . . . . . 57

3.3.2 Rapid vs. Insulating Limit . . . . . . . . . . . . . . 59

4 Further Investigation $\quad 63$

4.1 Effect of Ice Drift on Preconditioning . . . . . . . . . . . . . . 64

4.1.1 Standard Formulation $\ldots \ldots \ldots \ldots \ldots 6$

4.1 .2 Alternative Formulation $\ldots \ldots \ldots \ldots \ldots$

4.1 .3 Discussion . . . . . . . . . . . . . . 71

4.2 Comparison with Other 1D Model Studies $\ldots \ldots \ldots \ldots \ldots$

4.3 Can Deep Convection Occur Under Ice? . . . . . . . . . . . . . . . 79

4.3.1 Analytical Scaling Predictions . . . . . . . . . . . . 80

4.3.2 Sensitivity to Surface Conditions $\ldots \ldots \ldots \ldots$

4.4 Limiting the Depth of Convection . . . . . . . . . . . . . . . . 99

4.4.1 Efficiency of Convective Adjustment $\ldots \ldots \ldots \ldots \ldots 9$

4.4 .2 Initial Deep Stratification $\ldots \ldots \ldots \ldots \ldots$

4.4 .3 Lateral Advection . . . . . . . . . . . . . . . . . . . . 102 
4.4.4 Theoretical Considerations . . . . . . . . . . . . . 104

4.5 Inter-Annual Changes in Convective Activity . . . . . . . . . . . 108

5 Summary and Conclusions

5.1 What have we learned about convection that is new? . . . . . . . 116

5.2 Future Directions . . . . . . . . . . . . . . . . 119

A Convective Adjustment Schemes

B Alternative Ice Drift Formulation

C Historical Data

D Optimization

151

Bibliography

155 


\section{List of Figures}

1.1 An idealized schematic of the Nordic Seas and surrounding regions. The major entry and exit routes are represented. The southward flowing East Greenland Current (white lines) transports the cold, fresh water flowing through the Fram Strait along the Greenland coast; much of it exits through the Denmark Strait into the North Atlantic. It also feeds the eastward flowing Jan Mayen Current. The red lines represent relatively warm, salty Atlantic water entering the Nordic Seas at shallow depths and making its way into the interior of the gyre. These two water masses interact and are transformed into Greenland Sea Bottom Water. Water leaves the basin at intermediate depths (blue lines) through both the Denmark Strait and the Faroe Bank Channel. (Figure taken from the World Wide Web site of the European Sub-polar Ocean Programme) . . . . . . . . . . . . . . . 18

1.2 The change in the density of seawater for a given change in salinity is larger close to the freezing point. The ratio of the haline to the thermal expansion coefficient for the Greenland Sea is about $26 \mathrm{~K} / \mathrm{psu}$. Therefore, for typical changes in temperature $\left(\sim 1^{\circ} \mathrm{C}\right)$ and salinity $(\sim 0.1 \mathrm{psu})$, the effect of salinity changes on the density of seawater is greater than the effect of temperature changes. . . . . . . . . . . . . . . 21

1.3 The water masses surrounding the Greenland Sea (from Pawlowicz et al.

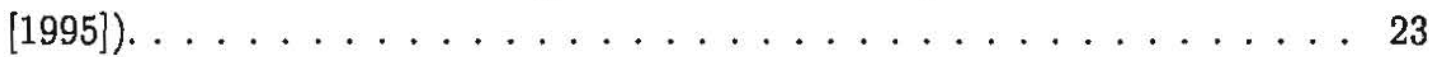

1.4 The surface currents in the Greenland Sea (from Morawitz et al. [1996)]. . 25 
1.5 Evolution of the ice cover in the Greenland Sea in 1988-89, showing the formation of an ice free bay ("Nordbukta") and below it an ice tongue extending to the northeast ("Is Odden") (from Pawlowicz et al. [1995]). . . 27

2.1 The location of the tomographic array during the 1988/89 Greenland Sea Project (from Pawlowicz et al. [1995]) . . . . . . . . . . . . . 31

2.2 Surface conditions and potential temperature from an inversion (Pawlowicz et al. [1995]) of tomographic data. . . . . . . . . . . . . . 32

2.3 The evolution of the potential temperature along the 6-4 path of the tomographic array during 1988/89 derived from an inversion of acoustic data by Pawlowicz et al. [1995]. Estimated uncertainties are about $\pm 0.2^{\circ} \mathrm{C}$ above 400 meters, $\pm 0.05^{\circ} \mathrm{C}$ from 400 to 1200 meters, and $\pm 0.02^{\circ} \mathrm{C}$ at 1500 meters. Starting in mid-February, an apparent temperature inversion develops as the cold surface water convectively mixes down to a depth of around 1500 meters. The convection signal, characterized by this vertical mixing, shows up above the noise level. . . . . . . . . . . . . 33

2.4 Two scenarios representing how an idealized water column could adjust to a surface heat loss when an ice cover is present. The total heat content of the water column in both cases is the same. However, in case (b) the mixed layer is deeper and warmer (closer to the "insulating limit") while in case (a) it is shallower and colder (the "rapid limit") . . . . . . . 36

2.5 A comparison of ECMWF 2-meter, NCEP 2-meter, and NCEP surface air temperatures at location $75^{\circ} \mathrm{N} \times 2.5^{\circ} \mathrm{W} \ldots \ldots \ldots \ldots \ldots \ldots$

3.1 Schematic of the model used in this study. . . . . . . . . . . . . 40

3.2 Potential Temperature and Salinity Evolution for baseline model run. Model parameters for this run are shown in table $3.2 \ldots \ldots \ldots \ldots$. . . . . 52

3.3 Model output for baseline model run. Model parameters for this run are

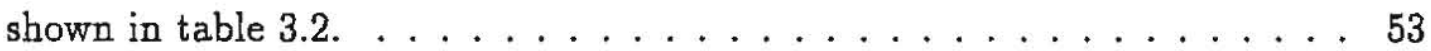


3.4 Comparison between tomographic and model estimated heat content evolution of the water column. The dashed line indicates the model output offset so that it initially matches the tomographic estimate. . . . . . . 56

3.5 The solid line shows the heat flux through ice for a constant $T_{A}-T_{F}=$ $-15^{\circ} \mathrm{C}$, given by $H_{s i}=\frac{k}{h+\frac{k}{\gamma}}\left(T_{A}-T_{F}\right)$. The dashed line shows the hybrid heat flux formulation; this consists of the thick ice limit, given by $H_{s i}=$ $\frac{k}{h}\left(T_{A}-T_{F}\right)$, when $h \geq \frac{k}{\gamma}=4 \mathrm{~cm}$ and of the the thin ice limit, given by $H_{s i}=\gamma\left(T_{A}-T_{F}\right)$, when $0<h<\frac{k}{\gamma}=4 \mathrm{~cm} . \ldots \ldots \ldots \ldots$

3.6 The solid line represents output from the baseline run, which uses a value of $\lambda=0.32 \mathrm{day}^{-1}$. The dashed line represents output from a run using the hybrid heat flux formulation and a value of $\lambda=0.19 \mathrm{day}^{-1}$. The resulting mixed layer evolution in both cases is very similar. However, there are sorne significant differences during the preconditioning period in the heat flux and ice thickness evolution. . . . . . . . . . . . . . 60

3.7 Model output for a series of runs with varying values of $\mu$, the coupling strength between the ice layer and the surface layer of water. . . . . . . . 61

4.1 The latent heat flux is a small fraction of the total surface heat flux in the central Greenland Sea. . . . . . . . . . . . . . . 6 65

4.2 The predicted evolution when there is no ice drift $(\lambda=0)$ and a constant air-sea temperature contrast $T_{A}-T_{F}=-15^{\circ} \mathrm{C}$ of (a) ice thickness and (b) rate of salinity increase during preconditioning. Notice that the ice thickness keeps growing with time while the rate of salinity increase keeps decreasing. . . . . . . . . . . . . . . . . .

4.3 The predicted evolution of (a) ice thickness and (b) rate of salinity increase during preconditioning when there is an ice drift $\left(\lambda=0.32\right.$ day $\left.^{-1}\right)$ and a constant air-sea temperature contrast $T_{A}-T_{F}=-15^{\circ} \mathrm{C}$. Notice that both the ice thickness and the rate of salinity increase reach a steady state. . . . 68 
4.4 The predicted value of (a) ice thickness and (b) rate of salinity increase during preconditioning after 100 days when there is an ice drift $(\lambda \neq 0)$ and a constant air-sea temperature contrast $T_{A}-T_{F}=-15^{\circ} \mathrm{C}$. Notice that the ice thickness decreases with increasing $\lambda$, while the rate of salinity increase becomes larger. . . . . . . . . . . . . . . .

4.5 A comparison between the baseline run in which the ice drift is proportional to $h$ with $\lambda=0.32{d a y^{-1}}^{(s o l i d ~ l i n e) ~ a n d ~ a ~ r u n ~ w i t h ~ a ~ c o n s t a n t ~ i c e ~ d r i f t ~}$ of $\nu=3.5 \mathrm{~cm} /$ day (dashed line). Both runs use the baseline heat flux formulation given by equation (3.13). Both predict almost the same mixed layer evolution. Notice that in the baseline run, the ice formed and ice drift are very similar, reflecting the near steady state conditions during preconditioning. In the constant ice drift run, the average amount of ice formed during the preconditioning roughly balances the ice drift. . . . . .

4.6 A comparison between a run with a constant ice drift of $\nu=3.2 \mathrm{~cm} /$ day (solid line) and a run in which the ice drift is proportional to $h$ with $\lambda=$ 0.19 day $^{-1}$ (dashed line). Both runs use the hybrid heat flux formulation as described in section 3.3. Both predict a very similar mixed layer evolution. During preconditioning, the ice formed and ice drift almost balance each other.

4.7 Model output for a run with no ice $\operatorname{drift}$ ( $\lambda$ was set to zero); otherwise, the setup of this run was identical to the baseline run. . . . . . . . . . . 74

4.8 The potential density (up to 2000 meters) computed using the potential temperature and salinity profiles which initialized the baseline run (figure 3.2). The thick red line is a linear approximation to the stratification $\left(1.2692 \times 10^{-5} \mathrm{~kg} / \mathrm{m}^{4}\right)$ which is used to obtain scale estimates of the mixed layer depth. . . . . . . . . . . . . . . . .

4.9 Model output for a run in which the air temperature remained very cold; otherwise, the setup of this run was identical to the baseline run. . . . . 87

4.10 Model output for a run in which the air temperature remained moderately cold; otherwise, the setup of this run was identical to the baseline run. . . 88 
4.11 Model output for a run in which the air temperature remained warm; otherwise, the setup of this run was identical to the baseline run. . . . . . 89

4.12 The air temperature profiles used for the various model simulations SIM1

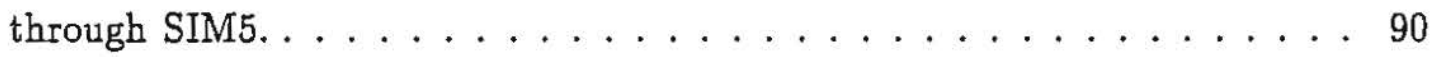

4.13 Model output for run SIM1. There is an intense cold spell in December, and the air temperature then remains very cold. . . . . . . . . . . 91

4.14 Model output for run SIM2. There is an intense cold spell in December, and the air temperature then becomes very warm. . . . . . . . . . 92

4.15 Model output for run SIM3. The air temperature remains relatively very warm. . . . . . . . . . . . . . . . . . . . . 94

4.16 Model output for run SIM4. The air temperature remains moderately cold. 95

4.17 Model output for run SIM5. The air temperature remains very cold. . . . . 96

4.18 Comparison of output from model runs with perturbations in the initial

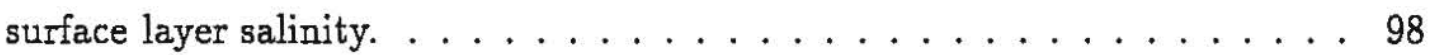

4.19 Potential temperature evolution for two runs carried out using the 2-pass convective adjustment scheme rather than the complete mixing scheme. The initialization and forcing of these runs are identical to the baseline run. 101

4.20 Modifications made to the initial salinity profile between $1000 \mathrm{~m}$ and $2000 \mathrm{~m}$, used to study the impact of the deep salinity stratification on the mixed layer depth. The profile Sdep2 was used in the baseline run. . . . . . . 102

4.21 The mixed layer depth evolution for the different initial salinity profiles shown in figure 4.20. Even a small change in the stratification can have a large effect on the mixing depth. . . . . . . . . . . . 103 
4.22 The buoyancy frequency derived from data taken during the Greenland Sea Tomography Experiment deployment cruise, on Sept. 18, 1988 at $74.5333^{\circ} \mathrm{N} \times 5.7883^{\circ} \mathrm{W}$. The vertical green line indicates the mean deep stratification of $8 \times 10^{-8} \mathrm{~s}^{-2}$. This is the stratification which must be penetrated during the mixed-layer deepening phase of the deep convection

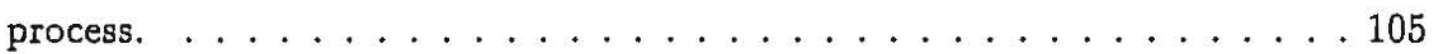

4.23 Daily net heat and freshwater fluxes from the NCEP and ECMWF reanalysis datasets. The horizontal green lines indicate the average surface fluxes of heat $\left(139.5 \mathrm{~W} / \mathrm{m}^{2}\right)$ and freshwater $\left(-1.1 \times 10^{-9} \mathrm{~m} / \mathrm{s}\right)$ out of the ocean during the period of deep mixing. . . . . . . . . 106

4.24 The air temperature and ice concentration in the central Greenland Sea exhibit a great deal of variability. The inter-annual variations in the above plots are suggestive of a decadal oscillation. . . . . . . . . . . 114

5.1 The convection process in the Greenland Sea. . . . . . . . . . . . 120

B.1 The predicted ice thickness evolution when there is an ice drift ( $\nu=$ $3.2 \mathrm{~cm} /$ day $)$ and with a constant air-sea temperature contrast $T_{A}-T_{F}=$ $-15^{\circ} \mathrm{C}$. Notice that the ice thickness reaches a steady state. . . . . . 128

B.2 The predicted ice thickness after 100 days when there is an ice drift $(\nu \neq 0)$ and with a constant air-sea temperature contrast $T_{A}-T_{F}=-15^{\circ} \mathrm{C}$. Notice that the equilibrium ice thickness decreases with increasing $\nu \ldots \ldots 129$

B.3 The predicted change in the rate of salinity increase caused by brine rejection when there is an ice drift $(\nu=3.2 \mathrm{~cm} /$ day $)$ and with a constant air-sea temperature contrast $T_{A}-T_{F}=-15^{\circ} \mathrm{C}$. Notice that it reaches a steady state as does the ice thickness. . . . . . . . . . . 130 
B.4 The predicted change in the rate of salinity increase caused by brine rejection after 100 days when there is an ice drift $(\nu \neq 0)$ and with a constant air-sea temperature contrast $T_{A}-T_{F}=-15^{\circ} \mathrm{C}$. Notice that the rate of salinity increase grows larger with increasing $\nu$. Ice drift has the effect of making the brine rejection more efficient. . . . . . . . . . . . 131

C.1 Surface conditions in the central Greenland Sea gyre for $1979-80 \ldots \ldots$. . . 133

C.2 Surface conditions in the central Greenland Sea gyre for 1980-81. . . . . . 134

C.3 Surface conditions in the central Greenland Sea gyre for 1981-82 . . . . . 135

C.4 Surface conditions in the central Greenland Sea gyre for 1982-83. . . . . . 136

C.5 Surface conditions in the central Greenland Sea gyre for 1983-84 . . . . . 137

C.6 Surface conditions in the central Greenland Sea gyre for $1984-85 \ldots \ldots \ldots 138$

C.7 Surface conditions in the central Greenland Sea gyre for 1985-86. . . . . . . 139

C.8 Surface conditions in the central Greenland Sea gyre for $1986-87 . \ldots \ldots \ldots 140$

C.9 Surface conditions in the central Greenland Sea gyre for $1987-88 \ldots \ldots \ldots 141$

C.10 Surface conditions in the central Greenland Sea gyre for 1988-89. . . . . . 142

C.11 Surface conditions in the central Greenland Sea gyre for 1989-90. . . . . . 143

C.12 Surface conditions in the central Greenland Sea gyre for 1990-91. . . . . . 144

C.13 Surface conditions in the central Greenland Sea gyre for 1991-92. . . . . . 145

C.14 Surface conditions in the central Greenland Sea gyre for 1992-93. . . . . . 146

C.15 Surface conditions in the central Greenland Sea gyre for 1993-94. . . . . . . 147

C.16 Surface conditions in the central Greenland Sea gyre for 1994-95. . . . . . . 148

C.17 Surface conditions in the central Greenland Sea gyre for $1995-96 \ldots \ldots \ldots 149$ 
C.18 Surface conditions in the central Greenland Sea gyre for 1996-97 . . . . . 150

D.1 A schematic diagram illustrating the optimization process. The vector of control variables $\mathrm{X}$ is passed to the forward model. The forward model computes the value of the cost function $\mathrm{J}$, which is passed to the adjoint model. The adjoint model computes the value of the gradient of the cost function with respect to the control variables. This information is passed to the minimization routine, which then tries to find a better estimate for the control variables which decreases the value of the cost function. . . . 152

D.2 The non-negativity term $J_{n n}$ in the cost function is used to prevent the water temperature from being artificially supercooled during the optimization process. . . . . . . . . . . . . . . . . . 153

D.3 The derivative of $J_{n n}$ is a well-behaved function. . . . . . . . . . 154 


\section{Chapter 1}

\section{Introduction}

The global thermohaline circulation is one of the major components of the global climate system. It plays an important role in regulating the poleward transport of heat [Oort and Vonder Haar 1976, Macdonald and Wunsch 1996] and thus in maintaining current climatic conditions. However, this circulation pattern may not be stable on very long timescales, as it has been shown to have multiple equilibrium states [Stommel 1961, Bryan 1986, Manabe and Stouffer 1988, Marotzke and Willebrand 1991]. In today's climate, the bottom water of the northern North Atlantic (which, next to the Antarctic Bottom Water, is the densest water in the open ocean) originates from dense water which flows from the Nordic Seas ${ }^{1}$ over three sills (see figure 1.1); as these overflows descend they entrain resident North Atlantic water and together they form the North Atlantic Deep Water [Warren 1981]. The Nordic Sea water overflows through the Denmark Strait (sill depth just over 600 meters), over the Iceland-Faroe Ridge (sill depth about $450 \mathrm{~m}$ ), and the Faroe Bank Channel (sill depth about $850 \mathrm{~m}$ ), and enters a basin whose maximum depth exceeds $3000 \mathrm{~m}$ [Swift 1984]. This process of marginal sea overflow and its effect on climate is an area of active research (see, for example, Price and Yang [1998] and references therein). Greenland Sea Deep Water is formed by deep convection in the center of the Greenland Sea and plays an important role in the circulation in the Nordic Seas and in the formation of the overflow water [Strass et al. 1993].

\footnotetext{
${ }^{1}$ Nordic Seas refers collectively to the Greenland, Iceland, and Norwegian Seas
} 
Oceanic convection has been studied for a long time through direct observations (e.g. MEDOC Group [1970]), laboratory experiments (e.g. Rossby [1965]), and theoretical studies (e.g. Anati [1970]). The review articles of Killworth [1983] and more recently Marshall and Schott [1998] provide extensive overviews of the progress which has been made in our understanding of convection in the oceans. There are a number of factors which make the nature of the convection in the ocean fundamentally different from convection in other settings. Oceanic convection is spatially localized. There is therefore an interesting interplay between geostrophy and convection in the oceans since the scales of motion associated with both of these processes are comparable, and convection can give way to baroclinic instability [Visbeck et al. 1996]. Salinity adds another complicating element to the puzzle. The equation of state for seawater is a non-linear function of temperature, salinity, and pressure, and this has some non-trivial dynamical consequences. When the salinity is above 24.7, the density maximum of water is at the freezing point (compared to $4.2^{\circ} \mathrm{C}$ for freshwater) [Pickard and Emery, 1990]. For this reason, the process by which water in a freshwater lake overturns is fundamentally different from the convection process in the oceans. As a result, ice can form in the ocean only when there is a stable near-surface salinity stratification. It is this interesting and fascinating property of seawater which differentiates the convection process in the Greenland Sea from many other regions.

\subsection{What drives deep convection?}

This is a question which can only be properly addressed when framed in the larger context of the general circulation of the oceans. One might argue that deep convection results solely from local surface forcing. However, deep convection is important for the maintenance of a stable stratification in the world ocean [Killworth 1983]. Thus, it cannot occur in isolation from the rest of the ocean. In particular, convection can only occur in a given location if the surface density matches the density at depth. If there is vigorous vertical mixing in some regions, such as at the boundaries [Marotzke 1997], then the vertical density gradient in the ocean may be eroded, setting the stage for convection to occur somewhere. That we only observe convection to occur in a few isolated regions likely has to do with the increased propensity for water to overturn in these regions relative to the 


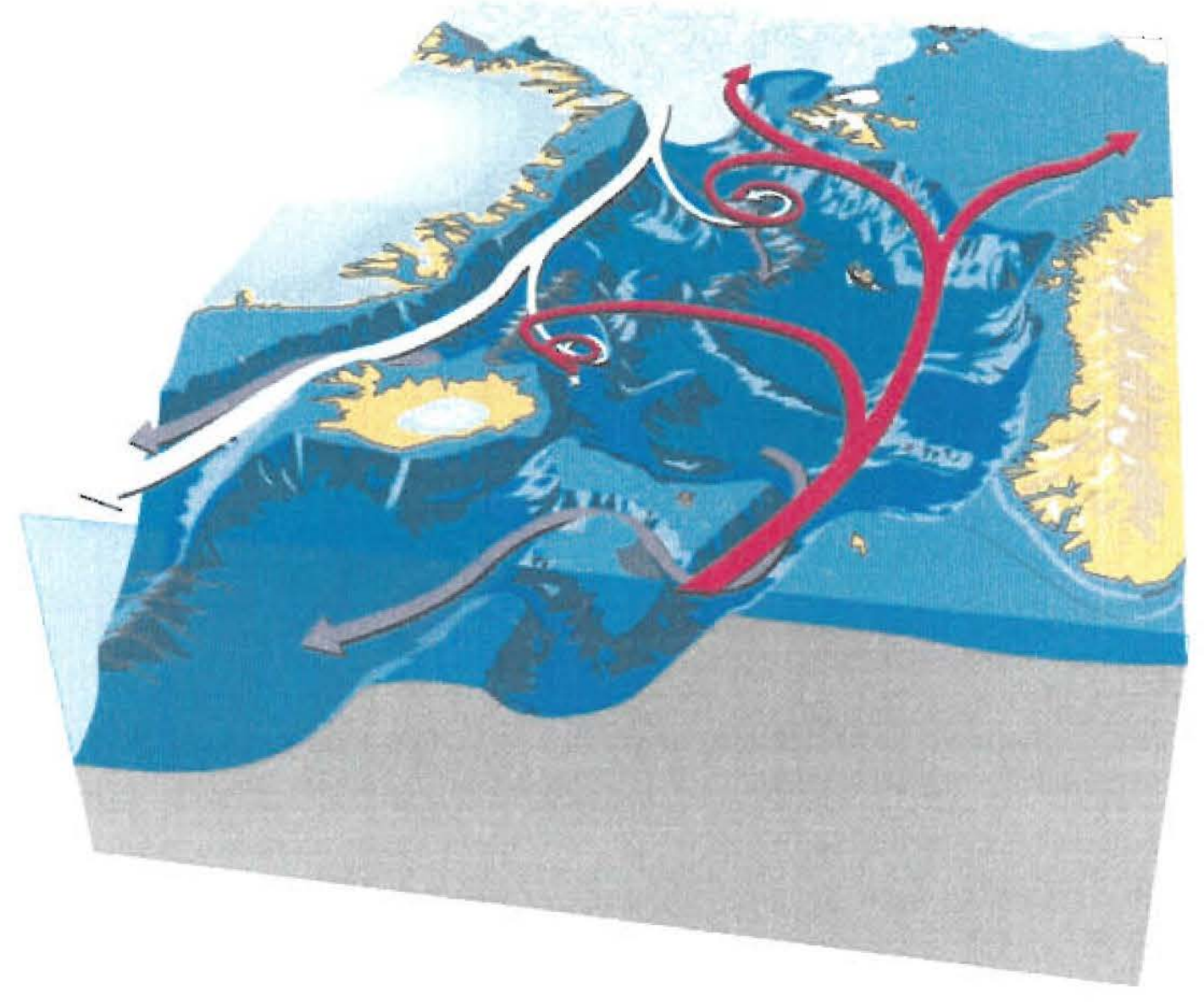

Figure 1.1: An idealized schematic of the Nordic Seas and surrounding regions. The major entry and exit routes are represented. The southward flowing East Greenland Current (white lines) transports the cold, fresh water flowing through the Fram Strait along the Greenland coast; much of it exits through the Denmark Strait into the North Atlantic. It also feeds the eastward flowing Jan Mayen Current. The red lines represent relatively warm, salty Atlantic water entering the Nordic Seas at shallow depths and making its way into the interior of the gyre. These two water masses interact and are transformed into Greenland Sea Bottom Water. Water leaves the basin at intermediate depths (blue lines) through both the Denmark Strait and the Faroe Bank Channel. (Figure taken from the World Wide Web site of the European Sub-polar Ocean Programme). 
rest of the ocean [e.g. Warren 1983], and *this* depends on the details of the local conditions (density structure of the water column, local dynamics, climatological conditions, etc.).

The basic mechanism driving deep convection is a densification and sinking of surface water. This could occur via a number of different processes, and the process could be catalysed by favorable conditions (such as a weak stratification of the water column, entrainment of saline water, and strong surface winds which result in greater surface heat fluxes and enhanced mixing of the water column).

The Greenland Sea has a weak stratification; properties do not vary much from the top to the bottom of the water column (the gradient reaching a maximum of perhaps $5^{\circ} \mathrm{C}$ in temperature and 1.5 in salinity, with much smaller variations in the wintertime) [Pawlowicz 1995]. This observation led Nansen to propose as early as 1906 that the occurrence of deepwater formation is very likely in the Greenland Sea, long before there was any direct observational evidence of this.

The ratio of the haline to the thermal expansion coefficient for the Greenland Sea is about $26 \mathrm{~K} / \mathrm{psu}$ (see figure 1.2). Thus, for typical changes in temperature $\left(\sim 1^{\circ} \mathrm{C}\right)$ and salinity $(\sim 0.1 \mathrm{psu})$, the effect of salinity changes on the density of seawater is greater than the effect of temperature changes. Therefore, due to the freshness of the surface waters, even a cooling of the surface water down to the freezing point does not cause a sufficient loss of buoyancy to erode the stable stratification. By which process then is deep convection triggered? A number of theories have been proposed.

Some studies have suggested the upwelling of saline intermediate water and subsequent cooling of this water as one way to overcome the fresh anomaly at the surface. Killworth [1979] suggested that this upwelling may occur inside baroclinic eddies, while Hakkinen [1987] proposed that the upwelling occurs at ice edges. Other studies have focused on the possibility of subsurface cooling of saline intermediate water by mechanisms such as cabelling and double diffusive / advective balances [Carmack and Aagaard 1973; McDougall 1983]. The broad range of mechanisms that were proposed is a reflection of the fact that no deep-mixed profiles had yet been observed, and hence there was no observational evidence to constrain the theories. 
The important role of surface ice formation and brine rejection in this process was not fully appreciated until recently, as evidenced by the fact that Killworth made no mention of it with reference to the Greenland Sea in his 1983 review article. Clarke et al. [1990] found that brine rejection (without wind-driven removal of the newly-formed ice) would accelerate the deep convection process through repeated freezing/melting cycles. Rudels [1990] considered the formation of dense convective plumes through this process, from brine-rich water at the base of newly formed ice. Aagaard and Carmack [1989] also suggested that brine rejection from newly formed ice plays a role.

In 1988-89, a major observational study was carried out of the circulation, general hydrography, and deepwater formation in the Greenland Sea. Analyses of observations from the Greenland Sea Project by the various research groups involved led to a description of how the deep convection process likely proceeded [Schott et al. 1994]. Brine rejection from ice formation is necessary to overcome the salt anomaly (i.e. to "precondition" the upper waters), but deep convection occurs as a result of surface forcing over open water after the ice has been removed. However, details of the process were still left unresolved. For example, it was not clear what caused the ice removal (ice advection or entrainment of warm water).

As we will discover, there is likely at least some element of truth in all of the aforementioned studies. All of the processes mentioned are players in the richly complex set of interactions which govern convective activity in the Greenland Sea. In this study, we will explore and identify the roles and relative importance of these different processes.

The thermal evolution of the gyre center during 1988-89 seems to divide naturally into three phases, which Pawlowicz et al. [1995] describe as follows:

- Phase 1: Preconditioning (Nov.-Jan.). During this phase the surface salinity is increased by brine rejection from ice formation and by entrainment of Arctic Intermediate Water (AIW), but the mixed layer deepens only slowly to a depth of around 150-200 meters.

- Phase 2: Deep mixing (Feb.-Mar.). During this phase the surface mixed layer deepens rapidly to approximately 1500 meters in the gyre center purely under the 


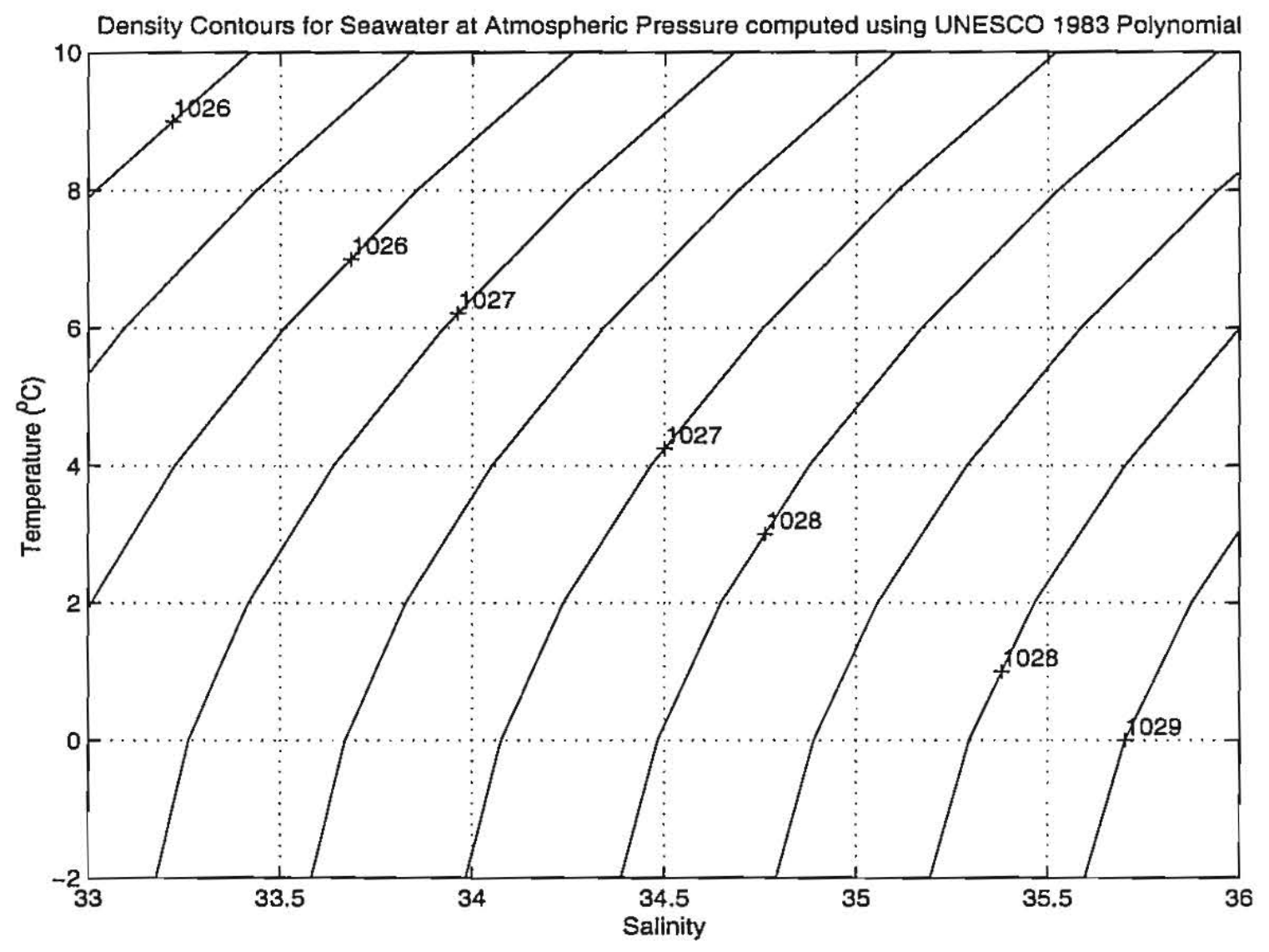

Figure 1.2: The change in the density of seawater for a given change in salinity is larger close to the freezing point. The ratio of the haline to the thermal expansion coefficient for the Greenland Sea is about $26 \mathrm{~K} / \mathrm{psu}$. Therefore, for typical changes in temperature $\left(\sim 1^{\circ} \mathrm{C}\right)$ and salinity $(\sim 0.1 \mathrm{psu})$, the effect of salinity changes on the density of seawater is greater than the effect of temperature changes. 
influence of local surface cooling. The rapid cooling occurs because ice disappears and thus its insulating effect on the mixed layer is lost.

- Phase 3: Restratification. During this phase, the products of deep mixing are replaced by AIW flowing in from the gyre edges.

An earlier study of the convection in the eastern Mediterranean Sea [MEDOC, 1970] also concluded that the evolution of a convective event naturally divides into the three phases just mentioned. The mechanism for buoyancy loss during the preconditioning phase is different however. It is evaporation of surface waters rather than ice formation which causes the increase in salinity. It also lowers the surface temperature through evaporative heat loss and creates a dense upper layer. Further, the seawater density is more strongly a function of temperature in this region than in the cold arctic region.

\subsection{Characteristics of the Greenland Sea Gyre}

There are a number of competing processes which may influence the formation of dense surface water. Some conditions that predispose a region to deep-reaching convection are common to all known deep convection sites [Marshall and Schott 1998]:

- Strong atmospheric forcing by thermal and/or haline fluxes.

- Weak stratification beneath the surface mixed layer.

- Weakly stratified underlying waters must be brought to the surface and be directly exposed to intense surface forcing. This condition is favored by cyclonic circulation.

It is possible that the characteristics of the convecting region and its surroundings may exert a strong influence in determining which effects dominate the process of densification. Indeed, the Greenland Sea gyre has a number of interesting and peculiar features which some have speculated play a central role in setting the deep convection process underway and in determining the strength of the convection. In particular, the convection process in the Greenland Sea gyre is thought to be closely linked to the bathymetry, surface conditions, and water mass properties of the region. In the following paragraphs, we 


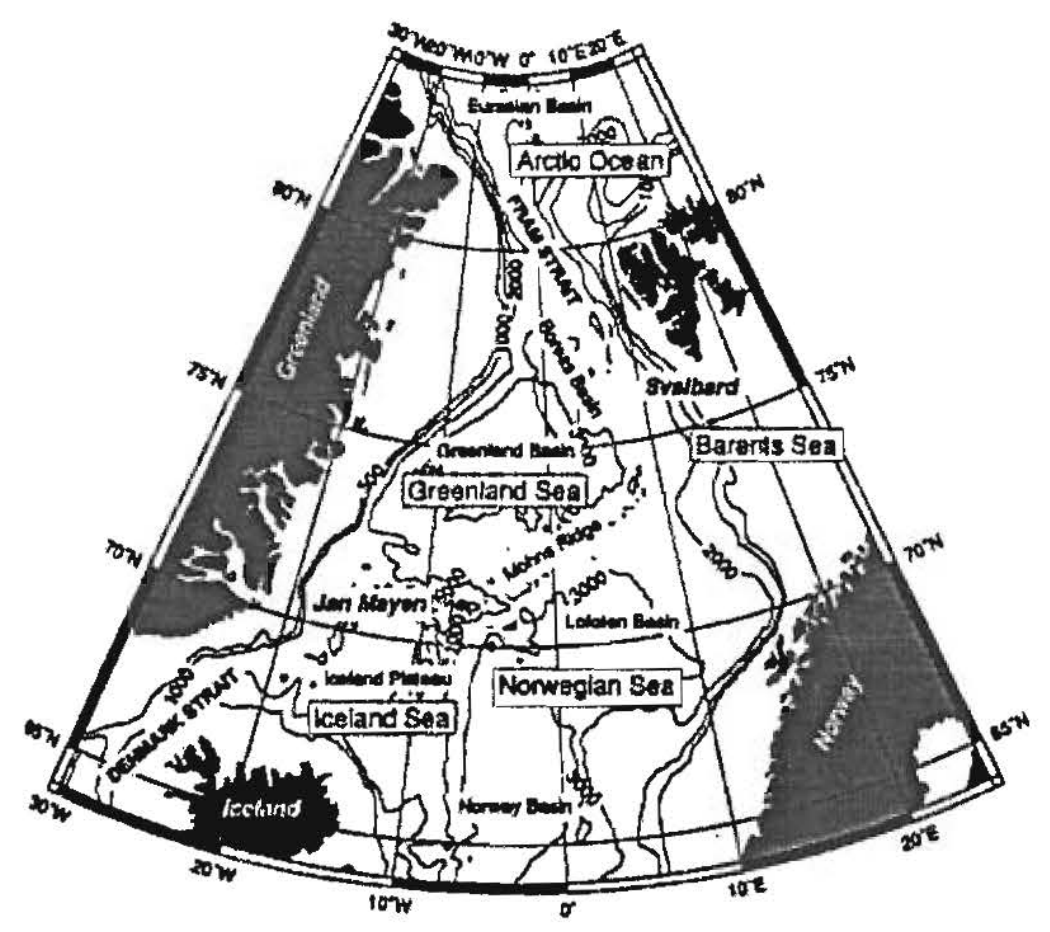

Figure 1.3: The water masses surrounding the Greenland Sea (from Pawlowicz et al. [1995]).

will briefly describe some of these characteristics and indicate how they may be relevant to the convection process.

The Greenland Sea gyre is a topographically confined basin (see figure 1.3). It is in the deepest waters at the center of the gyre (roughly 3000 meters in depth) that deep convective events have been observed. This deep central gyre region is bounded by a shallow shelf to the northeast and northwest, the East Greenland slopes to the west, and the Jan Mayen Fracture Zone and Mohns Ridge to the south and east. As a result, all of the exchange with the Atlantic and Arctic Oceans occurs through narrow straits. The gyre is connected to the Arctic Ocean to the north through the Fram Strait and to the Atlantic Ocean to the south through the Denmark Strait and the Faroe Bank Channel. The flow through these passages is quite large. Approximately $20 \%$ of the total ice area of the Arctic Basin annually exits through the Fram Strait [Barry et al. 1993]. 
The surface circulation in the Greenland Sea gyre is cyclonic due to the positive curl of the wind stress in the basin [Pawlowicz 1995]. The surface currents (indicated in figure 1.4) consist of the southward flowing East Greenland Current (EGC) near the western boundary of the basin, the eastward flowing Jan Mayen Current to the south (north of Jan Mayen Island), the Polar Ocean Front in the southeast, and the northward flowing West Spitzbergen Current on the eastern side of the basin. Cold, fresh ice melt and ice are advected from the Arctic Ocean, through the Fram Strait, into the Greenland Sea by the EGC. This surface flow overlies a warmer and more saline subsurface layer with a temperature maximum at around 200 meters depth. This temperature maximum is part of the Arctic Intermediate Water (AIW). The Jan Mayen Current breaks off from the East Greenland Current and heads eastward following the Jan Mayen Fracture Zone. The surface cyclonic gyre circulation is completed by waters continuing northward following the western bank of the Mohns Ridge.

Beneath the surface layer, the intermediate waters near the gyre center are colder, denser, and less stratified than waters at the same depth on the periphery. There is therefore a "doming" of the isopycnals near the gyre center, and they slope downward towards the warmer perimeter. This is consistent with the observed net cyclonic circulation. In addition to fresh Arctic water, the Greenland Sea also receives saline Atlantic Water, which mixes with the low-salinity surface water to form the coldest and least saline of the deepwater masses north of the Greenland-Scotland Ridge [Carmack 1986]; this is called the Greenland Sea Deep Water (GSDW).

It is likely that the characteristics of these water masses are maintained by the mixing down of cold surface waters through convective overturning. The physical processes associated with the production of the deep and intermediate water in this region are the subject of this study. Dickson et al. [1996] found that the deep temperatures and salinities (below 2000 meters) in the central Greenland Sea have been gradually warming since the mid-1970's as a result of the suppression of convective renewal, and due to lateral exchange with the Eurasian and Norwegian basins.

In the summer the near-surface layer in the Greenland Sea is warmed by solar radiation and the water is fresh due to the previous winter's ice melt and advection of polar waters across the polar front. According to Esbensen and Kushnir [1981], insolation 


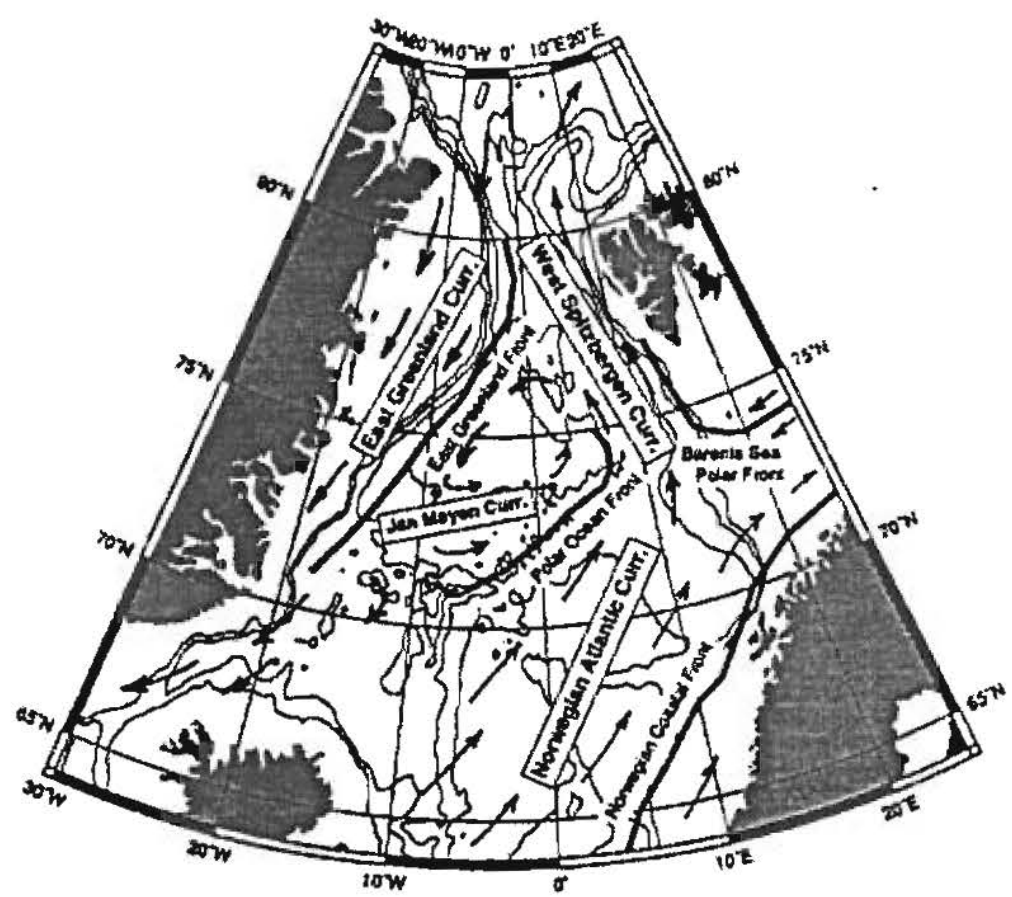

Figure 1.4: The surface currents in the Greenland Sea (from Morawitz et al. [1996)]. 
is significant between May and September; it causes a net heat gain of about $50 \mathrm{~W} / \mathrm{m}^{2}$ at the beginning and end of this period, and reaches a maximum of about $200 \mathrm{~W} / \mathrm{m}^{2}$ in June. In the fall, the surface waters cool rapidly as air temperatures drop and insolation decreases. However, the water column remains stable due to the low salinity of the surface waters. Cooling is confined to a thin surface layer which rapidly approaches the freezing point. Observations show that by January 1989 the majority of the Greenland Sea became ice-covered as the ice edge moved in from the west (see figure 1.5). The salinity in the upper waters then increased; this may have been due to brine rejection from ice formation, and also possibly from entrainment of Arctic Intermediate Water from below. This salinity increase gradually eroded the pycnocline.

The strong winds in the wintertime result in a greater sensible heat flux from the surface layer due to the enhanced air-sea heat exchange; the bulk formula parametrization reflects this:

$$
H_{T}=C_{H} C_{p} \rho_{a} u\left(T_{s}-T_{a}\right),
$$

where $C_{H}$ is a dimensionless empirical parameter, $\left(T_{0}-T_{a}\right)$ is the air-sea temperature difference, $\rho_{a}$ is the air density, and $u$ is the wind speed [Gill, 1982, page 26]. The strong winds also cause ice to drift. The prevailing northerly winds advect ice towards the southwest from the central gyre region. A large embayment generally appears in the marginal ice zone in February and March, though with large inter-annual changes in extent [Pawlowicz et al. 1995]. The winds and surface currents also cause ice to build up in certain areas; in particular, a large ice tongue develops south and east of the embayment (figure 1.5). Observations of both of these features have been recorded by whalers and sealers since the early part of this century. They are often refered to by their Norwegian names: Nordbukta and Is Odden. In Nordbukta, the ice-free region, loss of the insulating ice cover exposes the surface layer to cold SST's. It is in this area and over this time that a convective chimney is observed in the temperature fields from inversions of tomographic data [Pawlowicz et al. 1995 and Morawitz et al. 1996]. These convectively formed waters are believed to replenish the deep waters in the Greenland Sea and overflow into the North Atlantic basin. In the Is Odden region convection is thought to be inhibited by the insulating effects of the sea ice cover. We believe that the stable surface stratification is the crucial factor here. We will return to this point in chapter 4. 

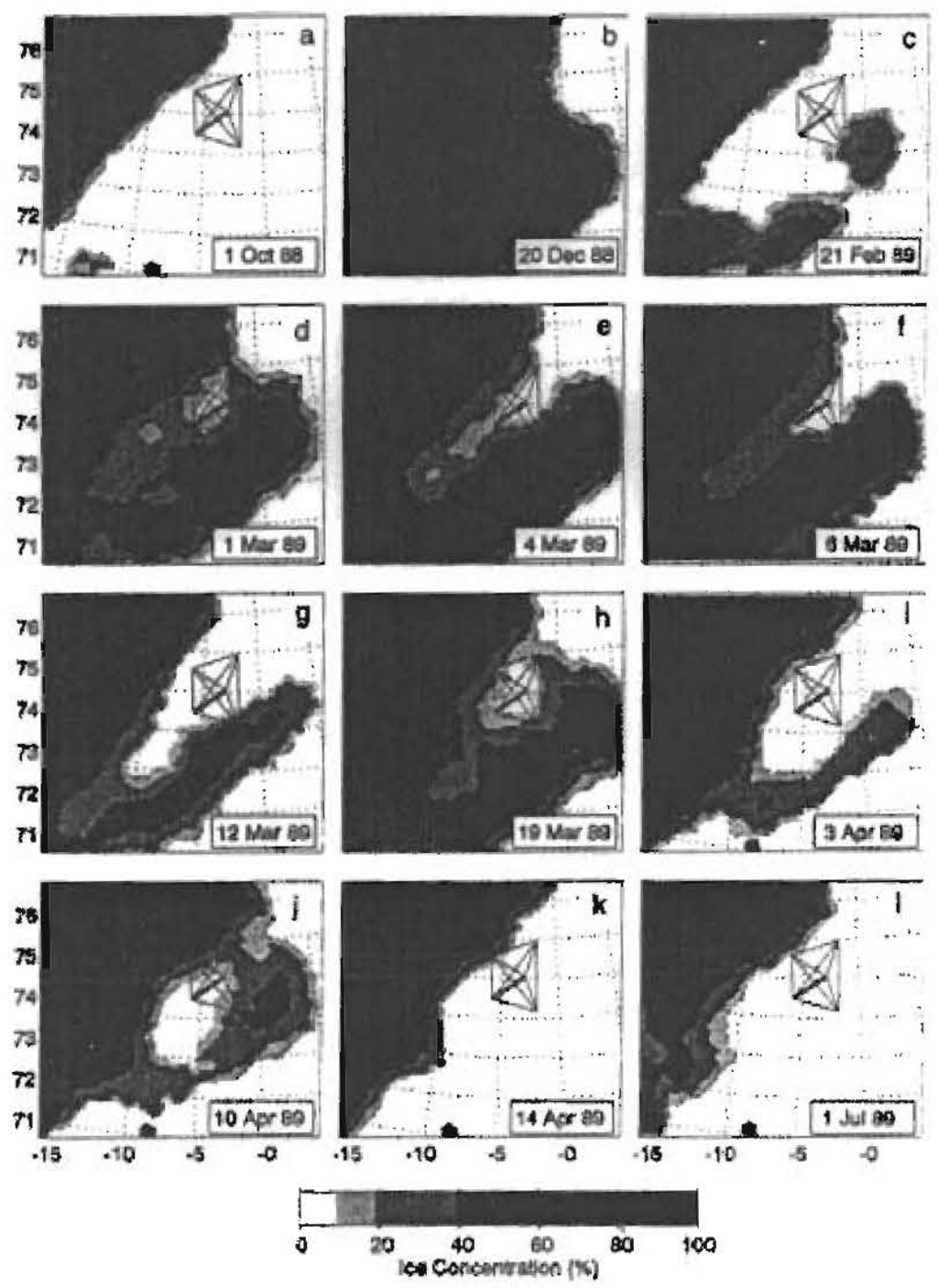

Figure 2. Ice concentrations over array region on (a) October 1, 1988, (b) December 20, 1988, (c) February 21, 1989, (d) March 1, 1989, (e) March 4, 1989. (f) March 6. 1989. (g) March 12. 1989, (h) March 19, 1989, (i) April 3. 1989. (j) April 10. 1989. (k) April 14, 1989, and (1) July 1. 1989. Dates of suecessive minima and maxima of the areal coverage are shown. Although contours are labeled as concentration, they also depend on ice thickness in the Odden tongue (the large diagonal feature along the southeast edge of the ice pack) through February-April. Concentrations below $10 \%$ are shown as open water (see text for details). Array paths for which temperature inverses are available are shown as thin lines: the 6.4 path is indicated by a thick tine. Note the small region that always remains ice free over the array center. Ice exists only to the west of the "permanent" ice edge fram April to October (Figures 2a, $2 \mathrm{k}$, and 21).

Figure 1.5: Evolution of the ice cover in the Greenland Sea in 1988-89, showing the formation of an ice free bay ("Nordbukta") and below it an ice tongue extending to the northeast ("Is Odden") (from Pawlowicz et al. [1995]). 


\subsection{Outline}

The main goal of this thesis is to understand how the onset of deep convection depends upon the surface forcing and density structure of the water column. In this study, we will focus on one particular region and try to understand the reasons why and processes by which this region becomes preselected as a site for convection, and to determine how much of this is a result of surface conditions. We aim to present a more detailed explanation of how the convection process proceeds in the Greenland Sea than has been previously presented. In addition, by looking at the inter-annual variability of convective activity in the Greenland Sea, we make an attempt to determine to what extent the degree of convective activity can be inferred from historical data.

In chapter 2 we describe the observations which we will make use of in this study. We first focus attention on data that was collected during the 1988-89 Greenland Sea Tomography Experiment. We present the temperature evolution averaged over a 105 kilometer wide patch near the center of the Greenland Sea gyre, as derived from an inversion of acoustic data by Pawlowicz et al. [1995]. We also point out some deficiencies in the derivation of this temperature evolution.

In chapter 3 we formulate a one-dimensional model that we developed to study the evolution of the convection process over a full season. Our model contains the full equation of state of seawater (EOS80), and is thus able to capture all of the non-linear (e.g. thermobaric) effects. It also contains an interactive thermodynamic ice model. The results from this modeling study are compared to the tomographic observations, and a number of interesting insights are gained. In particular, we are able to study details of how the preconditioning process occurs, and examine the effects of restratification by looking at the heat content evolution. Our model results are also found to agree well with the observations of Roach et al. [1993]. We also examine the sensitivity of the model to the strength of the couplings between the atmosphere and ice and between the ice and the mixed layer. We discuss the effects on the model evolution of varying the strengths of these couplings and interpret the changes in physical terms.

In chapter 4 we examine in detail the mechanism by which the deep convection process occurs, and identify the physical processes which are dominant at each stage in the 
process. We show analytically how ice drift enhances the efficiency of the brine rejection process during preconditioning, and derive an expression for the rate of salinity increase in the mixed layer. Our results are then compared to three previous modeling studies of the same convection event in 1988-89: Pawlowicz et al. [1995], Visbeck et al. [1995], and Morawitz et al. [1996]. The results of these previous studies are not in full agreement with each other, and we explore the reasons for these discrepancies. They differ in their conclusions as to whether or not the advection of ice away from the region of convection is a necessary ingredient in the preconditioning process. We present our own conclusions about the importance of ice advection to the convection process and demonstrate how the results of all of these studies depend upon certain details of the model formulation and the initialization. We then explore how the mixed layer evolution is modified by changes in the surface conditions and in the initial stratification of the water column. On the basis of analytical results from scale analyses and model simulations, we demonstrate that an extreme cold spell in December 1988 lasting about one month followed by moderately cold temperatures play an important role in the evolution of the convective event as observed through tomographic measurements. We demonstrate that haline driven deep convection underneath an ice cover is possible, but unlikely to occur in the Greenland Sea. Following this, we examine the question of which process or processes can limit the depth of convection. Based on all of these results, we develop a coherent picture of the evolution of the convection process which is more detailed than that presented in any previous work. In the final section of chapter 4 , we comment on the likelihood that deep convection occurred in the Greenland Sea in the past two decades from an examination of historical data, and relate these findings with what is known about the inter-annual variability of convective activity in the Greenland Sea.

In chapter 5 we summarize our findings and present a detailed account of how the evolution of the convection proceeded in the Greenland Sea in 1988-89. Finally, we close with a brief discussion of additional work to be carried out along the lines of our research and present a context for future directions. 


\section{Chapter 2}

\section{Greenland Sea Observations}

\subsection{Tomographic Temperature Data}

Analysis and inversion of the tomographic data to obtain a temporal evolution of the temperature profiles was done by Pawlowicz et al. [1995]. In the current study, we will focus on the derived tomographic time series from the 4-6 path of the tomographic array (see figure 2.1). A contour plot of the temperature data is shown in figure 2.2. The total uncertainty in the tomographic temperature estimates are about $\pm 0.2^{\circ} \mathrm{C}$ above 400 meters, $\pm 0.05^{\circ} \mathrm{C}$ from 400 to 1200 meters, and $\pm 0.02^{\circ} \mathrm{C}$ at 1500 meters. The warm surface mixed layers in the fall and summer, evident in figure 2.2 , are not well resolved and the uncertainties approach $\pm 1^{\circ} \mathrm{C}$ for the upper 60 meters during these times. Pawlowicz et al. [1995] further estimate that biases of order 200 meters may exist in the estimates of the mixed layer depths during February and March, although small relative changes in temperature are well resolved.

It is clear from figure 2.3 that the signal of the convection event is only just barely within these error estimates. However, there is a clear trend in the data and there is no doubt that convection to mid-depths did actually occur. The exact depth to which convection reached is more difficult to ascertain, though all the published analyses of the data collected during 1988-1989 quote a depth of about 1500 meters. During the months of December and January when a cold and shallow mixed layer exists, there is a sharp break in temperature at the base of the mixed layer which is very badly resolved by the tomography. Therefore, in an attempt to construct a reasonable temperature 


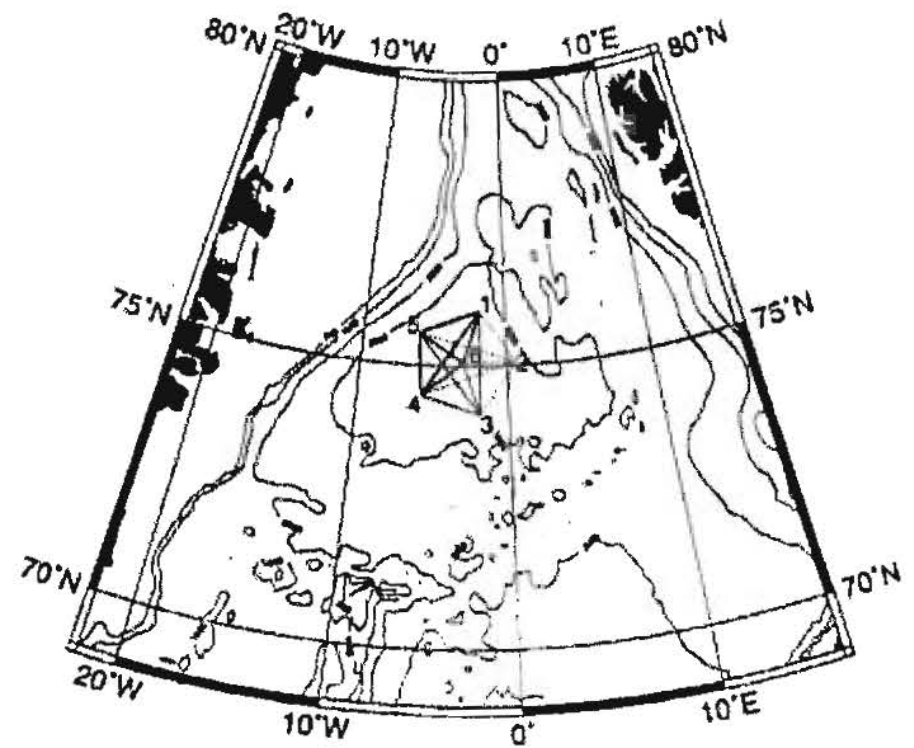

Figure 1. Locasion of the Greenland Sea Tomography Experiment. Mooring 2 falled completely after 1 month, and mooring 3 acted oaly as a cource, thus recjprocal transalissions were made only over the paths indicated by thick solid lines, and one-wiry transsnissions over the paths indicated by thin solld lines. $N_{0}$ useful transmistions were reconded over dached pathe.

Figure 2.1: The location of the tomographic array during the 1988/89 Greenland Sea Project (from Pawlowicz et al. [1995]). 


\section{Surface Conditions and Potentlal Temperature Evolution from Tomographic Inversion}

ECMWF

$2 m$ Air Temp. $\left({ }^{\circ} \mathrm{C}\right)$

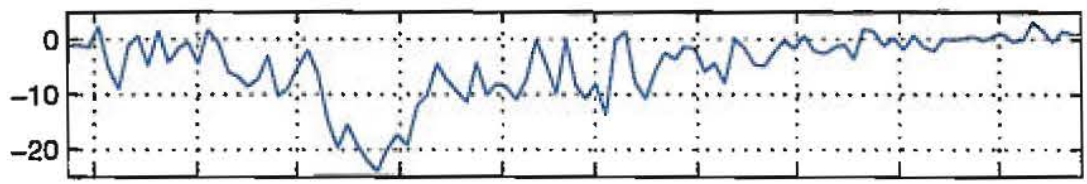

SSMI

Ice Concentration

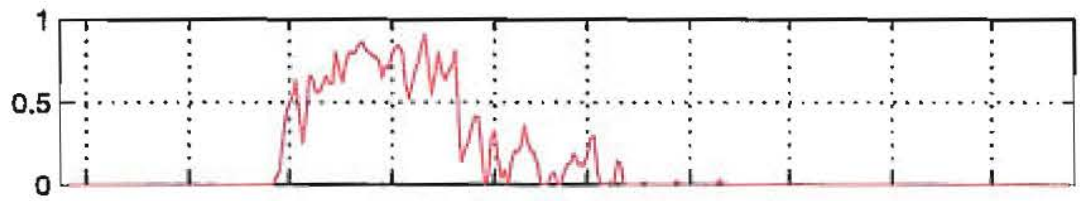

ECMWF

$\mathrm{E}-\mathrm{P}(\mathrm{mm} / \mathrm{day})$

NCEP U-windspeed (m/s)

NCEP V-windspeed (m/s)
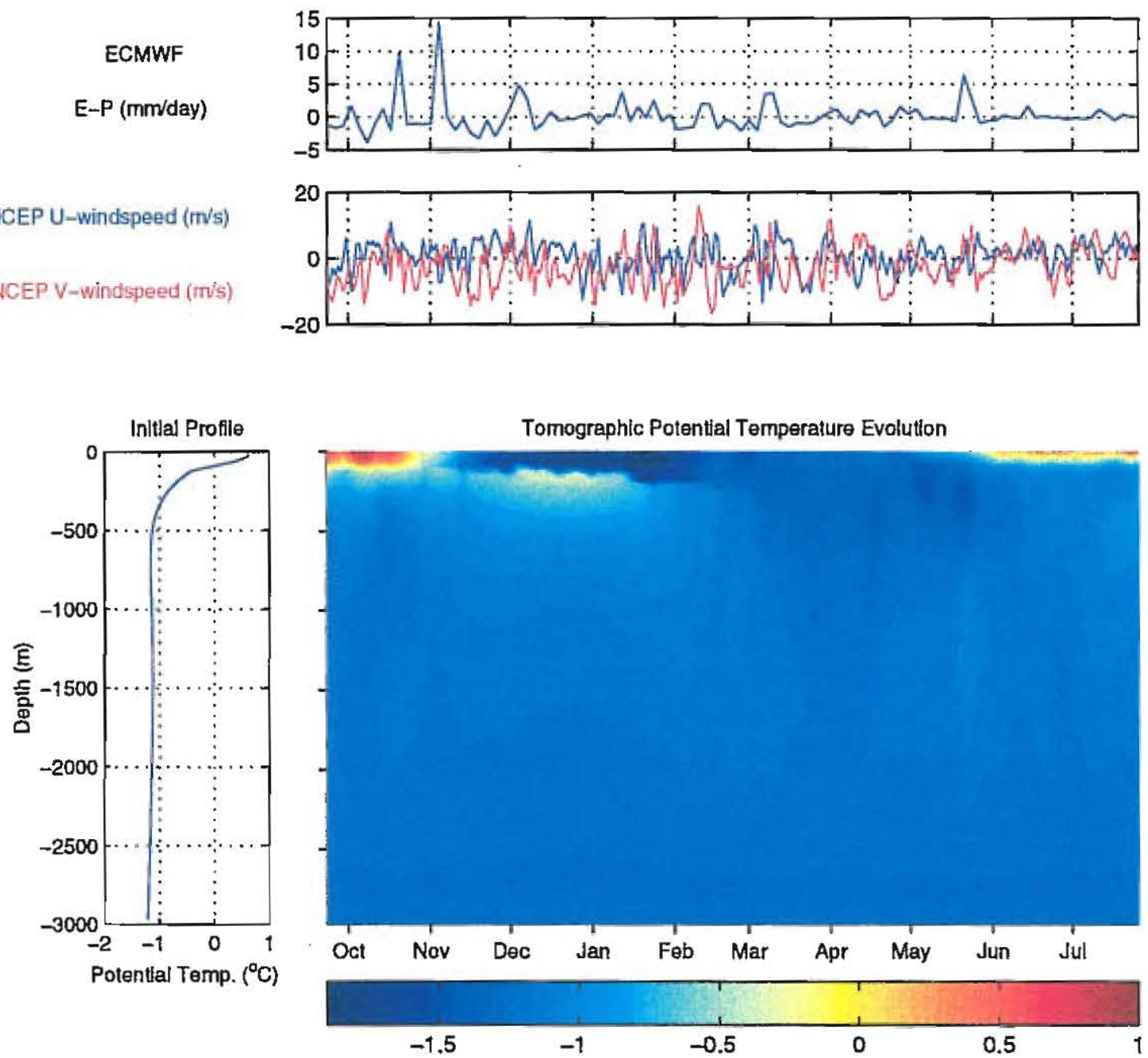

Figure 2.2: Surface conditions and potential temperature from an inversion (Pawlowicz et al. [1995]) of tomographic data. 


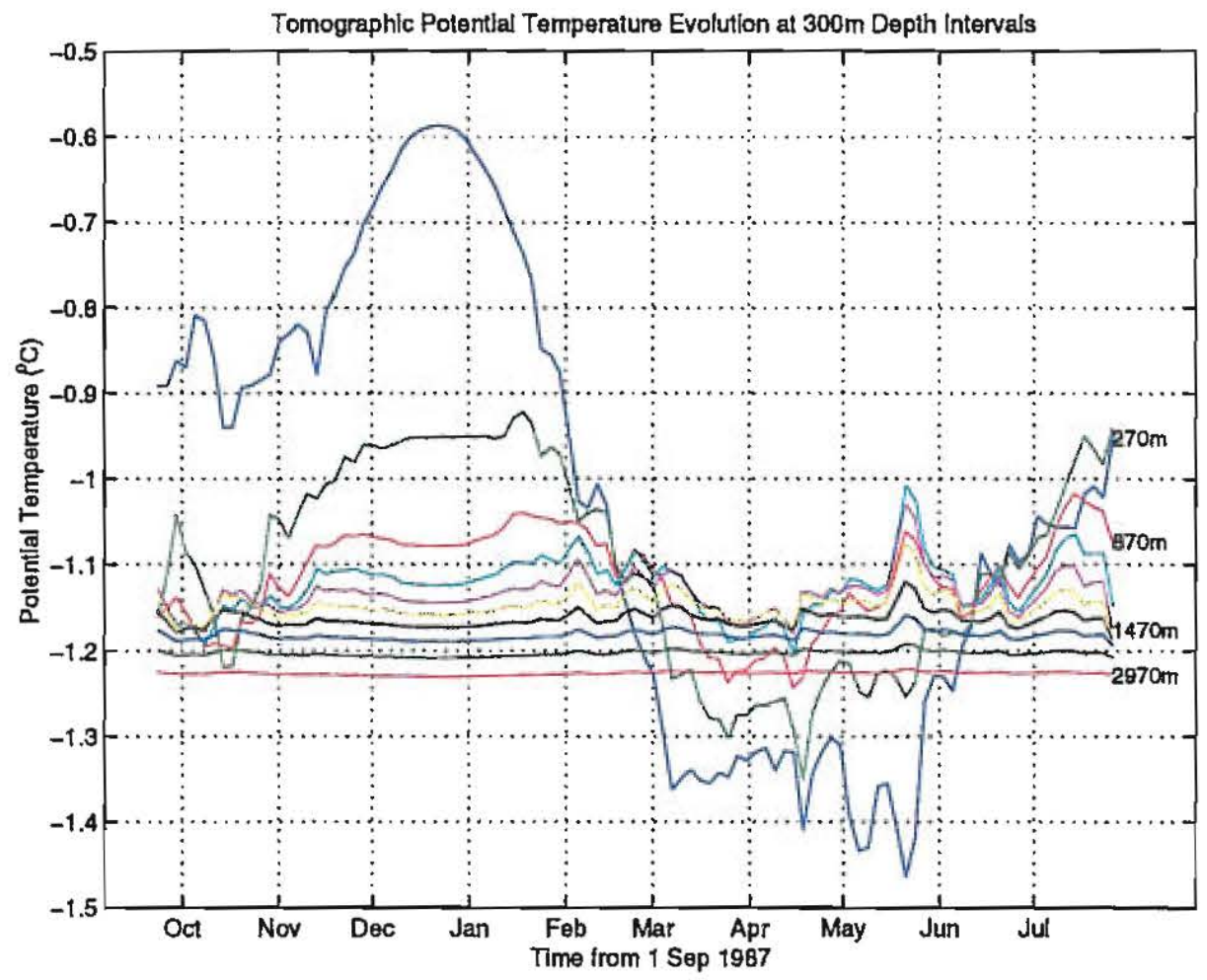

Figure 2.3: The evolution of the potential temperature along the 6-4 path of the tomographic array during 1988/89 derived from an inversion of acoustic data by Pawlowicz et al. [1995]. Estimated uncertainties are about $\pm 0.2^{\circ} \mathrm{C}$ above 400 meters, $\pm 0.05^{\circ} \mathrm{C}$ from 400 to 1200 meters, and $\pm 0.02^{\circ} \mathrm{C}$ at 1500 meters. Starting in mid-February, an apparent temperature inversion develops as the cold surface water convectively mixes down to a depth of around 1500 meters. The convection signal, characterized by this vertical mixing, shows up above the noise level. 
profile for this period, Pawlowicz et al. [1995] use heat content estimates derived from the tomographic data to fit a simple model of the temperature profile. This model's only free parameter is the mixed layer depth; above this the temperature is set to the freezing point and below this the profile is assumed to be similar to bottle casts from late November. While this synthetic data seems to match well to the temperature evolution before and after this period, we believe that it is not the most consistent fit with other observations, namely the ice evolution. Instead, we propose an alternative evolution which is equally consistent with the tomographic heat content estimates.

Looking at the temperature evolution in figure 2.2, we see that from mid-November through mid-January the surface layer is very cold and shallow. The heat loss to the atmosphere during this period contributes only to ice formation, since the surface layer is already at the freezing point and cannot get any colder. In mid-January there is a small increase in the depth of the cold surface layer and a corresponding sharp drop in the heat content of the water column (figure 3.4). Since the air temperature generally shows a warming trend around this time, this loss in heat content most likely corresponds to the sharp drop in the ice concentration which occurs at about the same time. The slight increase in the surface layer depth, by about 30 meters, entrains about $1 \times 10^{8} \mathrm{~J} / \mathrm{m}^{2}$ of excess heat, assuming that the surface layer remains at the freezing point. Assuming an ice thickness of about 0.2 meters, it takes about $0.6 \times 10^{8} \mathrm{~J} / \mathrm{m}^{2}$ to melt the ice cover. The remaining heat is lost to the atmosphere, resulting in a heat flux of about $150 \mathrm{~W} / \mathrm{m}^{2}$. This is consistent with an air-sea temperature contrast of $-15^{\circ} \mathrm{C}$. The heat budget therefore seems to be consistent. However, the implication is that the coupling between the surface layer and the ice layer is infinitely strong, and that any excess heat entrained from below is used preferentially to melt the ice layer and not to increase the temperature of the surface layer. This assumption was implicitely built into the simple model used by Pawlowicz et al. [1995] in their assertion that the surface mixed layer temperature remains at the freezing point. We also note that although the mixed layer evolution described by the synthetic data appears to match well to the tomographic data, there may be large biases in the mixed layer depth of the latter.

The limit of infinite coupling between the ice and mixed layers has been used in some modelling efforts; Killworth [1979] calls this the "rapid limit", referring to the rate of heat transfer. At the opposite extreme is the "insulating limit" which occurs 
when the ice and mixed layers are completely decoupled. Killworth also states that the coupling strength appropriate to the real ocean lies somewhere between these two limits. Observations made during CEAREX 89 north of Fram Strait in late winter [McPhee 1992, figure $17(\mathrm{c})$ ] confirm this statement. Those observations are consistent with a coupling value of between 100 and $600 \mathrm{~W} / \mathrm{m}^{2} / \mathrm{K}$. This being the case, we should then expect that some of the heat entrained from below will be used to warm the surface layer and some to melt the ice. Since we know that most of the ice does melt, the result will be a deeper and warmer surface layer, as shown in figure 2.4(b). Note however that for a small change in the mixed layer temperature, the ocean-atmosphere temperature difference will not change much, and neither will the net heat loss at the surface of the ocean. It is the distribution of heat within the water column, and not the total heat content, that will change significantly.

This ambiguity in determining the temperature evolution exists because we do not have observations of the salinity evolution of the system, and thus we cannot infer with certainty the density profile of the water column. In other words, we do not have enough information to determine unambiguously the depth of the mixed layer. If we did, it would then be possible to work backwards and infer the strength of the coupling between the ice and mixed layers instead of assuming it.

We will explore and illuminate this issue of the "rapid limit" versus the "insulating limit" further in chapter 3 , in the context of a model simulation of the entire convective event.

\subsection{Other Data Used}

We have made use of Numerical Weather Prediction (NWP) model data from both the National Centers for Environmental Prediction (NCEP) and the European Centre for Medium-Range Weather Forecasting (ECMWF) reanalysis datasets. The NCEP data has a resolution of $1^{\circ} \times 1^{\circ}$ (or about $111.2 \mathrm{~km} \times 28.8 \mathrm{~km}$ at a latitude of $75^{\circ} \mathrm{N}$ ). The ECMWF data has a resolution of $2.5^{\circ} \times 2.5^{\circ}$ (or about $278.0 \mathrm{~km} \times 71.9 \mathrm{~km}$ at a latitude of $75^{\circ} \mathrm{N}$ ). As a note of caution, we would like to point out that one must be careful in interpreting the data from these datasets. Figure 2.5 shows a comparison between 
(a)

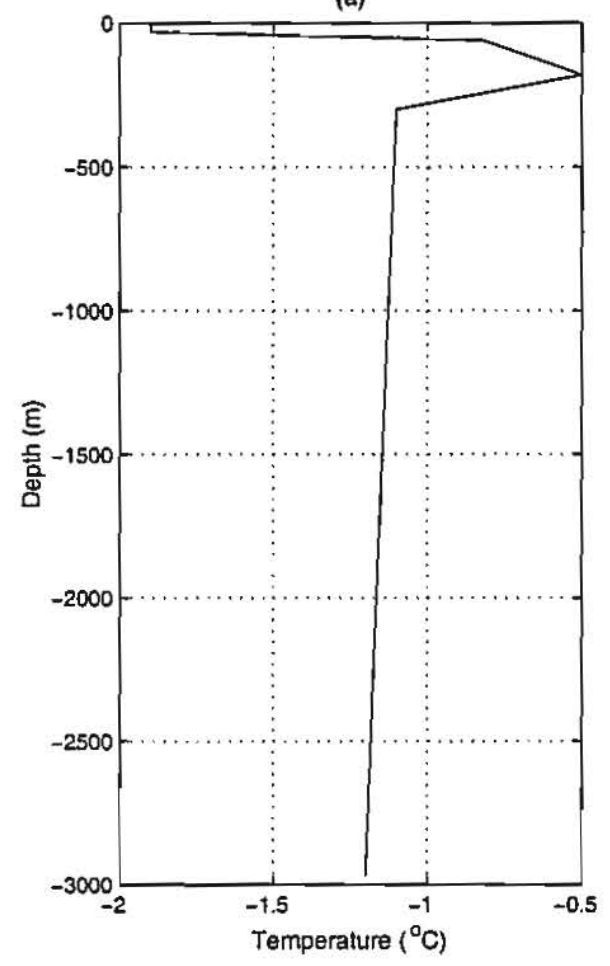

(b)

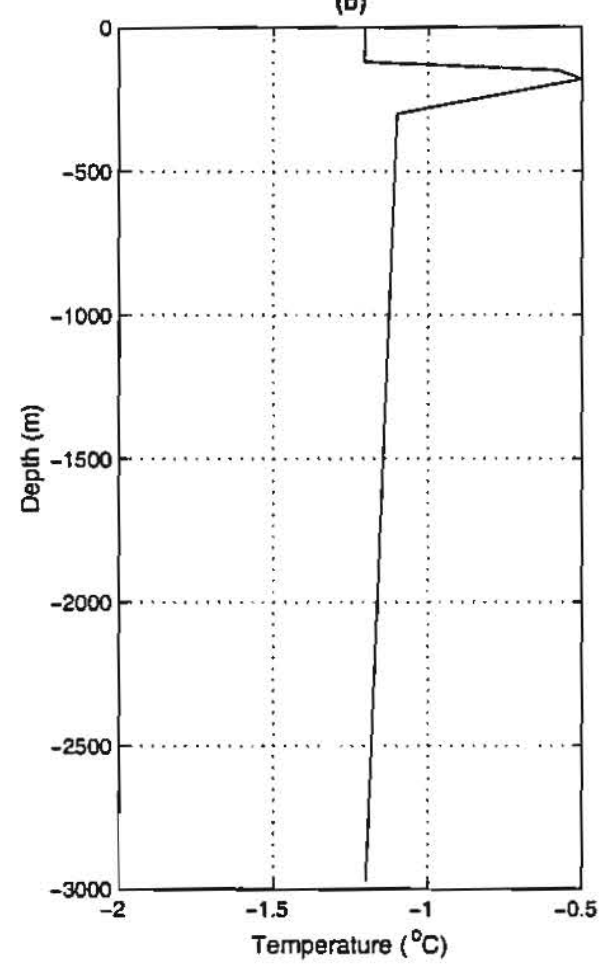

Figure 2.4: Two scenarios representing how an idealized water column could adjust to a surface heat loss when an ice cover is present. The total heat content of the water column in both cases is the same. However, in case (b) the mixed layer is deeper and warmer (closer to the "insulating limit") while in case (a) it is shallower and colder (the "rapid limit"). 


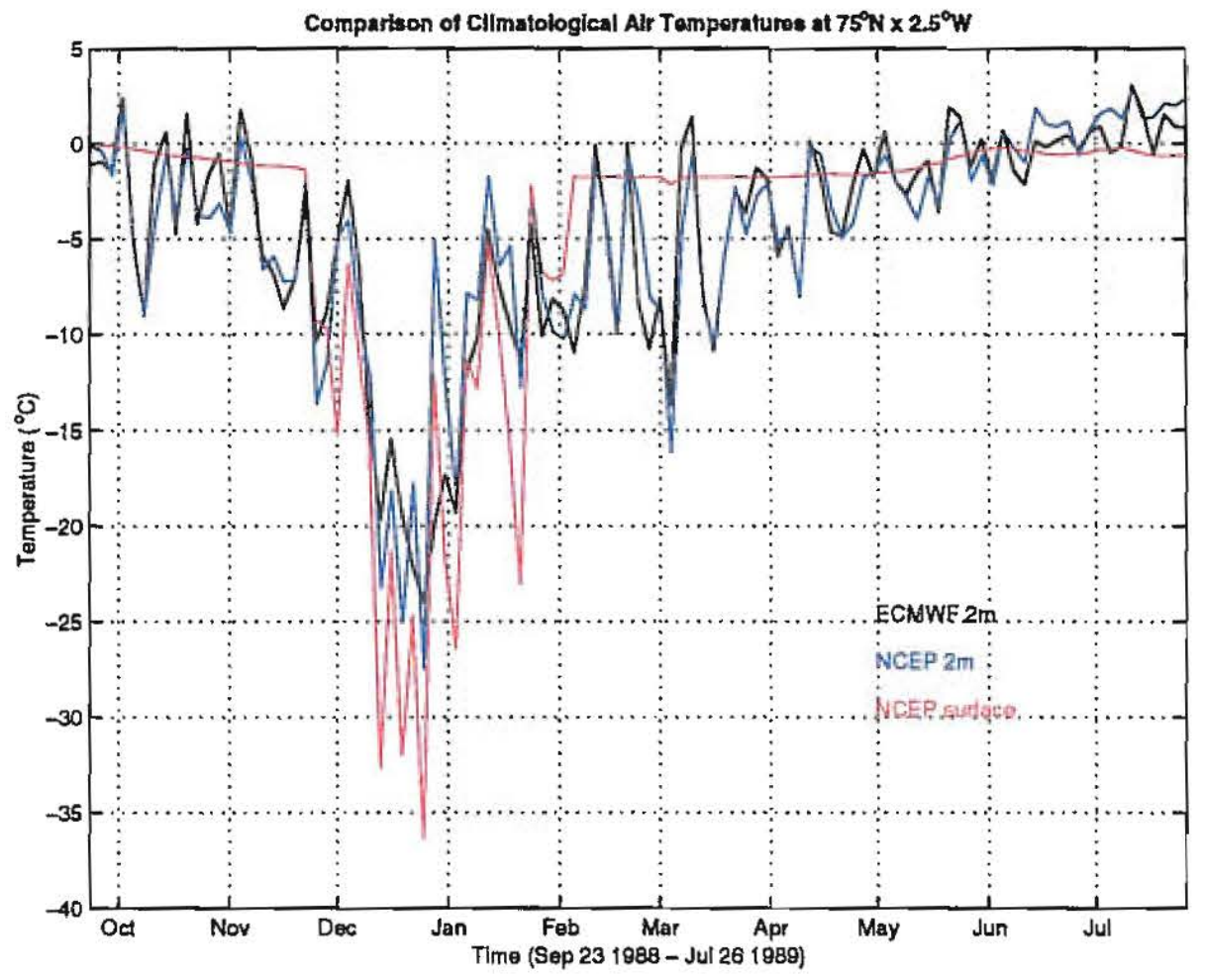

Figure 2.5: A comparison of ECMWF 2-meter, NCEP 2-meter, and NCEP surface air temperatures at location $75^{\circ} \mathrm{N} \times 2.5^{\circ} \mathrm{W}$.

air temperature records from the NCEP reanalysis database at the sea surface and at 2 meters and from the ECMWF reanalysis database at 2 meters (the ECMWF dataset did not include a surface air temperature field). While the 2 meter records from the two datasets agree quite well, the surface air temperature shows large deviations. Even though we would expect the difference between the air temperature at the sea surface and at 2 meters to be small due to strong mixing in the planetary boundary layer, the temeperature record at the sea surface shows much less variability and a warm bias when compared to the 2-meter record. This is likely due to the effect of the sea surface temperatures on the air temperature at the surface, and is probably sensitive to the details of the planetary boundary layer model used by NCEP.

Further, the United Kingdom Meteorological Office (UKMO) data from the same period (as shown in Pawlowicz et al. [1995], figure 3b) differs considerably from both the ECMWF and NCEP records. While a wintertime cold spell lasting about two months 
is evident in all three datasets, it is shifted forward by about one month in the UKMO dataset relative to the other two datasets. This is quite worrisome, and may account for some of the discrepancies between the model predictions of Morawitz et al. [1996] and observations. We will return to this point in chapter 4 .

For our model simulations (which we will present in the following chapters), we have decided to use the ECMWF reanalysis data since it is in good agreement with the NCEP reanalysis data, and is likely more reliable than the UKMO data (which is not a reanalysis dataset).

In section 4.2.2, we have attempted to relate the ice cover and air temperature evolution to the occurrence of convection based on the knowledge that we have gained about how the convection process occurs. For these purposes we have used ice cover estimates obtained from the EOS Distributed Active Archive Center (DAAC) at the National Snow and Ice Data Center (NSIDC), University of Colorado, Boulder, CO. These data were derived from microwave measurements made with the Scanning Multichannel Microwave Radiometer (SMMR) on NASA's Nimbus-7 satellite which was launched in 1978, and more recently (since 1987) with NASA's Defense Meteorological Satellite Program (DMSP) Special Sensor Microwave/Imager (SSM/I) instruments. Daily sea ice concentrations were generated by the Oceans and Ice Branch, Laboratory for Hydrospheric Processes at NASA GSFC, using SMMR brightness temperatures that were processed at NASA GSFC and SSM/I brightness temperatures processed at NSIDC. The data are gridded at a resolution of $25 \times 25 \mathrm{~km}$. Estimated errors in this product are of order $5 \%$ for first year ice concentration, with a concentration of $15 \%$ corresponding to the ice edge. Concentrations smaller than this can be considered to be open water. There are some ambiguities in the dataset arising from the different microwave characteristics of firstyear and newly formed ice. Further details about this dataset be found in Cavalieri et al. [1997]. 


\section{Chapter 3}

\section{Mixed Layer Model Formulation, Sensitivity, and Predictions}

\subsection{Model Formulation}

We have developed a model to study the evolution of the convection process. The model responds one-dimensionally to surface buoyancy forcing, in the form of heat and freshwater fluxes. A thermodynamic ice model is coupled to the system. A convective adjustment scheme is used to vertically mix statically unstable layers. The density and heat capacity of each layer in the water column are computed using the full non-linear (EOS80) equation of state for seawater.

Convection is inherently a three dimensional process, involving not only vertical mixing but also the lateral advection of properties [Marshall and Schott, 1998]. It is natural then to wonder to what extent we can represent features of this process using a one dimensional model. Others have used a variety of one dimensional models to study convection in the Greenland Sea (Pawlowicz et al. [1995], Visbeck et al. [1995], Morawitz et al. [1996]) and elsewhere (Lemke [1987], Lascaratos et al. [1993], and others). All of them claim to have had at least some degree of success.

Pawlowicz [1995] points out that the surface temperature in the Greenland Sea responds primarily to surface fluxes, and thus a 1D model can work reasonably well most of the time at predicting the surface temperature. However, this does not necessarily imply that the horizontal mass transport is negligible; rather, it occurs on scales smaller than that of the surface flux changes so that heat advection is not significant. In a study 


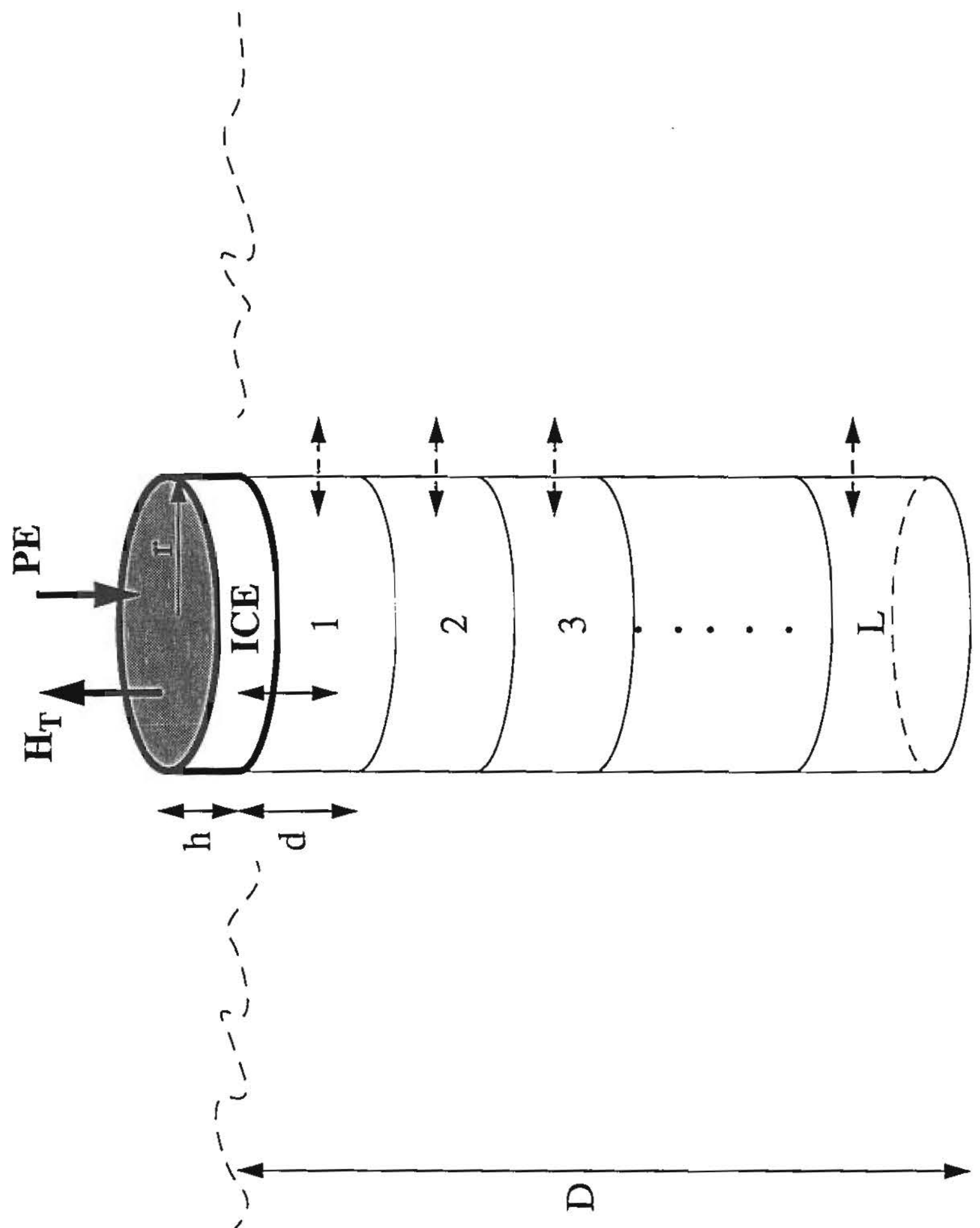

Figure 3.1: Schematic of the model used in this study. 
by Hakkinen [1995], a decrease of the model-predicted heat content of the upper $2000 \mathrm{~m}$, implying deep convection, was explained to a high degree by local heat loss.

Further, lateral effects are only important at certain times when the horizontal gradients are large [Marshall and Schott 1998], and they probably do not affect the onset of convection. We can see this by looking at the time evolution of changes in the total heat content of the water column. We will see that it matches well with the tomographic results prior to the period of mixed layer deepening, when we expect lateral effects to become important (figure 3.4).

The criterion for mixing in both convective adjustment and mixed layer models always depends on one parameter which is related to the static stability at the base of the mixed layer. In other unrelated modeling studies of oceanic mixing, it has been observed that a one-dimensional scaling correctly predicts the bulk properties of the system. For example, D. Fong [1998] observed this using a three dimensional ocean model to study wind generated coastal plumes.

The present study makes the assumption that the convection is non-penetrative. In the open ocean, non-penetrative convection gives much more realistic simulations of mixing than fully penetrative convection [Killworth 1979, Anati 1970]. Further, the stirring effects of wind and surface waves decay rapidly with depth, and so little energy is available for penetration caused by stirring. The fact that no density steps have been observed in hydrographic profiles from the Greenland Sea suggests that deep mixing by convective plumes is, to zero order, non-penetrative [Marshall and Schott 1998].

Thermobaric effects, those which occur as a result of the pressure dependence of the thermal expansion coefficient, can be important in the Greenland Sea. As a result, a plume of saline water can experience an additional decrease in stability as it moves downward in a water column, and thus lead to enhanced vertical accelerations. The model used in this study contains the full non-linear (EOS-80) equation of state, and thus thermobaric effects are included. However, it would be interesting to see exactly how these thermobaric effects manifest themselves. This could, in principle, be accomplished by comparing our model runs to a set of runs carried out using a simplified equation of state in which the thermobaric effects are not included. This was not done as part of the current study and is left for future investigation. 


\subsubsection{Parameterizations}

This model represents a water column of depth $\mathrm{D}$ as $\mathrm{L}$ layers of equal thickness $\mathrm{d}$ (see figure 3.1). The water properties within each layer (temperature and salinity) are completely homogenized. The model uses potential temperatures referenced to the surface. The water surrounding the column is asumed to have some characteristic constant ambient T-S profile. Mixing by baroclinic eddies is represented as a horizontal exchange between the column and ambient water with a specified restoring timescale $\tau_{\text {eddy }}$.

Vertical mixing is carried out by a convective adjustment scheme. Two different schemes have been implemented in this model ${ }^{1}$. The one which will be used for most of the runs is a complete mixing scheme which was proposed by Yin and Sarachik [1994]. It completely and instantaneously removes all static instabilities at every timestep. The other scheme is a 2-pass scheme similar to one which has been used in the GFDL MOM model. Differences in model output resulting from these different schemes are discussed in section 4.4. A decription of each of these convective adjustment schemes and details of their implementation in this model are given in appendix A.

The air-sea heat exchange is represented as a linear function of the air-sea temperature gradient. The air temperature is prescribed, and the water temperature is determined by the model evolution. The ice formation rate is determined by a heat balance at the surface. Ice forms above the surface layer as soon as the temperature of the surface layer falls below the freezing temperature of seawater $T_{F}$. The ice layer is assumed to have a negligible impact on the mass budget of the water column (the model uses the Boussinesq approximation, so that the volume of the water column is conserved but the total mass is not strictly conserved) and to be homogeneous and of uniform depth with no internal structure (such as air pockets, brine pockets, etc.). Further, the ice is assumed to be completely fresh ${ }^{2}$. The surface freshwater flux is assumed to precipitate in the form of snow/ice when the air temperature is below $0^{\circ} \mathrm{C}$ and as liquid freshwater otherwise. In the latter case, the water drains directly into the surface layer even if an ice layer is present and changes the salinity of the surface layer. The freshwater flux in this case is

\footnotetext{
${ }^{1}$ See Marotzke, 1991 for a discussion and comparison of different convective adjustment schemes.

${ }^{2}$ In reality the salinity of first-year sea ice is 4 to 10 , and can be as high as 15 for newly-formed sea ice [Pickard and Emery 1990, page 228-229].
} 
represented as a virtual salinity flux ${ }^{3}$. In this approximation the change in salinity is written as:

$$
\Delta S \approx S \frac{(E-P) \Delta t}{D}
$$

where $D$ is the depth of the volume of fluid and $E-P$ is the net evaporation and $\Delta t$ is a time interval. Since the variation in salinity is very small compared to the actual salinity, we may set $S=S_{\text {ref }}$ in the above equation (in the Boussinesq approximation), where $S_{\text {ref }}$ is a reference salinity which is usually chosen to be 35 (in practical salinity units).

The main effect of the surface wind stress when there is an ice cover over the ocean is to cause the ice to drift. A parameterization of this ice drift is included in the model, and is discussed later in this chapter. When the ocean surface is ice-free, then the wind stress can have a significant effect on the heat flux, according to equation 1.1. This effect, as well as the latent loss due to evaporation are not represented in this model.

In the wintertime, there is very little sunlight in the Arctic. It is therefore reasonable to neglect heating by solar shortwave radiation. However, as we mentioned earlier in section 1.2, in the summertime insolation is an important source of heat for the surface waters. Therefore, a constant heat flux of $50 \mathrm{~W} / \mathrm{m}^{2}$ was added during these months to account for insolation.

It is assumed that ice has no sensible heat storage and the ice layer is of uniform depth and constant density (no internal structure). Leads, thermal longwave emissions, and albedo will also be ignored.

This model, in the limit of no convection (single layer), no salinity effects, and no lateral eddy mixing, is similar to one constructed by Welander [1976]. His model assumes the existence some constant source of heating from below.

As we will see later, freezing-melting cycles can occur in our model because there is a finite ice to surface layer coupling which does not force the surface layer water temperature to be at the freezing point when there is an ice cover. In models which assume an infinitely strong coupling, the temperature of the surface layer is set to the freezing

\footnotetext{
${ }^{3}$ This means that rather than adding an amount of freshwater to the surface layer, an equivalent amount of salinity is removed from the surface layer (resulting in no change in the volume of the water column).
} 
point whenever there is an ice cover. Therefore, such models are not able to simulate freezing-melting cycles.

The density of pure ice is $916.8 \mathrm{~kg} / \mathrm{m}^{3}$; however the density of sea ice may differ from this value (depending, for example, on whether there are brine pockets or if the brine has escaped and there are air pockets). Sea ice density has been observed to vary in the range 924 to $857 \mathrm{~kg} / \mathrm{m}^{3}$ [Pickard and Emery 1990, page 229]. For this study, we will assume a constant value of $920 \mathrm{~kg} / \mathrm{m}^{3}$.

\subsubsection{Model Equations}

The model behavior is defined by one of two sets of equations, depending on whether or not there is ice present.

For ice-free conditions $(h=0)$, the heat flux between the atmosphere and the surface water is given by

$$
H_{a s}=\gamma\left(T_{1}-T_{A}\right)
$$

where $\gamma$ is the thermal coupling strength between the atmosphere and the surface layer. The prognostic equations are:

$$
\begin{aligned}
h & =0 \\
\rho_{w} d c_{p} \dot{T}_{1} & =\tilde{Q}_{1}^{T}-\gamma\left(T_{1}-T_{A}\right) \\
\rho_{w} d \dot{S}_{1} & =\tilde{Q}_{1}^{S}
\end{aligned}
$$

where $\tilde{Q}_{i}^{T}$ is the total heat flux between the water column and the ambient water at the $i^{\text {th }}$ level:

$$
\tilde{Q}_{i}^{T}=\frac{\rho_{w} d c_{p}}{\tau_{e d d y}}\left(T_{i}^{A M B}-T_{i}\right)
$$

and $\bar{Q}_{i}^{S}$ is the salt flux between the water column and the ambient water at the $i^{\text {th }}$ level:

$$
\bar{Q}_{i}^{S}=\frac{\rho_{w} d}{\tau_{e d d y}}\left(S_{i}^{A M B}-S_{i}\right) .
$$

$\tau_{e d d y}$ is the timescale for restoring to the ambient profile by lateral advection, $\rho_{w}$ is the density of water, and $c_{p}$ is the heat capacity of water. 
For ice-covered conditions $(h>0)$, the heat flux between the atmosphere and the upper surface of the ice is given by

$$
H_{a s}=\gamma_{i}\left(T_{A}-T_{S}\right)
$$

where $T_{A}$ is the air temperature, $T_{S}$ is the temperature at the upper surface of the ice layer in contact with the atmosphere, and $\gamma_{i}$ is the thermal coupling strength between the atmosphere and the ice. The heat flux through the ice layer is given by

$$
H_{s i}=\frac{k}{h}\left(T_{S}-T_{F}\right)
$$

where $T_{F}$ is the freezing point of water and $k$ is the heat conduction strength through ice. The lower surface of the ice layer, in contact with water, is assumed to be at temperature $T_{F}$. The heat flux between the ice and surface layer of water is given by

$$
H_{i w}=\mu\left(T_{1}-T_{F}\right)
$$

where $\mu$ is the coupling strength between the ice and mixed layers and $T_{1}$ is the temperature of the top layer of the water column. We impose an energy balance condition at the atmosphere-ice interface

$$
H_{a s}=H_{s i},
$$

from which we derive the following expression for the surface temperature $T_{S}$

$$
T_{S}=\frac{k}{h}\left(\frac{\gamma_{i} T_{A}+\frac{k}{h} T_{F}}{\frac{k}{h}+\gamma_{i}}-T_{F}\right) .
$$

Thus,

$$
H_{a s}=H_{s i}=\frac{k}{h+\frac{k}{\gamma_{i}}}\left(T_{A}-T_{F}\right) .
$$

The prognostic equations when $(h>0)$ are:

$$
\begin{aligned}
\rho_{i} L_{f} \dot{h} & =\left(H_{s i}-H_{i w}\right) \\
\rho_{w} d c_{p} \dot{T}_{1} & =\left(\bar{Q}_{1}^{T}-H_{i w}\right) \\
\rho_{w} d \dot{S}_{1} & =\tilde{Q}_{1}^{S}+\rho_{i} S_{r e f} \dot{h}
\end{aligned}
$$

The equations above can be reduced to the following set of equations for $S, T, h$ :

$$
\begin{aligned}
\rho_{i} L_{f} \dot{h} & =\frac{k}{h+\frac{k}{\gamma_{i}}}\left(T_{A}-T_{F}\right)-\mu\left(T_{1}-T_{F}\right) \\
\rho_{w} d c_{p} \dot{T}_{1} & =\tilde{Q}_{1}^{T}-\mu\left(T_{1}-T_{F}\right) \\
\rho_{w} d \dot{S}_{1} & =\tilde{Q}_{1}^{S}+\rho_{i} S_{\text {ref }} \dot{h}
\end{aligned}
$$


To ensure a smooth transition between the ice-free and ice-covered heat flux laws, we require

$$
\gamma_{i}=\gamma .
$$

After each timestep in the forward integration of these equations, the convective adjustment scherne is applied.

This model, although relatively simple, captures many of the important physical processes. It is possible to incorporate other effects into this model in a simple way, and are a subject for further investigation. Leads can be parametrized by a modification of the surface heat and freshwater fluxes to allow for direct exchanges between the atrnosphere and surface layer even when some ice is present. For example, one can define an ice cover parameter $\epsilon$ which is the ratio of ice covered surface area to total surface area. Then, the surface fluxes can be represented as a sum of the ice-covered and ice-free fluxes, weighted by $\epsilon$ and $1-\epsilon$, respectively. More sophisticated sea ice models, such as the one presented by Parkinson and Washington [1979], incorporate representations of many other processes.

\subsubsection{Ice Drift}

Ice drift will have the effect of changing the local ice thickness in a basin, increasing it in certain regions and decreasing it in other areas. The processes by which this occurs involve details of internal ice dynamics, and this treatment is beyond the scope of the current study. However, we can parameterize this ice drift in a simple way which is consistent with our idealization of the ice cover as a slab, by assuming that there is an ice volume gradient. A one-dimensional ice volume conservation law is given by

$$
\frac{d h}{d t}=\frac{\partial h}{\partial t}+u \frac{\partial h}{\partial x}=\text { Freezing }- \text { Melting }
$$

where we have assumed that there is an ice volume gradient $\frac{\partial h}{\partial x}$ which is positive in the direction of the ice drift, and that the net freezing rate (right hand side of equation (3.21)) is positive. According to our parameterization of the ice drift,

$$
u \frac{\partial h}{\partial x}=\lambda h .
$$

Thus, $\lambda$ scales as follows

$$
\lambda \sim \frac{u}{h} \frac{\Delta h}{\Delta x}
$$


assuming that the ice volume gradient and the speed of the ice drift are constant.

The wintertime mean winds are towards the southwest with a speed of approximately $5 \mathrm{~m} / \mathrm{s}$ [Visbeck et al. 1995]. As a rule of thumb, ice drifts at about $1 / 50$ of the wind speed [Macklin 1983]. This suggests an ice drift speed of $10 \mathrm{~cm} / \mathrm{sec}$. This estimate is in agreement with observations in the Greenland Sea [Toudal et al. 1996] of ice drifting at speeds of $10-20 \mathrm{~cm} / \mathrm{sec}$. The ice sheet moves away from the central gyre region at a constant speed to the southwest. Lagrangian drifter studies [Poulain et al. 1996] indicate that there is a cyclonic circulation around the central gyre region; however, there is no evidence to suggest that there is any surface flow into the central gyre region from the periphery. So it is not unreasonable to assume that little or no ice will be entrained into the central gyre from the northeast to replenish the ice being advected away. This means there will be a net divergence in the ice flow, which is consistent with observations of the opening of the ice-free bay in the central gyre region (figure 1.5).

Based on the above scaling, we find an estimate for $\lambda$ in the range $0.03-0.41 d^{-1} y^{-1}$ for $u$ between 10 and $20 \mathrm{~cm} / \mathrm{sec}$ and $h$ and $\Delta h$ between 10 and $25 \mathrm{~cm}$, where $\Delta h$ varies over a distance $\Delta x=105 \mathrm{~km}$ (which is the distance between moorings 4 and 6 in the central Greenland Sea gyre (figure 2.1)). This corresponds to a timescale of between 2 and 30 days.

A sufficient amount of ice must be advected away from the convecting region to remove the surface fresh anomaly. In two months, an ice drift resulting in a reduction in ice thickness at a rate of $3.2 \mathrm{~cm} /$ day (e.g. with an average ice thickness of $10 \mathrm{~cm}$ and $\lambda=0.32 \mathrm{day}^{-1}$ ) will result in $\Delta h=1.9$ meters of ice being removed (close to $5 \%$ of the depth of the surface layer!). The equivalent change in salinity of the top 60 meters (roughly the depth of the halocline) caused by the removal of this much ice, given by

$$
\Delta S=S_{\text {ref }} \frac{\Delta h}{D_{m l}} \frac{\rho_{\text {ice }}}{\rho_{w}},
$$

is 1 psu. This, as we can see from figure 3.2, is very close the average salinity difference between the top two layers and the deeper water. 


\subsubsection{Surface Thermal Forcing}

The other modeling studies of the evolution of convection in the Greenland Sea that we are aware of have specified a surface heat flux from the output of numerical weather prediction (NWP) models. We have elected not to do this, and instead to parametrize the surface heat flux in terms of the surface air temperature. There are a number of very good reasons for specifying the air temperature rather than directly forcing the model with surface heat fluxes.

First of all, the heat flux parameterization which we have used is faithful to the surface boundary layer dynamics to lowest order, as represented in the bulk formula (equation 1.1). We can therefore expect it to capture most of the dominant physical effects. A specified heat flux does not permit a feedback between the atmosphere and the ocean.

Secondly, NWP air temperatures are more robust than heat fluxes. In particular, Visbeck et al. [1995] state that the ECMWF model heat fluxes do not acknowledge the local ice cover very well. Therefore, they applied ad hoc adjustments to the NWP heat fluxes during the ice covered period.

Thirdly, since there is a large observed variability in the air temperature in the Greenland Sea which may have an impact on convective activity, it is particularly useful to be able to examine directly the impact on the convection process of changing air temperatures.

Finally, and most importantly, since ice plays such a central role in the evolution of the wintertime mixed layer in the Greenland Sea, it is important to have a robust representation of the ice evolution in the model. However, since the surface heat flux is dependent on the ice cover, one cannot specify a priori the heat flux and then independently have the model determine the evolution of the ice cover. This latter is pre-determined when the surface heat flux is specified. The model then does not have the freedom to predict the evolution of the ice cover. 


\subsection{Baseline Run}

We will start out by defining a baseline run which will be used as a reference for later experiments in which certain parameters are varied. This run does not nesessarily represent the closest fit of the model to the observations. It is likely that a more carefully tuned set of parameter values or initial conditions will lead to a closer fit. However, our main purpose is to understand the role and interaction of the processes which are represented in the model. Thus, we felt that it was more appropriate whenever possible to choose the model parameter values to best represent the physical processes and to initialize the model run with observed conditions. This will ensure that our parameterizations of the physical processes which are represented are robust. In addition, discrepancies between model output and observations can then more cleanly be interpreted in terms of physical processes that are not represented in the model or observational uncertainties.

\subsubsection{Model Configuration}

We will begin by describing our choice of parameter values. The value of $k$ has been determined from laboratory studies to have a value of $2 \mathrm{~W} / \mathrm{m} / \mathrm{K}$ and is well documented [Hobbs 1974]. The open ocean air-sea coupling strength for the surface heat flux was chosen to be $50 \mathrm{~W} / \mathrm{m}^{2} / \mathrm{K}$. This corresponds to a forcing timescale of about one month, and is the value that was used by Zhang et al. [1995] who coupled a thermodynamic sea-ice model to an ocean general circulation model (GCM). The maximum depth of convection was found to be sensitive to the value of the ice drift inverse timescale $\lambda^{-1}$. We chose a value of $0.32 d a y^{-1}$ to yield a maximum convection depth of about 1500 meters. This value is consistent with our estimate above, based on the observed ice drift speed. The model was run with a one day timestep. The most uncertain parameter value is the strength of the coupling $\mu$ between the ice and surface layers. We chose to use a value of $500 \mathrm{~W} / \mathrm{m}^{2} / \mathrm{K}$, corresponding to a timescale of about 3 days. However, the model-predicted mixed layer depth is not sensitive to $\mu$ over a large range of values. We will discuss the model's sensitivity to $\mu$ in detail later on.

The model was forced with air temperature and net freshwater fluxes from the ECMWF reanalysis database. It was initialized with temperature and salinity data from 


\begin{tabular}{|c|c|c|}
\hline Symbol & Constant & Value \\
\hline $\mathrm{d}$ & Thickness of each layer & $30 \mathrm{~m}$ \\
\hline $\mathrm{L}$ & Number of layers & 100 \\
\hline $\mathrm{D}$ & Total depth of water column & $3000 \mathrm{~m}$ \\
\hline $\mathrm{r}$ & Horizontal Scale & $105 \mathrm{~km}$ \\
\hline$T_{F}$ & Freezing temperature of seawater & $-1.9^{\circ} \mathrm{C}$ \\
\hline$L_{f}$ & Latent heat of fusion of seawater & $3.33 \times 10^{5} \mathrm{~J} \mathrm{~kg}^{-1}$ \\
\hline$S_{\text {ref }}$ & Reference salinity & 35.0 \\
\hline$\rho_{\text {ice }}$ & Density of sea ice & $920 \mathrm{~kg} / \mathrm{m}^{3}$ \\
\hline
\end{tabular}

Table 3.1: Constants contained in the model, along with their values.

\begin{tabular}{|c|c|c|}
\hline Symbol & Parameter & Baseline Run Value \\
\hline$\gamma$ & Air - surface water layer coupling & $50 \mathrm{~W} \mathrm{~m}^{-2} \mathrm{~K}^{-1}$ \\
\hline$\gamma_{i}$ & Air - ice surface coupling & $50 \mathrm{~W} \mathrm{~m}^{-2} \mathrm{~K}^{-1}$ \\
\hline$k$ & Heat conductivity through ice & $2 \mathrm{~W} \mathrm{~m}^{-1} \mathrm{~K}^{-1}$ \\
\hline$\mu$ & Ice - surface layer coupling & $500 \mathrm{~W} \mathrm{~m}^{-2} \mathrm{~K}^{-1}$ \\
\hline tstep & Integration timestep & 1 day \\
\hline$\lambda$ & Ice drift inverse timescale & 0.32 day $^{-1}$ \\
\hline
\end{tabular}

Table 3.2: Parameter values used in the model baseline run. 
a conductivity-temperature-depth (CTD) cast made during the tomographic array deployment cruise at a location close to mooring $4\left(74.5333^{\circ} \mathrm{N} \times 5.7883^{\circ} \mathrm{W}\right)$ on Sept. 18 , 1988. As Pawlowicz et al. [1995] point out, there was a large spatial variation in the surface salinity, and in a CTD cast made near mooring 6 a surface salinity of about 34.3 was observed. If we had chosen to initialize our model with this profile instead, our model results would have changed. We will discuss the effects on the model output of changing the initial surface salinity later on.

\subsubsection{Results}

The model evolution in figures 3.2 and 3.3 shows how the preconditioning process unfolds. Starting in mid-November, the air temperatures cool and the surface layer responds by forming ice at a rate of up to $5 \mathrm{~cm} /$ day. The thickness of the ice layer increases, although it is kept in check by the ice drift. In early December the air temperature drops sharply and correspondingly the ice layer thickness doubles. By late December, there has been a sufficient amount of brine rejection for the surface layer to penetrate into the second layer. The result is a large influx of heat into the surface layer which rapidly melts half of the ice cover ${ }^{4}$. Since the air temperature is still very cold (around $-20^{\circ} \mathrm{C}$ ), the sensible heat loss is sufficient to keep the surface layer cold and to form more ice. Therefore, the brine rejection continues until the salinity increase is sufficient to penetrate the third layer. At this point, the entrained heat again melts much of the ice cover. Now, since the air temperature is warming, there is no new ice formation and the existing ice quickly disappears. The ice-free surface layer, which has warmed to close to $-1^{\circ} \mathrm{C}$, is thus exposed to large sensible heat losses of up to $500 \mathrm{~W} / \mathrm{m}^{2}$. Since the large fresh anomaly in the nearsurface layers has been removed, this heat flux is sufficient to cause a steady deepening of the mixed layer which continues until May. The surface heat flux then reverses sign as a result of insolation, and the mixed layer deepening ceases ${ }^{5}$.

\footnotetext{
${ }^{4}$ Note that when there is an ice cover present, we have defined the net surface heat flux to be the heat flux into the ice layer.

${ }^{5}$ In figure 3.3(e), we have plotted both the mixing depth (which is the maximum depth to which a static instability mixes at each timestep) and the mixed layer depth (which is the depth of the homogenized layer). At any given time it is possible for the mixed layer depth to be large, as a result of earlier mixing, even if no mixing is actually occurring at that time.
} 
Potential Temperature and Salinity Evolution for Model Baseline Run
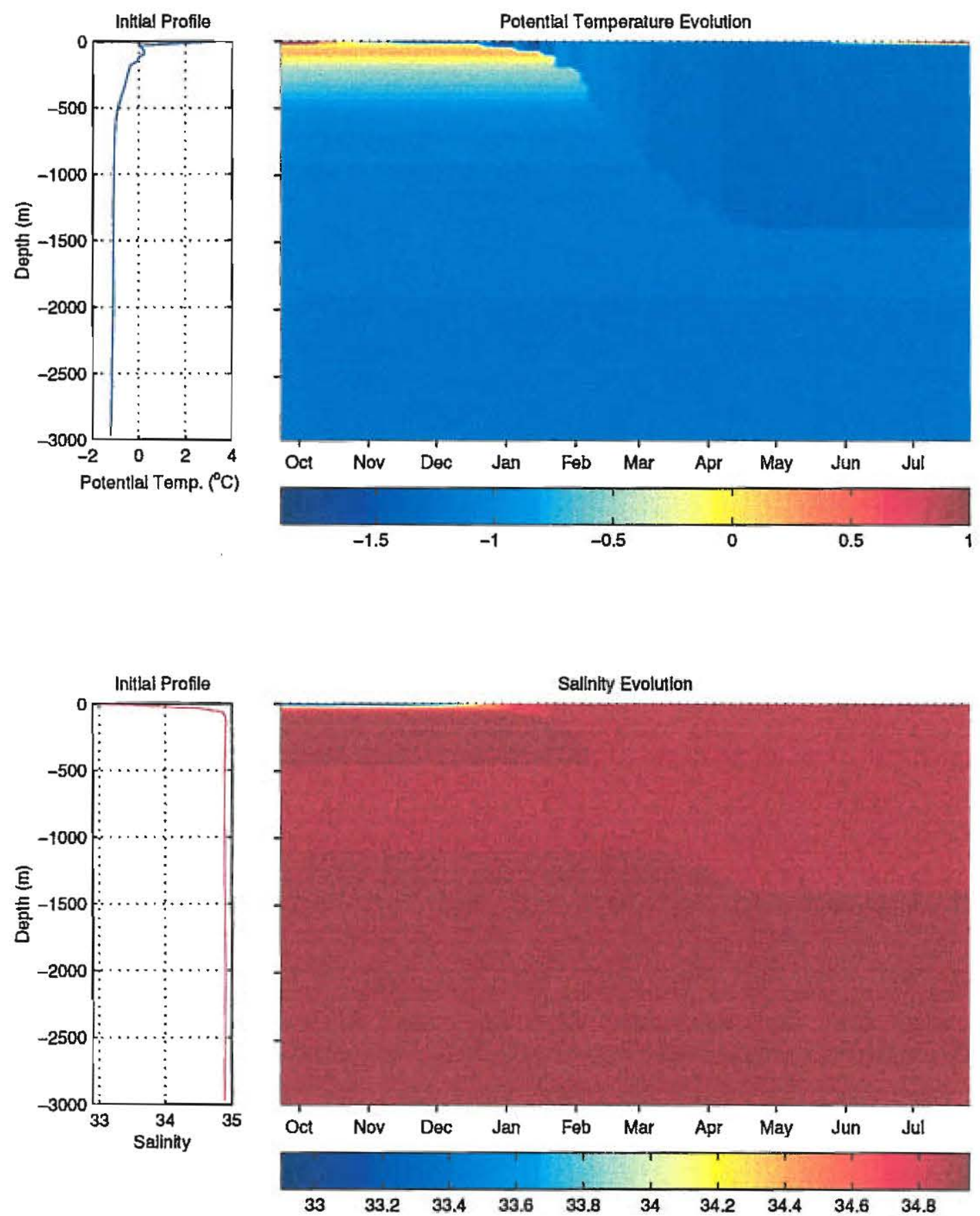

Figure 3.2: Potential Temperature and Salinity Evolution for baseline model run. Model parameters for this run are shown in table 3.2. 


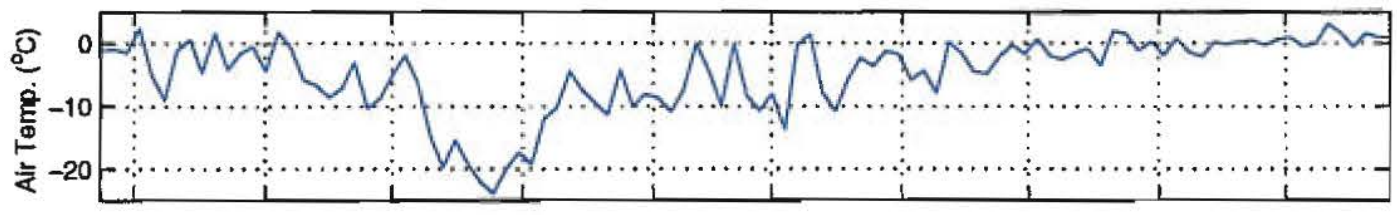

(a)

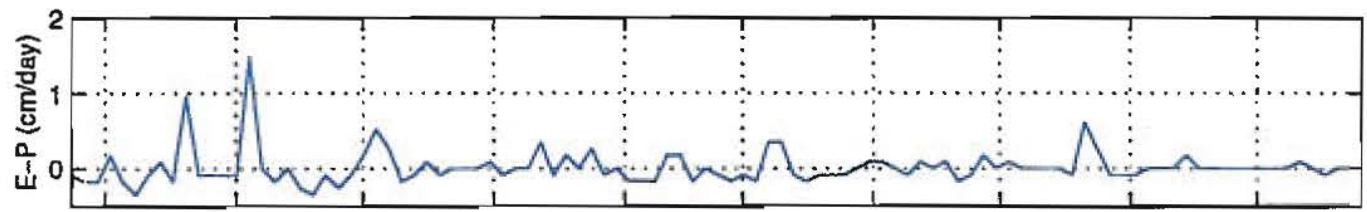

(b)
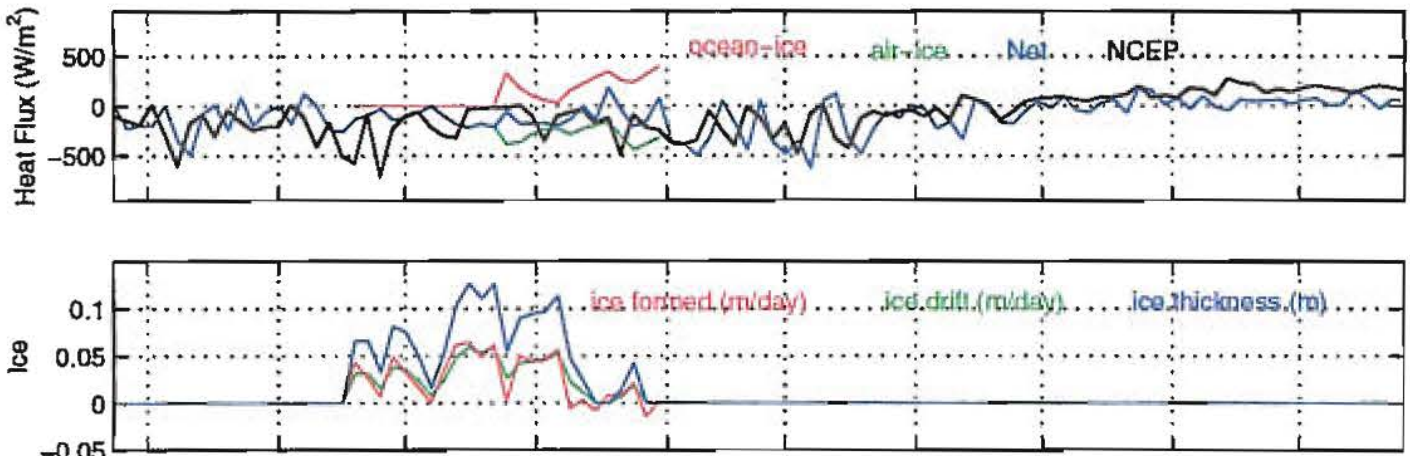

(d)

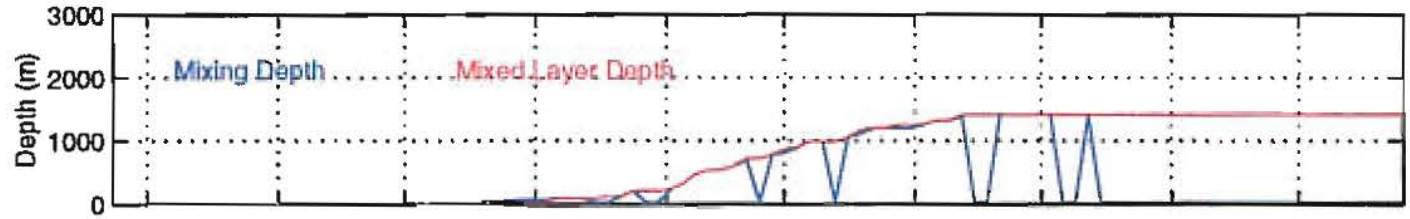

(e)
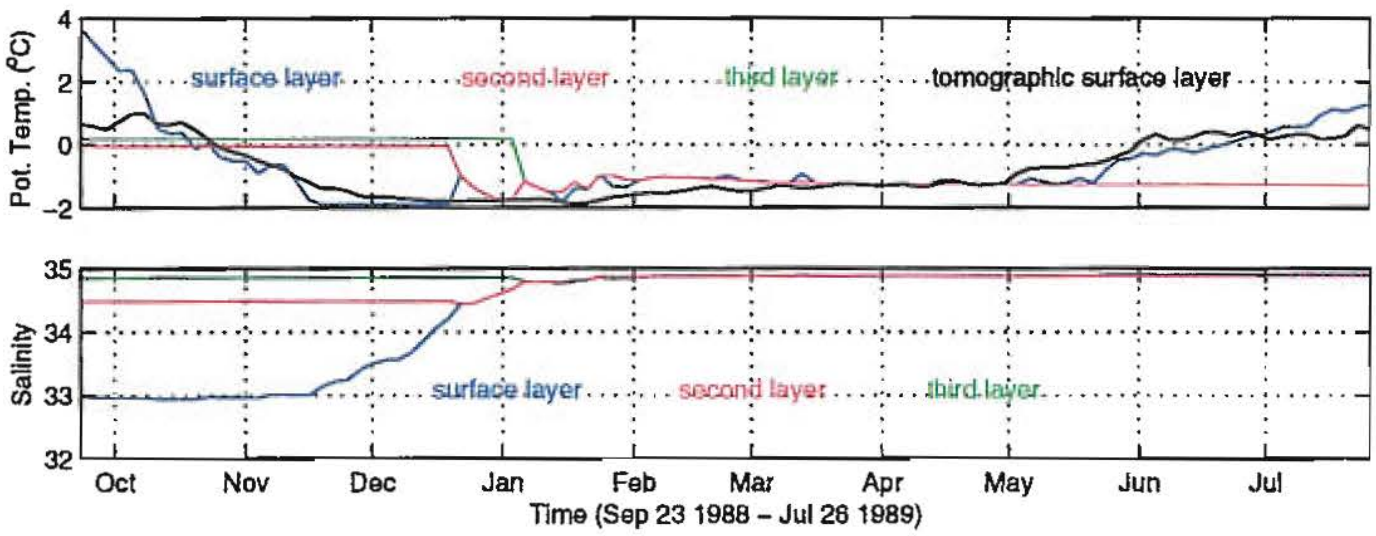

(g)

Figure 3.3: Model output for baseline model run. Model parameters for this run are shown in table 3.2 . 
This evolution is generally consistent with observations that were made to the northeast of the region that we are considering (along the 1-6 path of the tomographic array), described by Roach et al. [1993]. Using a variety of observational methods, they observe that the process of preconditioning leads to convective overturn which brings warmer water to the surface and results in the rapid disappearance of ice. By early December, the mixed layer has cooled to the freezing point. The salinity increases through brine rejection resulting from ice formation at a rate of about $0.016 \mathrm{~m} /$ day. When the vertical density gradient had been sufficiently eroded, a period of high $>300 \mathrm{~W} / \mathrm{m}^{2}$ heat flux provided enough buoyancy loss to convectively mix the upper water column to at least 200 meters. During the initial sinking, the vertical velocities were estimated at $\approx 3 \mathrm{~m} / \mathrm{s}$. The deepening of the thermocline raised surface temperatures by over $1^{\circ} \mathrm{C}$, resulting in nearly $1.5 \times 10^{5} \mathrm{~km}^{2}$ of ice melt within two days. They measured average rates of ice drift to be about $11 \mathrm{~km} /$ day to the southwest, consistent with a wind-driven flow.

\subsubsection{Comparison with Tomographic Observations}

Qualitatively, the potential temperature evolution predicted by the model (figure 3.2) shares many features in common with the tomographic record (figure 2.2). The timing of the onset of convection, the duration of the ice-covered period, and the maximum depth of convection are all consistent. The main discrepancy between the two occurs during the restratification period following the deep mixing (starting around May). This is not surprising since this model run contains no lateral advection. In chapter 4 we will discuss the effects of lateral advection. The heat content evolution computed from the model output differs considerably from the heat content estimates computed from the tomographic data. The initial large discrepancy is entirely accounted for by the large difference in the initial temperature of the surface layer. The profile that we used to initialize our model has a surface layer temperature of almost $4^{\circ} \mathrm{C}$, compared to less than $1^{\circ} \mathrm{C}$ in the tomographic data. When we removed this bias, the resulting heat content evolution (dashed line in figure 3.4) matched quite well with the tomographic estimate until about February. However, at around the time when the mixed layer started deepening, the model output showed a larger drop in heat content than the tomographic observations. This is probably in large part due to the non-local influx of heat due to lateral advection. Another 
possibility is that since the tomographic inversion gives temperatures averaged over a 105 $\mathrm{km}$ path, and the actual convecting patch has been estimated to be only about $60 \mathrm{~km}$ in diameter [Morawitz et al. 1996], there may be biases resulting from water outside the convecting patch being included in the average temeprature. Sutton et al. [1997] compared tomographic heat content estimates to the heat content changes that would have resulted from climatological heat fluxes alone. Their plot showing the comparison looks qualitatively very much like figure 3.4. They found that departures from a one dimensional heat balance occurred during the latter half of January and then again starting in mid-February. They suggest, based on observations, that there may have been a significant advection of warm water from the northern edge of the gyre during those times. This would explain the larger measured heat content relative to our model predictions.

At the end of November, when the mixed layer is at the freezing point, a few hydrographic profiles observed during R/V Meteor stations on November 28 and 29, 1988 indicate that the mixed layer has deepened (to about 60-80 meters) and has become more saline (between 33.85 and 34.55). Pawlowicz et al. [1995] argue that since there is no significant change in the net water column salt content during this period, the increase in salinity near mooring 6 to about 34.6 is due to entrainment alone as the mixed layer depth increases from about 40 to 80 meters. However, such an increase in the mixed layer would also imply a significant warming of the mixed layer due to the deepening of the thermocline. Yet our model results indicate that there had already been a substantial amount of ice formation by this time (figure 3.3(d)), and SSM/I data indicate an ice concentration of close to $50 \%$ at the end of November (figure 2.2). This suggests that some brine rejection must have occured, and that the mixed layer could not have deepened and warmed everywhere. Further, as Pawlowicz [1995] mentions, there is a large spatial variability in the surface temperature and salinity, and none of the R/V Meteor stations were directly in the 6-4 path of the tomographic array. Therefore, we conclude that while there was probably a salinity increase in the mixed layer in a region around mooring 6 caused by entrainment as Pawlowicz et al. [1995] suggest, this was not a widespread occurrence and brine rejection likely also played a role. Since our model does not include a representation of the effects of wind stirring, we cannot determine directly how our results would change if wind stirring were included. 


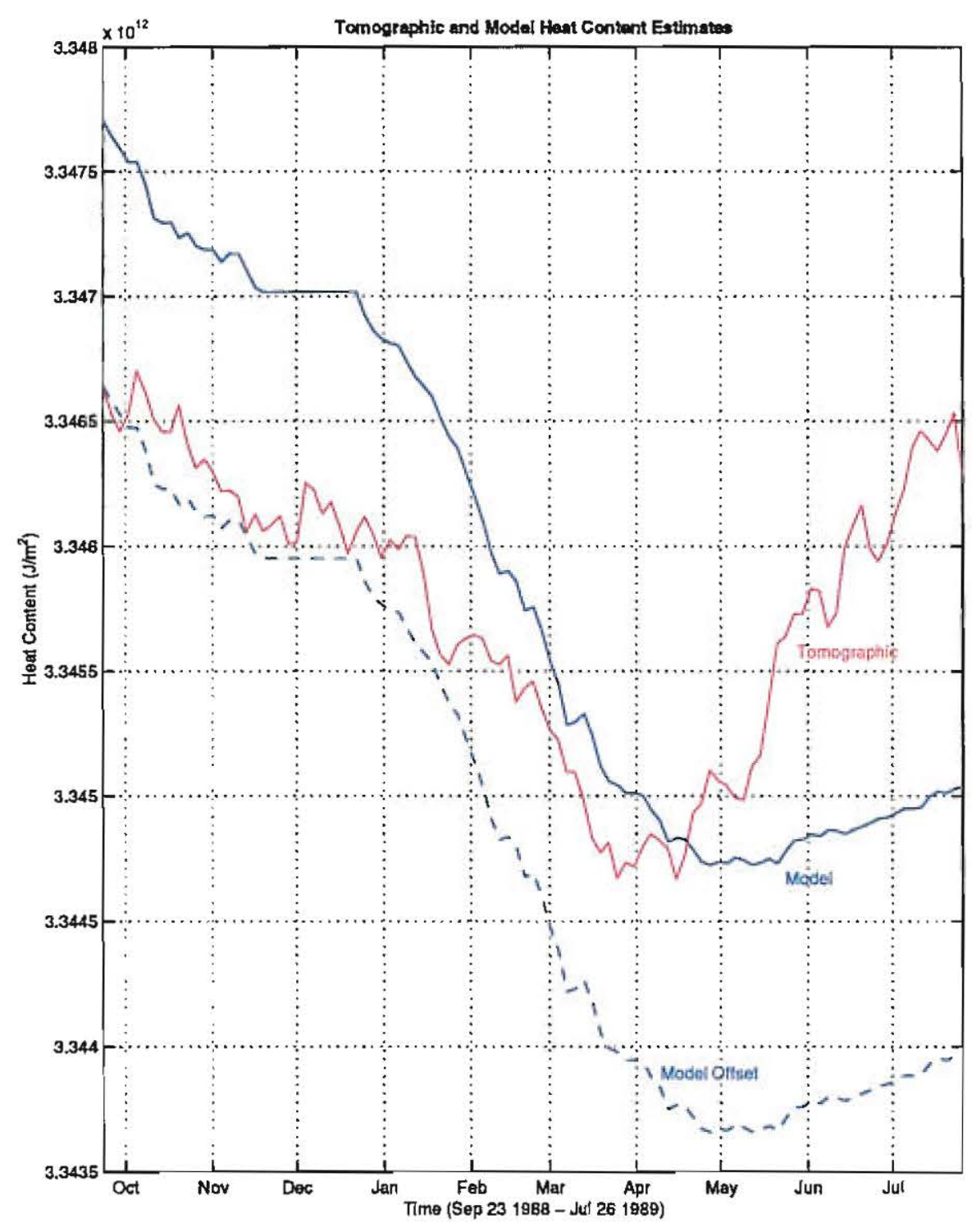

Figure 3.4: Comparison between tomographic and model estimated heat content evolution of the water column. The dashed line indicates the model output offset so that it initially matches the tomographic estimate. 


\subsection{Limiting Cases and Model Sensitivity}

\subsubsection{Atmosphere - Ice Coupling}

We now examine two limiting cases of equations (3.13) for ice-covered conditions, when the ice is very thin and very thick. We then present an alternative heat flux formulation to the one presented in section 3.1. It is a hybrid of the two limiting cases discussed below.

Thick ice limit : $h>>k / \gamma$

In this limit, the heat flux through the ice is given by

$$
H_{s i}=\frac{k}{h}\left(T_{A}-T_{F}\right) .
$$

As we can see in figure (3.5), this approximation is quite good when the ice thickness is very large (greater than $30 \mathrm{~cm}$ ), but it substantially overestimates the heat flux when the ice thickness is closer to $h_{c}=k / \gamma$ (chosen to be $4 \mathrm{~cm}$ ).

Thin ice limit : $h<<k / \gamma$

In this limit, the expression (3.13) for the heat flux through the ice becomes

$$
H_{s i}=\gamma\left(T_{A}-T_{F}\right) .
$$

This heat flux is independent of the ice thickness $h$. It is strictly correct after the surface layer has cooled to the freezing point, just when ice formation begins. However, as ice forms this quickly becomes a very bad approximation (see figure 3.5).

\section{Hybrid Formulation}

We now present a heat flux formulation which consists of a hybrid between the thick and thin ice limits. The heat flux is given by the thick ice limit when the ice thickness is 


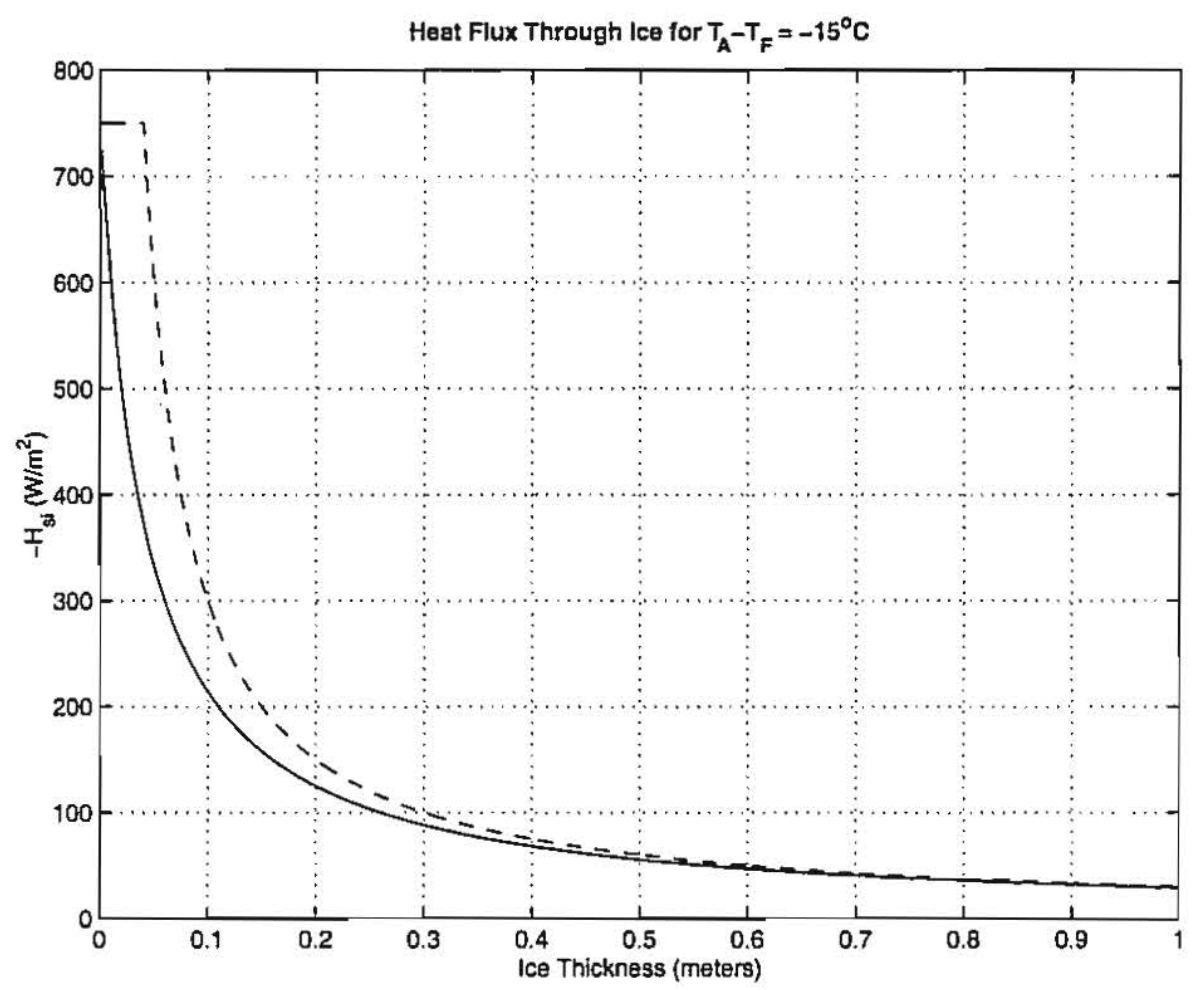

Figure 3.5: The solid line shows the heat flux through ice for a constant $T_{A}-T_{F}=-15^{\circ} \mathrm{C}$, given by $H_{s i}=\frac{k}{h+\frac{k}{\gamma}}\left(T_{A}-T_{F}\right)$. The dashed line shows the hybrid heat flux formulation; this consists of the thick ice limit, given by $H_{s i}=\frac{k}{h}\left(T_{A}-T_{F}\right)$, when $h \geq \frac{k}{\gamma}=4 \mathrm{~cm}$ and of the the thin ice limit, given by $H_{s i}=\gamma\left(T_{A}-T_{F}\right)$, when $0<h<\frac{k}{\gamma}=4 \mathrm{~cm}$. 
greater than a critical ice thickness $h_{c}=k / \gamma$ and by the thin ice limit when $h<h_{c}$. A comparison of a model run using this hybrid formulation with a run using the baseline formulation presented in section 3.1 is shown in figure (3.6). In order to obtain similar results for the mixed layer evolution, a significantly smaller value of $\lambda$ had to be used in the hybrid run compared with the baseline run $\left(0.19\right.$ day $^{-1}$ versus $\left.0.32 d a y^{-1}\right)$, corresponding to a longer timescale for ice advection. This is not surprising since the heat flux and ice advection are coupled through their dependence on the ice thickness $h$. Thus, there is a feedback effect. The hybrid formulation overestimates the heat flux. This means more ice is formed. Thicker ice means the ice advection rate $\lambda h$ is larger. Hence, even more ice is formed, leading to more brine rejection and a stronger preconditioning.

\subsubsection{Rapid vs. Insulating Limit}

In this section we examine how the model output changes as the strength of the coupling $\mu$ between the mixed layer and ice layer is varied (see figure 3.7). $\mu=0 \mathrm{~W} / \mathrm{m}^{2} / \mathrm{K}$ corresponds to the insulating limit while a very large value of $\mu$ corresponds to the rapid limit.

As we mentioned in chapter 2, observations made north of Fram Strait during CEAREX 89 [McPhee 1992, figure 17(c)] are consistent with coupling values between 100 and $600 \mathrm{~W} / \mathrm{m}^{2} / \mathrm{K}$. Zhang et al. [1995] used a value of $180 \mathrm{~W} / \mathrm{m}^{2} / \mathrm{K}$ in their study, and they found that their model results were not sensitive to the exact value as long as it remained between 125 and $250 \mathrm{~W} / \mathrm{m}^{2} / \mathrm{K}$. We found that with a value of $180 \mathrm{~W} / \mathrm{m}^{2} / \mathrm{K}$, our model results differed from the baseline run (which used a value of $500 \mathrm{~W} / \mathrm{m}^{2} / K$ ) during the preconditioning period. In particular, the surface layer was warmer and the ice thickness was greater than in the baseline run. However, the length of the preconditioning period and the subsequent mixed layer deepening were almost the same. As we get very close to either limiting case though, this is no longer the case.

In the limiting case of $\mu=0 \mathrm{~W} / \mathrm{m}^{2} / K$, and for $\mu=5 \mathrm{~W} / \mathrm{m}^{2} / K$, both the thickness and duration of the ice cover are larger than in the baseline case, and haline driven convection quickly reaches all the way to the bottom of the water column. The surface layer temperature is markedly warmer than in the other cases. 

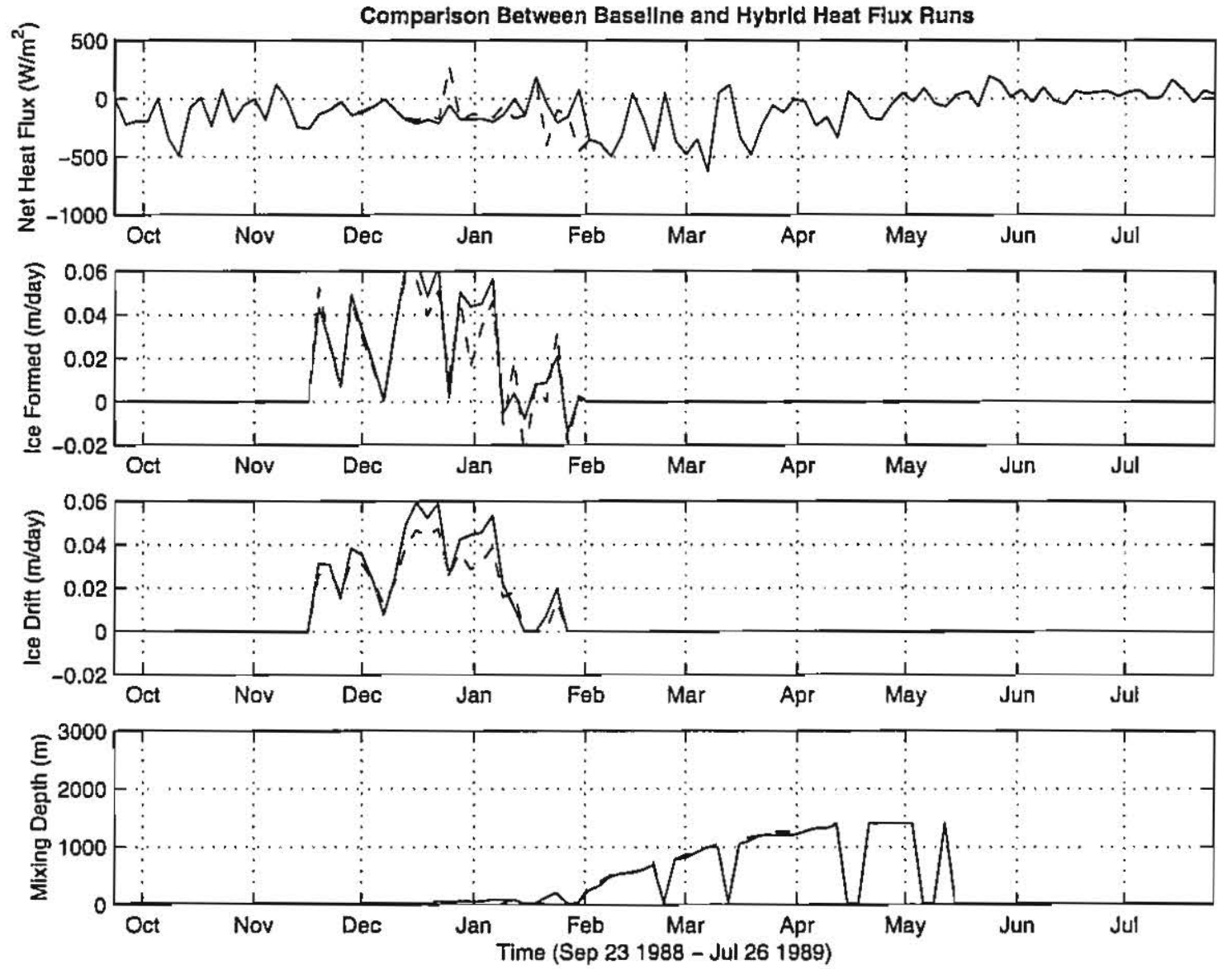

Figure 3.6: The solid line represents output from the baseline run, which uses a value of $\lambda=0.32$ day $^{-1}$. The dashed line represents output from a run using the hybrid heat flux formulation and a value of $\lambda=0.19 \mathrm{day}^{-1}$. The resulting mixed layer evolution in both cases is very similar. However, there are some significant differences during the preconditioning period in the heat flux and ice thickness evolution. 


\section{Comparison of Model Output for $\mu$ Variation Runs}
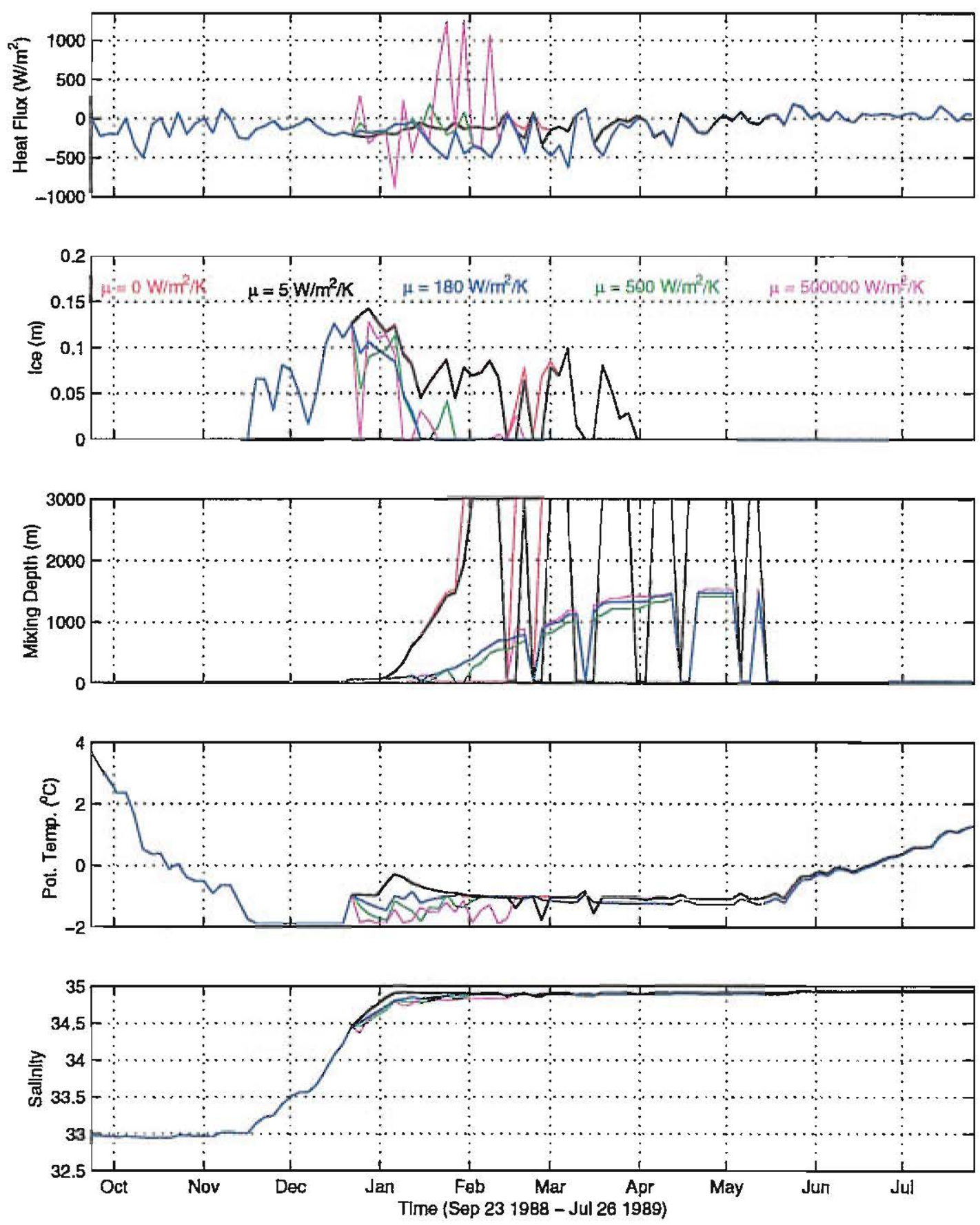

Figure 3.7: Model output for a series of runs with varying values of $\mu$, the coupling strength between the ice layer and the surface layer of water. 
For very large values of $\mu$, the flux of heat into the ice layer gets very large even when the mixed layer is only slightly above the freezing point. The result is that the mixed layer stays very close to the freezing point. As a result, less ice forms and the mixed layer stays slightly fresher. Therefore, the maximum mixed layer depth is a little smaller.

It is interesting to note that the differences in the mixing depth between the intermediate cases $\left(\mu=180 \mathrm{~W} / \mathrm{m}^{2} / \mathrm{K}\right.$ and $\left.\mu=500 \mathrm{~W} / \mathrm{m}^{2} / \mathrm{K}\right)$ and the rapid limit case $\left(\mu=500000 \mathrm{~W} / \mathrm{m}^{2} / K\right)$ are not very large. This is due to the fact that for much of the ice covered period the mixed layer is exactly at the freezing point, and subsequently it is not very far away from the freezing point.

In summary, it would appear that as we move from the insulating limit to the rapid limit the details of the preconditioning process change noticeably. However, as long as we don't get too close to either limiting case, the subsequent evolution of the deepening layer remains qualitatively the same. 


\section{Chapter 4}

\section{Further Investigation}

We will now undertake a more detailed examination of some aspects of the convection process. Our focus will be on the convection event in the central Greenland Sea observed in 1989, which we described in chapter 2. However, our ultimate goal is to gain a general understanding of how the convection process proceeds in the Greenland Sea, and to attempt to explain the inter-annual variability in the occurrence of convective activity.

There are a number of obvious candidates when it comes to identifying the processes responsible for catalyzing or inhibiting convection. The usual suspects are the surface heat and freshwater fluxes, ice formation and the associated brine rejection, the density structure of the water column, and lateral fluxes of heat and freshwater into the convecting region. However, we do not have a clear understanding of some basic issues such as the following:

- All of these processes can feed back on one another. What is the impact of this interaction on the occurrence of deep convection?

- Is the onset of convection sensitive to details of changes in the surface meteorology, and if so, then how and to what extent?

- How does the deep stratification of the water column affect the deepening of the mixed layer?

In this chapter we will attempt to answer these and other related questions. 


\subsection{Effect of Ice Drift on Preconditioning}

A necessary condition for deep convection to occur is the removal of the surface fresh anomaly which is responsible for creating a strong stable near-surface stratification. The two processes which can lead to an erosion of this fresh layer are brine rejection through ice formation, and evaporation. Ice formation will result if the sensible heat loss is sufficiently large to supercool the surface water. Evaporation can occur when the surface water is in direct contact with the atmosphere, either in the absence of an ice cover or through leads when there is an ice cover. Associated with evaporation is a latent heat loss by the surface water. In this section, we will examine details of the preconditioning process. In particular, we will assess the relative importance of the two salinification processes and the impact of ice drift.

Freshwater may be extracted out of the mixed layer ${ }^{1}$ either by ice formation $(F)$ :

$$
F=\frac{H_{S}}{L_{f} \rho_{w}}
$$

or evaporation $(E)$ :

$$
E=\frac{H_{L}}{L_{v} \rho_{w}}
$$

where $H_{S}$ is the sensible heat flux, $H_{L}$ is the latent heat flux, $L_{f}=3.33 \times 10^{5} \mathrm{~J} / \mathrm{kg}$ is the latent heat of fusion, and $L_{v}=2.5 \times 10^{6} \mathrm{~J} / \mathrm{kg}$ is the latent heat of vaporization. So,

$$
\frac{E}{F}=\frac{\text { evaporation }}{\text { ice formation }}=\frac{H_{L}}{H_{S}} \cdot \frac{L_{f}}{L_{v}} .
$$

The resulting salinity increase in the mixed layer is given by

$$
\frac{d S}{d t}=\frac{F+E}{D_{m l}} \cdot S_{\text {ref }}=\frac{S_{\text {ref }}}{\rho_{w} D_{m l}}\left[\frac{H_{S}}{L_{f}}+\frac{H_{L}}{L_{v}}\right]
$$

where $D_{m l}$ is the mixed layer depth. From data, we find that on average (see figure 4.1) the latent heat flux is less than one quarter of the total heat flux during the months of February through April. It is smaller than this during the ice-covered period of preconditioning preceding this. So for conditions typical of the Greenland Sea, $E$ is much less

\footnotetext{
${ }^{1}$ Note that by mixed layer, I am really referring to a very thin $\approx 60 \mathrm{~m}$ layer which exists because of the strong stable salinity stratification.
} 


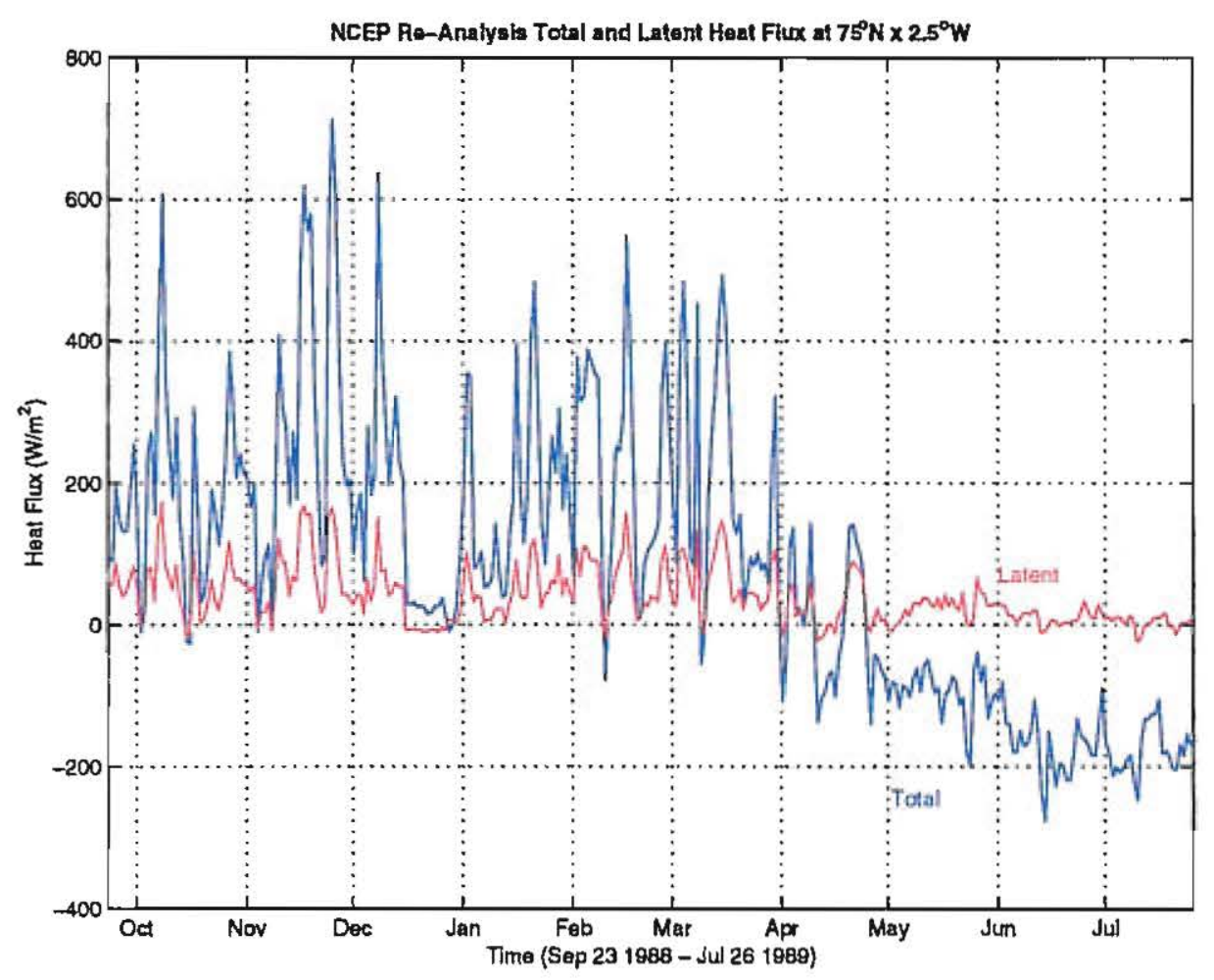

Figure 4.1: The latent heat flux is a small fraction of the total surface heat flux in the central Greenland Sea.

than $F$, and so brine rejection is the dominant preconditioning mechanism. Evaporation and the associated latent heat flux are relatively unimportant as preconditioning agents. Evaporation can be important in driving the mixed layer deepening after preconditioning, when ice formation has ceased and the ice cover has disappeared.

In the following sections, we will examine the effect of ice drift during the preconditioning period, when there is already a substantial ice layer present. During this period, ice is continually forming and drifting away. We will assume that $H_{L}<<H_{S}$ (as discussed above) and that $T_{m l}=T_{F}$ (a necessary condition when ice is forming). 


\subsubsection{Standard Formulation}

Neglecting $H_{L}$, the total heat flux $H_{T} \approx H_{S}$. Then, $H_{T}$ can be expressed in terms of the rate of ice formation:

$$
H_{T}=-\rho_{\text {ice }} L_{f}\left(\frac{\partial h}{\partial t}+\lambda h\right)
$$

where $\lambda$ is inverse timescale for the reduction in the ice thickness resulting from ice drift (i.e. $\lambda^{-1}$ is the time it takes to reduce the ice thickness by 1 meter by advection). $H_{T}$ can also be expressed in terms of the temperature gradient (equation 3.25) when $T_{m l}=T_{F}$. With these two expressions, we can derive a first-order non-linear ODE for $h(t)$,

$$
\frac{\partial h(t)}{\partial t}+\lambda h(t)=-\frac{k\left(T_{A}-T_{F}\right)}{\rho_{\text {ice }} L_{f}\left(h(t)+\frac{k}{\gamma}\right)} .
$$

The solution to this equation when $\lambda=0$ is

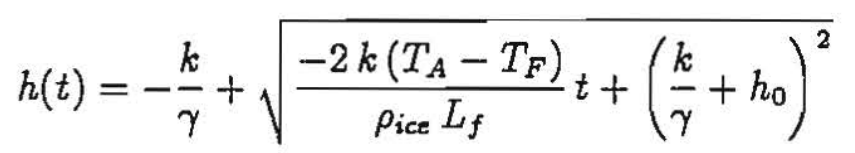

where $h_{0}$ is the initial ice thickness. We will now assume that there is already a substantial ice cover present, so that $h_{0}>>\frac{k}{\gamma}$ and we can use the thick ice limit that we discussed in section 3.3. Then, solution above for $\lambda=0$ reduces to ${ }^{2}$

$$
h(t)=\sqrt{-\frac{2 k\left(T_{A}-T_{F}\right)}{\rho_{\text {ice }} L_{f}} t+h_{0}^{2}} .
$$

Inserting this into

$$
\frac{d S}{d t}=-\frac{S_{\text {ref }} k}{\rho_{\text {ice }} D_{m l}} \frac{\left(T_{A}-T_{F}\right)}{h(t) L_{f}}
$$

yields an expression for the rate of change of the surface salinity.

According to the tomographic data, the observed initial fresh anomaly of about 1.5 psu must get eroded away within three months. Figure 4.2 shows a graph of the predicted ice thickness as a function of time and the associated change in the rate of increase in salinity due to brine rejection. We have assumed a mixed layer depth of 60 meters, which

\footnotetext{
${ }^{2}$ This is Stefan's law with a constant surface temperature $T_{A}$ [Stefan 1891, as cited in Leppäranta 1993].
} 
(a) Ice Thickness vs. Time for $\lambda=0$

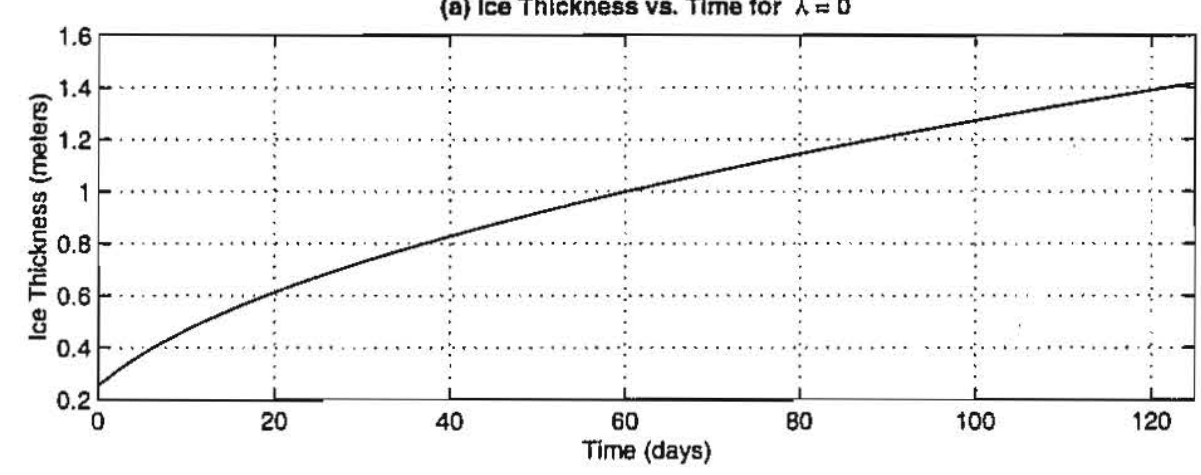

(b) Rate of Salinity Increase vs. Time for $\lambda=0$

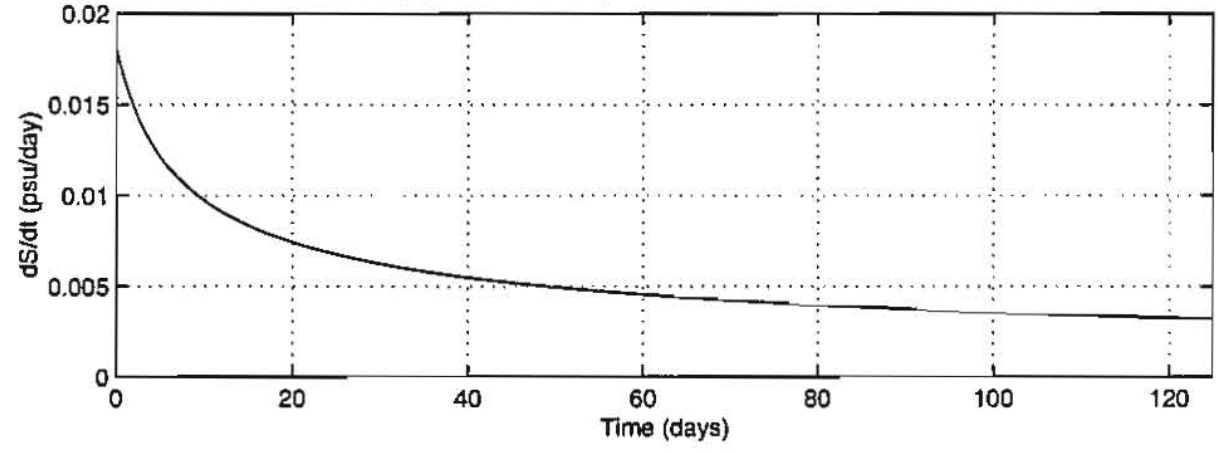

Figure 4.2: The predicted evolution when there is no ice drift $(\lambda=0)$ and a constant air-sea temperature contrast $T_{A}-T_{F}=-15^{\circ} \mathrm{C}$ of (a) ice thickness and (b) rate of salinity increase during preconditioning. Notice that the ice thickness keeps growing with time while the rate of salinity increase keeps decreasing.

is approximately the halocline depth. Notice that the rate of salinity increase drops off sharply as the ice thickness grows and increases the thermal insulation. The resulting rate of brine rejection is insufficient to overcome the observed fresh anomaly during the preconditioning period. In fact, figure 4.2 indicates that even with a much smaller initial fresh anomaly of about $0.6 \mathrm{psu}$, as was observed in one CTD cast near mooring 6 in September 1988, the rate of salinity increase is still too small to erode this stratification.

When $\lambda \neq 0$, then the solution is given by ${ }^{3}$

$$
h(t)=\sqrt{e^{-2 \lambda t}\left(\frac{k\left(T_{A}-T_{F}\right)}{\rho_{\text {ice }} L_{f} \lambda}+h_{0}^{2}\right)-\frac{k\left(T_{A}-T_{F}\right)}{\rho_{\text {ice }} L_{f} \lambda}} .
$$

\footnotetext{
${ }^{3}$ To our knowledge these analytical considerations have never before appeared in the literature.
} 
(a) Ice Thickness vs. Time for $\lambda=0.32$

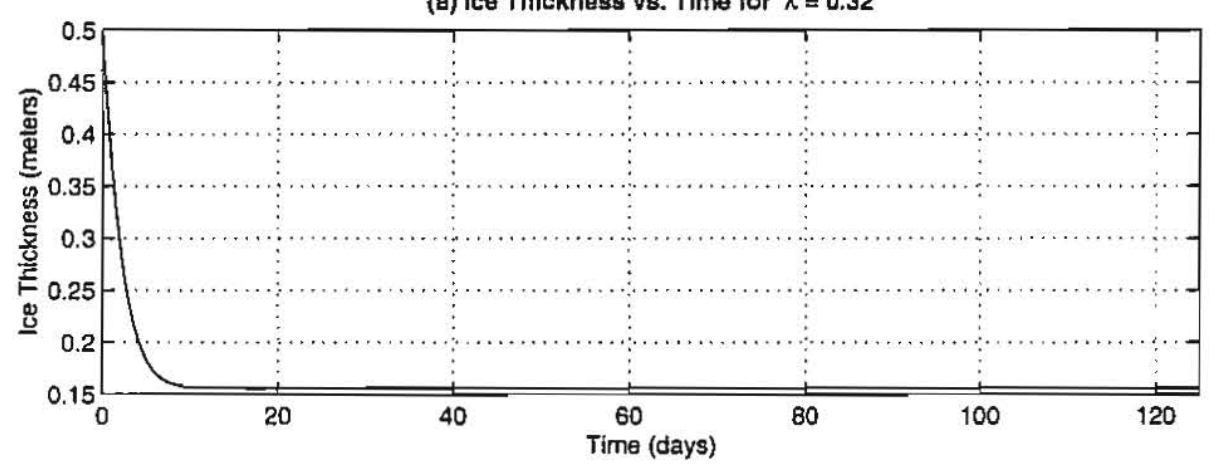

(b) Rate of Salinity Increase v8. Time for $\lambda=0.32$

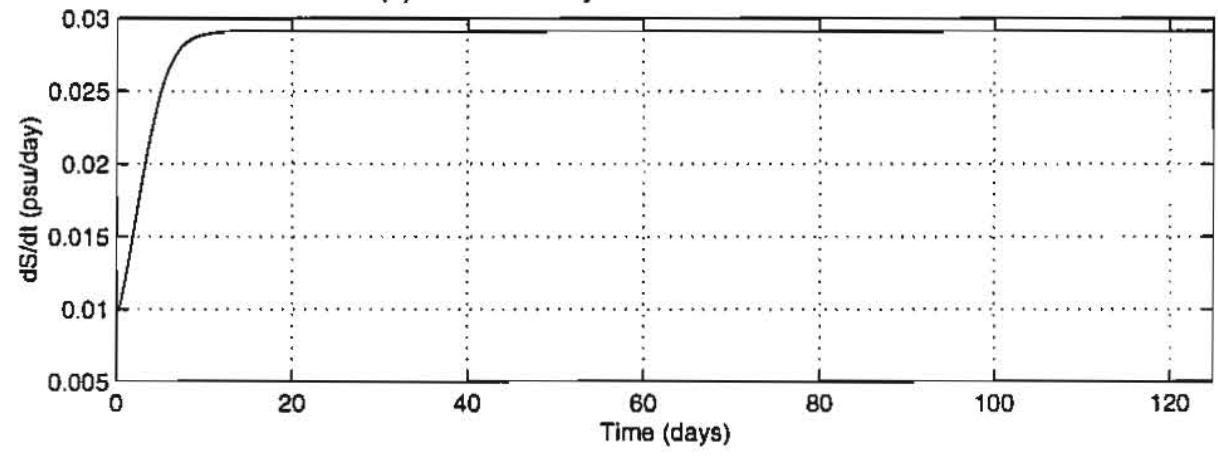

Figure 4.3: The predicted evolution of (a) ice thickness and (b) rate of salinity increase during preconditioning when there is an ice drift $\left(\lambda=0.32\right.$ day $\left.^{-1}\right)$ and a constant air-sea temperature contrast $T_{A}-T_{F}=-15^{\circ} \mathrm{C}$. Notice that both the ice thickness and the rate of salinity increase reach a steady state.

Plots of the predicted ice thickness as a function of time and for various values of $\lambda$ are shown in figures 4.3 and 4.4. Notice that, unlike the case with no ice drift, the ice thickness reaches a steady state where the rate of new ice formation balances the rate of ice export. The steady state ice thickness $h_{s s}$ gets smaller as the ice drift increases (i.e. as $\lambda$ becomes larger), according to:

$$
h_{s s}=\sqrt{\frac{-k\left(T_{A}-T_{F}\right)}{\rho_{\text {ice }} L_{f} \lambda}} .
$$

From figure 4.3, we see that the salinity will increase at a rate of about 0.028 $\mathrm{psu} /$ day when $\lambda=0.32 \mathrm{day}^{-1}$. This will result in a salinity increase of about $2.5 \mathrm{psu}$ in three months, sufficient to erode the surface fresh anomaly (figure 3.2 ). 
(a) lce Thickness vs. $\lambda$ at 100 days

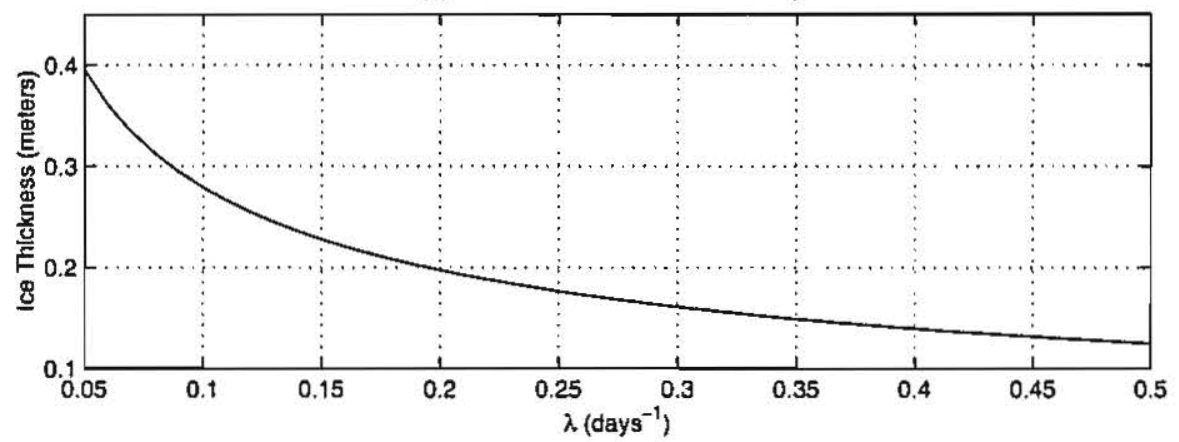

(b) Rate of Salinity Incraase vs. $\lambda$ at 100 days

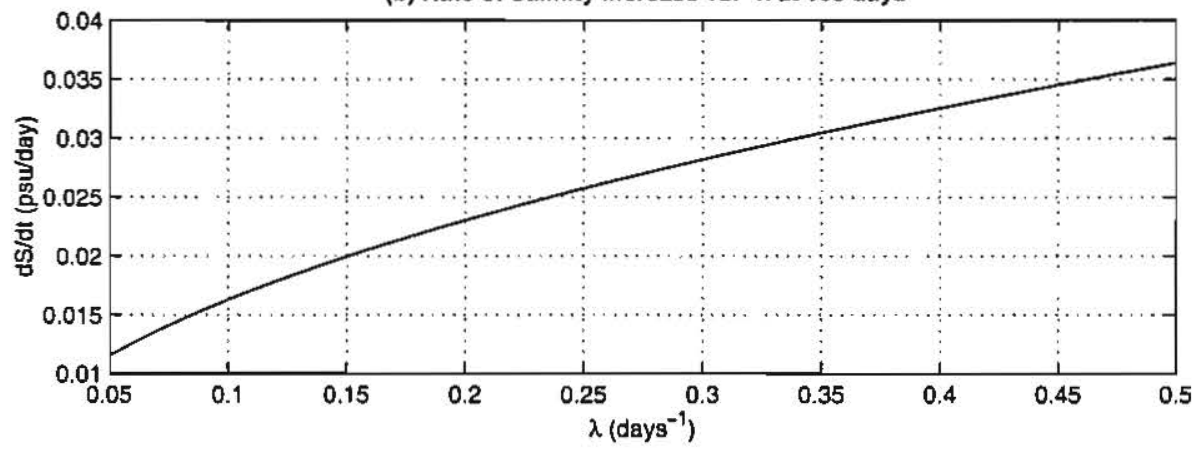

Figure 4.4: The predicted value of (a) ice thickness and (b) rate of salinity increase during preconditioning after 100 days when there is an ice drift $(\lambda \neq 0)$ and a constant air-sea temperature contrast $T_{A}-T_{F}=-15^{\circ} \mathrm{C}$. Notice that the ice thickness decreases with increasing $\lambda$, while the rate of salinity increase becomes larger. 


\subsubsection{Alternative Formulation}

A simpler parameterization of the ice drift is to assume that the ice drifts at a constant rate $\nu$, independent of the ice thickness $h$; i.e.

$$
u \frac{\partial h}{\partial x}=\nu
$$

where $\nu$ is the constant rate of decrease in $h$ when ice is present. This is the formulation that was used by Visbeck et al. [1995]. Then, $\nu$ scales as

$$
\nu \sim u \frac{\Delta h}{\Delta x} .
$$

Based on this scaling, we find an estimate for $\nu$ in the range $0.8-4.1 \mathrm{~cm} /$ day for $u$ between 10 and $20 \mathrm{~cm} / \mathrm{sec}, h$ between 10 and $25 \mathrm{~cm}$, and $r=105 \mathrm{~km}$ (which is the distance between moorings 4 and 6 in the central Greenland Sea gyre (figure 2.1). The value of $0.8 \mathrm{~cm} /$ day used by Visbeck et al. [1995] in their modeling study is at the lower limit of this estimate.

With this formulation, the differential equation governing the ice thickness evolution becomes

$$
\frac{\partial h(t)}{\partial t}+\nu=-\frac{k\left(T_{A}-T_{F}\right)}{\rho_{\text {ice }} L_{f} h(t)} .
$$

The analytical solution to this equation is considerably more complicated than the solution (4.10), even though the ice drift formulation is simpler. Details of this solution are given in appendix B. Both this analytical solution and model results (figures 4.5 and 4.6) are consistent with a value of around $\nu=3.2-3.5 \mathrm{~cm} /$ day. The average rate of the ice drift in our baseline run (figure 3.3 ) is $3.3 \mathrm{~cm} /$ day. If we use the constant ice drift parameterization, then we find that to best match the observed mixed layer evolution, an ice drift of $3.5 \mathrm{~cm} /$ day (with the baseline heat flux formulation) or $3.2 \mathrm{~cm} /$ day (with the hybrid heat flux formulation) is needed (table 4.1). These values are all considerably larger than the value of Visbeck et al. [1995] $(0.8 \mathrm{~cm} /$ day $)$. We will explore the reasons for this discrepancy later on in this chapter. 


\begin{tabular}{|c|c|c|}
\hline Heat Flux & $\boldsymbol{\nu}(\mathbf{c m} / \mathbf{d a y})$ & $\boldsymbol{\lambda}\left(\mathbf{d a y}^{-1}\right)$ \\
\hline \hline baseline & $\overline{3.5}$ & 0.32 \\
\hline hybrid & 3.2 & 0.19 \\
\hline
\end{tabular}

Table 4.1: The strength of the ice drift required to closely match the observed mixed layer evolution for two different formulations of the surface heat flux and two different parameterizations of the ice drift (see text for details). All other details of the model configuration are identical to the baseline run described in chapter 3.

\subsubsection{Discussion}

The strength of the ice drift required for the model to most closely match the observed mixed layer evolution varies depending upon the heat flux formulation used (table 4.1). When constant ice advection $\nu$ is used, the relative difference between the values of $\nu(3.2 \mathrm{~cm} /$ day with the baseline heat flux vs. $3.5 \mathrm{~cm} /$ day with the hybrid heat flux formulation) is smaller than the relative difference between the values of $\lambda$ ( $0.32 \mathrm{day}^{-1}$ baseline vs. $0.19 \mathrm{day}^{-1}$ hybrid) because in the former case, the amount of ice advected is independent of the actual amount of ice present. Hence the ice drift in that case is not coupled to the heat flux. In the latter case the ice drift is coupled to the heat flux through the ice thickness $h$; thus there is a feedback between the ice drift and heat flux (as discussed in section 3.3).

In addition to exporting freshwater, the ice drift also exports "cold" (i.e. it results in a net positive heat flux into the mixed layer) at a rate of $125 \mathrm{~W} / \mathrm{m}^{2}$ when $\nu=3.2 \mathrm{~cm} /$ day. This is the amount of heat that would need to be extracted from the water column to melt this ice if it were not exported. However, the increase in buoyancy caused by this heat flux is minimal compared with the buoyancy loss caused by the freshwater export.

A model run was carried out in which there was no ice drift $(\lambda=0)$; otherwise, the run was identical to the baseline run. The results are shown in figure 4.7. The surface waters remain too fresh throughout the winter and convection cannot occur. Surface evaporation erodes this fresh anomaly very slightly before ice forms, but this process is not vigorous enough by itself to remove an appreciable amount of freshwater and destabilize the water column. 

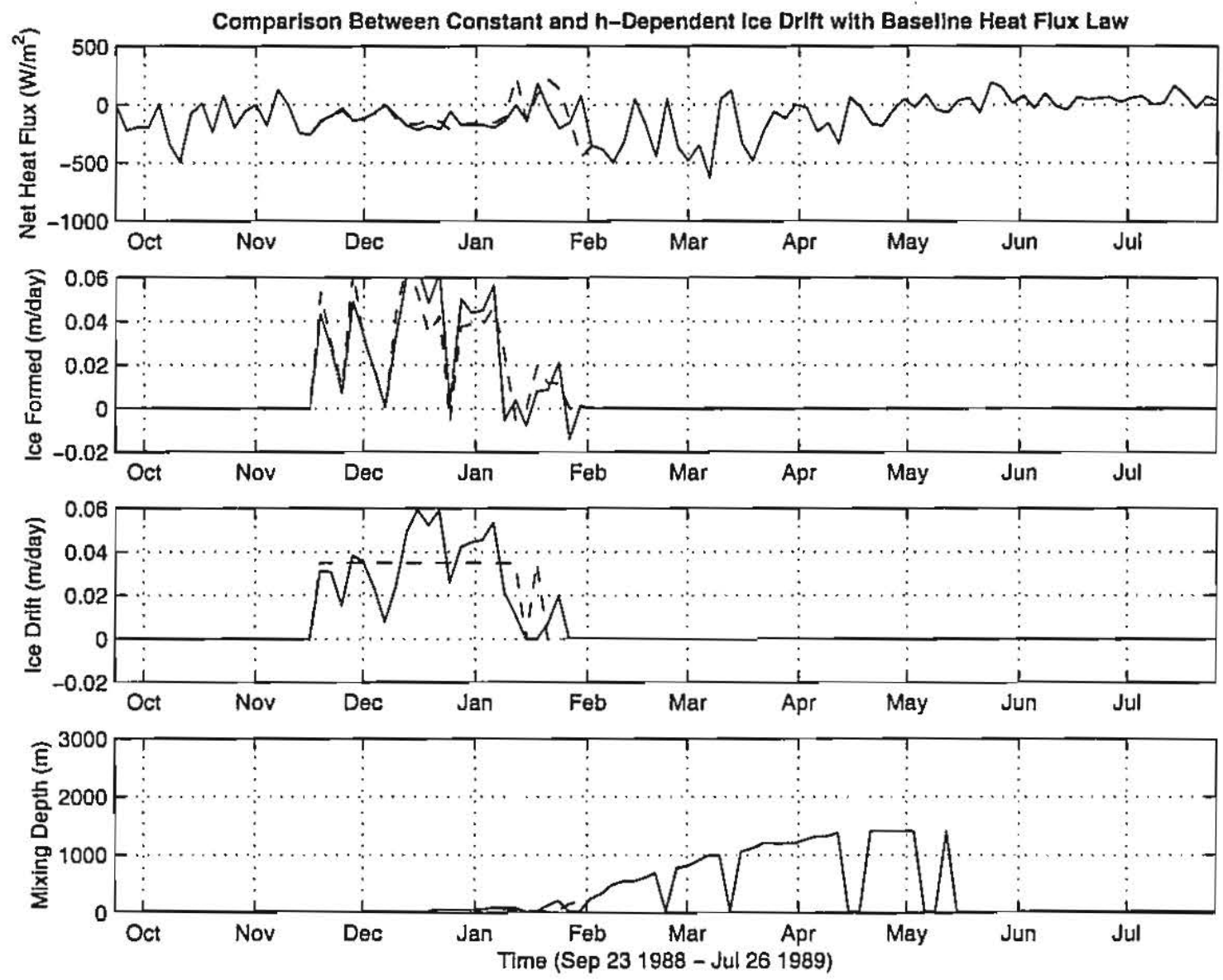

Figure 4.5: A comparison between the baseline run in which the ice drift is proportional to $h$ with $\lambda=0.32 \mathrm{day}^{-1}$ (solid line) and a run with a constant ice drift of $\nu=3.5 \mathrm{~cm} /$ day (dashed line). Both runs use the baseline heat flux formulation given by equation (3.13). Both predict almost the same mixed layer evolution. Notice that in the baseline run, the ice formed and ice drift are very similar, reflecting the near steady state conditions during preconditioning. In the constant ice drift run, the average amount of ice formed during the preconditioning roughly balances the ice drift. 

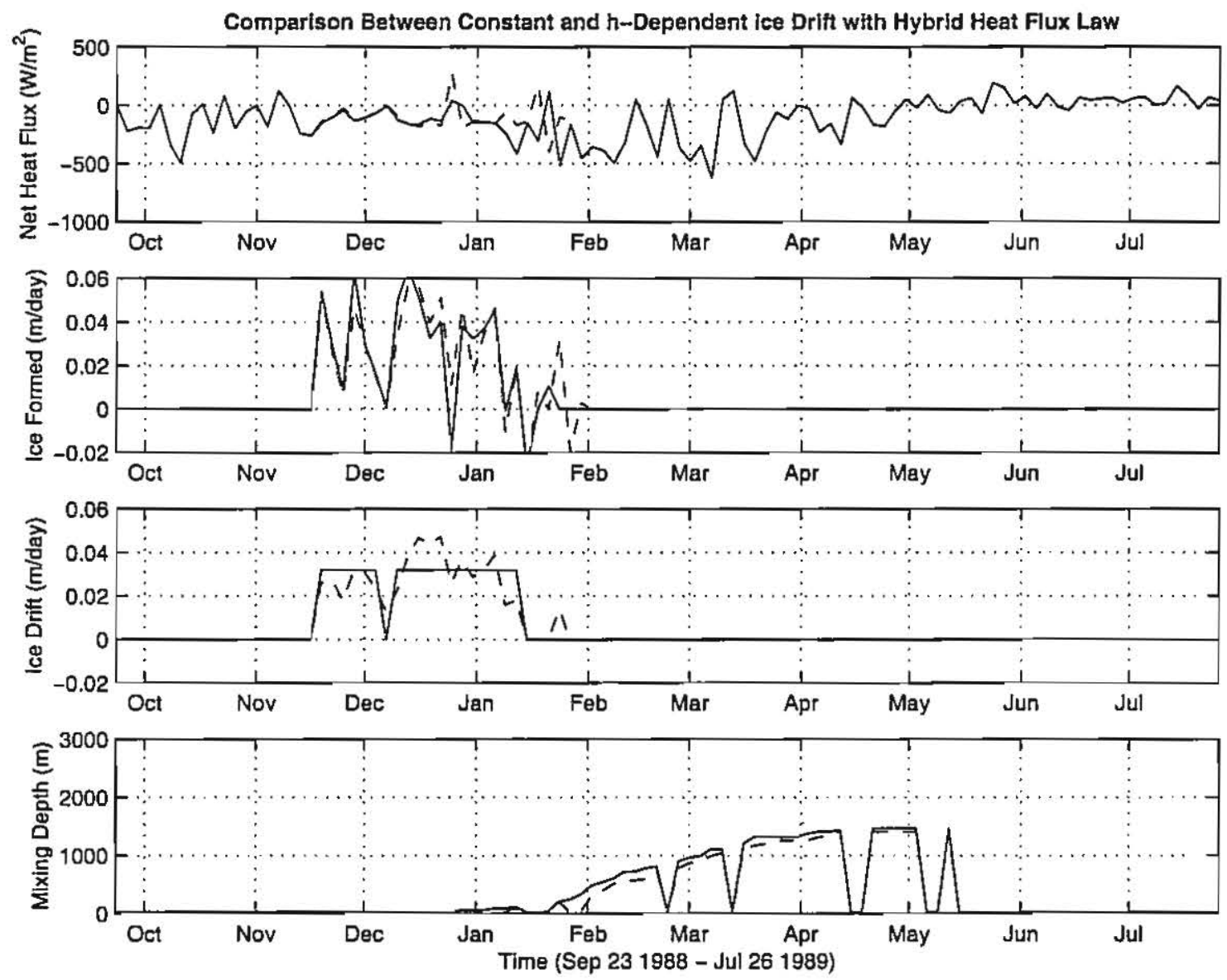

Figure 4.6: A comparison between a run with a constant ice drift of $\nu=3.2 \mathrm{~cm} /$ day (solid line) and a run in which the ice drift is proportional to $h$ with $\lambda=0.19$ day $^{-1}$ (dashed line). Both runs use the hybrid heat flux formulation as described in section 3.3. Both predict a very similar mixed layer evolution. During preconditioning, the ice formed and ice drift almost balance each other. 


\section{Model Output for Run $\lambda=0$}
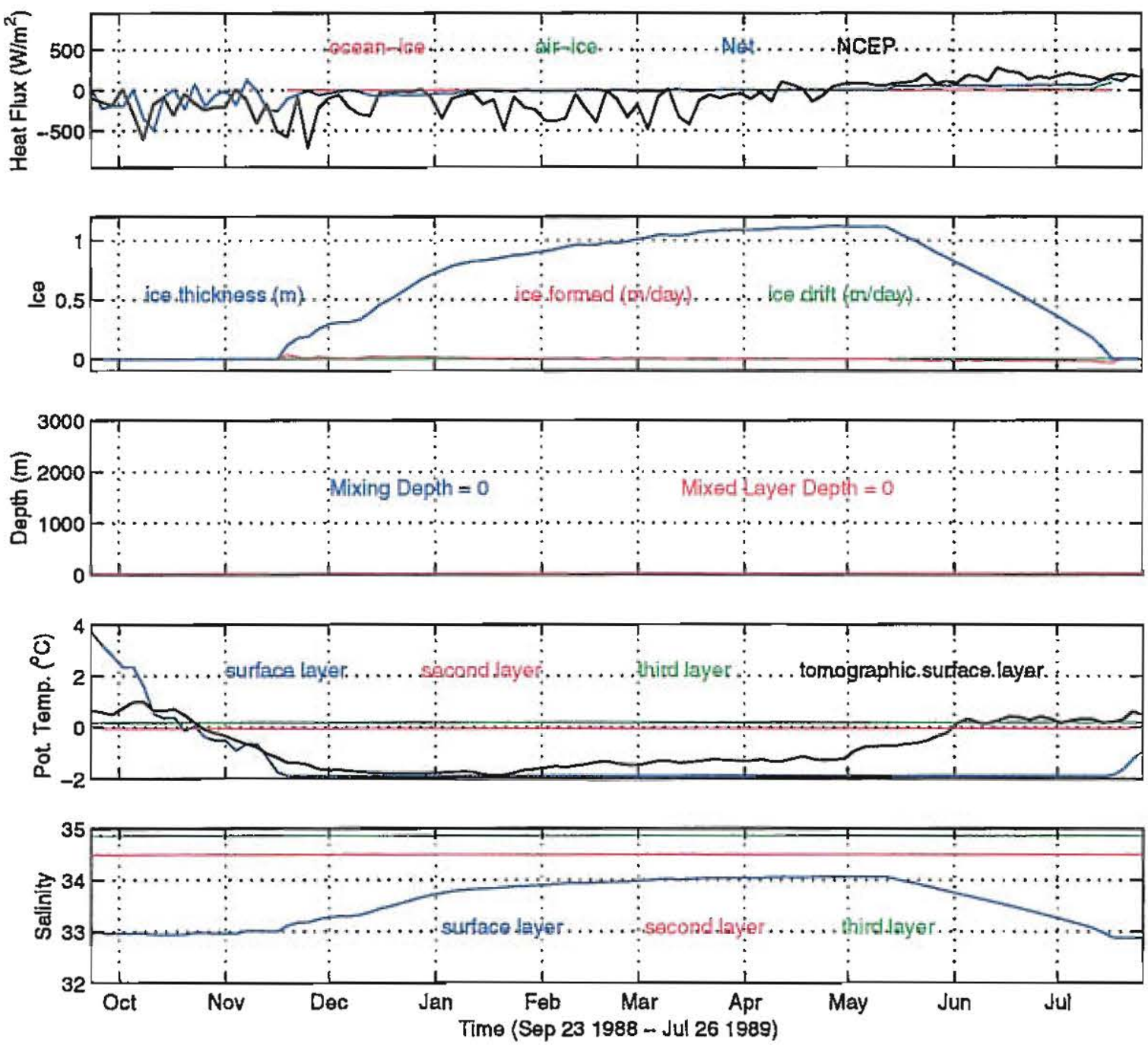

Figure 4.7: Model output for a run with no ice drift ( $\lambda$ was set to zero); otherwise, the setup of this run was identical to the baseline run. 
So we conclude that ice drift is necessary to remove the observed fresh anomaly. In effect, ice drift makes the brine rejection process more efficient. It also removes the excess of freshwater, so that when the ice melts, a fresh anomaly no longer prevents convection from occurring.

What happens if no ice formation occurs in some winter (such as in 1983-84, according to figure $\mathrm{C} 6$ in appendix $\mathrm{C})$ ? Then evaporation is the only preconditioning agent active. In this case, ECMWF data for the six month period from November 1983 to May 1984 indicate that the net average evaporation rate was about $2.5 \times 10^{-9} \mathrm{~m} / \mathrm{s}$. The corresponding rate of salinification, given by

$$
\frac{d S}{d t}=\frac{F_{W}}{D_{m l}} S_{\text {ref }}
$$

is $4.34 \times 10^{-10}$ psu. Over a period of 90 days, this results in an increase in salinity of $0.0034 \mathrm{psu}$. This is not nearly enough to erode the fresh anomaly present in the fall. The conclusion then is that without brine rejection, the surface waters in the Greenland Sea will not be preconditioned for deep convection.

\subsection{Comparison with Other 1D Model Studies}

Before comparing the sometimes contradictory results of the various other one dimensional model studies which have been carried out to study the development of a convection event in the Greenland Sea, there are a number of important issues related to the configuration and initialization of the models which should first be discussed.

All of the studies use a mixed layer model of some sort. Since they all use a check for static instability to initiate vertical mixing, we would expect them to behave qualitatively in a similar fashion. However, they do not all use the same vertical resolution and this can have a significant effect on the model evolution. Consider the case where there is a strong initial salinity stratification. As brine rejection increases the salinity of the top layer, the thickness of this layer will determine the rate at which the thermocline deepens and heat is entrained. This will have a significant impact on the rate of ice melt and warming of the surface layer, and hence on the a rate of further ice formation and brine rejection. 
There is a large variability in the observed salinity profiles in the Greenland Sea, both spatially and temporally [Pawlowicz, 1995]. Depending on how large the surface stratification is, the conclusions about how much brine rejection is needed to yield a model evolution which is consistent with observations may be very different.

Finally, the strength of the coupling between the ice layer and the surface layer which is either specified or implicit in the model formulation has an effect on the output. As we saw in the previous section, the results change as one moves from the insulating limit (no coupling) to the rapid limit (infinite coupling).

There have been three previous attempts to model the mixed layer properties during the 1988-89 convective event that we are aware of: Pawlowicz et al. [1995], Visbeck et al. [1995], and Morawitz et al. [1996], hereafter referred to as P95, V95, and M95 respectively.

P95 used the quasi-static mixed layer model of Killworth [1979]. This model is quasi-static in the sense that heat, salt, ice, and density balances are needed only at one point in time to obtain a solution. Based on the total surface heat flux, this model sets bounds on the mixed layer depth. The heat fluxes at particular times were inferred from changes in the tomographic heat content estimates, and CTD profiles from the tomographic array deployment cruise were used. Based on this study, they concluded that ice advection is necessary, but they were still unable to obtain mixed layer depths that match observations. Their explanation of possible reasons for this discrepancy are: 1) the initialization (with profiles from the deployment cruise in Sept 1988, as we use) may not have sampled the regions most susceptible to convective overturn; 2) their model assumes the rapid limit, hence only a lower bound will be obtained on the mixed layer depth; 3) only penetrative convection is allowed.

M96 use a one-dimensional model which is non-penetrative and stability driven. Surface heat and freshwater forcing is applied using UKMO model fluxes. A representation of ice formation and brine rejection is included. They claim that the main problem with the P95 results is that the latter's model assumes the rapid limit. By using their model, which they say is somewhere between the two extremes, and a net evaporation of 0.002 $\mathrm{m} /$ day (which is larger than observed values of $\mathrm{E}-\mathrm{P}$; their model ignores precipitation), M96 find that observed mixed layer profiles in the central gyre can be explained without 
the need to invoke ice advection. They initialize their model with temperature and salinity profiles from hydrographic casts in the central gyre from autumn 1988, although they do not indicate the locations or dates of these casts.

V95 use a Krauss-Turner type mixed layer model coupled to a thermodynamic ice model. Surface heat and freshwater fluxes from the ECMWF model were used as surface forcing, and an ad hoc reduction in these fluxes by $60 \%$ was applied under ice-covered conditions. They conclude that ice advection is necessary to match the observed mixed layer evolution. From the information that they provide, we infer that they use an ice to mixed layer coupling strength of about $5 \mathrm{~W} / \mathrm{m}^{2} / \mathrm{K}$. This is very close to the insulating limit. They initialize their model runs with a mean hydrographic profile from November 1988. As Pawlowicz [1995] describes, there is a large spatial and temporal variability in the surface salinity. Therefore, to obtain meaningful results, we believe it is important to initialize model runs with actual data from tha area in question rather than averaged profiles.

It is worthwhile to note that in both V95 and M96, NWP model heat fluxes were used to force the model. M96 used UKMO fluxes which, as we discussed in chapter 2, may have some problems. Interestingly, these three studies seem to have been carried out in three different ice to mixed layer coupling regimes: P95 in the rapid limit, M96 somewhere between the two limits, and V95 close to the insulating limit. The fact that V95 were close to the insulating limit may explain why they were able to obtain a mixed layer depth evolution which was consistent with observations while using a substantially smaller rate of ice advection $(8 \mathrm{~mm} /$ day $)$ than we use.

Our results directly contradict conclusions reached by both P95 and M96. P95 attribute the failure of their model to correctly predict the maximum depth of the mixed layer to three causes, which we mentioned above. Our study casts doubt on all of these explanations. We initialized our model runs using the same temperature and salinity profiles as them, yet we were able to predict the observed mixed layer depth. We have shown that for the evolution of this particular convection event, the maximum depth of convection in the rapid limit is not very different from results obtained using a weaker coupling strength. And finally, our model does not permit penetrative convection either. 
The claim by M96 that no ice advection is needed to obtain convection down to the observed depths conflicts with our results. We have demonstrated through both analytical scaling arguments and model runs that deep convection in the Greenland Sea without brine rejection, given the observed conditions in the Greenland Sea in 1988-89, is not possible. Notice that our scaling results are independent of the ice to mixed-layer coupling strength and model-related issues. We did find that in model runs carried out in the insulating limit, and with a relatively large E-P, it is possible to achieve a mixed layer deepening to around 1500 meters without any ice advection and with observed air temperatures, but only if the initial surface stratification is weak. To obtain this behavior, we had to increase the initial salinity of the surface layer by $1.5 \mathrm{psu}$ and of the second layer by 0.2 psu. However, the details of the mixed layer evolution were then not consistent with the tomographic temperature record. In particular, the mixed layer deepens too early in the season and the temperature of the deepening mixed layer is too warm. This is, of course, because in the insulating limit all of the surface heat loss is used to form ice (as seen in figure 3.7), and the mixed layer deepening is driven entirely by a salt flux resulting from brine rejection. In this case the convection occurred underneath the ice cover, and so ice advection to remove this ice was not needed. The presence of this ice, however, reduced the surface heat flux dramatically (by a factor of 10) and so ice formed slowly. Further, the ice cover persisted much longer than the satellite data indicates. Since M96 do not mention exactly which profiles were used to initialize their model, it is possible that their predicted mixed layer evolution was obtained as a result of a much weaker initial surface stratification, thus removing the need for strong preconditioning. However, we have not seen any profiles from the central gyre region with a stratification that is sufficiently weak.

Our results agree with the main conclusion of V95 that ice export is necessary to bring the model predicitions into line with the observed evolution. However, we predict a larger rate of ice export. One possible reason is that since the V95 model is closer to the insulating limit, the amount of brine rejection for a given surface heat loss is larger. Further, V95 adjusted both the ice export rate and the surface heat flux by trial and error until their model evolution was close to observations. Therefore, the size of the ice export rate that they determine is dependent upon the strength of the heat flux that they assumed. Another reason for the discrepancy between the V95 results and ours is that V95 used average temperature and salinity profiles from the central Greenland Sea from 
November 1988 to initialize their model, and the surface stratification was smaller than in the profiles which we used. Therefore, a smaller increase in mixed layer salinity was required for preconditioning.

Therefore, our results do not contradict the results of V95 when differences in model formulation and initialization are properly accounted for. However, our results do disagree with P95 and M96, as discussed above. Since both our model results and those of V95 depend upon the choice of initialization, surface forcing, and ice to mixed layer coupling strength, and there is a large uncertainty in all of these quantities, we must conclude that neither set of results is inconsistent with the available observations and both point to the necessity of ice advection.

We should emphasize that our main aim in the discussion above is not to make a judgement about the quality of the other mixed layer models themselves by comparison to our own. Rather, we are making the case that seemingly unimportant details in each of these models, such as the ice-ocean coupling strength and model initialization, have important consequences for the results, and that the conclusions reached are sensitive to these details. The disagreement between the conclusions of the studies cited above are a result of differences in such details.

\subsection{Can Deep Convection Occur Under Ice?}

It is clear from the data that the onset of convection in 1989 coincides with a warming of the air temperature and a disappearance of the ice cover. The first question that comes to mind is whether it was just a fluke that these three events coincided, or whether they are causally related. If the latter is true, then the further question arises of how these events are related and whether these conditions are necessary for the formation of a deep mixed layer in the Greenland Sea. We will approach these questions in two ways. First we will present some analytical scaling arguments, and then we will carry out some model simulations. It may seem counter-intuitive that the air temperature must warm before convection can occur. This leads us to wonder: 
1. Can convection occur beneath a layer of ice or must the ice cover first disappear? Conventional wisdom tends to prefer the latter.

2. What would happen if the winter were exceptionally mild and the air temperature never got very cold? Would it still be possible for convection to occur?

In this section, we will examine in detail what happens when the water column has been preconditioned for convection, at the onset of convection. A warming of the air temperature will have the effect of reducing the rate of ice formation, leading to a reduction in the ice cover. This in turn permits a much more vigorous buoyancy loss at the surface due to the loss of the insulating effects of ice. However, if the air temperature warms too much immediately after the preconditioning period, then the surface buoyancy loss will not be sufficient to drive a substantial mixed layer deepening.

\subsubsection{Analytical Scaling Predictions}

We will examine what happens during the time immediately after the surface fresh anomaly has been completely eroded away, and the salinity of the water column is (almost) uniform. At this stage, a buoyancy flux is needed to drive the convection. This can be provided by either a heat or salt flux, or both. Can a sufficiently large buoyancy flux be obtained if ice is still present? It is often presumed that deep convection does not occur under ice. For example, in the Weddell Sea coastal polynyas are formed when strong winds blow ice offshore. This is thought to be an essential ingredient in the convection process in that region. We will examine more closely the two possible scenarios.

The density profile of the water below the mixed layer will be assumed to be a constant linear increase with depth. Based on the potential temperature and salinity profiles that were used to initialize the baseline model run, we estimate the density gradient (see figure 4.8) to be $1.269 \times 10^{-5} \mathrm{~kg} / \mathrm{m}^{4}$. The density as a function of depth is then given by

$$
\rho(z)=\rho\left(D_{m l}\right)+\frac{\partial \rho}{\partial z}\left(z-D_{m l}\right)
$$




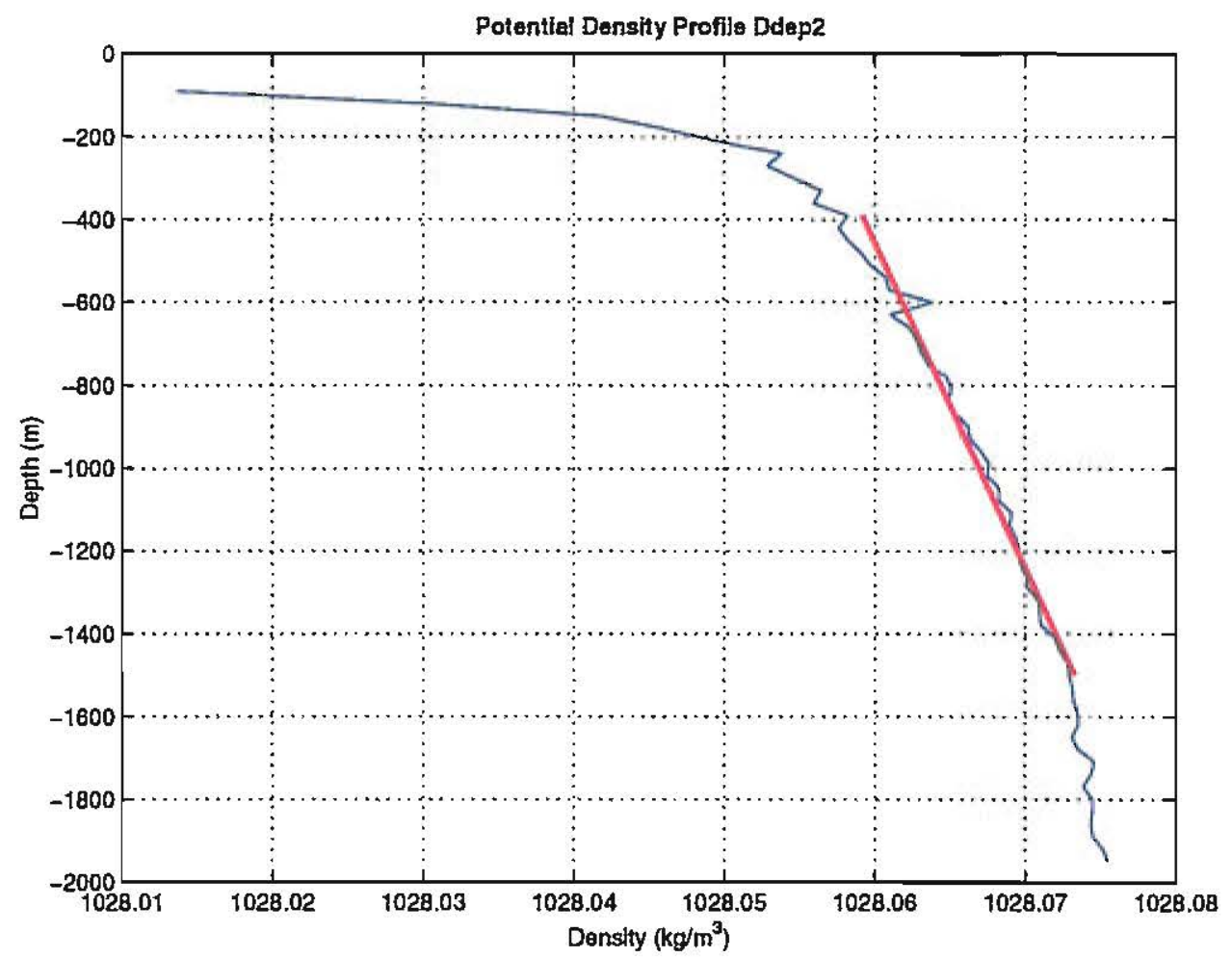

Figure 4.8: The potential density (up to 2000 meters) computed using the potential temperature and salinity profiles which initialized the baseline run (figure 3.2). The thick red line is a linear approximation to the stratification $\left(1.2692 \times 10^{-5} \mathrm{~kg} / \mathrm{m}^{4}\right)$ which is used to obtain scale estimates of the mixed layer depth. 
where $D_{m l}$ is the mixed layer depth. Thus, the change in buoyancy $b(z)$ as a function of depth is given by

$$
\begin{aligned}
\frac{d}{d t} \int b(z) d z & =\frac{g}{\rho_{w}} \frac{d}{d t}\left[\int\left(\rho(z)-\rho\left(D_{m l}\right)\right) d z\right] \\
& =\frac{g}{\rho_{w}} \frac{\partial \rho}{\partial z}\left(z-D_{m l}\right) \frac{d z}{d t} .
\end{aligned}
$$

Therefore,

$$
\frac{g}{\rho_{w}} \frac{\partial \rho}{\partial z}\left(z-D_{m l}\right) \frac{d z}{d t}=\frac{g}{\rho_{w}} \frac{\alpha}{c_{p}} H_{\alpha}+\frac{g}{\rho_{w}} \frac{\beta S_{r e f}}{L_{f}} H_{\beta}
$$

where $\alpha=0.3 \times 10^{-4} \mathrm{~K}^{-1}$ is the thermal expansion coefficient, $\beta=7.9 \times 10^{-4} \mathrm{psu}^{-1}$ is the haline expansion coefficient, $H_{\alpha}$ is the heat flux between the atmosphere and the ocean mixed layer, and $H_{\theta}$ is the latent heat flux involved in freezing or melting ice.

\section{Convection Under Ice}

If the air temperatures were to remain very cold throughout the winter months, then the ice cover would not disappear. A scale analysis is carried out to ascertain whether or not the occurrence of deep convection under ice is possible in the Greenland Sea under these conditions. Ice covered conditions would be maintained if the air temperature were to remain at around $-25.0^{\circ} \mathrm{C}$ or so, since the resulting surface heat loss would be sufficient to balance the heat entrained as the mixed layer deepens. We will assume that the ice thickness remains constant, and that new ice formation is balanced by the advection of ice.

The response of the water column to the surface heat loss

$$
H_{s i}=\frac{k}{h+\frac{k}{\gamma}}\left(T_{A}-T_{F}\right)
$$

depends upon the strength of the coupling between the ice and the mixed layer, as discussed previously. If the coupling is very weak (the insulating limit), then the surface heat loss will be used to form ice only, and not to reduce the heat content of the water column. Buoyancy will be removed from the water through brine rejection alone. In the other limit, if the coupling is very strong (the rapid limit), then the mixed layer temperature will remain at the freezing point, and most of the surface heat loss will be used to cool 
the water column. The insulating limit will result in a larger buoyancy change in the water column than the rapid limit. Therefore, the former will yield an upper bound on the maximum depth of the mixed layer, while the latter will result in a lower bound.

In the insulating limit, the surface heat loss will cause ice formation and a change in the buoyancy of the mixed layer will result from the brine rejection. Thus $H_{\beta}=H_{s i}$, and rate of increase of the depth of the mixed layer is given by the following expression:

$$
\frac{g}{\rho_{w}} \frac{\partial \rho}{\partial z}\left(z-D_{m l}\right) \frac{d z}{d t}=\frac{g \beta S_{r e f}}{\rho_{w} L_{f}} \frac{k}{h+\frac{k}{\gamma}}\left(T_{A}-T_{F}\right) .
$$

where $D_{m l}$ is the initial mixed layer depth and $L_{f}$ is the latent heat of fusion. Taking the time integral, we derive the following expression for the depth of the mixed layer"

$$
z(t)=D_{m l}+\left(\sqrt{\left(2 B\left(t-t_{0}\right)\right.}\right)
$$

where

$$
B \equiv-\frac{\beta S_{r e f}}{L_{f}} \frac{k}{h+\frac{k}{\gamma}} \frac{\left(T_{A}-T_{F}\right)}{\frac{\partial \rho}{\partial z}} .
$$

The tomographic data (figure 2.2) indicates that the mixed layer deepens from about 250 meters in mid-February to its maximum depth in about 45 days. We will assume that ice is formed at the same rate at which it is drifting away, so that the ice thickness remains constant. With $\left(T_{A}-T_{F}\right)=-20^{\circ} \mathrm{C}, k=2.0 \mathrm{Wm}^{-1} \mathrm{~K}^{-1}$, and $h=0.2 \mathrm{~m}$, we find that the mixed layer will deepen to 3000 meters by the month of April; in other words, convection will reach to the bottom of the water column. If $h=0.5 \mathrm{~m}$ (implying an ice advection rate of $2 \mathrm{~cm} /$ day), then convection will still reach down to 2200 meters.

In the rapid limit, the surface heat loss will preferentially go towards cooling the mixed layer; once the mixed layer is at the freezing point, any additional heat loss will cause ice formation, leading to a latent heat gain and brine rejection. The buoyancy change in the water column will thus have both a thermal and a haline component. The resulting rate of increase of the mixed layer depth, again assuming that the ice thickness

\footnotetext{
${ }^{4}$ This expression has the same form as the well-known result of Turner [1973] for the depth $z(t)$ of a chimney with constant stratification $N$ when a constant destabilizing buoyancy $B_{0}$ is applied: $z=\frac{\sqrt{2 B_{0} t}}{N}$, a result which has been confirmed in laboratory experiments [Ivey et al. 1995]. However, to our knowledge we are the first to derive an expression for the deepening of a chimney which includes the effects of ice.
} 
remains constant at $20 \mathrm{~cm}$, and that the rate of new ice formation is balanced by the rate of ice advection $\nu$, is given by:

$$
\frac{g}{\rho_{w}} \frac{\partial \rho}{\partial z}\left(z-D_{m l}\right) \frac{d z}{d t}=\frac{g}{\rho_{w}} \frac{\alpha}{c_{p}}\left[\frac{k}{h+\frac{k}{\gamma}}\left(T_{A}-T_{F}\right)+\rho_{\text {ice }} L_{f} \nu\right]+g \beta S_{\text {ref }} \frac{\rho_{\text {ice }}}{\rho_{w}} \nu .
$$

Integrating in time, we derive an expression for $z(t)$ of the same form as equation 4.22 , with

$$
B \equiv-\frac{\alpha}{c_{p} \frac{\partial p}{\partial z}}\left[\frac{k}{h+\frac{k}{\gamma}}\left(T_{A}-T_{F}\right)+\rho_{i c e} L_{f} \nu\right]+\frac{\beta S_{\text {ref }} \rho_{i c e} \nu}{\frac{\partial p}{\partial z}} .
$$

With an ice drift rate $\nu$ of between 1 and $4 \mathrm{~cm} /$ day and $\left(T_{A}-T_{F}\right)=-20^{\circ} C$, we find that by April the mixed layer will deepen to between 1800 and 2950 meters. Even with an ice thickness of $50 \mathrm{~cm}$, the mixed layer would reach a depth of between 1650 and 2900 meters.

On the basis of these scale estimates, we conclude that the mixed layer will deepen considerably if the air temperature remains very cold and an ice cover is maintained. Since the actual strength of the coupling between the ice and mixed layer is probably somewhere in between the two limits that we considered above, the mixed layer in this scenario will reach depths of much greater than the 1500 meters observed in the Greenland Sea. We infer, therefore, that the observed mixed layer evolution in 1988-89 is not consistent with a very cold winter with a sustained air temperature of about $-20^{\circ} \mathrm{C}$.

Rudels [1990] concludes that deep, haline convection driven by freezing at the sea surface is possible in the Greenland Sea. We have just demonstrated that this is possible only under conditions of sustained cold air temperatures. Rudels claims that in order for convection to reach the bottom, a heat loss of $0.43 \times 10^{9} \mathrm{~kJ} / \mathrm{m}^{2}$ is required over a period of about 17 days. The implies an outrageously large heat flux; however, we believe that this may be due to a misprint and the quoted numbers are too large by a factor of 1000 . Operating under this assumption, according to Rudels a sustained heat flux of almost $300 \mathrm{~W} / \mathrm{m}^{2}$ through ice is required. Assuming an ice cover of about $20 \mathrm{~cm}$, this suggests an air temperature of -30 to $-35^{\circ} \mathrm{C}$. Sustained air temeperatures this cold are rarely, if ever, observed in the Greenland Sea. Therefore, while our scale estimates above agree with Rudels' work, we do not believe that this is a likely scenario for the Greenland Sea. 


\section{Ice-free Convection}

If the air temperature were to warm substantially near the end of the preconditioning phase, then the ice cover would quickly diminish. The rate of ice formation would be smaller than the rate of ice melt and ice advection. In the resulting ice-free conditions, the buoyancy flux due to the surface heat loss will cause the mixed layer to deepen at a rate determined by:

$$
\frac{g}{\rho_{w}} \frac{\partial \rho}{\partial z}\left(z-D_{m l}\right) \frac{d z}{d t}=-\frac{g}{\rho_{w}} \frac{\alpha}{c_{p}} \gamma\left(T_{A}-T_{m l}\right) .
$$

The resulting mixed layer depth is again given by an expression of the form (4.22), with

$$
B \equiv-\frac{\alpha \gamma\left(T_{A}-T_{m l}\right)}{c_{p} \frac{\partial \rho}{\partial z}} .
$$

With $\left(T_{A}-T_{m l}\right)=-10^{\circ} \mathrm{C}$, we find that the maximum predicted mixed layer depth in April is 1750 meters. This estimate is a little larger than the observed maximum of about 1500 meters. However, the actual average temperature was somewhat warmer than the value we have used. If the air temperature were to warm further, to an average air-sea difference of $-5^{\circ} \mathrm{C}$, then the maximum mixed layer depth in April would be 1300 meters. With a temperature difference of $-1^{\circ} \mathrm{C}$, the maximum depth would be only about 750 meters. We conclude, therefore, that the warming in the air temperature which was observed to occur in January 1989 is consistent with the observed depth of the mixed layer.

\section{Model Simulations}

We carried out a number of model simulations to test the conclusions we reached above through our scale analysis. We biased the air temperature during the months of January through April by $-20^{\circ} \mathrm{C},-10^{\circ} \mathrm{C}$, and $+5^{\circ} \mathrm{C}$ relative to the ECMWF profile for $1988-89$ and examined the effect on the model evolution compared to the baseline run (figure 3.3).

In first case T-20 (figure 4.9), the air temperature is sufficiently cold that the ice formation and brine rejection process continues, driven by the strong thermal fluxes, and the mixed layer deepens to the bottom. There is a near balance between the rate of new 
ice formation and ice advection from mid-January through mid-May, and as a result the ice thickness stays relatively constant.

In the T-10 case (figure 4.10), there is a brief period of thermally driven mixed layer deepening between mid-January and March and convection reaches the bottom. Following this, ice forms again and between mid-March and May there is again a near balance between the rate of ice formation and ice advection.

In the third case $\mathrm{T}+5$ (figure 4.11), the air temperature is too warm following the preconditioning to cause a sufficiently large heat flux to deepen the mixed layer. As a result, deep convection does not occur, even though the water column has been preconditioned. So, if the air temperature warms too much following preconditioning, deep convection will not occur.

The conclusion we come to as a result of these scale estimates and model simulations is that in order for the mixed layer to deepen to approximately 1500 meters over a period of two months following the preconditioning phase, as observed in the Greenland Sea, the air temperature must first rise moderately to allow for a reduction in the ice cover. A much warmer air temperature would result in only a small mixed layer deepening, and a much colder air temperature would cause the mixed layer to deepen to the bottom through haline driven convection. Further, if the air temperature had not risen and the ice cover had persisted, the resulting evolution would have been inconsistent with observations of the ice cover.

\subsubsection{Sensitivity to Surface Conditions}

In this section we will attempt to further explore and corroborate the conclusions reached in the preceding sections on the basis of our numerical modeling studies. In particular, we will examine the sensitivity of our results to changes in surface conditions, namely the air temperature and the initial surface stratification. 

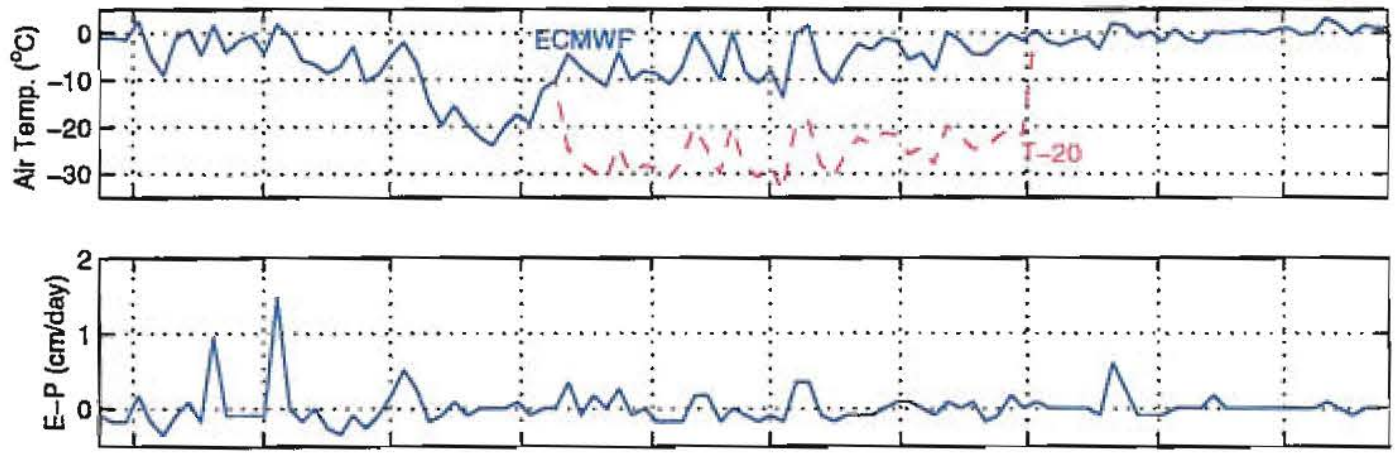

(b)

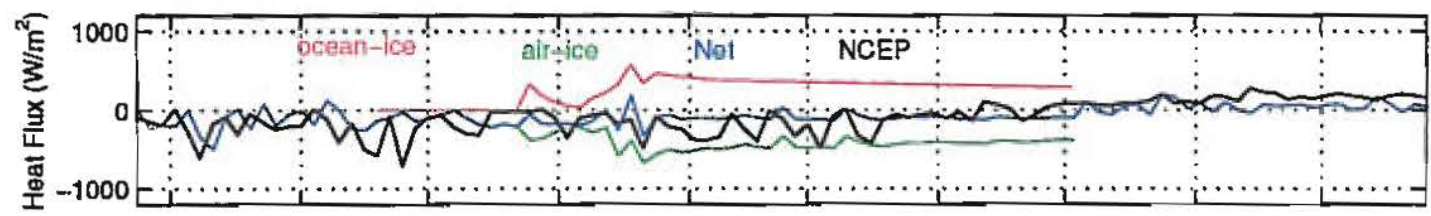

(c)

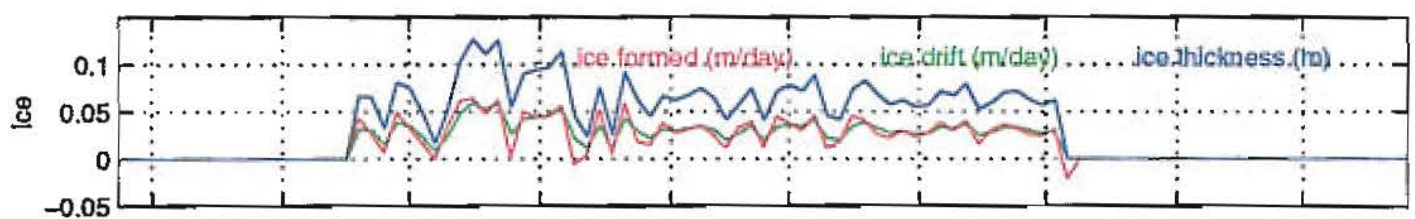

(d)

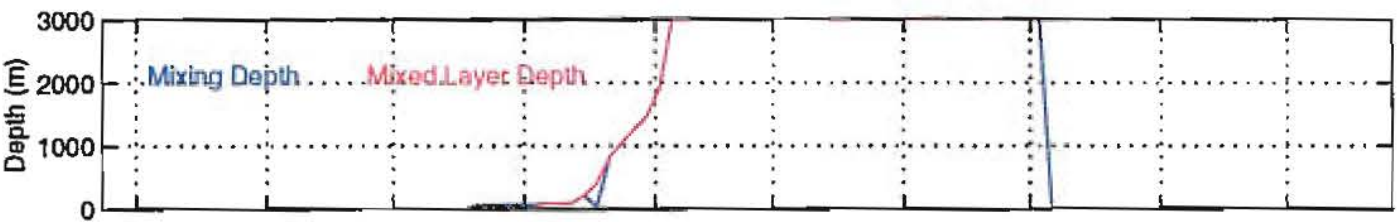

(e)
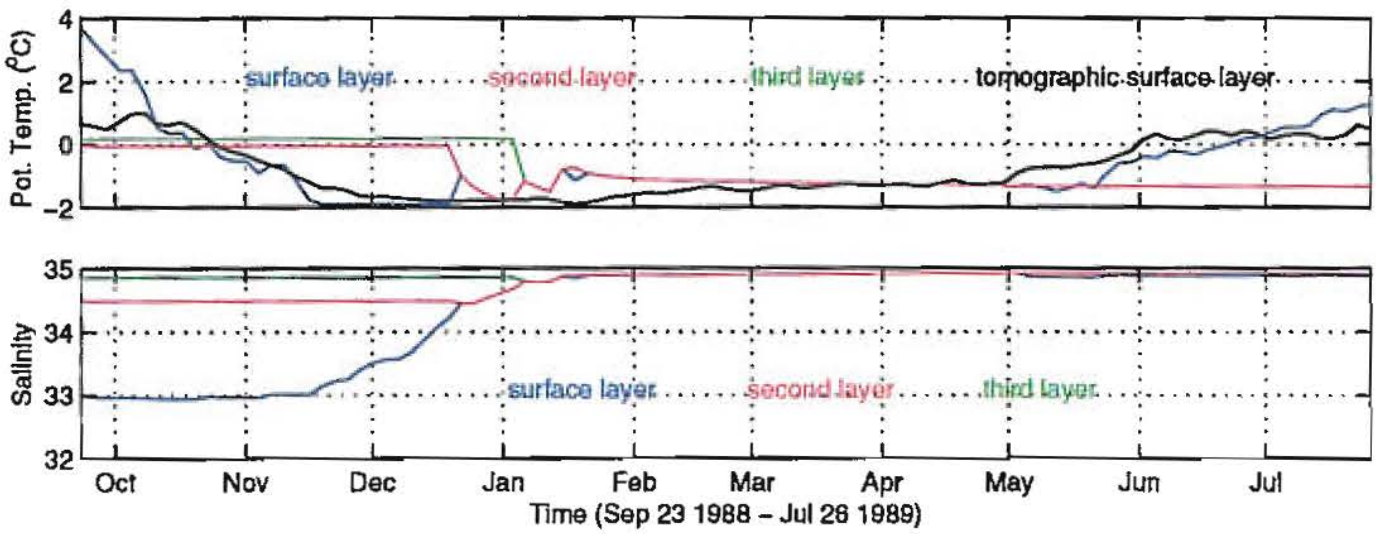

(g)

Figure 4.9: Model output for a run in which the air temperature remained very cold; otherwise, the setup of this run was identical to the baseline run. 


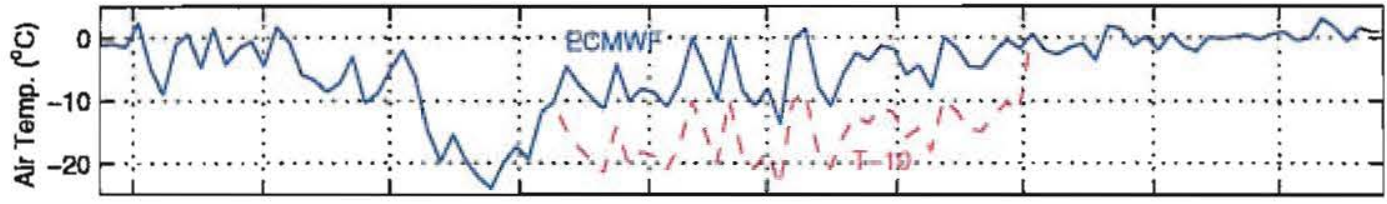

(a)

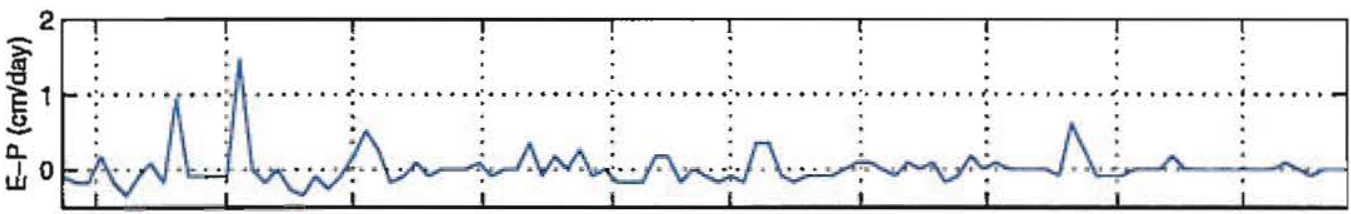

(b)

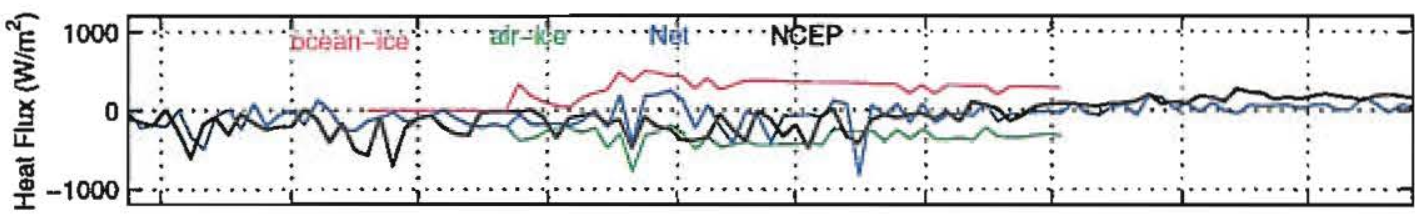

(c)

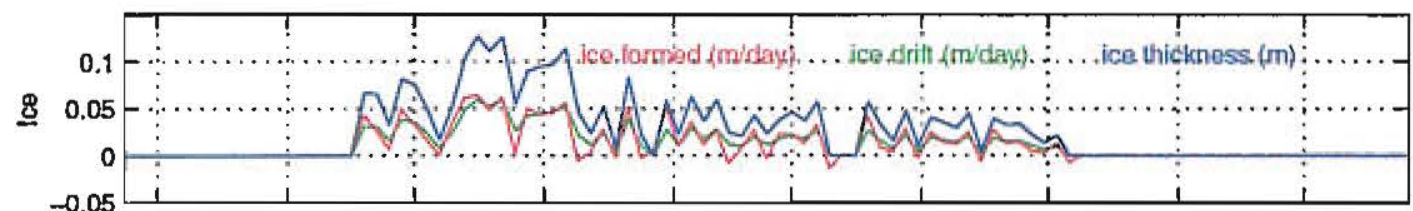

(d)

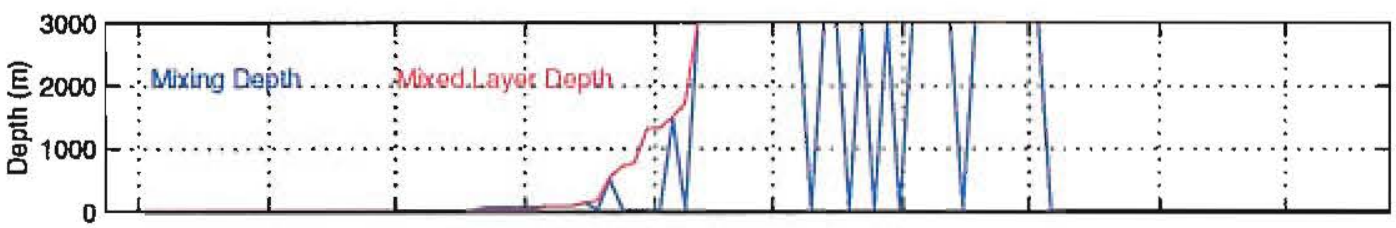

(e)
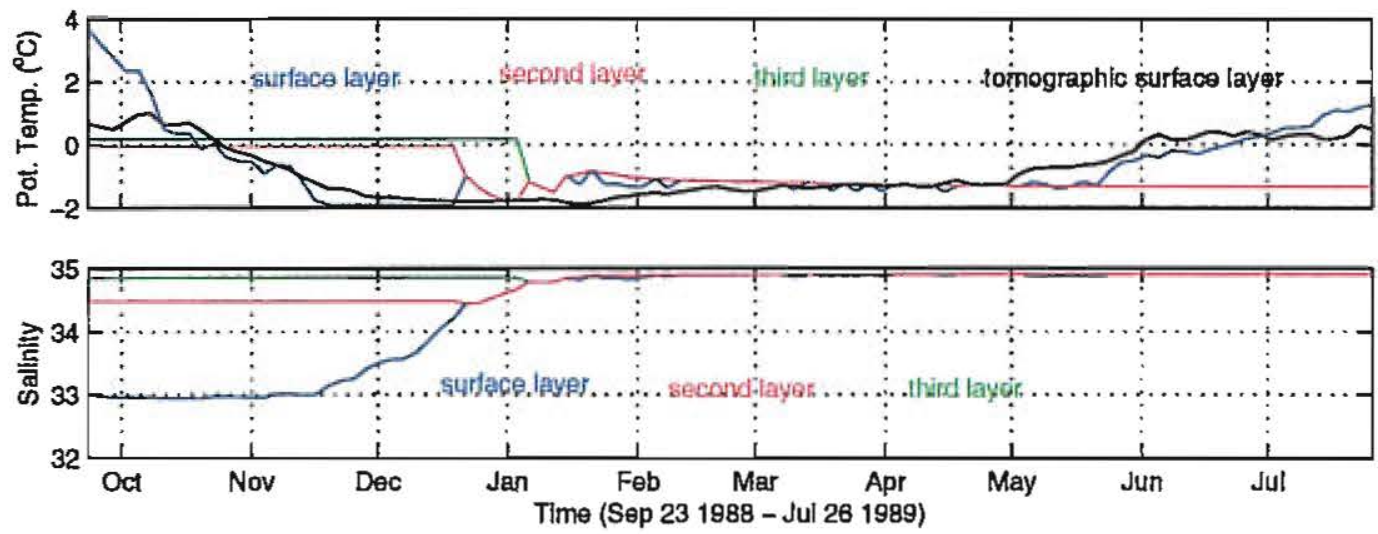

(g)

Figure 4.10: Model output for a run in which the air temperature remained moderately cold; otherwise, the setup of this run was identical to the baseline run. 


\section{Surface Forcing and Model Output for Run T+5}

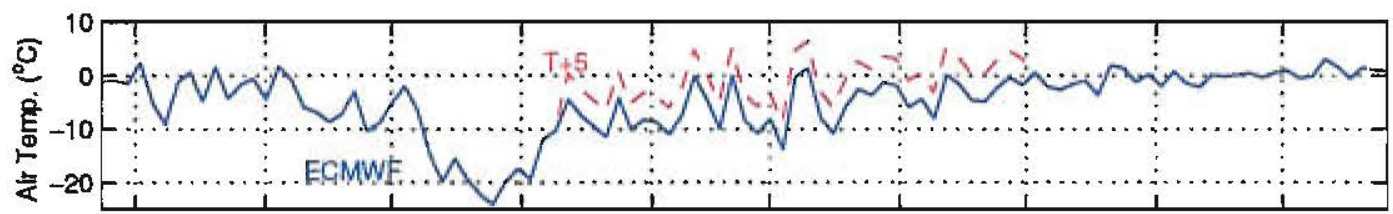

(a)

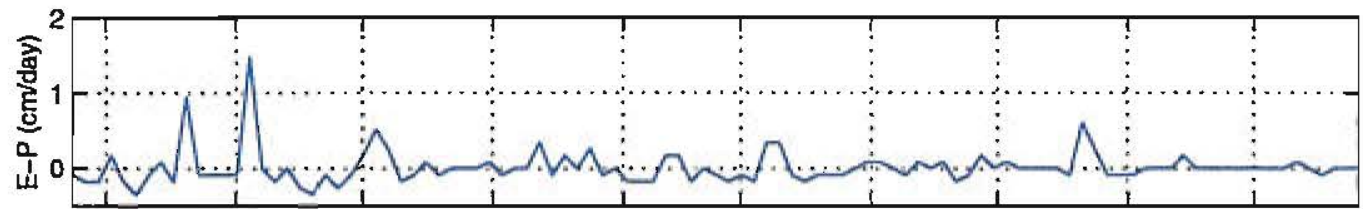

(b)

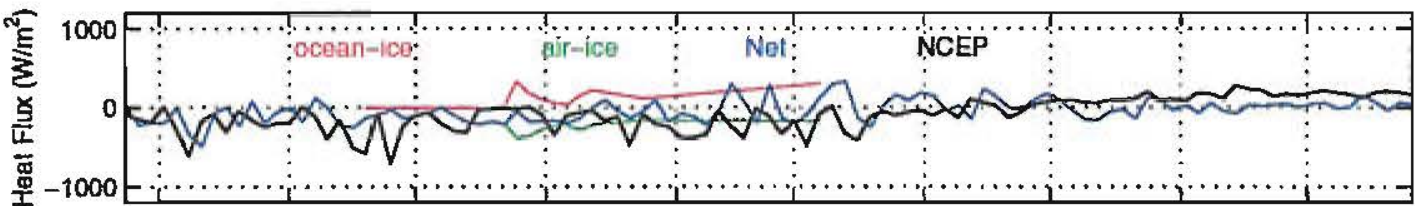

(c)

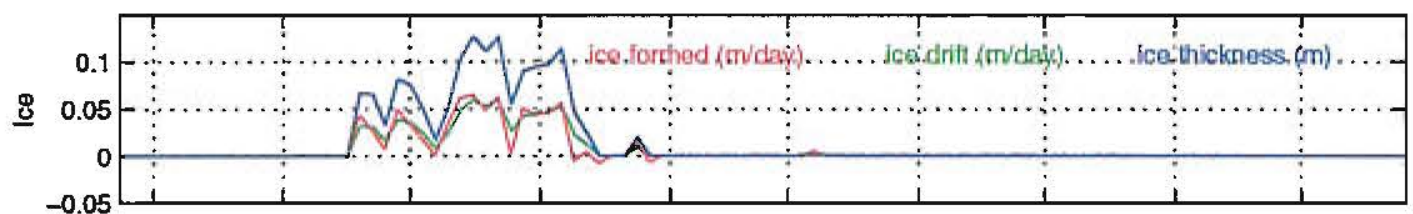

(d)

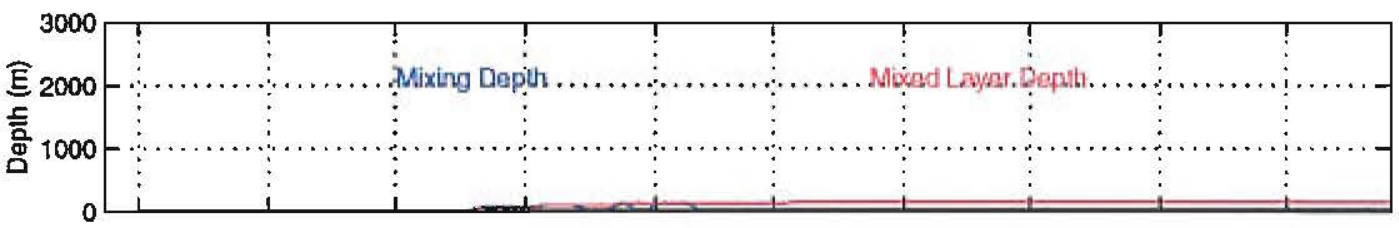

(e)
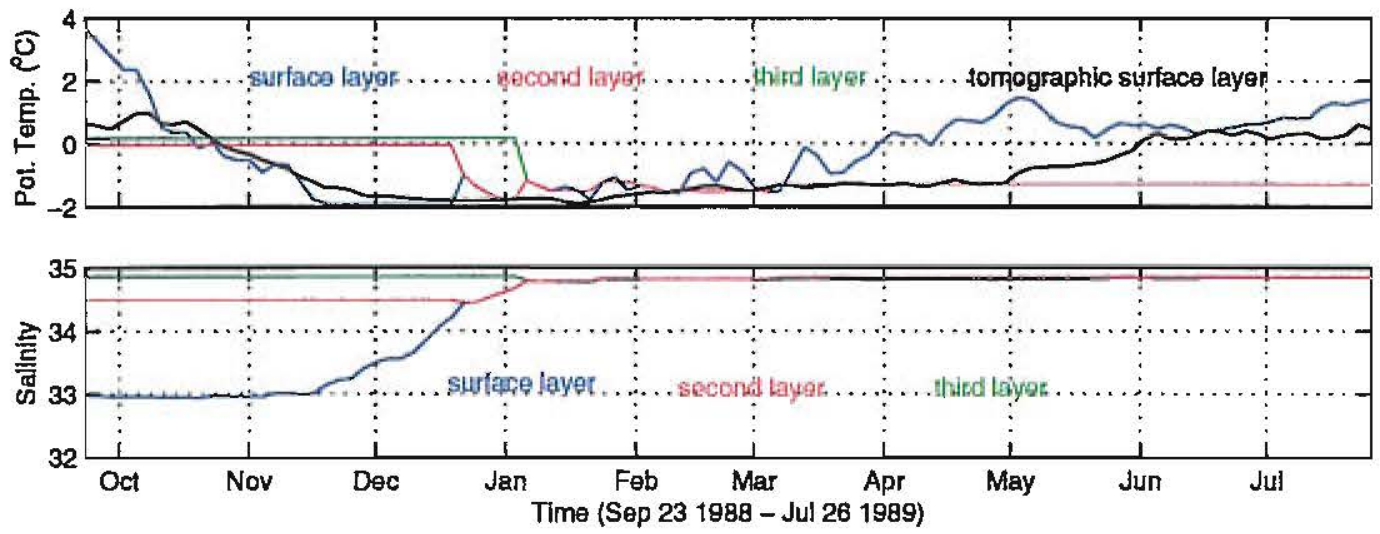

(g)

Figure 4.11: Model output for a run in which the air temperature remained warm; otherwise, the setup of this run was identical to the baseline run. 


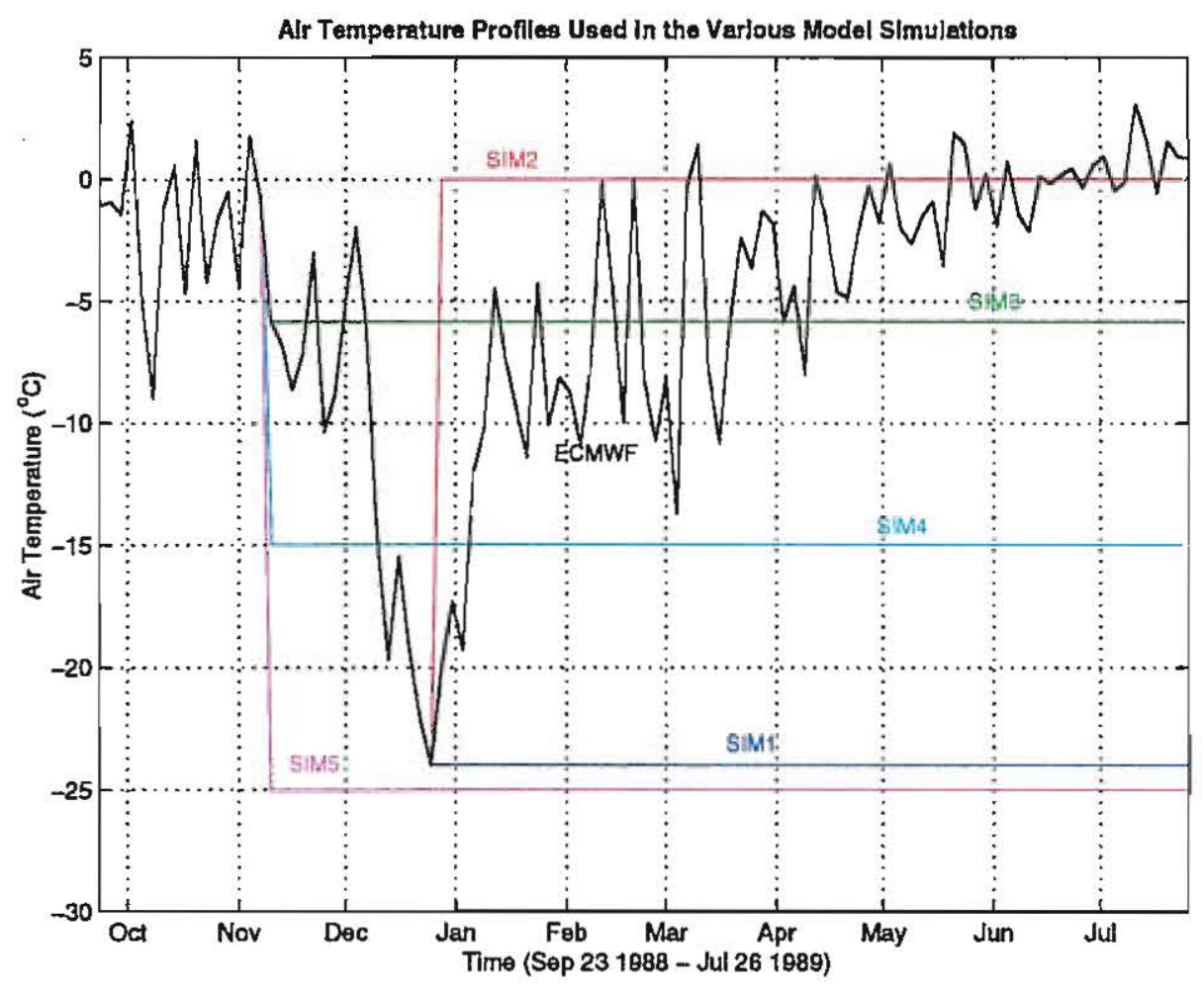

Figure 4.12: The air temperature profiles used for the various model simulations SIM1 through SIM5.

\section{Air Temperature}

We will address the question of what would have happened if the surface air temperature evolution had been different by running a series of simulations in which the air temperature evolution in 1988-89 in changed, as shown in figure 4.12. SIM1 and SIM2 examine the cases in which there is an intense cold spell in December, but then the air temperature either remains very cold or becomes very warm. SIM3 and SIM4 examine the cases in which the intense cold spell never happened, but instead the air temperature remained relatively warm. SIM5 examines the case where the intense cold spell started much earlier and persisted indefinitely. The results of these simulations are shown in figures 4.13-4.17.

In SIM1, the air temperature remains sufficiently cold that the ice cover never diasppears. After the preconditioning period, the thickness of the ice cover reaches a steady state in which the rate of new ice formation matches the rate of ice drift. This 

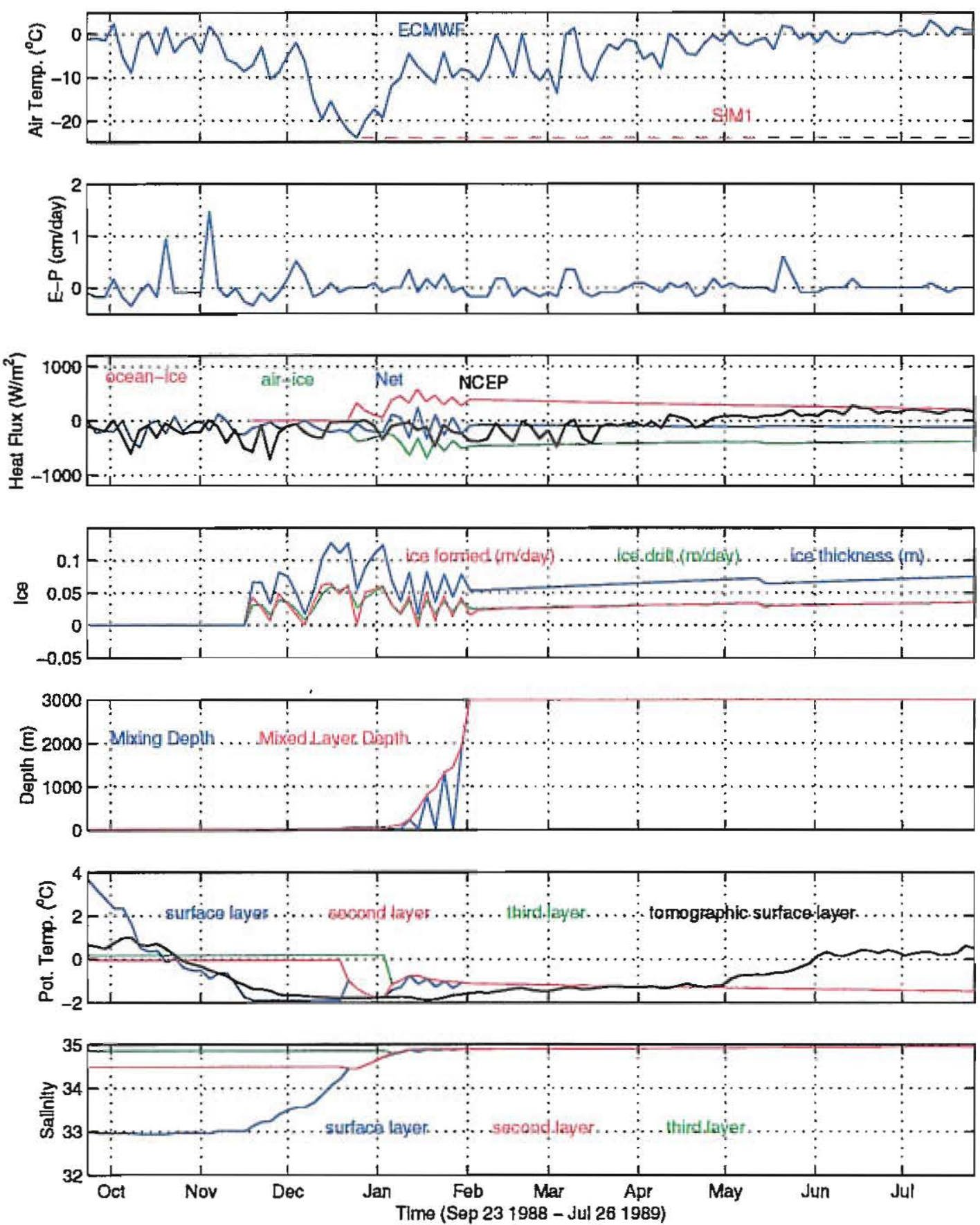

(g)

Figure 4.13: Model output for run SIM1. There is an intense cold spell in December, and the air temperature then remains very cold. 


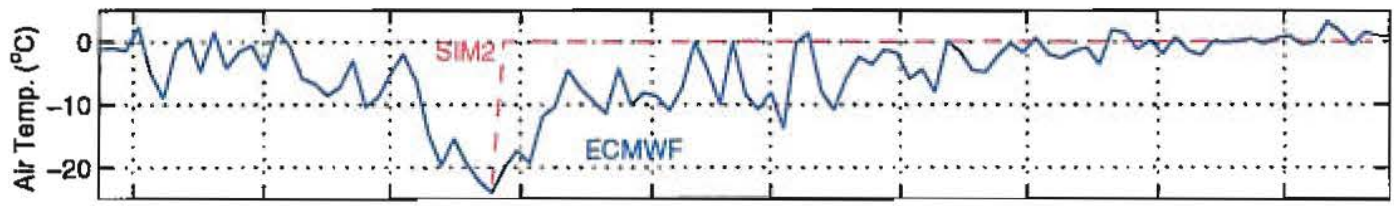

(a)

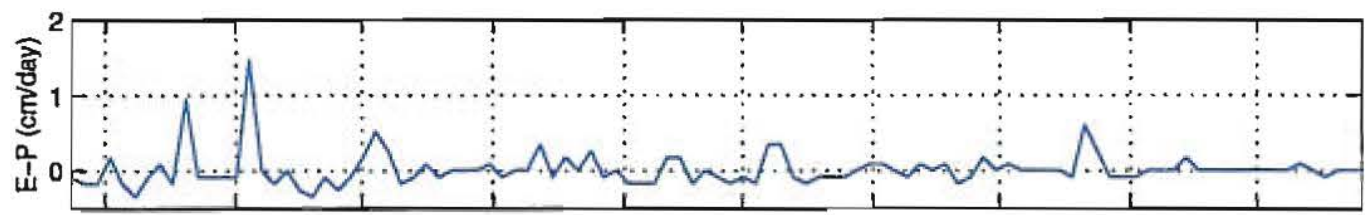

(b)

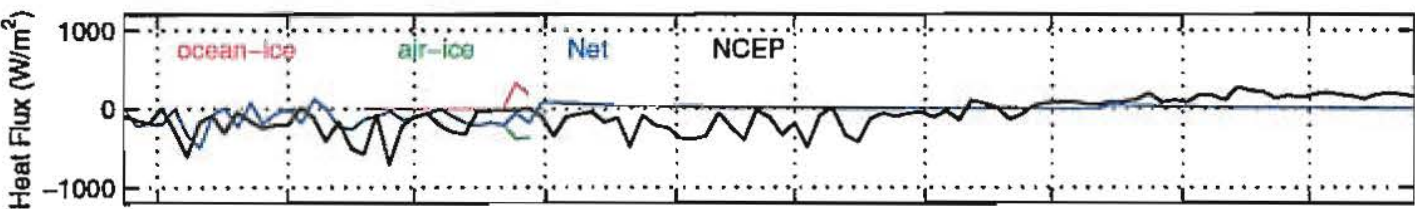

(c)

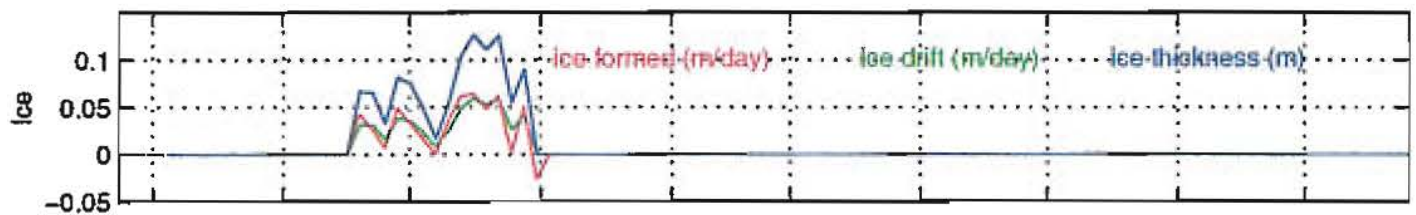

(d)

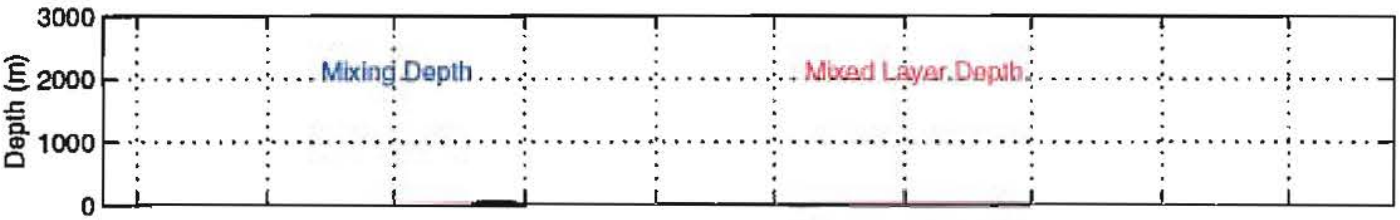

(e)
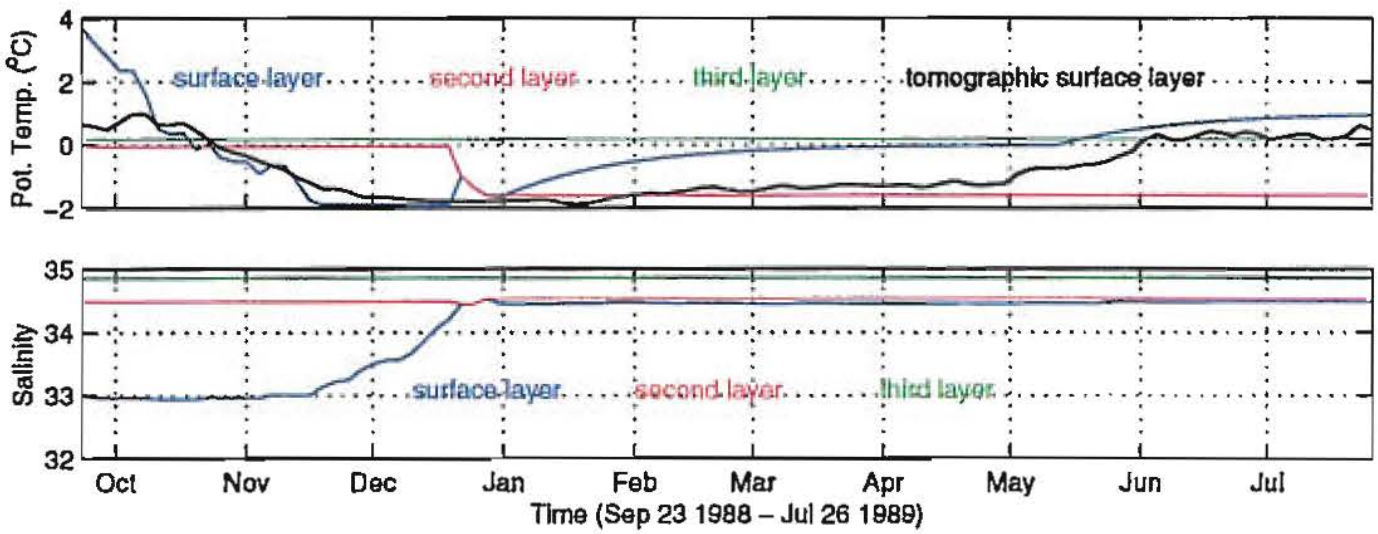

(g)

Figure 4.14: Model output for run SIM2. There is an intense cold spell in December, and the air temperature then becomes very warm. 
behavior was predicted by the analytical work which we presented in section 4.1. Some of the surface heat loss is used to form ice. The remainder of the heat loss is extracted from the entire water column, which has been homogenized. The ongoing ice formation causes the salinity of the water column to continually increase as well.

In SIM2, the cold spell is enough to remove the salinity jump between the surface layer and the second layer. However, when the air temperature suddenly warms, the ice cover melts and a small surface fresh anomaly is restored, inhibiting convection. Thereafter the surface layer warms and further increases the stable stratification at the surface.

In SIM3, the ice thickness is in steady state during the preconditioning period. As soon as the surface layer mixes down to the third layer, enough heat has been brought up to melt away the ice cover and warm the mixed layer. Thereafter no more ice forms. However, since the surface fresh anomaly has been removed, mixed layer then deepens slowly but steadily under the influence of the moderate surface heat loss.

In SIM4, the preconditioning phase proceeds in a similar fashion to SIM3, except that the ice thickness gets considerably larger due to the larger surface heat loss. Again the ice melts away completely once the surface layer mixes down two layers and heat is brought up. However, in this case the surface fluxes are large enough to drive convection straight to the bottom. There is a continued intense surface heat loss of over $800 \mathrm{~W} / \mathrm{m}^{2}$ which cools the entire water column. Ice formation then starts again and the salinity of the homogenized water column increases.

In SIM5, the surface heat loss is so intense that the ice cover never disappears, even when the surface layer deepens and heat is brought up. The mixed layer rapidly deepens all the way to the bottom, driven by a surface heat loss of up to $1000 \mathrm{~W} / \mathrm{m}^{2}$. The ice then reaches a steady state thickness and the evolution proceeds as described in SIM1.

Interestingly, although no convection deeper than about 2000 meters has ever been observed in the Greenland Sea, Smethie et al. [1986] concluded from a study of deep water properties that convection down to 3000 meters must occur sporadically. The discussion above demonstrates that it is entirely possible, and even likely, that this could 


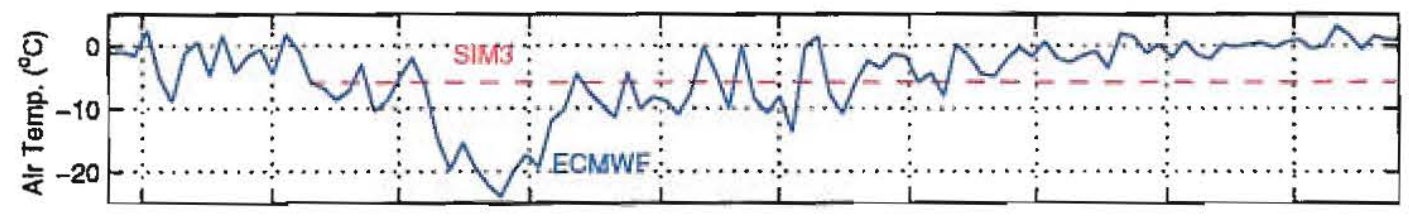

(a)

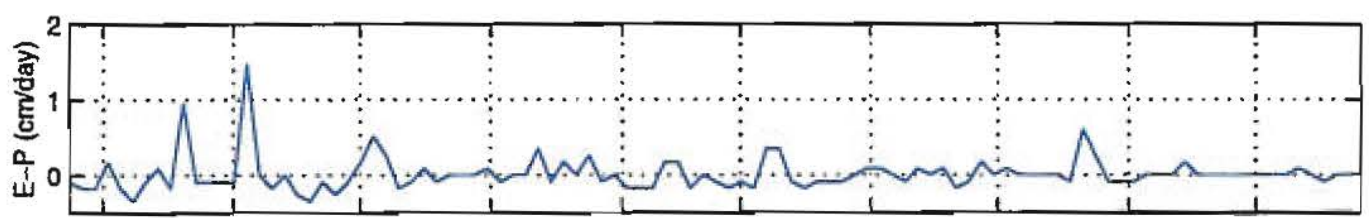

(b)

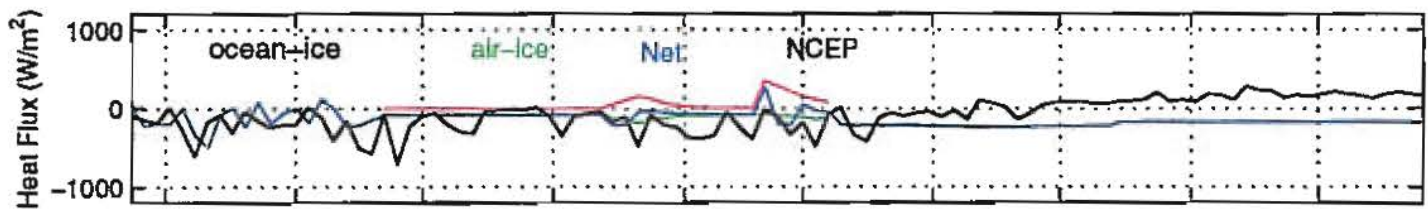

(c)
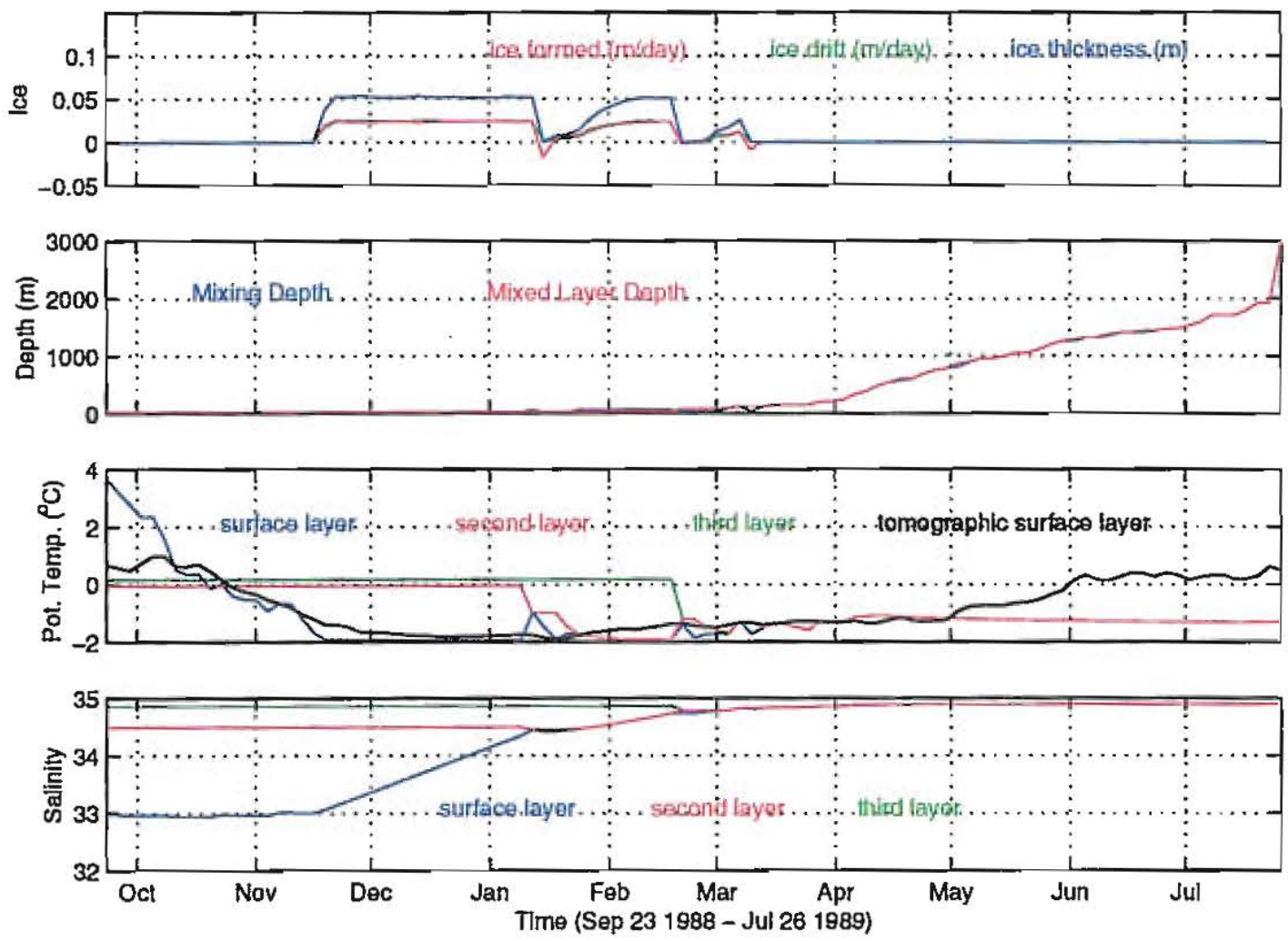

(g)

Figure 4.15: Model output for run SIM3. The air temperature remains relatively very warm. 


\section{Surface Forcing and Model Output for Run SIM4}

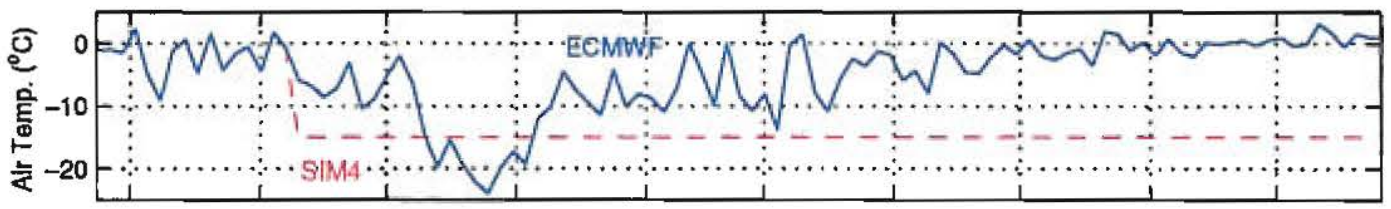

(a)

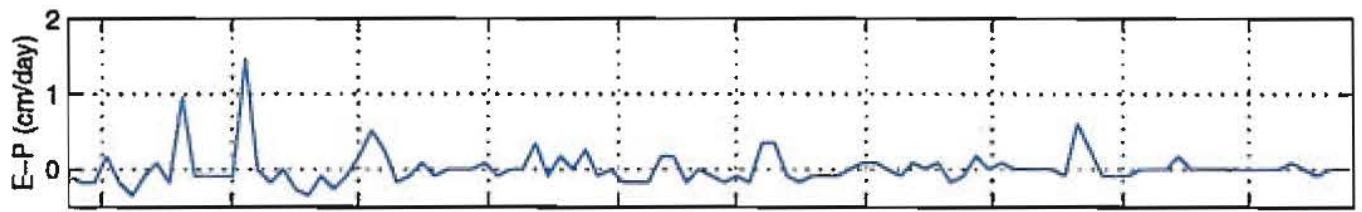

(b)

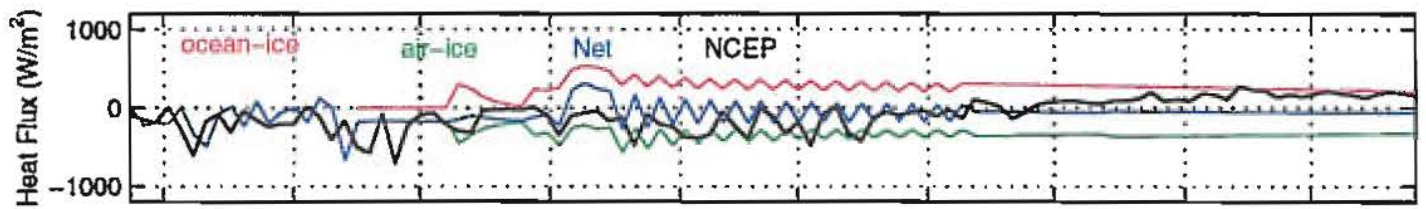

(c)

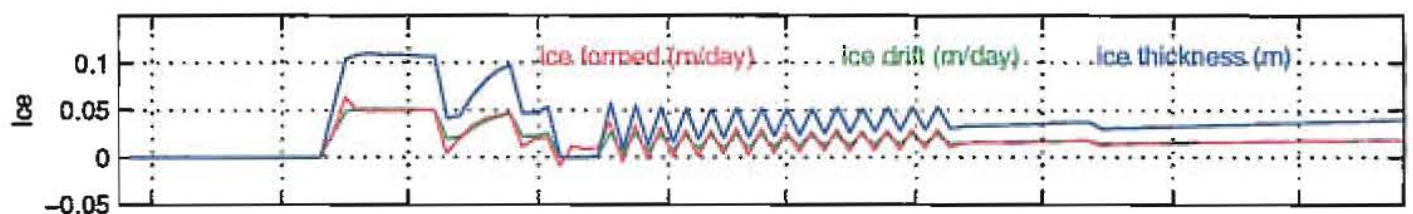

(d)

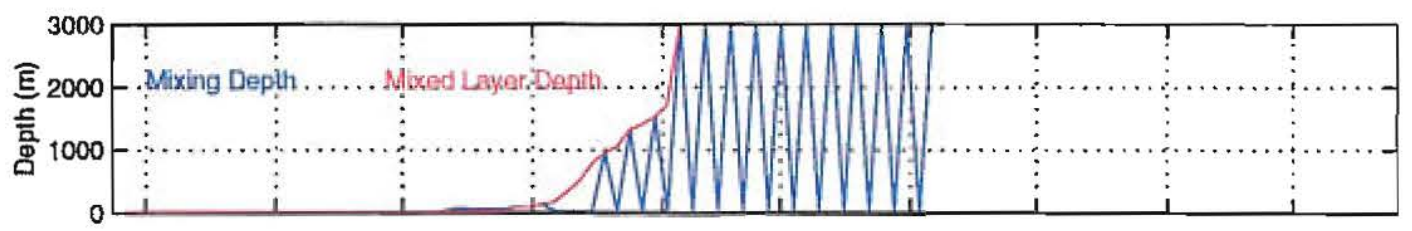

(e)

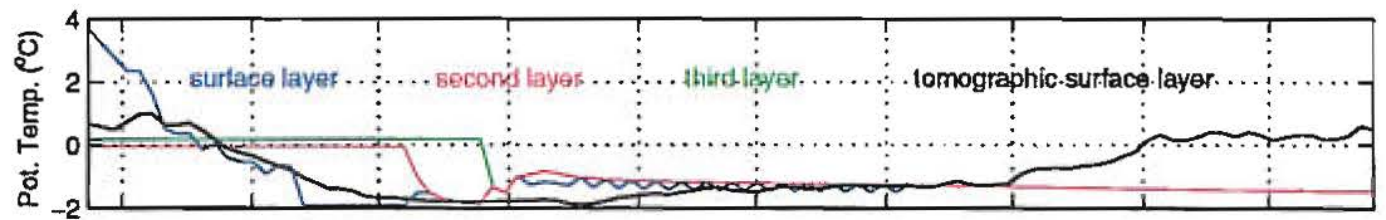

(1)

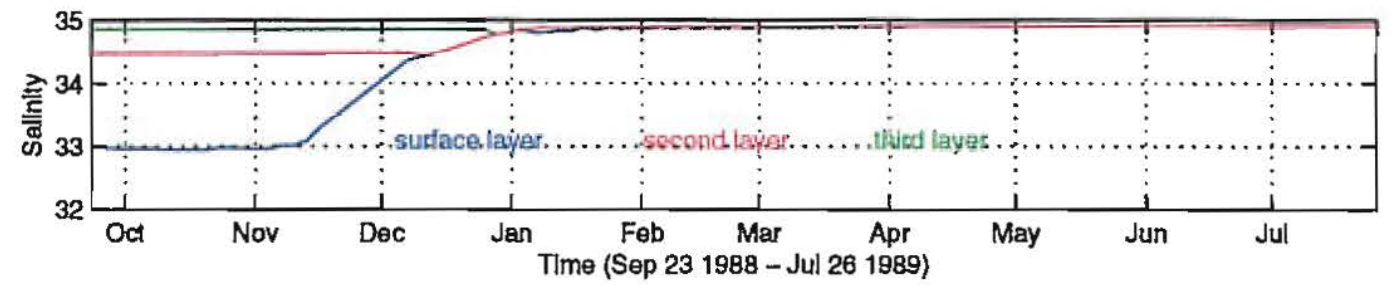

(g)

Figure 4.16: Model output for run SIM4. The air temperature remains moderately cold. 


\section{Surface Forcing and Model Output for Run SIMS}

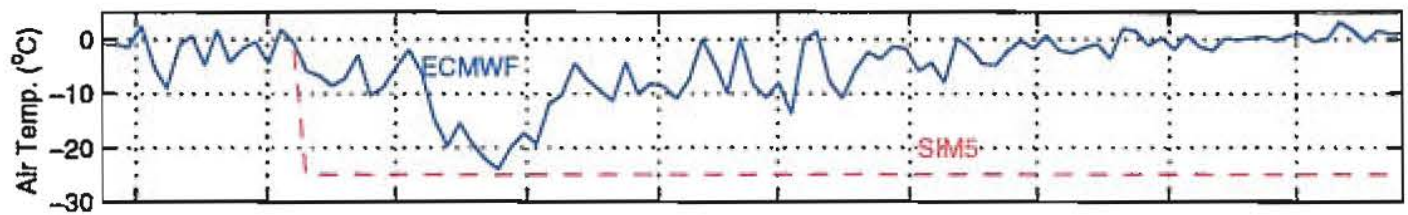

(a)

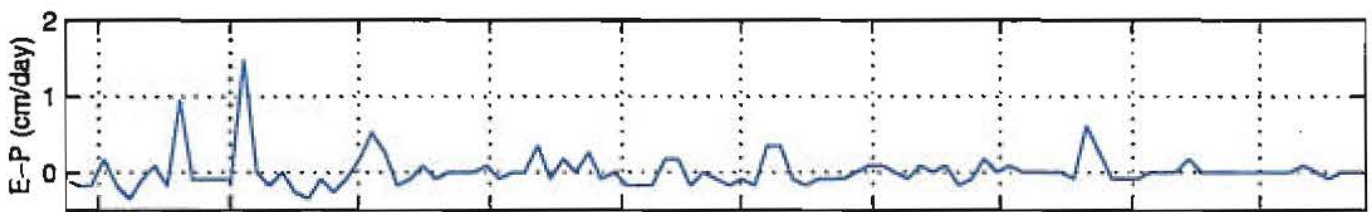

(b)

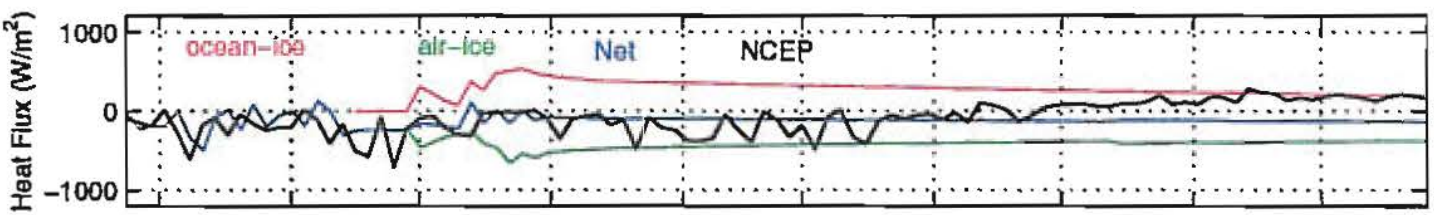

(c)

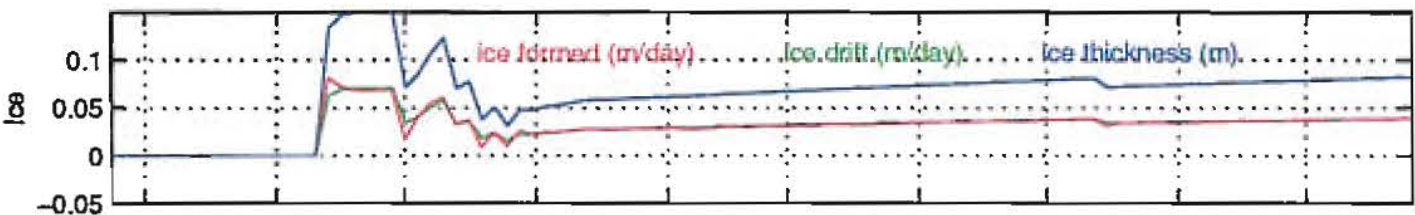

(d)

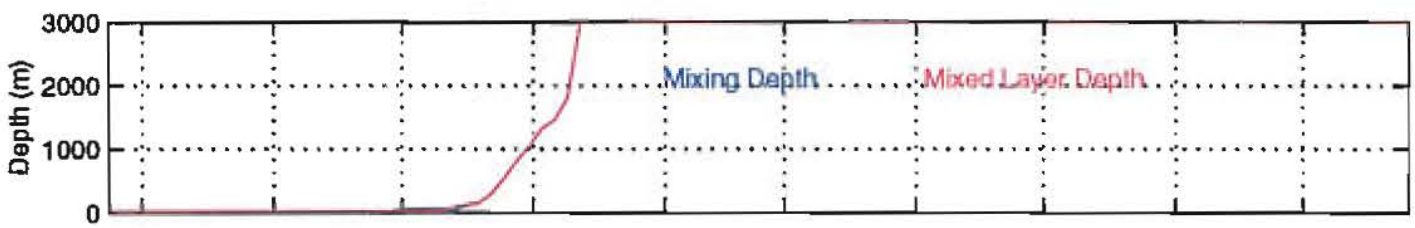

(e)
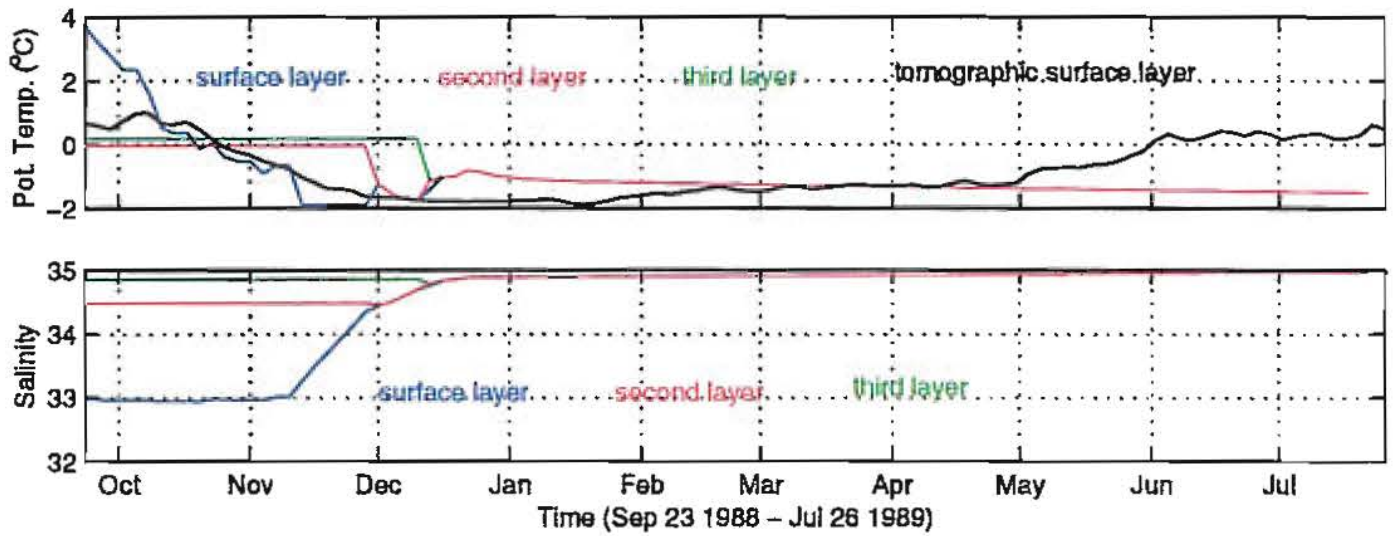

(g)

Figure 4.17: Model output for run SIM5. The air temperature remains very cold. 
have happened in a season when the air temperatures were very cold (at least $-15^{\circ} \mathrm{C}$ ) for an extended period of time. However, sufficiently cold winters have not been observed in the past two decades (appendix C). It may be possible that this occurs in small-scale chimneys though, in regions of intense localized cooling.

\section{Sensitivity to Initial Surface Stratification}

We now consider what the effects are on the model evolution of varying the strength of the initial surface stratification. A series of model runs was carried out to examine what happens when the size of the initial surface fresh anomaly is varied. The results are shown in figure 4.18. We can clearly see that the magnitude of the initial fresh anomaly influences the maximum depth of the mixed layer deepening. This observation is relevant to the comparison with previous modeling efforts that we discussed earlier. These studies did not all use the same initial conditions.

When the initial surface fresh anomaly is very large, ice forms but no convective mixing occurs because the brine rejection is not enough to erode this fresh layer. Therefore, no heat is brought up from below and the ice never melts. This, we believe, is the reason that the ice tongue Is Odden (see figure 1.5) exists. The East Greenland Current advects very fresh polar water into the region (see figure 1.4), resulting in a very fresh surface layer. Therefore, the salinity of the surface layer never gets large enough to mix down and entrain heat from deeper layers. Hence, the ice that forms never disappears throughout the winter.

The stratification in the central Greenland Sea is weakened because of the doming of the isopycnals which occurs there (due at least in part to the cyclonic circulation). In this region, the initial surface fresh anomaly will be somewhat smaller than near the edges of the gyre. The ice melts when large amounts of heat are entrained from deeper layers, forming the ice free bay referred to as Nordbukta. Some refreezing of ice-free water has been observed to the southeast of the convecting region, near the Jan Mayen Current [Roach et al. 1993]. In this region the stratification of the surface layer was penetrated and enough heat was brought up to melt the ice. However, ice then formed again over this deeper mixed layer and the density jump at the base of this layer was never eroded. 
Comparison of Model Output for Inltial Surface Sallnity Variation Runs

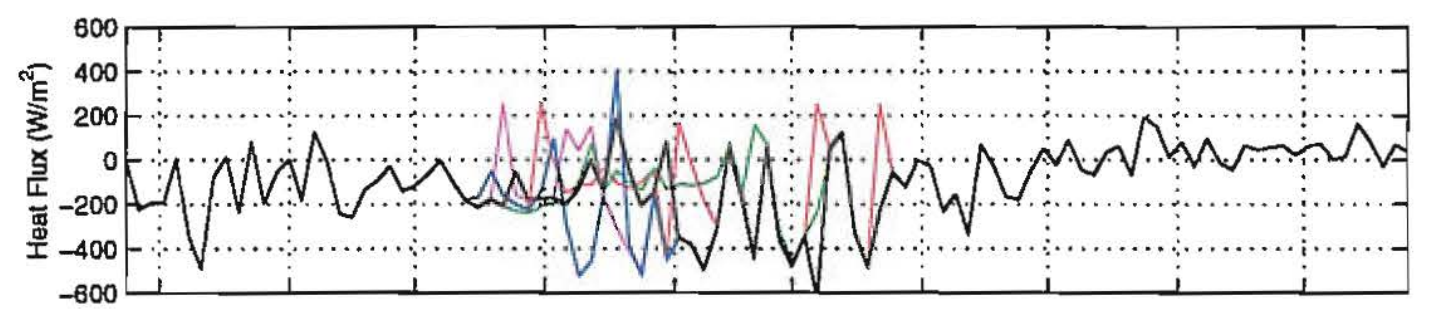

(a)

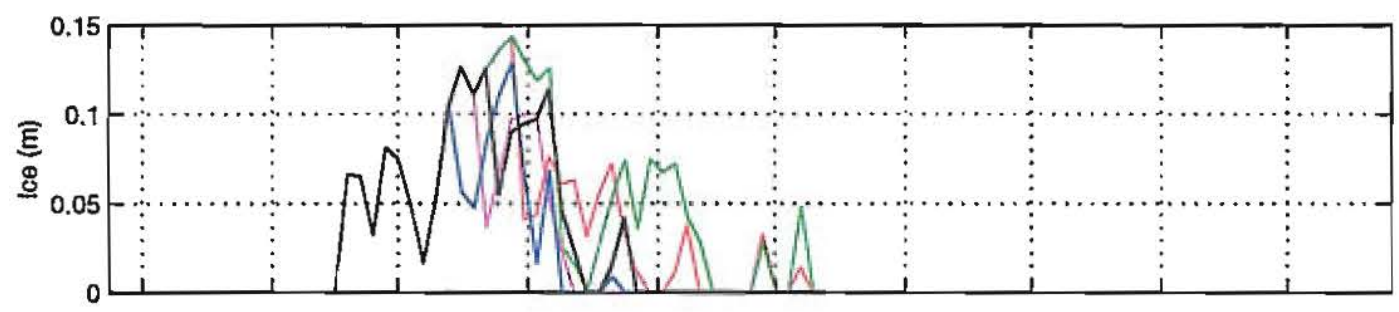

(b)

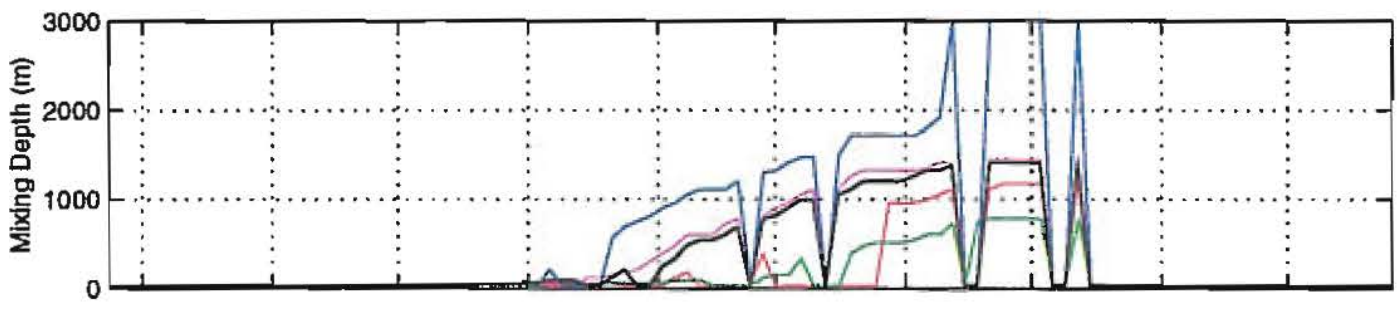

(c)

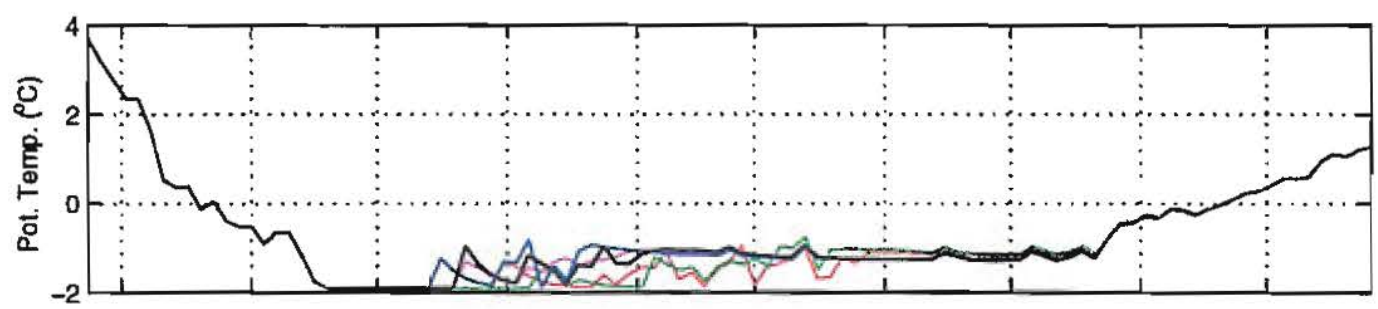

(d)

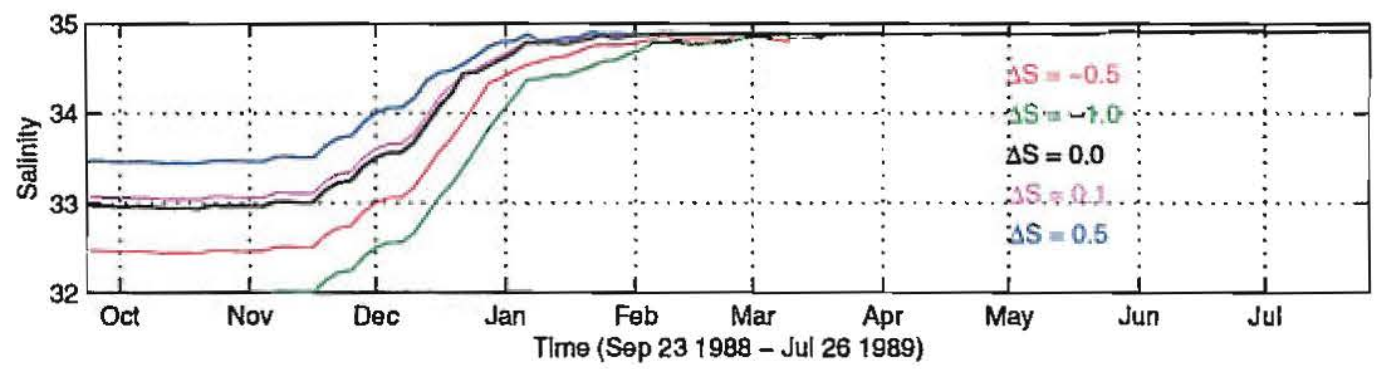

(e)

Figure 4.18: Comparison of output from model runs with perturbations in the initial surface layer salinity. 
As an aside, it is interesting to note the mutual dependence loop between salinity and ice: the existence of a fresh anomaly at the surface is vital for ice formation, and ice formation is essential for the removal of this fresh anomaly.

\subsection{Limiting the Depth of Convection}

We have carefully examined the processes leading to the onset of convection, and we have determined that the details of the initial conditions and surface forcing both play an important role. However, we would also like to understand what limits the depth of convection once the mixed layer starts to deepen. In a convective adjustment model, the mixed layer will deepen as long as it is statically unstable at the base. This suggets that the processes responsible for limiting the depth of the convective mixing must affect the deep stratification of the water column. We have identified three possibilities:

1. A pre-existing stable stratification at depth.

2. A restratification of the deepening homogenized mixed layer by lateral advection resulting from baloclinic eddy activity.

3. The efficiency of the mixing scheme used in the model.

\subsubsection{Efficiency of Convective Adjustment}

Clearly it is undesirable for the third option to be a controlling factor. Hence, it is important to choose a mixing scheme which is appropriate for the process being studied. Klinger et al. [1996] showed that the water column adjusts within 12 hours, and that the results of a non-hydrostatic GCM are not sensitive to the exact value of the mixing timescale. Therefore, convective adjustment with instantaneous mixing was found to be a consistent parameterization. We are interested in processes occurring on a daily timescale, and thus it is appropriate to use a convective adjustment scheme which completely and instantaneously removes all static instabilities in the water column. For this reason a complete mixing scheme similar to the one presented by Yin and Sarachik [1994] was 
chosen for this study. When the model was run using the standard 2-pass convective adjustment scheme that is used with the GFDL MOM model, we can see that the results are considerably different when a single pass is made through the convection scheme at each model timestep (see figure 4.19). When we set the number of passes through the scheme at each model timestep to be very large, then the results converge to the results obtained using the complete mixing scheme, as we would hope and expect. However, making so many passes through the convective adjustment scheme is computationally slow and inefficient.

With this convective adjustment scheme, a parcel of water in a given layer will mix down at most two layers for each pass through the scheme. Thus, the mixing timescale for this scheme is

$$
\tau_{c}=\frac{L}{N_{C O N}} \cdot \text { tstep . }
$$

Since we expect that $\tau_{c}$ should be no larger that half a day, this implies that $N_{C O N}=100$ for a one day model timestep. In other words, the GFDL 2-pass scheme mixes efficiently enough only if at least 100 passes through it at every one day timestep. Results of a model run which used the GFDL 2-pass scheme with $N_{C O N}=100$, and was in every other way identical to the baseline run, are shown in figure 4.19. These results are almost identical to the baseline run results.

If the convective mixing becomes less efficient, then this can become the depthlimiting factor for the mixed-layer deepening. This behavior is undesirable.

\subsubsection{Initial Deep Stratification}

From observed profiles, we can see that a very small but positive stratification does exist at depth. We carried out some sensitivity experiments in which the degree of the deep stratification was varied, and we found that indeed this deep stratification does play a decisive role in determining the maximum depth to which the mixed layer deepens. We perturbed the magnitude of the initial haline stratification between $1000 \mathrm{~m}$ and $2000 \mathrm{~m}$, as shown in figure 4.20 . The maximum depth of convection changed by up to 200 meters (figure 4.21) for perturbations of $5 \times 10^{-6} \mathrm{psu} / \mathrm{m}$ over 1000 meters. Note that the size of 


\section{Potentlal Temperature Evolution Using 2-Pass Convective Adjustment Scheme}
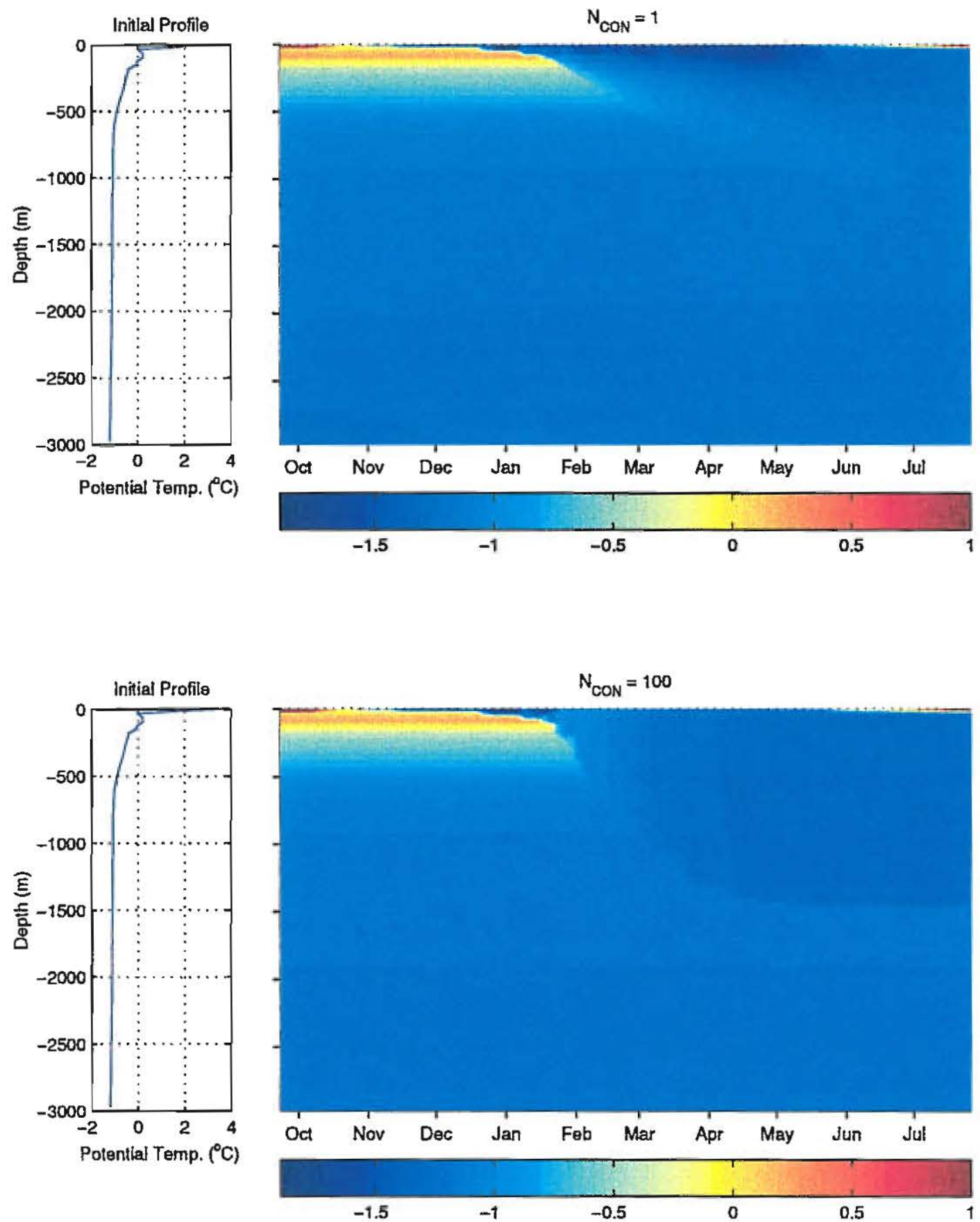

Figure 4.19: Potential temperature evolution for two runs carried out using the 2-pass convective adjustment scheme rather than the complete mixing scheme. The initialization and forcing of these runs are identical to the baseline run. 


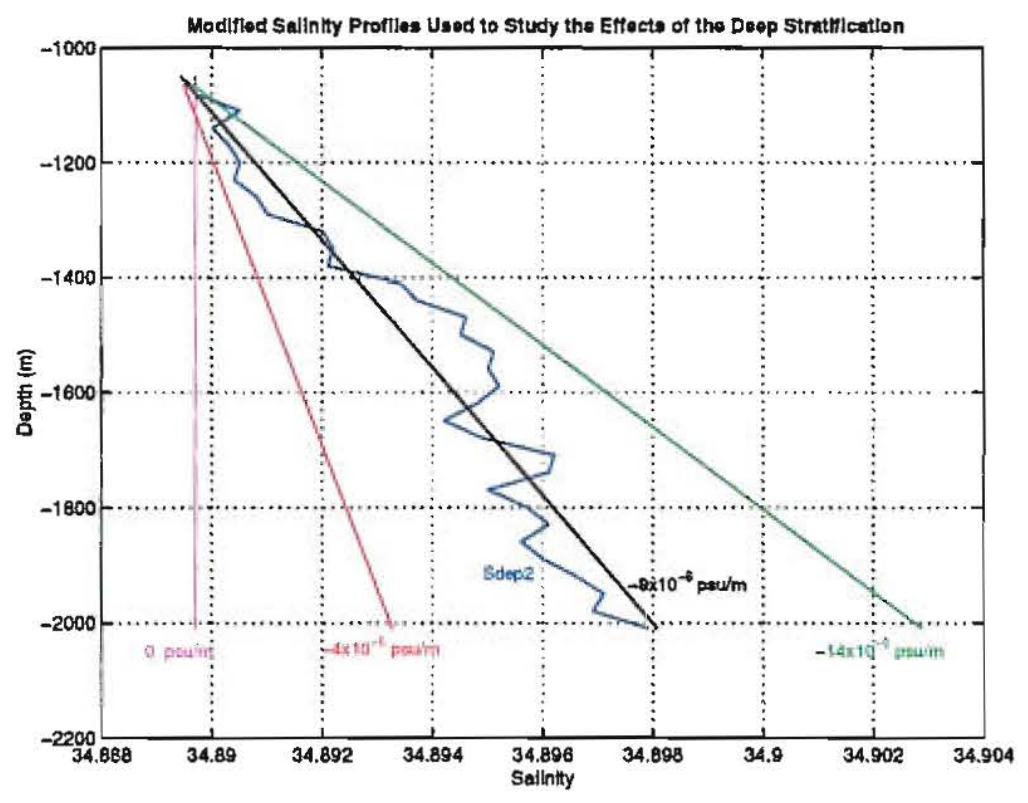

Figure 4.20: Modifications made to the initial salinity profile between $1000 \mathrm{~m}$ and $2000 \mathrm{~m}$, used to study the impact of the deep salinity stratification on the mixed layer depth. The profile Sdep2 was used in the baseline run.

these perturbations is within typical observational uncertainties. In the limit where the salinity stratification is removed completely in this depth range, the mixed layer deepened all the way down to $2000 \mathrm{~m}$ and then was arrested by the stable stratification below 2000 meters.

\subsubsection{Lateral Advection}

One good way to assess the importance of lateral advection is by using data assimilation to find a best fit of the model to the tomographic temperature record, using the eddy restoring timescale $\tau_{\text {eddy }}$ (see equations 3.6 and 3.7 ) as a control variable of the optimization. We are currently carrying out such a study. Unfortunately, due to some technical difficulties we will not have results ready in time to be included in this thesis. A description of the method used to carry out this data assimilation study is presented in appendix D. We are also using this method to determine the optimal initial temperature and salinity profiles which yield a model evolution which is as close as possibe to the observations. 


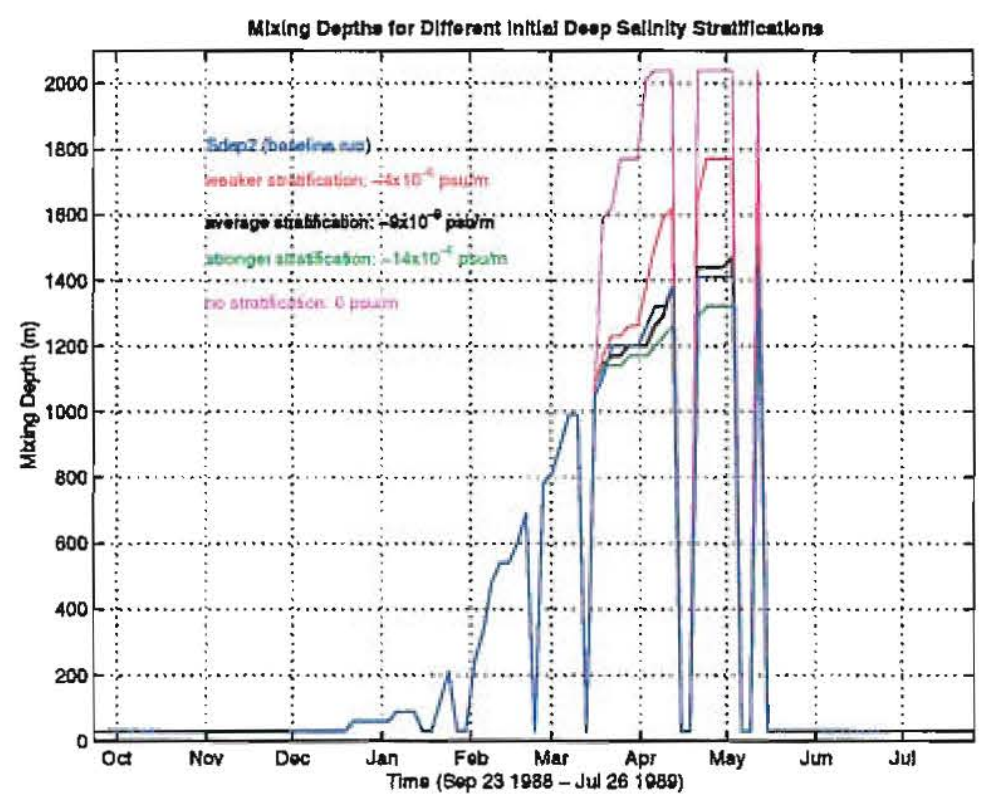

Figure 4.21: The mixed layer depth evolution for the different initial salinity profiles shown in figure 4.20. Even a small change in the stratification can have a large effect on the mixing depth.

Due to the non-linearities of the model, the degree of sensitivity of the model evolution to many of the model parameters, and the relatively meager dataset with which to constrain the model, it has proved difficult to obtain useful results through data assimilation. We have found that it is important to configure the optimization very carefully and to make a judicious choice of control variables. Nevertheless, we are hopeful that interesting results will be forthcoming.

Even though lateral advection does not appear to be needed as an agent for limiting the maximum depth of convection (a result consistent with the previous modeling studies mentioned earlier in section 4.2), the model baseline run clearly demonstrates that it is needed to restore the stratification of the homogenized deep mixed layer to match what is seen in the late spring observations. Surface processes cannot accomplish this as there is no mechanism to create a deep stable stratification from the surface. In the late spring a shallow stable stratification is created at the surface by the warming air temperatures and increasing insolation. However, this caps any further mixing to deeper levels. 
Further, a comparison of the model-predicted heat content changes with the tomographic data suggests that non-local advection was significant (as we discussed in section 3.2.3) after the onset of the mixed layer deepening.

A model run was carried out in which the stratification in the initial temperature and salinity profiles below 500 meters was removed. As expected, the mixed layer deepened all the way to the bottom. We then turned on a restratification to ambient temperature and salinity profiles with a restoring timescale of 500 days. We found that the maximum mixed layer depth was limited to about 1500 meters. However, the mixed layer properties were considerably different than in the baseline run due to the interaction with the warmer ambient waters.

\subsubsection{Theoretical Considerations}

To further address this question, we turn to the work of Visbeck, Marshall, and Jones [1996]. For non-penetrative mixed layer deepening (a good approximation, as discussed earlier), they derived the following expression for the rate of deepening of the mixed layer:

$$
\frac{\partial h}{\partial t}=\frac{B_{0}}{N^{2} h} .
$$

This assumes that the convective layer overturns sufficiently rapidly that it is always wellmixed vertically, and that entrainment buoyancy fluxes across the base of the mixed layer can be neglected.

When a balance exists between the surface buoyancy flux and the lateral fluxes, the maximum depth of convection is given by:

$$
h_{\text {final }}=3.9 \frac{\left(B_{0} r\right)^{\frac{1}{3}}}{N}
$$

and is reached in a time:

$$
t_{\text {final }}=12\left(\frac{r^{2}}{B_{0}}\right)^{\frac{1}{3}} .
$$

The buoyancy frequency profile at location $74.5333^{\circ} \mathrm{N} \times 5.7883^{\circ} \mathrm{W}$ on Sept. 18, 1988 is shown in figure 4.22 . We can see that the deep stratification (below $700 \mathrm{~m}$ ) is fairly 


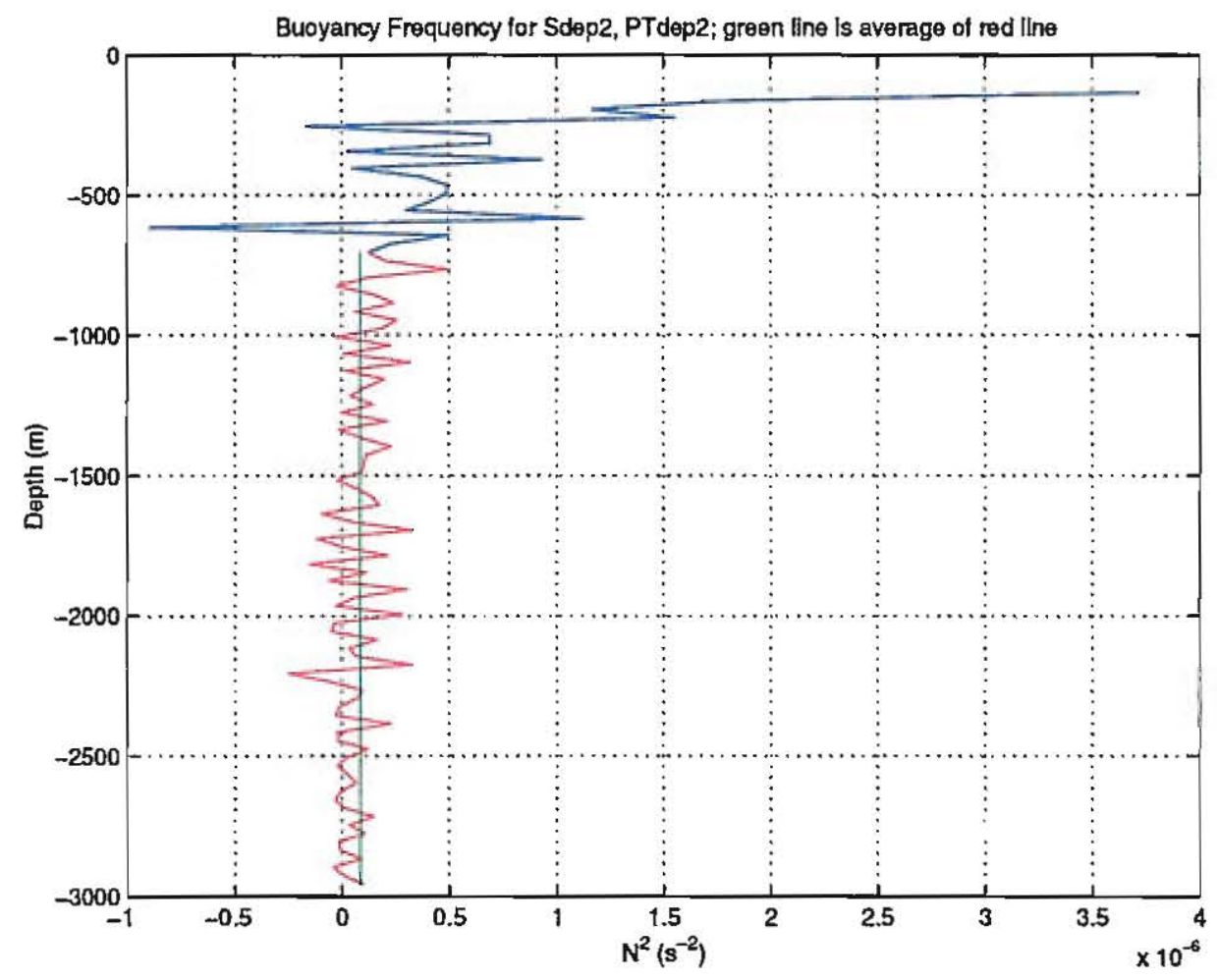

Figure 4.22: The buoyancy frequency derived from data taken during the Greenland Sea Tomography Experiment deployment cruise, on Sept. 18,1988 at $74.5333^{\circ} \mathrm{N} \times 5.7883^{\circ} \mathrm{W}$. The vertical green line indicates the mean deep stratification of $8 \times 10^{-8} \mathrm{~s}^{-2}$. This is the stratification which must be penetrated during the mixed-layer deepening phase of the deep convection process. 

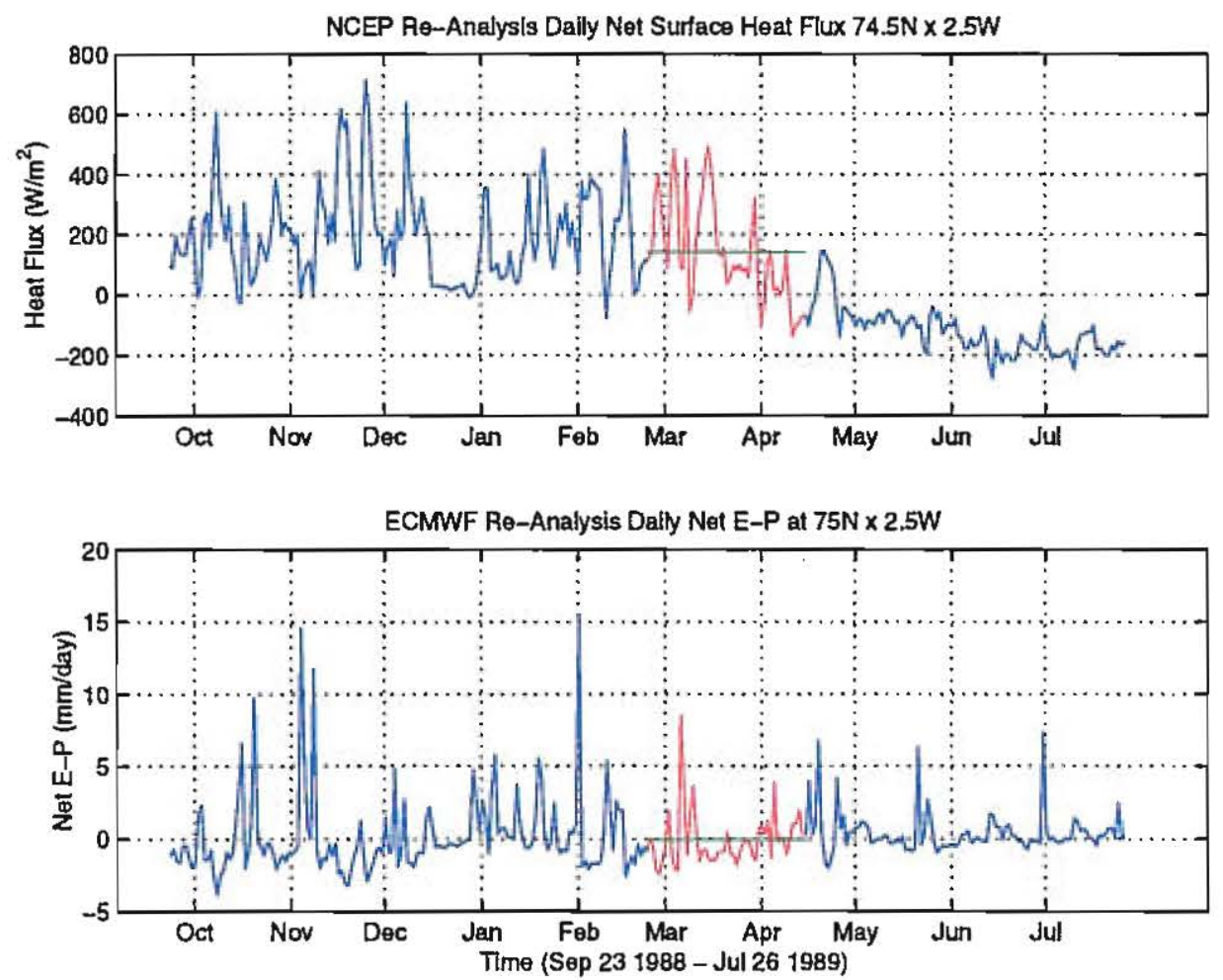

Figure 4.23: Daily net heat and freshwater fluxes from the NCEP and ECMWF reanalysis datasets. The horizontal green lines indicate the average surface fluxes of heat $\left(139.5 \mathrm{~W} / \mathrm{m}^{2}\right)$ and freshwater $\left(-1.1 \times 10^{-9} \mathrm{~m} / \mathrm{s}\right)$ out of the ocean during the period of deep mixing. 
constant, with a value of about $8 \times 10^{-8} \mathrm{~s}^{-2}$. From the tomographic temperature record (figure 2.2), we see that the mixed layer has deepened to about $200 \mathrm{~m}$ by the beginning of February and reaches its maximum depth of about 1500 meters by mid-April. The average surface heat flux during this period was $139.5 \mathrm{~W} / \mathrm{m}^{2}$ and the average surface freshwater flux was $-1.1 \times 10^{-9} \mathrm{~m} / \mathrm{s}$ (figure 4.23 ). During this time, the average buoyancy loss at the surface is given by

$$
B=\frac{g}{\rho_{0}}\left(\frac{\alpha}{c_{p}} H_{T}+\beta S_{\text {ref }} \rho_{0}(E-P)\right)
$$

where $\alpha=0.3 \times 10^{-4} K^{-1}$ and $\beta=7.9 \times 10^{-4} \mathrm{psu}^{-1}$ for typical conditions in the Greenland Sea near the surface. Inserting the appropriate values into this expression ${ }^{5}$, we find that the average buoyancy loss during the convecting period was approximately $1.43 \times$ $10^{-8} \mathrm{~m}^{2} / \mathrm{s}^{3}$. This was almost entirely due to the sensible heat loss; the net buoyancy change caused by the surface freshwater flux was negligible in comparison, since the integrated E-P over this period was almost zero.

It is important to note, however, that while the net integrated freshwater flux during the deep convection period was negligible, the evaporation rate in early March was quite large and resulted in a buoyancy loss of $1-2 \times 10^{-6} \mathrm{~m}^{2} / \mathrm{s}^{3}$, comparable in magnitude to the buoyancy loss due to the sensible heat flux.

Using these values for the average buoyancy loss and stratification, we find that $h_{\text {final }} \approx 1300 \mathrm{~m}$ and $t_{\text {final }} \approx 88$ days. These values are in reasonably good agreement with the tomographic temperature record. This suggests that the convecting chimney indeed reached a state of equilibrium, with the surface buoyancy loss being offset by the lateral buoyancy transport of geostrophic eddies. As the air temperature warms and the surface buoyancy loss is reduced, these eddies eventually break up the chimney and restratify the water column.

It would appear, therefore, that with the observed surface buoyancy flux in the spring of 1989 , either the deep stratification or lateral advection could have been the

\footnotetext{
${ }^{5}$ We have assumed that the lateral extent of the convecting patch $r=60 \mathrm{~km}$. This is consistent with the estimate of Morawitz et al. [1996], who carried out a three dimensional inversion using all available data (including moored thermistor, hydrographic, and tomographic measurements).
} 
depth limiting factor which determined the final mixed layer depth. It was most likely a combination of both.

\subsection{Inter-Annual Changes in Convective Activity}

There is a large inter-annual variation in the occurrence of convective activity in the central Greenland Sea gyre. In this section, we will attempt to relate information about the surface conditions in the central Greenland Sea gyre from numerical weather prediction (NWP) model output to the occurrence of convective activity.

The idea of examining historical data for indicators of convective activity is not a new one. Pawlowicz [1995] attempted to relate changes in large-scale areal ice coverage to deep convection during the period 1982-91. He suggests that the years showing the deepest convection also show ice forming quite early (by November or December of the previous year), followed by a period of very low ice concentrations. The early ice formation removes the fresh anomaly early in the winter, and then a long period of surface cooling can drive deep convection. However, his correlations were inconclusive.

Following in a similar vein, we compared the ice concentration record from SSM/I data to air temperatures at similar locations from the ECMWF and NCEP model datasets. It is unlikely that purely haline driven deep convection occurred on large scales in the Greenland Sea because air temperatures did not remain cold enough to sustain this process. The winter of 1988-89 was one of the coldest ones on record, according to the NWP model data, and we know that in that season the mixed layer deepening was thermally driven. Therefore, we will look only for correlations which are indicative of large-scale deep convection which is qualitatively similar to that observed in 1988-89. From our previous discussion, we can infer the following criteria for determining characteristics of surface conditions which are amenable to large-scale deep convection:

- A cold spell resulting in a substantial amount of ice formation.

- Winds blowing to cause ice to drift away from the convecting region. This is necessary both to increase the efficiency of the brine rejection process and to remove 
freshwater (in the form of ice) so that when the remaining ice melts, a large surface freshwater anomaly is no longer present.

- A sudden melting of some or all of the ice cover caused by heat mixed up from below the surface. Note that in some relatively warm years, a small ice concentration may disappear because the air temperature warms sufficiently so that very little new ice is being formed and the existing ice cover gets advected away. It may be difficult to distinguish this process from ice melt caused by heating from below, but if the ice concentration was relatively small then we can infer that large-scale convective activity likely did not occur.

- Cold air temperatures following the melting of the ice cover, but without any further ice formation. This indicates that the SST was warmed by heating from below, resulting from convective mixing. The length and intensity of the cold spell will now determine how deep the water mixes (E-P and lateral advection may also be important at this stage).

The amount of surface buoyancy loss and brine rejection needed to precondition the water column for deep convection depends upon the initial stratification in the central Greenland Sea gyre. Since we do not have this information available for most years, it is difficult to deduce from the surface conditions alone whether or not convection occurred. However, whenever convection does occur, there is a significant amount of heat entrained and this has a dramatic effect on the ice cover. The heat which is mixed up to the surface melts the ice very quickly. For example, if a 30 meter deep surface layer at the freezing point sits atop an equally deep layer at $0^{\circ} \mathrm{C}$, then the amount of heat entrained when these two layers mix (assuming the resulting homogenized 60 meter deep layer is at $-1.5^{\circ} \mathrm{C}$ and the surface heat loss is $250 \mathrm{~W} / \mathrm{m}^{2}$ ) is sufficient to melt $33 \mathrm{~cm}$ of ice. We can look for this telltale sign to infer whether or not convection took place. This suggests that we should look for a sudden drop in ice concentration which is not strongly correlated with a sharp rise in air temperature. It is clear from our previous analysis that some amount of ice formation and brine rejection is necessary to remove a surface fresh anomaly; evaporation at the surface is not sufficiently strong.

Guided by this description of necessary conditions for convection to occur in the Greenland Sea, we examined the historical data (appendix C) in an attempt to determine 
the years in which deep convection is likely to have occurred. The figures in appendix C show ice concentration, air temperature, net evaporation minus precipitation, and wind speed data for a fourteen seasons (September through August) from 1979 to 1993. Data for four additional seasons from 1993 to 1997 was extracted from the NCEP reanalysis database (since we do not have ECMWF data available for these years). From these observations, we draw some inferences about the susceptibility of the central Greenland Sea gyre to convective activity. Our analysis of the historical data suggests the following.

- 1979-80, 1980-81, 1982-83, 1984-85, 1989-90, 1990-91, 1992-93, and 1995-96: These winters were relatively mild (with temperatures never colder than about $-15^{\circ} \mathrm{C}$ ). However, there were periods of low ice concentrations (up to 0.5 ). This suggests that there may have been localized ice formation, possibly resulting from isolated cooling events. Nevertheless, it is unlikely that convection on large scales occurred.

- 1983-84, 1991-92, 1993-94, and 1994-95: These were all very mild winter seasons (with temperatures never colder than about $-10^{\circ} \mathrm{C}$ ) and very little or no ice formation occurred. This was followed by warm $\left(0^{\circ} \mathrm{C}\right)$ springtime air temperatures. The surface waters were not likely to have been preconditioned for deep convection, and it is very unlikely that any convective mixing of the water column occurred.

- 1981-82 and 1985-86: These were relatively cold winters and substantial ice formation occurred (with ice concentrations greater than 0.75 ), likely reducing the stable stratification substantially. However, when the ice cover disappeared, the air temperatures were relatively very warm (around $-1^{\circ} \mathrm{C}$ ). Thus, the surface heat loss was not likely large enough to drive a rapid mixed layer deepening.

- 1986-87: This was a very cold winter (with temperatures reaching about $-25^{\circ} \mathrm{C}$ ) and a lot of ice formation occurred (with ice concentrations up to 0.9 ), likely destabilizing the water column. However, when the ice cover disappeared, around mid-April, the air temperatures were relatively warm (around $-10^{\circ} \mathrm{C}$ ). Thus, although some convective activity may have occurred, it is unlikely that the mixed layer got very deep.

- 1987-88: This was only a moderately cold winter (with temperatures not below about $-15^{\circ} \mathrm{C}$, and warmer than $-10^{\circ} \mathrm{C}$ most of the time) although ice concentra- 
tions were $>50 \%$ for about a month. This was followed by an extended period of moderately cold air temperatures (around $-10^{\circ} \mathrm{C}$ ) with ice-free conditions. Thus, if the initial stratification was not too large, it is possible that some mixed layer deepening occurred.

- 1988-89 and 1996-97: These winters were very cold (with temperatures reaching about $-25^{\circ} \mathrm{C}$ ) and a lot of ice formation occurred (with ice concentrations of about 0.9-1.0). This was followed by an extended period of moderately cold air temperatures (around $-5^{\circ} \mathrm{C}$ ) and a sudden drop in ice concentrations. It is very likely that large-scale convective activity occurred with a substantial deepening of the mixed layer.

Although there were no direct observational efforts in place to observe convection in the Greenland Sea until 1987, indirect evidence exists from tracer studies [Schlosser et al. 1991]. These suggest that vigorous convective activity occurred through the 1960's and 1970's, and then was completely shut down through most of the 1980's. Convection to intermediate depths was observed in the winter of 1987-88 and 1988-89. Subsequently, observations from the Greenland Sea Monitoring (GSM) station indicate that there was no convective activity in the winters of 1989-90 and 1992-93. During 1991-92, convection only reached down to about 800 meters. In 1994, convection to intermediate depths was again observed in moored ADCP measurements, and in 1996 deep convection down to 2000 meters was observed. A summary of the historical record of convective activity in the Greenland Sea, from both direct observations inferences, is presented in table 4.2 along with references.

Our inferences about the likelihood of large-scale convective activity agree well with this historical record of convective activity, or at least do not contradict it. The two exceptions are 1993-94 and 1995-96. However, the convection observed in these years were localized events. In the first case, the observation was made from a moored ADCP [C. Mertens, pers. comm. 1998]. In the second case, the observation was made from CTD measurements in May 1996 by J. Backhaus during Valdivia cruise 158 [J. Backhaus, pers. comm. 1998]. A localised convective chimney about 7 nautical miles $(13 \mathrm{~km})$ wide which extended down to 2000 meters was detected at the approximate location $75^{\circ} \mathrm{N} \times 0^{\circ} \mathrm{W}$. The ice edge in May 1996 was at about $0^{\circ} \mathrm{W}$, suggesting that ice-edge upwelling (as 


\begin{tabular}{|c|c|c|}
\hline Year & Observation & Source \\
\hline 1960's-1970's & Convection was strong & Schlosser et al. [1991] \\
\hline $1979-80$ & No information & \\
\hline $1980-81$ & Probably no convective activity & Schlosser et al. [1991] \\
\hline $1981-82$ & Maximum depth $\approx 100 \mathrm{~m}$ & Clarke et al. [1990] \\
\hline $1982-83$ & $\begin{array}{l}\text { Probably no convective activity } \\
\text { No evidence of deep convection from } \\
\text { observations made Feb.-June } 1982\end{array}$ & $\begin{array}{c}\text { Schlosser et al. [1991] } \\
\text { Clarke et al. [1990] }\end{array}$ \\
\hline 1983-84 & $\begin{array}{l}\text { Convection to the bottom } \\
\text { Above conclusion is questionable } \\
\text { Probably no convective activity }\end{array}$ & $\begin{array}{l}\text { Nagurny and Popov [1985] } \\
\text { Meincke et al. [1992] } \\
\text { Schlosser et al. [1991] }\end{array}$ \\
\hline $1984-85$ & Probably no convective activity & Schlosser et al. [1991] \\
\hline $1985-86$ & Probably no convective activity & Schlosser et al. [1991] \\
\hline $1986-87$ & Maximum depth $\approx 200 \mathrm{~m}$ & GSP group [1990] \\
\hline $1987-88$ & Maximum depth $\approx 1350 \mathrm{~m}$ & GSP group [1990] \\
\hline $1988-89$ & Maximum depth $\approx 1600 \mathrm{~m}$ & GSP group [1990] \\
\hline $1989-90$ & $\begin{array}{l}\text { Convection to } 250 \mathrm{~m} \\
\text { Above estimate may be too large } \\
\text { No convection, ML depth }<200 \mathrm{~m}\end{array}$ & $\begin{array}{c}\text { Budeus et al. [1993] } \\
\text { Pawlowicz [1995] } \\
\text { Visbeck et al. [1995] }\end{array}$ \\
\hline $1990-91$ & No convection observed & C. Mertens [pers. comm. 1998] \\
\hline $1991-92$ & $\begin{array}{l}\text { No convection observed; } \\
\text { mixing to } 800 \mathrm{~m} \text { inferred }\end{array}$ & C. Mertens [pers. comm. 1998] \\
\hline $1992-93$ & No convection observed & C. Mertens [pers. comm. 1998] \\
\hline $1993-94$ & $\begin{array}{l}\text { Convection to about } 700 \mathrm{~m} \text { observed } \\
\text { from moored ADCP measurements }\end{array}$ & C. Mertens [pers. comm. 1998] \\
\hline $1994-95$ & No information & \\
\hline $1995-96$ & $\begin{array}{l}\text { Isolated } 13 \mathrm{~km} \text { wide convective } \\
\text { chimney } 2000 \mathrm{~m} \text { deep observed }\end{array}$ & J. Backhaus [pers. comm. 1998] \\
\hline 1996-97 & No information & \\
\hline
\end{tabular}

Table 4.2: The maximum depth of convection in the central Greenland Sea gyre, as suggested by different types of measurements from a variety of sources. 
described by Hakkinen [1987]) may have played a role. SSM/I data indicates that there was an increase in the ice concentration at about this time to $25 \%$ in the central gyre region, although the remainder of 1996 was ice-free. This suggests that although there was no large-scale ice formation, there may have been strong localized preconditioning near the ice edge, resulting in relatively small scale $\mathrm{O}(10 \mathrm{~km})$ convective chimneys. This is in contrast to the larger scale $O(50-100 \mathrm{~km})$ chimneys that can develop when the ice formation is more extensive, as in 1988-89.

Killworth [1983] suggested that there is a reasonable statistical probability that small-scale well-mixed chimneys had been missed by the few wintertime stations that had been gathered up to that time. The observation by Backhaus suggests that Killworth may have been right, and that small-scale convective activity can occur in years when large-scale convection is unlikely. Interestingly, there is a large inter-annual variation in the wintertime air temperatures and ice extent in the central Greenland Sea gyre. In fact, the historical record from 1960-1997 (see figure 4.24) is suggestive of an oscillation on a roughly decadal timescale. There is some evidence which suggests that episodes of significant salinity reduction in the North Atlantic, associated with extensive sea ice in the Greenland Sea, may be a manifestation of a decadal oscillation in the Arctic climate system [Barry et al. 1993]. The years in which large-scale convection is known or inferrred to have occurred in the Greenland Sea matches up well with the cold periods in the historical record, and the years in which no large-scale convective activity was observed matches up well with the relatively warm periods. In the warmer years, convection may occur only in small scale chimneys resulting from localized cooling events; such events would be more difficult to observe directly. The effect of localized ice formation may also be amplified due to the ice-albedo feedback, resulting in enhanced localized cooling of the air. This effect is probably not very large though because of the small wintertime insolation.

A characteristic of all late summer salinity profiles from the Greenland Sea is the very strong but shallow stable stratification at the surface [Pawlowicz 1995]. An interesting question to ask is what would happen if this fresh anomaly extended a little deeper, say to 100 meters? How strong of a surface heat flux would then be needed to cool this surface layer to the freezing point to permit ice formation? If the surface layer is initially at about $0^{\circ} \mathrm{C}$, then it would take $8 \times 10^{8} \mathrm{~J} / \mathrm{m}^{2}$. This would require a sustained heat loss at the surface of about $1000 \mathrm{~W} / \mathrm{m}^{2}$ for three months! In other words, 

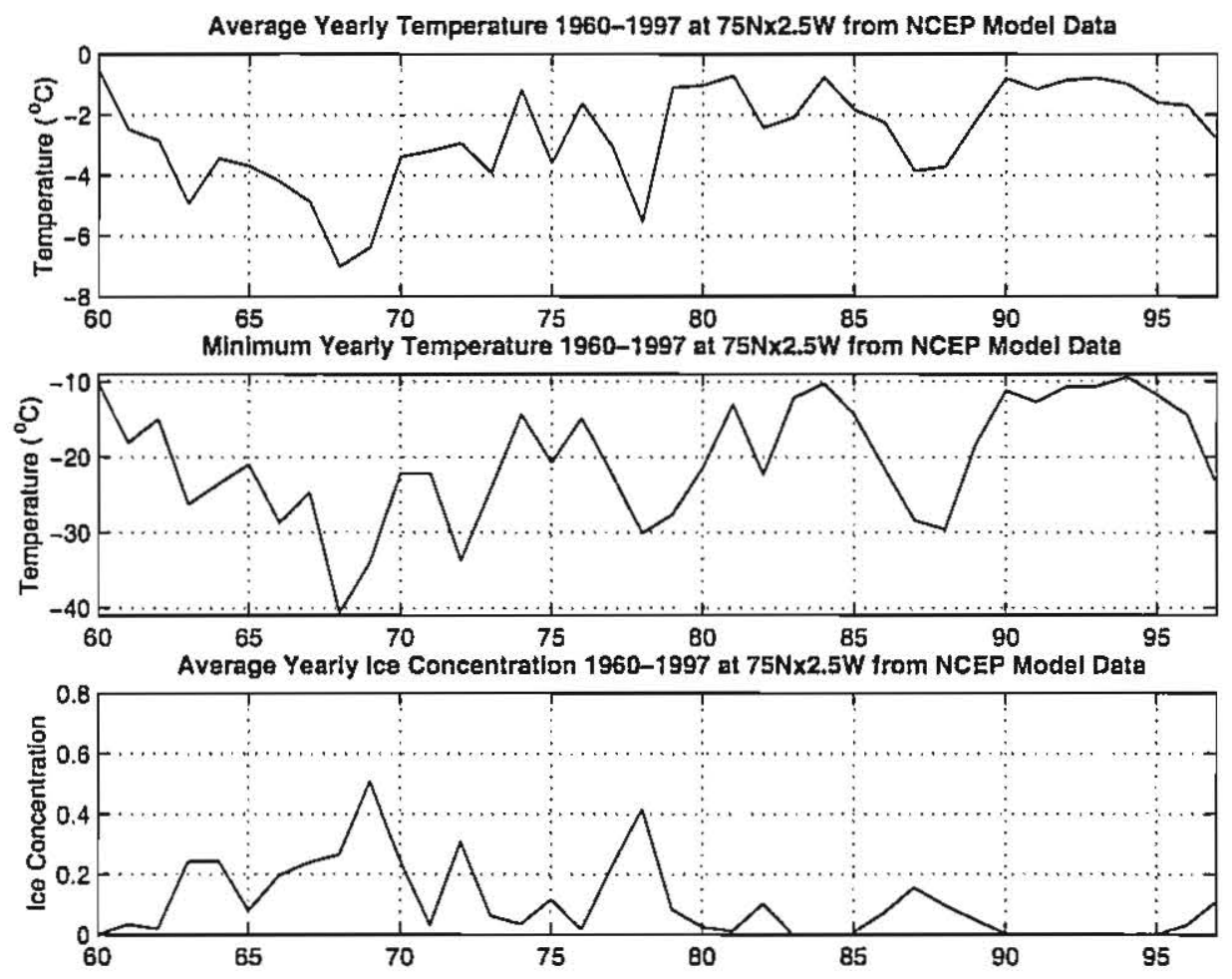

Figure 4.24: The air temperature and ice concentration in the central Greenland Sea exhibit a great deal of variability. The inter-annual variations in the above plots are suggestive of a decadal oscillation. 
the average wintertime temperature would have to be around $-20^{\circ} \mathrm{C}$, cold even by arctic standards! The fact that ice formation has been observed to occur throughout large parts of the Greenland Sea suggests that the fresh surface mixed layer that develops in the summertime must never penetrate very deep into the water column.

Freshwater imported into the Greenland Sea may be one reason why no ice formation is observed in some years. An increase of over $100 \%$ in the outflow of multi-year ice from the arctic into the Nordic Seas was observed in spring/summer 1996, and this showed up as a strong negative salt anomaly in a hydrographic section [J. Backhaus pers. comm 1998]. The resulting increased freshwater flux into the Greenland Sea may have increased the depth of the surface fresh layer, thus inhibiting ice formation. Hakkinen [1995], using a fully prognostic Arctic ice-ocean model, concluded that the occurrence of deep convection in the Greenland Sea gyre is controlled by the extensive sea ice export into the Greenland Sea from the Arctic Ocean and/or by local wind conditions in the Greenland Sea. In that study, the weak stratification was attributed to extreme wintertime wind events. 


\section{Chapter 5}

\section{Summary and Conclusions}

\subsection{What have we learned about convection that is new?}

Through a combination of model simulations and analytical scale analyses, we have demonstrated that the following factors are crucial to the evolution of the convection event as observed in the Greenland Sea in 1988-89:

1. cold air temperatures leading to substantial ice formation.

2. brine rejection as a preconditioning agent.

3. ice advection.

4. ice formation rate to drop (caused by a rise in the air temperature).

5. after the ice disappears, additional thermal buoyancy loss resulting from moderately cold $\approx-10^{\circ} \mathrm{C}$ air temperatures.

We have determined that the assumed strength of the coupling between the ice and the mixed layer, the rate of ice drift, and the deep stratification of the water column all play a role in determining the depth of convection. They all affect the buoyancy flux by controlling the rate of change of salinity in the water column, though as a result of distinctly different physical processes. 
The strength of the ice to mixed layer coupling also influences details of the preconditioning process, namely the mixed layer temperature and the thickness of the ice cover. However, for the convection event studied here, we have shown that the evolution is not very sensitive to the strength of this coupling as long as we are not too close to the insulating or rapid limiting cases.

Further, we have shown that deep haline driven convection underneath an ice cover is possible, but only if the air temperatures remain very cold for an extended period of time. These conditions are not typically seen in the climatological record for the Greenland Sea. 1968-69 is the most recent period on record when this may have been possible (figure $4.24)$.

We have confirmed the main conclusion of Visbeck et al. [1995] that ice drift is an essential component of the preconditioning process prior to the onset of deep convection. However, we have found that the rate of reduction of the ice thickness must be between 3.2 and $3.5 \mathrm{~cm} / \mathrm{day}$, given the initial profiles which we have used. These values are about four times larger than the value obtained by Visbeck et al. [1995]. The discrepancy is likely due to the weaker ice-mixed layer coupling strength used by Visbeck et al. [1995], and to differences in the model initialization and surface forcing.

Our model results were found to be generally consistent with the observations of Roach et al. [1993] to the extent that they both lead to a similar description of the process by which convection occurs. When the surface layer reaches the freezing point, ice forms at a rate of up to $5 \mathrm{~cm} /$ day and the salinity increases through brine rejection. Meanwhile, ice drifts to the southwest at a rate of between 10 and $20 \mathrm{~cm} / \mathrm{sec}$. This process of preconditioning leads to convective mixing which brings warmer water to the surface and rapidly melts much of the ice cover. In the model run the surface fluxes were sufficiently large that ice formation continued until convective mixing again brought warm water to the surface and caused much of the ice to melt. The ice-free surface is then exposed to large sensible heat losses of up to $500 \mathrm{~W} / \mathrm{m}^{2}$. The vertical density has been sufficiently eroded by the preconditioning that this heat flux provides enough buoyancy loss to deepen the mixed layer through convective mixing. The deepening of the thermocline raises the sea surface temperature to about $-1^{\circ} \mathrm{C}$. 
We have determined that the advection of warm water into the convecting region likely occurred, based on a comparison of our model heat content estimates with tomographic heat content estimates, and observations [Sutton et al. 1997] suggesting that there may have been a significant advection of warm water from the northern edge of the gyre. Our estimates of the timescale for the mixed layer deepening and the maximum depth of the mixed layer, based on the work of Visbeck et al. [1996], also suggests that lateral advection was important.

We have also found, based upon an examination of the historical record since 1960, that large-scale convective activity in the Greenland Sea occurs in exceptionally cold winters; these seem to recur roughly each decade. The coincidence of exceptionally cold wintertime air temperatures and large-scale convective activity in the central Greenland Sea gyre suggests that there may be a a direct link between the occurrence of convection and the global climate system. This is consistent with the suppression of deep convection throughout most of the 1980's (inferred from tracer studies) when the wintertime air temperatures were relatively mild. However, it is likely that smaller scale convection does occur in milder winters. This is likely driven by localized cooling events or upwelling at ice edges caused by the differential in the wind drag coefficients over ice-covered and open ocean.

Our analysis of the convection process in the Greenland Sea suggests that it proceeds as outlined in figure 5.1. The air temperature cools. If the wind stirring is vigorous enough, the mixed layer may deepen through turbulent entrainment processes. If the surface heat loss is sufficiently large, the mixed layer will cool to the freezing point, leading to ice formation and brine rejection. The presence of winds causing ice to drift away from the formation region will enhance the brine rejection process. When the density of the surface layer matches that of the layer beneath it, it will convectively overturn and heat will be entrained. This will cause some or all of the ice to melt, and the insulating effect of the ice cover will be diminished. If the air temperature is very cold, ice formation will continue, and this process will continue through additional freezing-melting cycles. If the air temperature remains cold for an extended period of time, haline-driven deep convection can occur through repeated freezing-melting cycles resulting in continued brine rejection. However, this is not typically the case in the Greenland Sea. After undergoing one or two of these cycles, the air temperature warms sufficiently and enough heat has 
been entrained from below that further ice formation is inhibited. The buoyancy loss at this stage is driven entirely by surface cooling and evaporation. The latter is typically small in the Greenland Sea. If this buoyancy loss is strong and the surface water has been sufficiently preconditioned through the brine rejection process, then the mixed layer will deepen rapidly. This is the behavior that was observed in 1988-89. If, on the other hand, the buoyancy loss is weak and/or the preconditioning phase was too brief and a substantial surface fresh anomaly still exists, then the mixed layer will either deepen slowly or not at all.

\subsection{Future Directions}

There has been much speculation about the relation between the inter-annual variability of convective activity in the Greenland Sea, the North Atlantic Oscillation (NAO), and the inverse correlation with convective activity in the Labrador Sea. However, at present our understanding of the physical mechanisms controlling these phenomena and the interaction between them is insufficient to lead to any firm conclusions.

There is now a continuous monitoring program in place in the Greenland Sea, carried out by the European Sub-Polar Ocean Programme (ESOP-2), which will provide us with high quality observations of both meteorological and ocean conditions, as well as direct measurements of ice thickness. This wealth of information should help us to make more definitive statements about some aspects of the convection process which are currently poorly understood. For example, we can infer the strength of the coupling between the ice and mixed layer if we have simultaneous and continuous measurements of temperature and salinity.

Data recently collected during the R/V Knorr cruise in the Labrador Sea in the winter of 1997 has already provided us with valuable information about the convective process there. Since the water in the Labrador Sea generally remains above the freezing point, ice does not play an important role in the convection process there as it does in the Greenland Sea. This suggests that the preconditioning must proceed primarily by sensible heat losses at the surface rather than brine rejection. Evaporation and latent heat fluxes may also play a role. It is therefore reasonable to expect that the inter-annual 


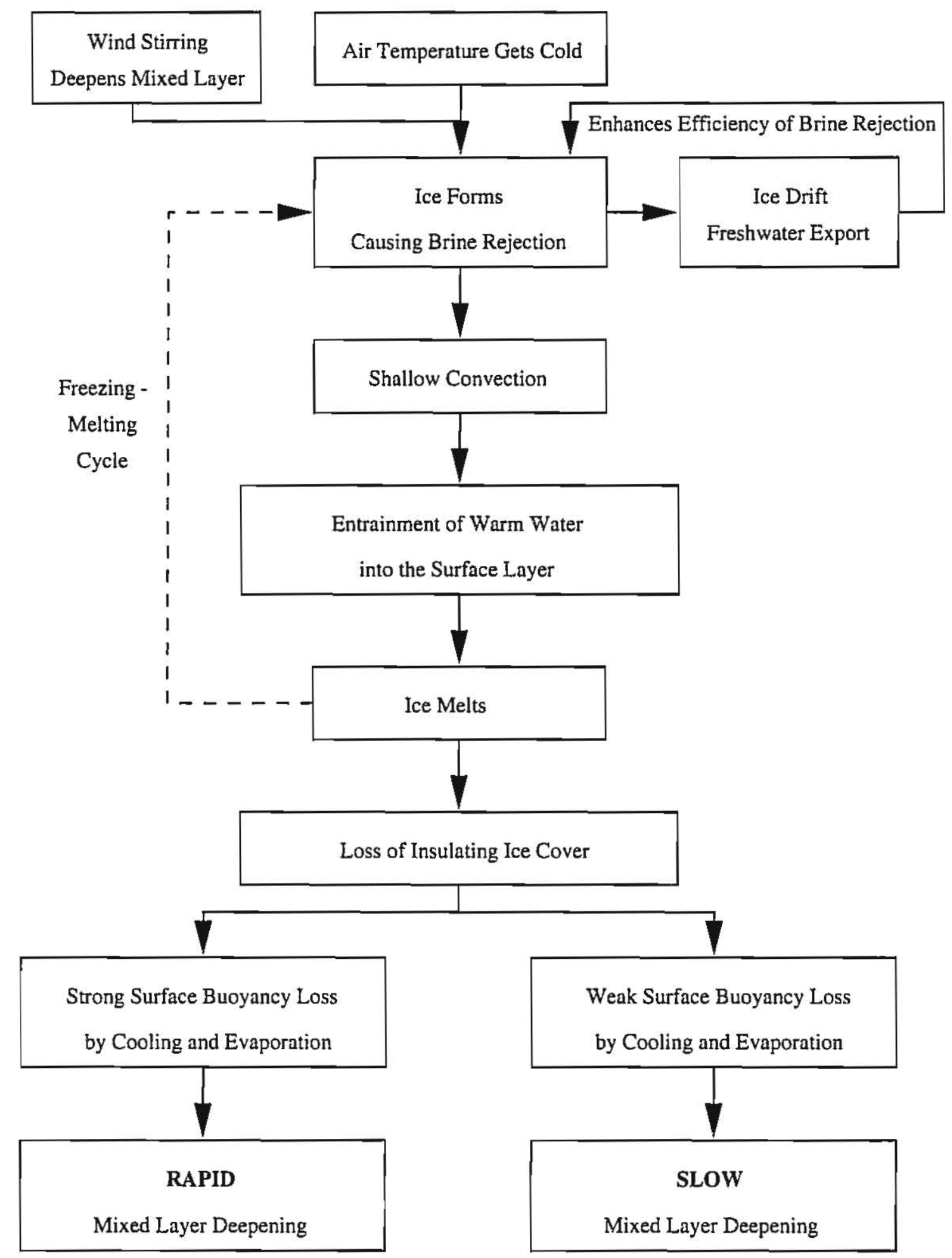

Figure 5.1: The convection process in the Greenland Sea. 
variability in convective activity in these two marginal seas will respond differently to changes in the climate system. Gaining an understanding of how the various components of the ocean, ice, and atmosphere systems interact and feedback on one another is vital if we wish to further our knowledge of the global climate system. By carrying out studies such as the one we have undertaken here, which examine details of various pieces of the puzzle through a combination of modeling and data analysis, we will continue to gain further useful insights into how our climate system operates. 


\section{Appendix A}

\section{Convective Adjustment Schemes}

Two different convective adjustment schemes were implemented in the model described in chapter 3. Below we will describe these two vertical mixing schemes, and give details about our implementation of these schemes.

\section{The Complete Mixing Scheme}

The complete mixing scheme which we have implemented in our model was proposed by Yin and Sarachik [1994]. It removes all static instabilities in the water column at each timestep. Below if a listing of the FORTRAN code which we used to implement this scheme.

C

C COMPLETE MIXING CONVECTIVE ADJUSTMENT SCHEME

C FOR A ONE-DIMENSIONAL VERTICAL COLUMN

C

C by Vikas Bhushan

C July 1997

C

C This routine takes the initial temperature and salinity for the

C L layers specified by the variables $S$ and $T$ and covectively

C mixes the water column, completely removing static instabilities.

C The variable mldepth keeps track of the depth of the surface

C mixed layer, which is the maximum depth to which water 
C originating in the surface layer has been mixed. The potential

C density of each layer, specified by the variable RHO, is computed

C by the external routine DENSITY.

$\mathrm{C}$

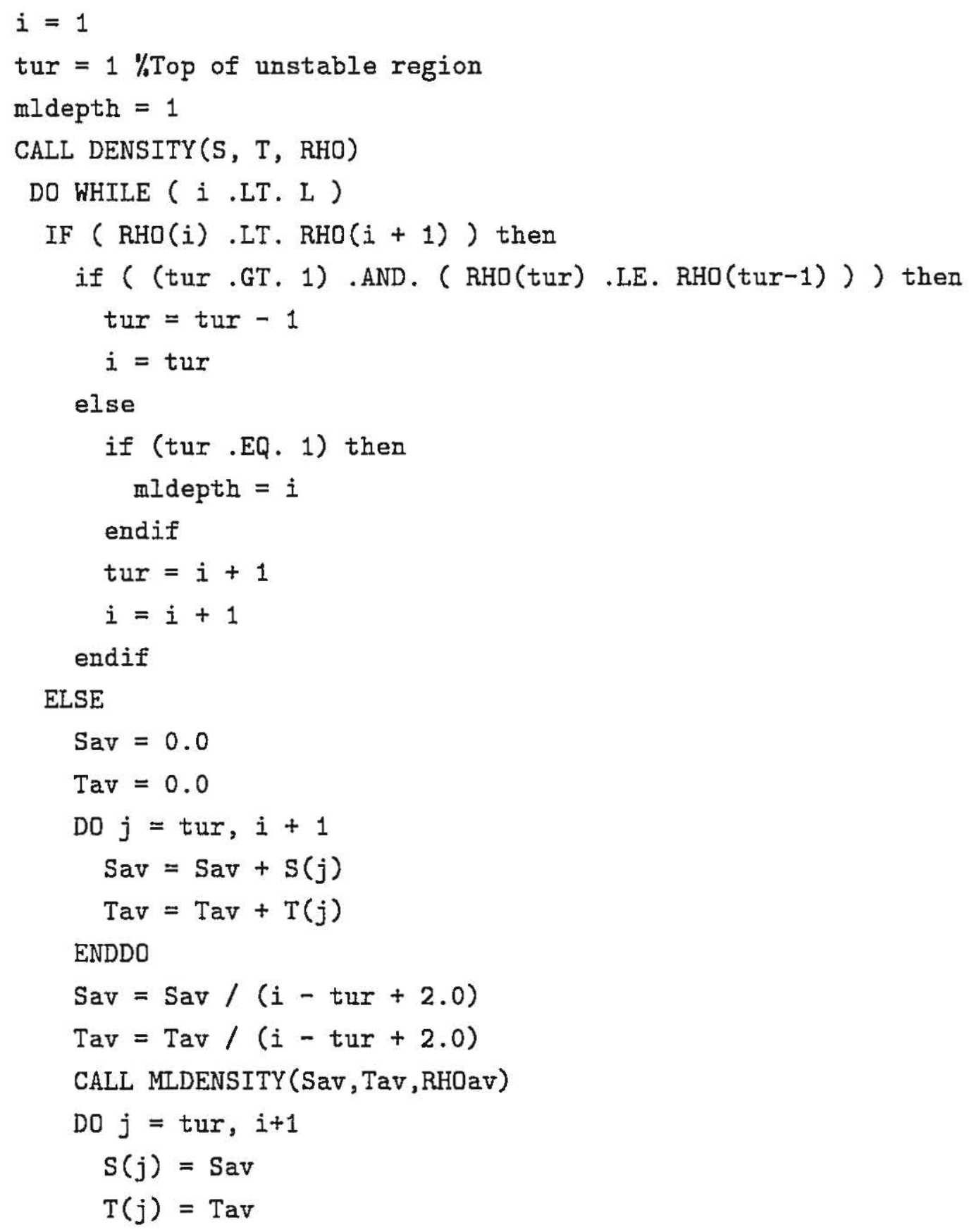




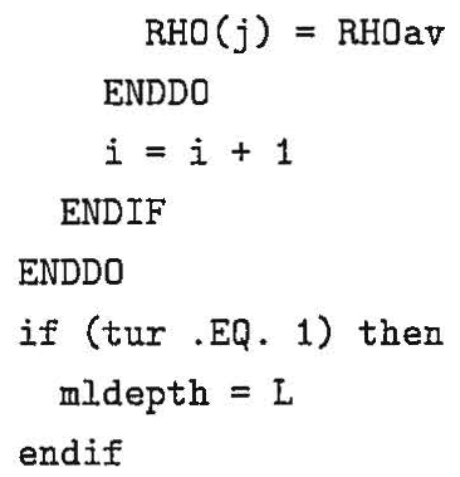

\section{The GFDL 2-Pass Scheme}

The The GFDL 2-pass scheme is the default convective adjustment scheme used in the GFDL MOM model. It looks for static instability between adjacent layers, and if found it mixes these two layers completely and instantaneously. It does this in two steps. The first step consists of checking layers $1 \& 2,3 \& 4$, etc. for static instability. If a pair of adjacent layers is found to be statically unstable, then they are mixed completely; otherwise they are left alone. The second step consists again of checking pairs of adjacent layers for static instability and then mixing if necessary, but this time the layers are paired $2 \& 3,4 \& 5$, etc. For each pass through this scheme, a parcel of water in a given layer can get mixed down at most two layers. This procedure is usually carried out more than once at for each model timestep. If it is carried out $N_{C O N}$ times, then a parcel of water in an unstable layer can get mixed down $2 N_{C O N}$ layers (up to the maximum depth of the water column). Therefore, the vertical mixing timescale associated with this mixing scheme is

$$
\tau_{c}=\frac{L}{N_{C O N}} \cdot \text { tstep . }
$$

Below is a listing of the FORTRAN code that we used to implement this scheme.

C

C 2-PASS CONVECTIVE ADJUSTMENT SCHEME

C FOR A ONE-DIMENSIONAL VERTICAL COLUMN

C

C by Vikas Bhushan

C April 1997 
This routine takes the initial temperature and salinity for

$C$ the $I$ layers specified by the variables $S$ and $T$ and

C covectively mixes the water column. NCON passes are made

C through the routine. The potential density of each layer,

C specified by the variable RHO, is computed by the external

C routine DENSITY.

C

DO 120 pass $=1$, NCON

C

DO $115 i=1,2$

CALL DENSITY (S, T, RHO)

DO $j=i, L-i, 2$

$m=(j+2-i) / 2$

$\operatorname{DRHO}(m)=\operatorname{RHO}(j)-\operatorname{RHO}(j+1)$

ENDDO

$\mathrm{DO} \mathrm{m}=1,(\mathrm{~L} / 2+1-i)$

if (DRHO(m) .GT. 0.0) then

$T(m+m-2+i)=0.5 *(T(m+m-2+i)+T(m+m-1+i))$

$T(m+m-1+i)=T(m+m-2+i)$

$S(m+m-2+i)=0.5 *(S(m+m-2+i)+S(m+m-1+i))$

$S(m+m-1+i)=S(m+m-2+i)$

endif

ENDDO

C

115 CONTINUE

C

120 CONTINUE 


\section{Appendix B}

\section{Alternative Ice Drift Formulation}

In this appendix, we will present details of the analytical solution to equation (4.14) when case when there is a constant rate of ice advection given by equation (4.12). With this formulation, the solution is considerably more complicated ${ }^{1}$ than the solution for the baseline case presented in chapter 4 where the ice advection is proportional to the ice thickness $h$ (equation 4.10). It is given implicitly by:

$$
\frac{h(t)}{\nu}+\frac{C}{\nu^{2}} \ln \left(\frac{\nu h(t)-C}{C}\right)+\left(t-t_{0}\right)=0
$$

where

$$
C \equiv-\frac{k\left(T_{A}-T_{F}\right)}{\rho_{\text {ice }} L_{f}} .
$$

An explicit solution for $h(t)$, found using Maple ${ }^{2}$, is ${ }^{3}$ :

$$
h(t)=\frac{C}{\nu}\left[1+\omega\left\{\frac{1}{C} \exp \left(-\frac{\nu^{2}}{C}\left(t-t_{0}\right)+\ln (C)-1\right)\right\}\right] .
$$

Plots of the predicted ice thickness as a function of time and for various values of $\nu$ are shown in figures B.1 and B.2. Notice that, like in the baseline case with $h$-dependent ice drift, the ice thickness reaches a steady state in which the rate of new ice formation

\footnotetext{
${ }^{1}$ To our knowledge these analytical considerations have never before appeared in the literature.

${ }^{2}$ Maple is a program for symbolic mathematical computation, distributed by the University of Waterloo.

${ }^{3}$ The omega function $\omega$ satisfies $\omega(x) \exp (\omega(x))=x$. Further details about this function can be found in F.N. Fritsch, R.E. Schafer and W.P Crowley, "Solution of the Transcendental Equation $\omega e^{\omega}=x^{\prime}$, Communications of the ACM, 16, No. 2, Feb. 1973.
} 
balances the rate of ice export. The steady state ice thickness $h_{s s}$ gets smaller as the rate of ice drift increases, according to:

$$
h_{s s}=-\frac{k\left(T_{A}-T_{F}\right)}{\rho_{i c e} L_{f} \nu} .
$$

The resulting change in the rate of salinity increase is shown in figure B.3. It also reaches a steady state, indicating that brine rejection will continue to be an effective process for increasing the mixed layer salinity, as long as the rate of ice drift is sufficiently large. From figure B.4, we see that the salinity will increase at a rate of about $0.018 \mathrm{psu} /$ day when $\nu=3.2 \mathrm{~cm} /$ day. This will result in a salinity increase of $1.6 \mathrm{psu}$ in three months, sufficient to erode the surface fresh anomaly (figure 3.2 ). 
Ice Thickness [m] vs. Time [days] for nu=3.2 cm/day

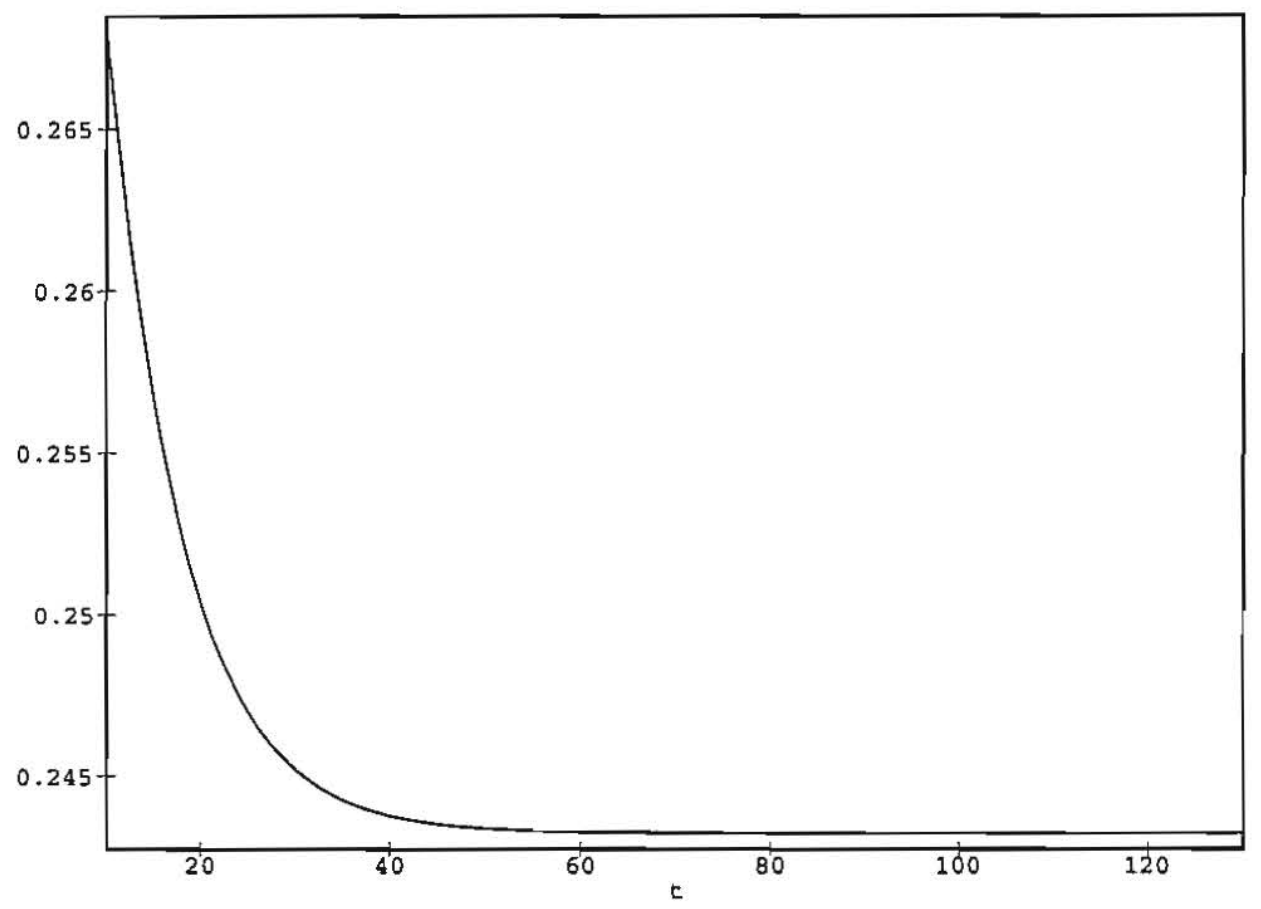

Figure B.1: The predicted ice thickness evolution when there is an ice drift ( $\nu=$ $3.2 \mathrm{~cm} /$ day) and with a constant air-sea temperature contrast $T_{A}-T_{F}=-15^{\circ} \mathrm{C}$. Notice that the ice thickness reaches a steady state. 


\section{Ice Thickness [m] vs. nu [cm/day] at 100 days}

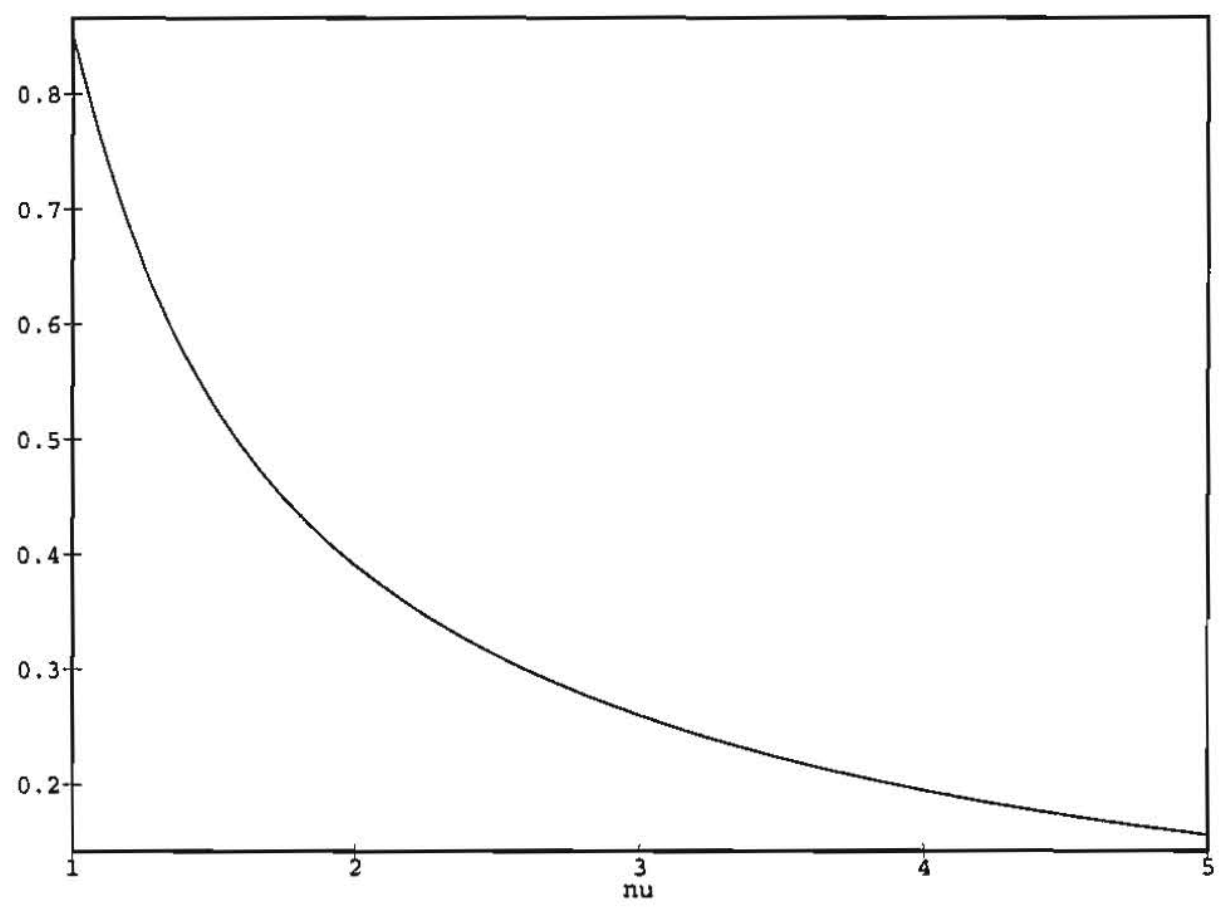

Figure B.2: The predicted ice thickness after 100 days when there is an ice drift $(\nu \neq 0)$ and with a constant air-sea temperature contrast $T_{A}-T_{F}=-15^{\circ} \mathrm{C}$. Notice that the equilibrium ice thickness decreases with increasing $\nu$. 
Rate of Salinity Increase [psu/day] vs. Time [days]

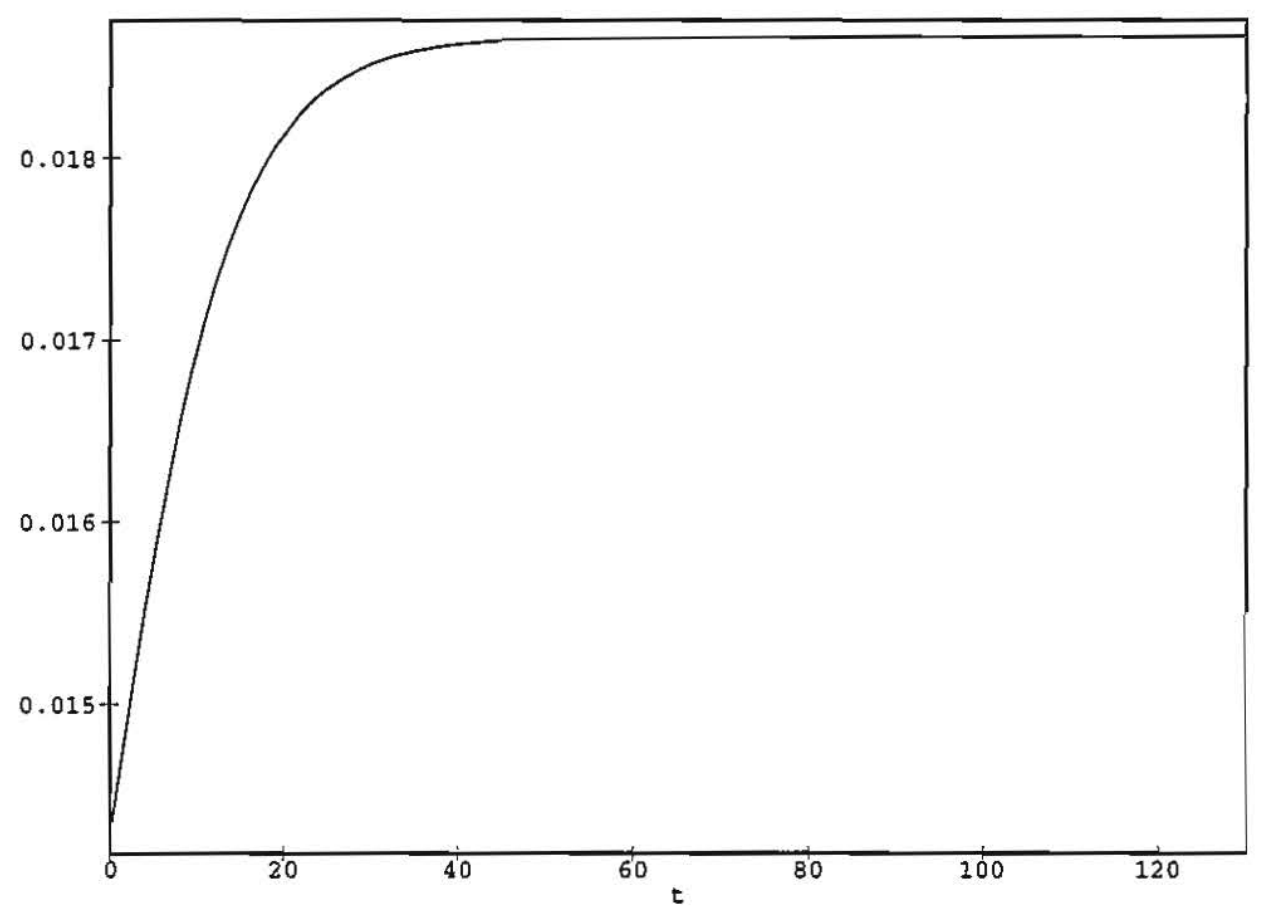

Figure B.3: The predicted change in the rate of salinity increase caused by brine rejection when there is an ice drift $(\nu=3.2 \mathrm{~cm} /$ day $)$ and with a constant air-sea temperature contrast $T_{A}-T_{F}=-15^{\circ} \mathrm{C}$. Notice that it reaches a steady state as does the ice thickness. 


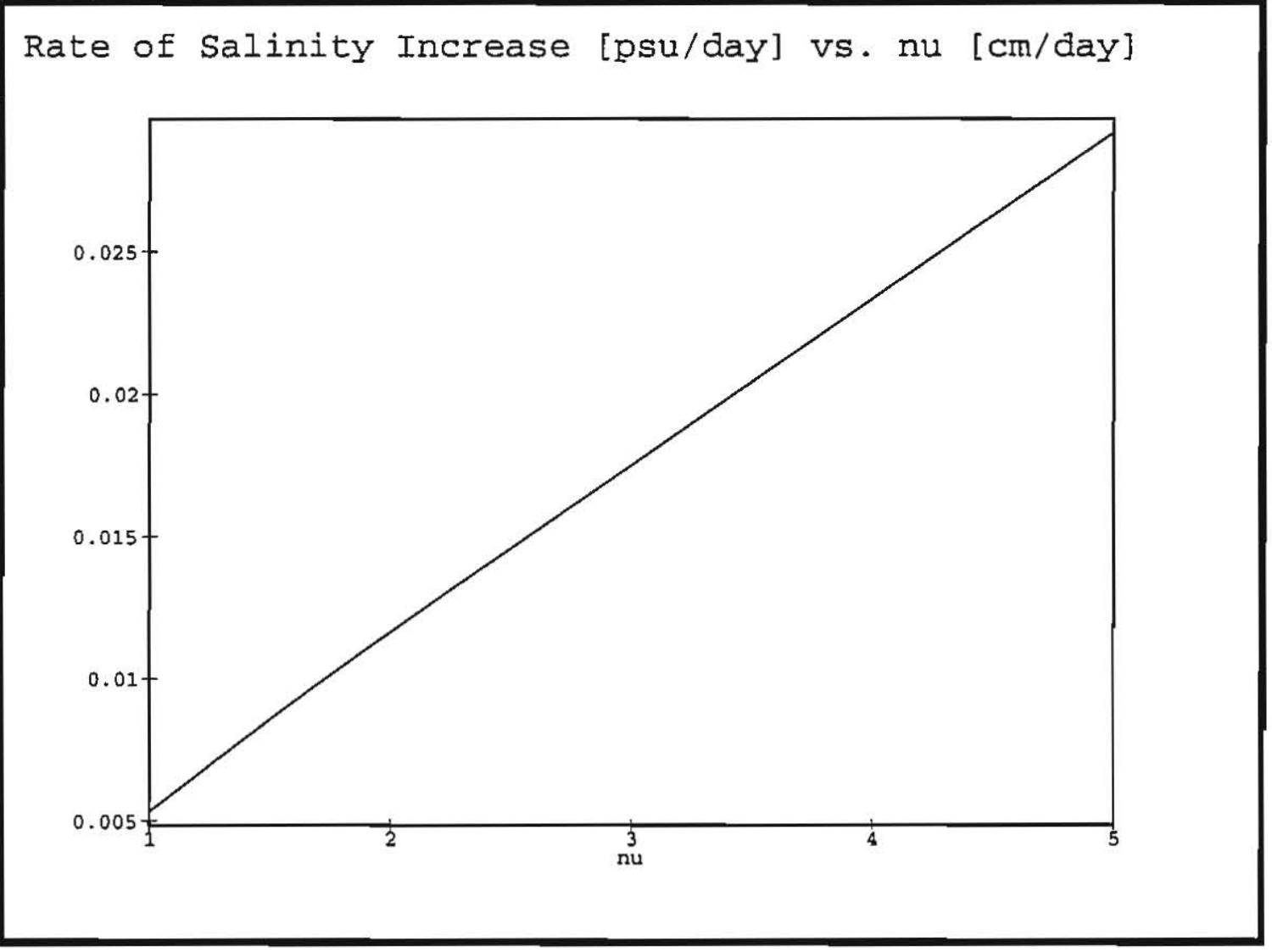

Figure B.4: The predicted change in the rate of salinity increase caused by brine rejection after 100 days when there is an ice drift $(\nu \neq 0)$ and with a constant air-sea temperature contrast $T_{A}-T_{F}=-15^{\circ} \mathrm{C}$. Notice that the rate of salinity increase grows larger with increasing $\nu$. Ice drift has the effect of making the brine rejection more efficient. 


\section{Appendix C}

\section{Historical Data}

The following pages show historical data for the central Greenland Sea gyre region, near $75 \mathrm{~N} \times 2.5 \mathrm{~W}$ (close to mooring 6 of the tomographic array of the 1988-89 Greenland Sea Tomography Experiment) and in the region where convective activity has been observed.

- Ice concentration data for 1979-1993 is from SMMR and SMM/I passive microwave measurements for the location $74.8944 \mathrm{~N} \times 2.4628 \mathrm{~W}$. Details are given in chapter 2 .

- $2 \mathrm{~m}$ air temperature, net evaporation minus precipitation, and zonal and meridional wind speeds at location $75 \mathrm{~N} \times 2.5 \mathrm{~W}$ for 1979-1993 are from the ECMWF reanalysis dataset, at a $2.5^{\circ} \times 2.5^{\circ}$ resolution.

- For 1993-1997, ice concentration, $2 \mathrm{~m}$ air temperature, precipitation, and heat flux data are from the NCEP reanalysis dataset, at a $1^{\circ} \times 1^{\circ}$ resolution. 

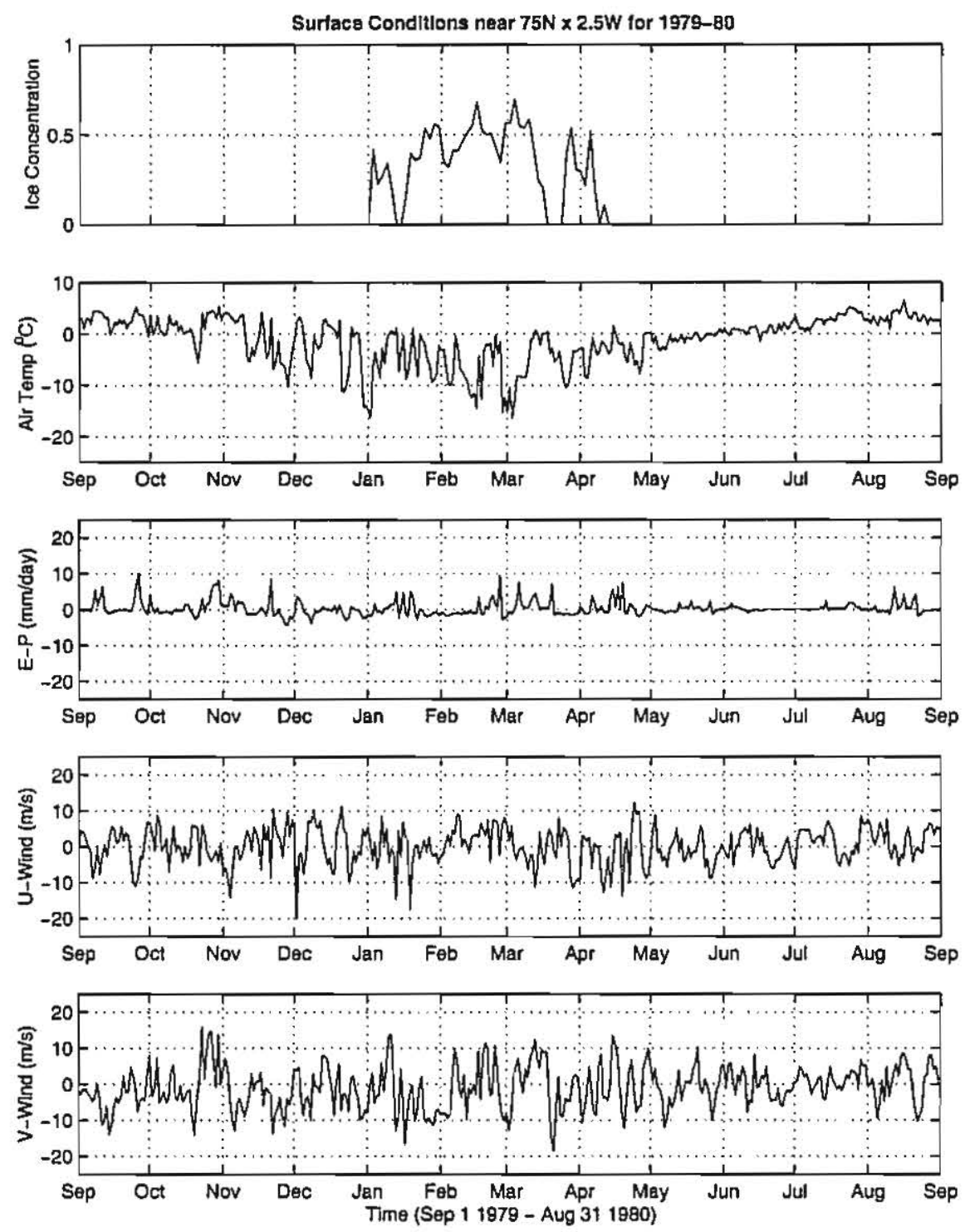

Figure C.1: Surface conditions in the central Greenland Sea gyre for 1979-80. 

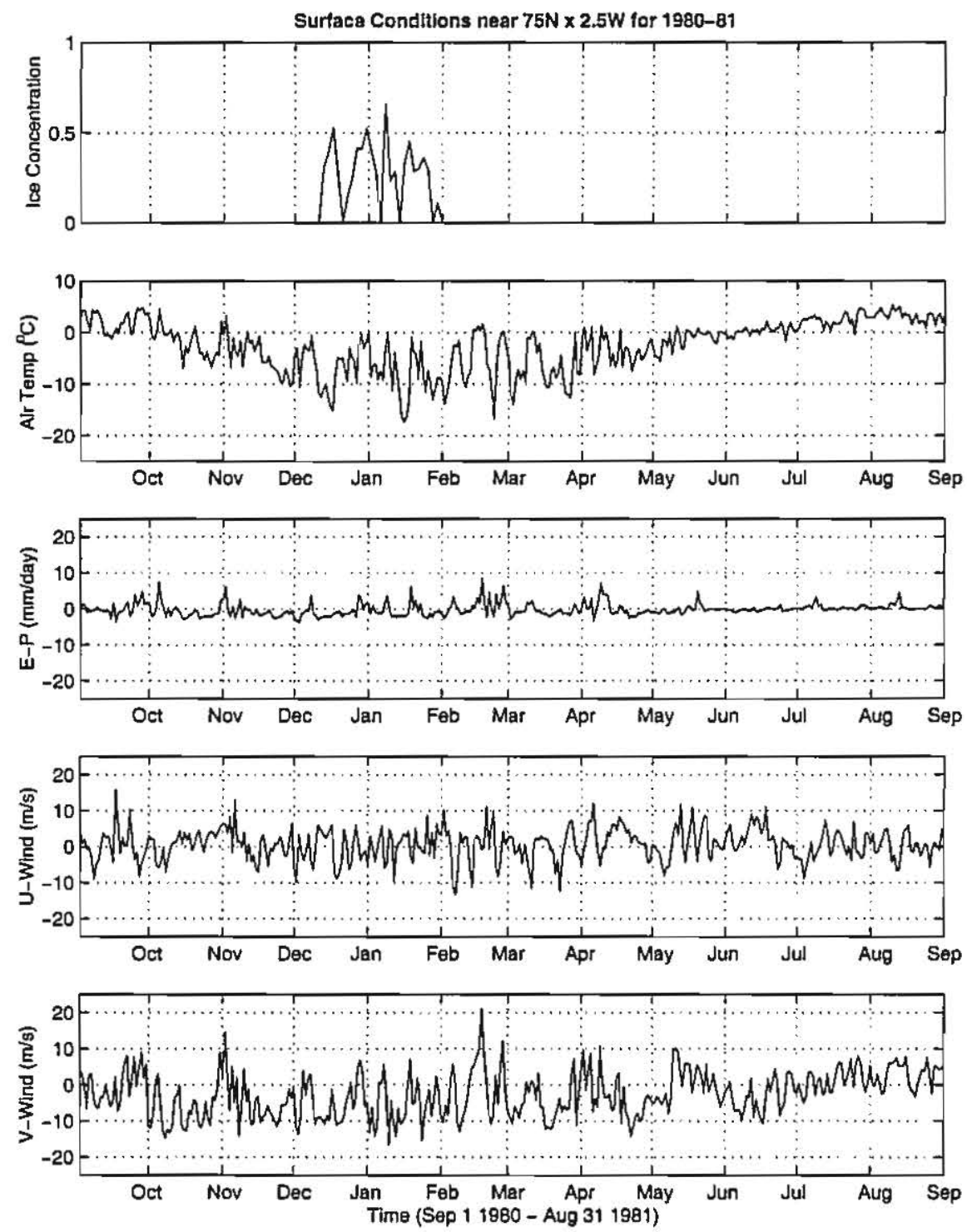

Figure C.2: Surface conditions in the central Greenland Sea gyre for 1980-81. 

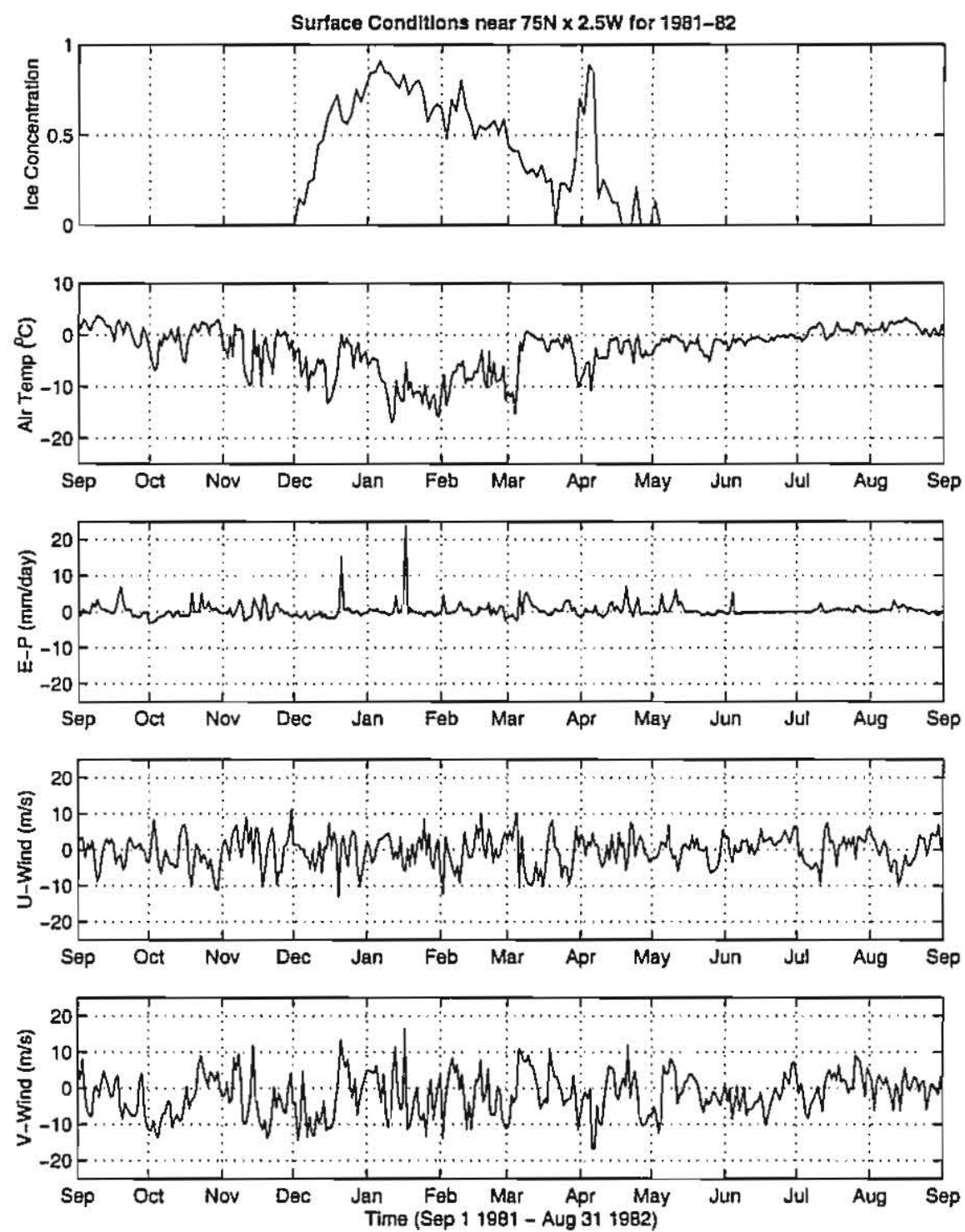

Figure C.3: Surface conditions in the central Greenland Sea gyre for 1981-82. 

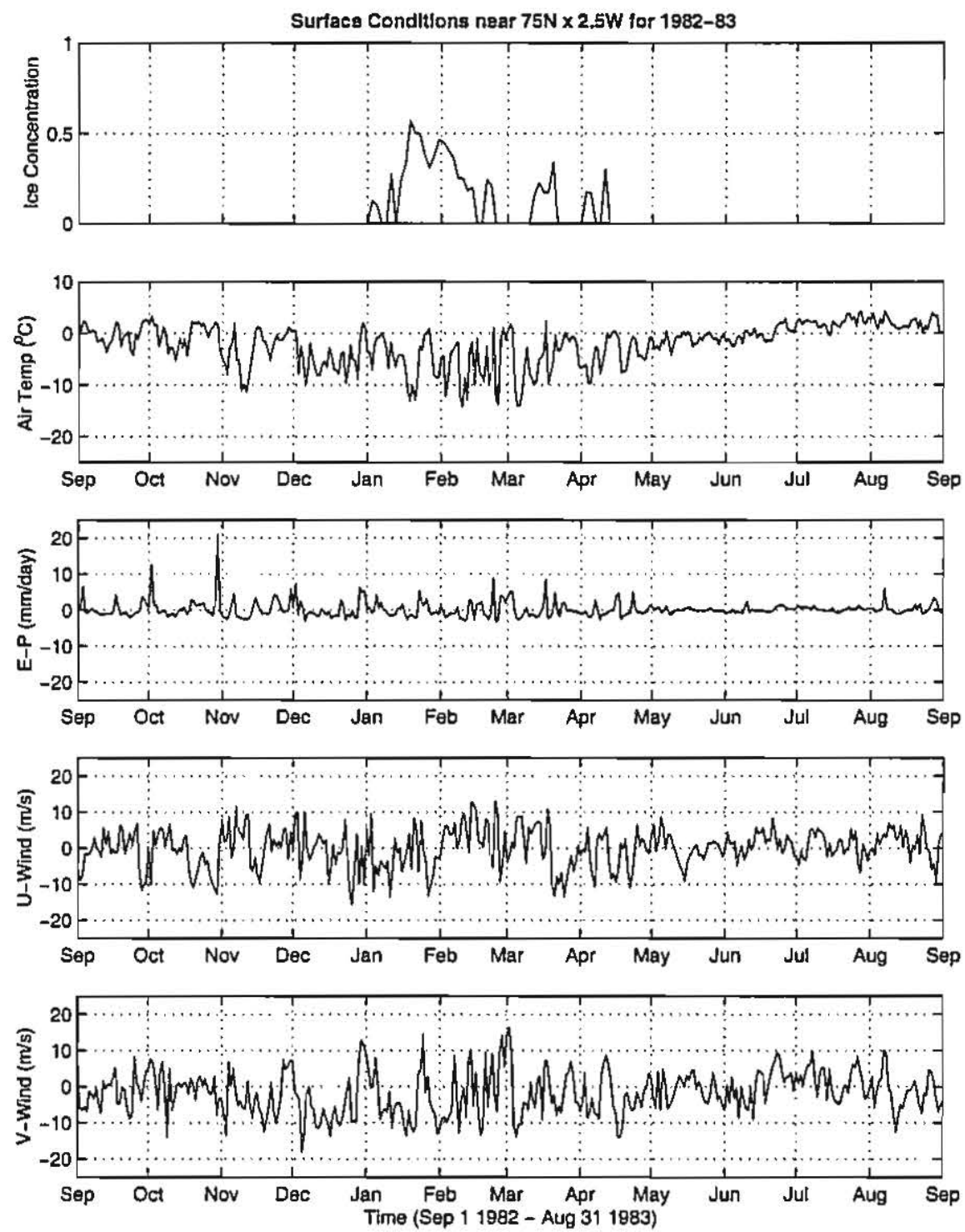

Figure C.4: Surface conditions in the central Greenland Sea gyre for 1982-83. 

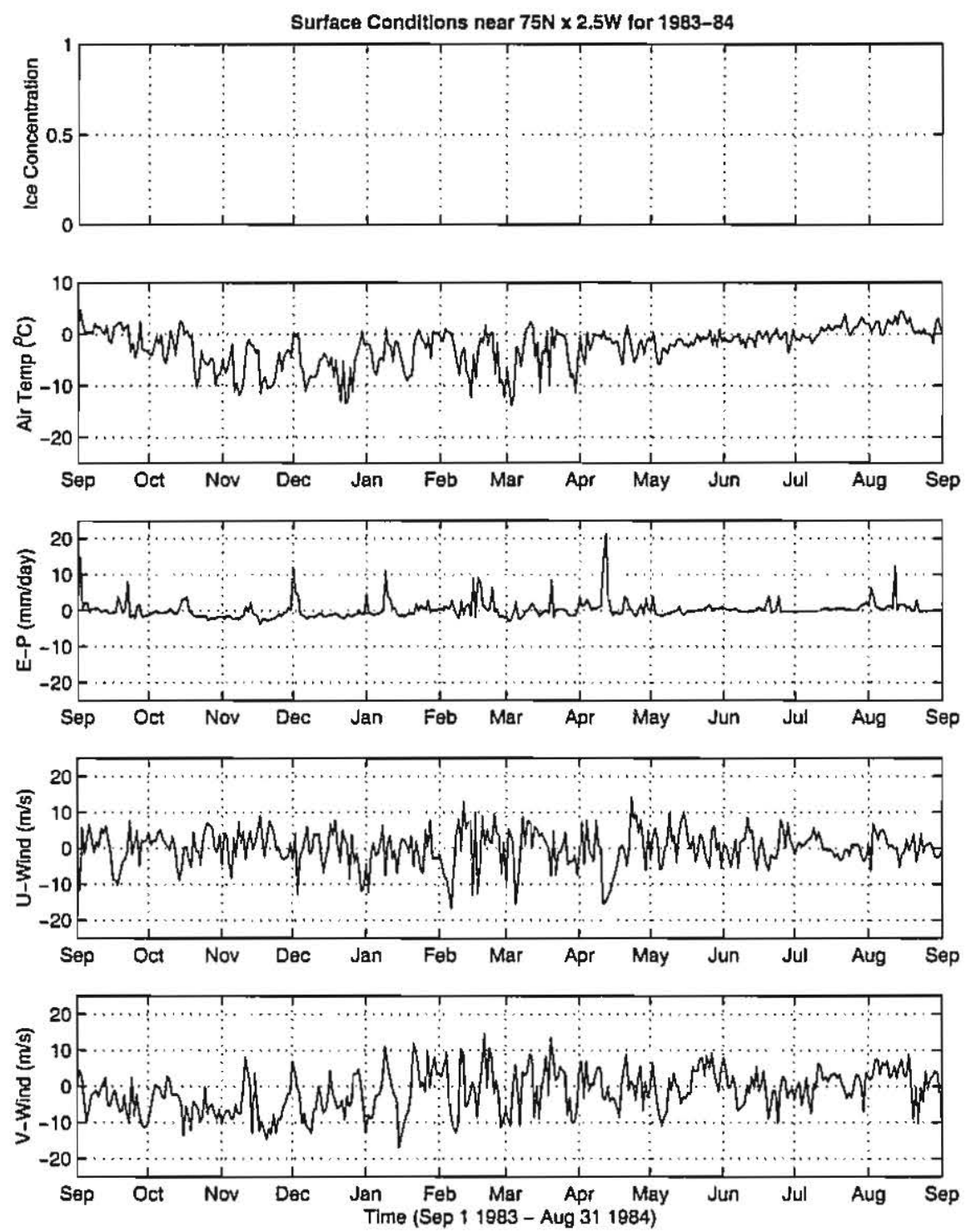

Figure C.5: Surface conditions in the central Greenland Sea gyre for 1983-84. 

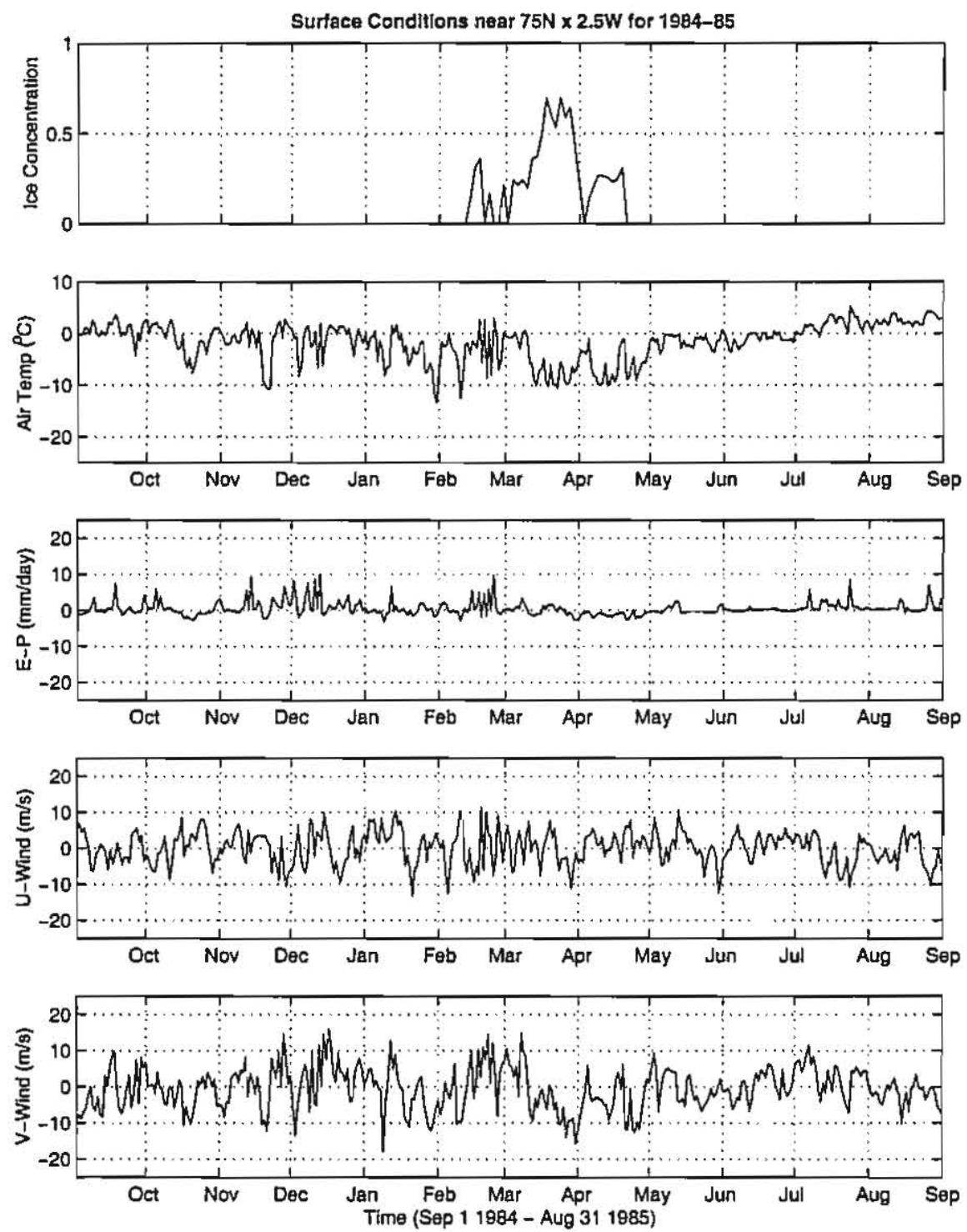

Figure C.6: Surface conditions in the central Greenland Sea gyre for 1984-85. 

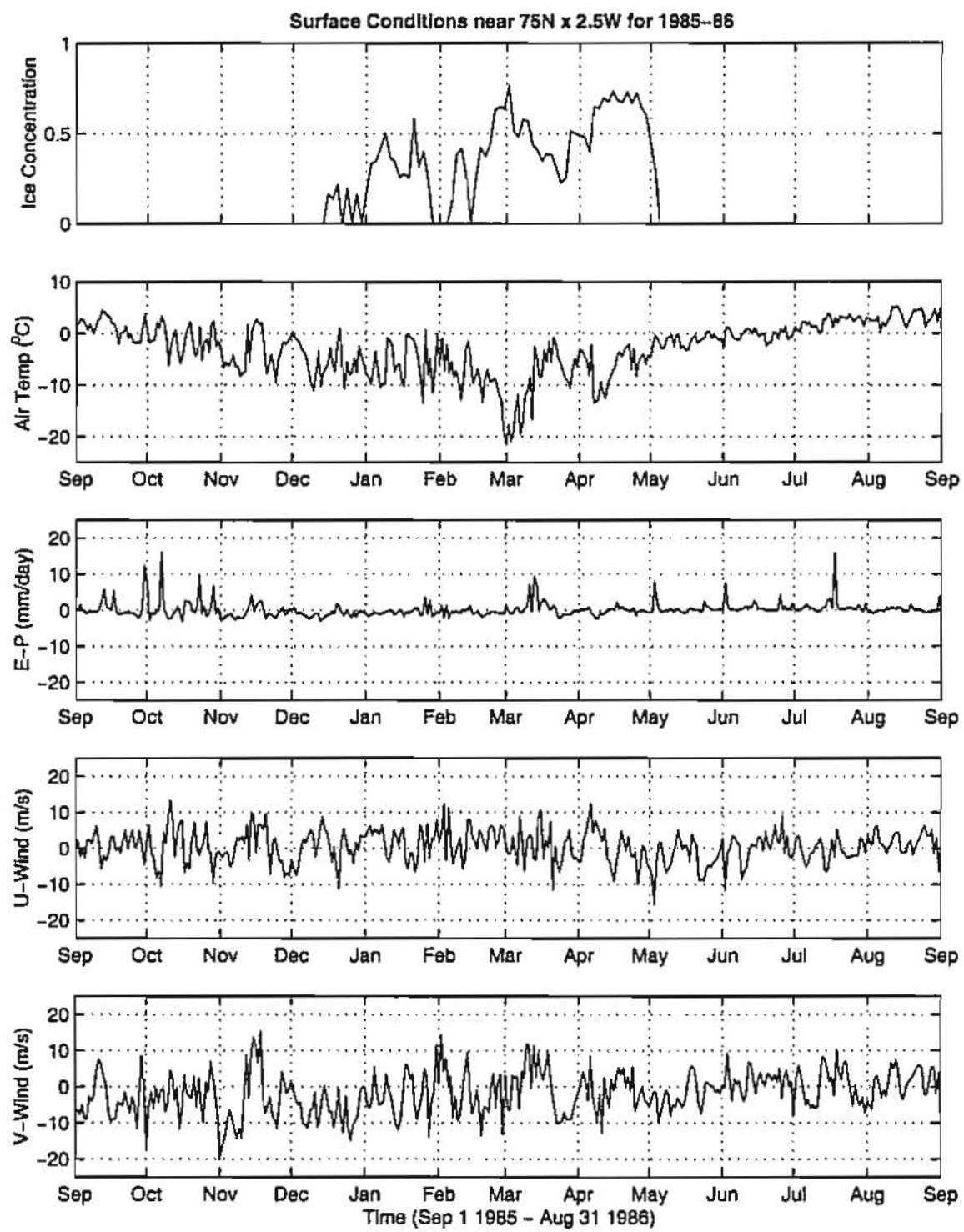

Figure C.7: Surface conditions in the central Greenland Sea gyre for 1985-86. 

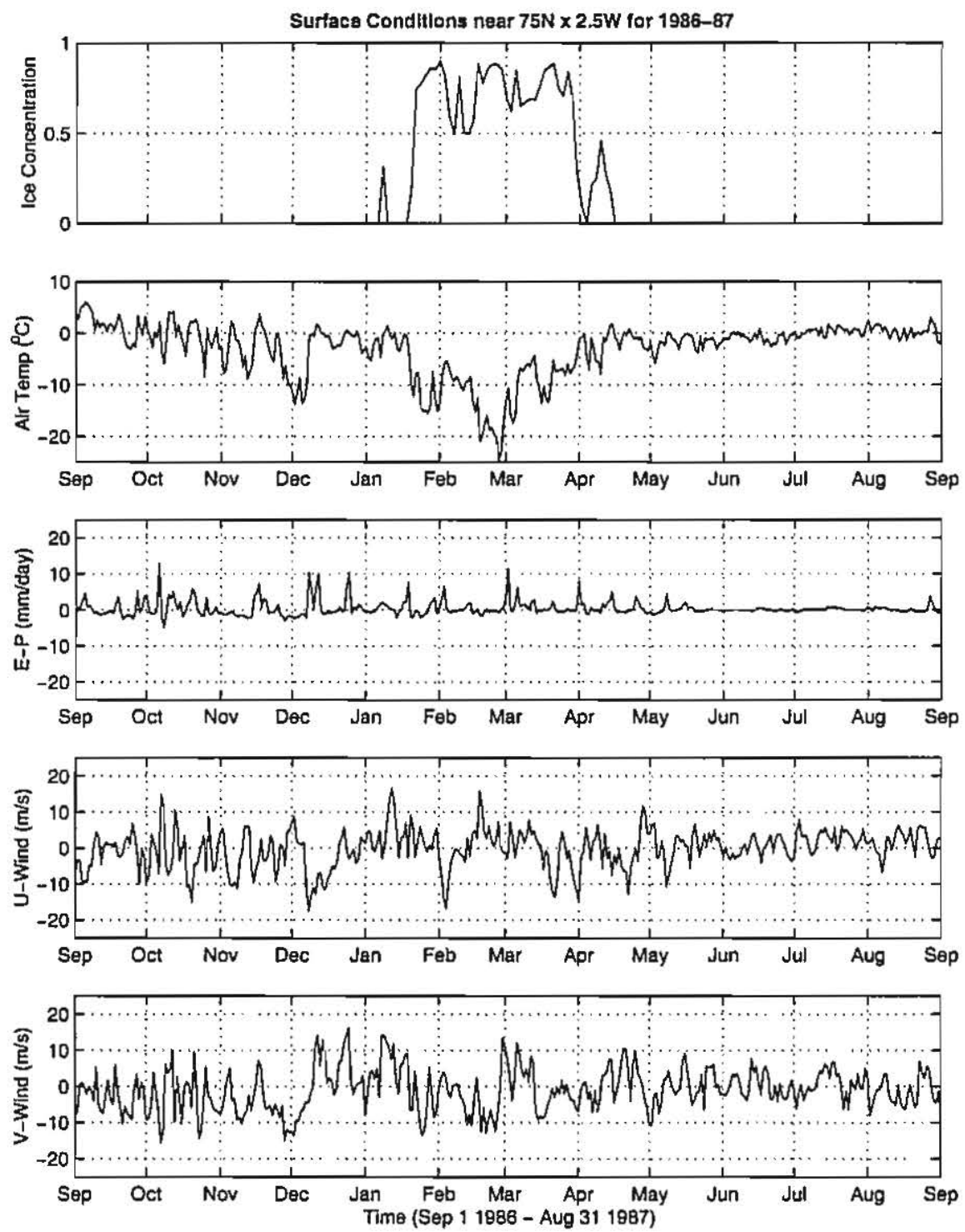

Figure C.8: Surface conditions in the central Greenland Sea gyre for 1986-87. 

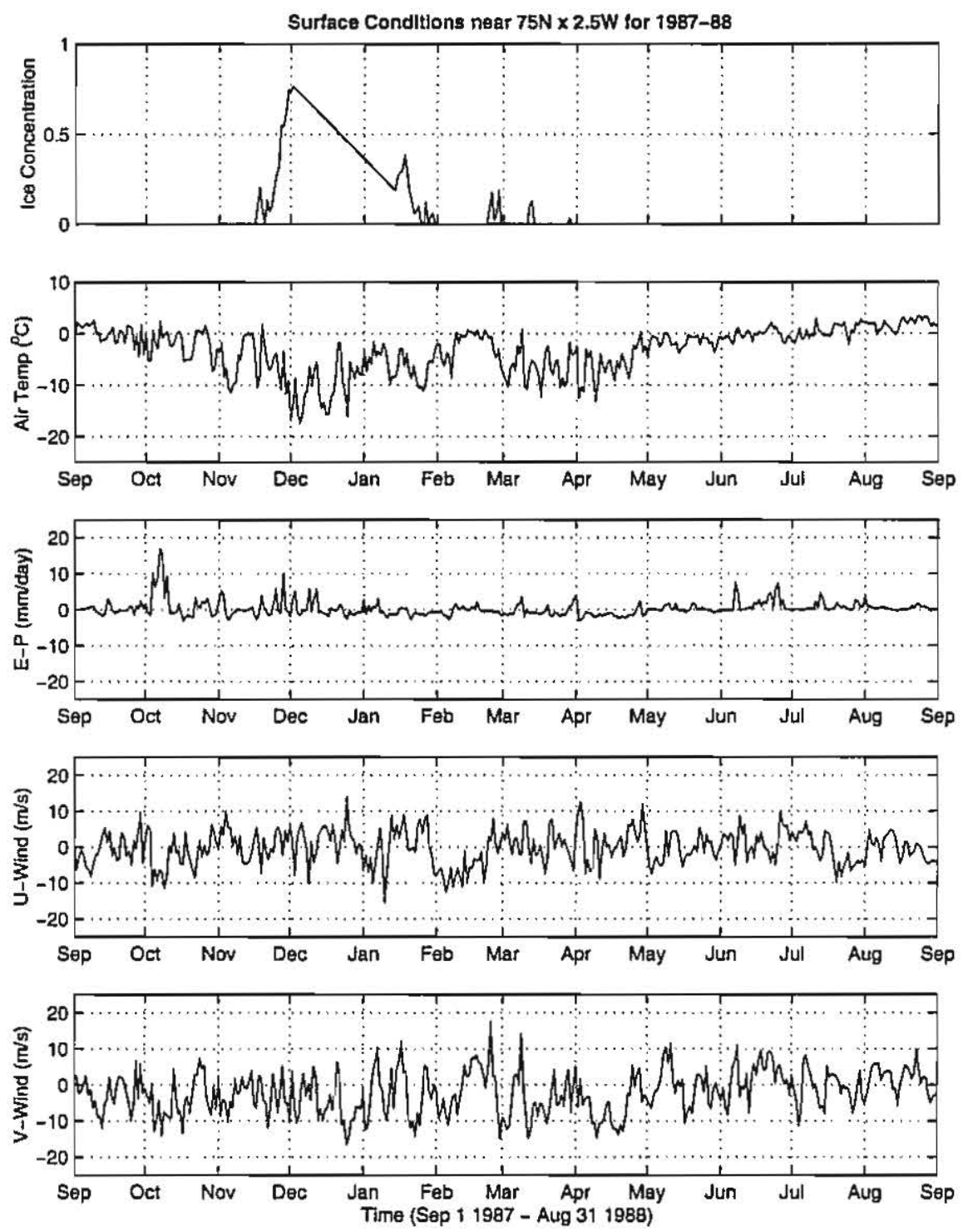

Figure C.9: Surface conditions in the central Greenland Sea gyre for 1987-88. 

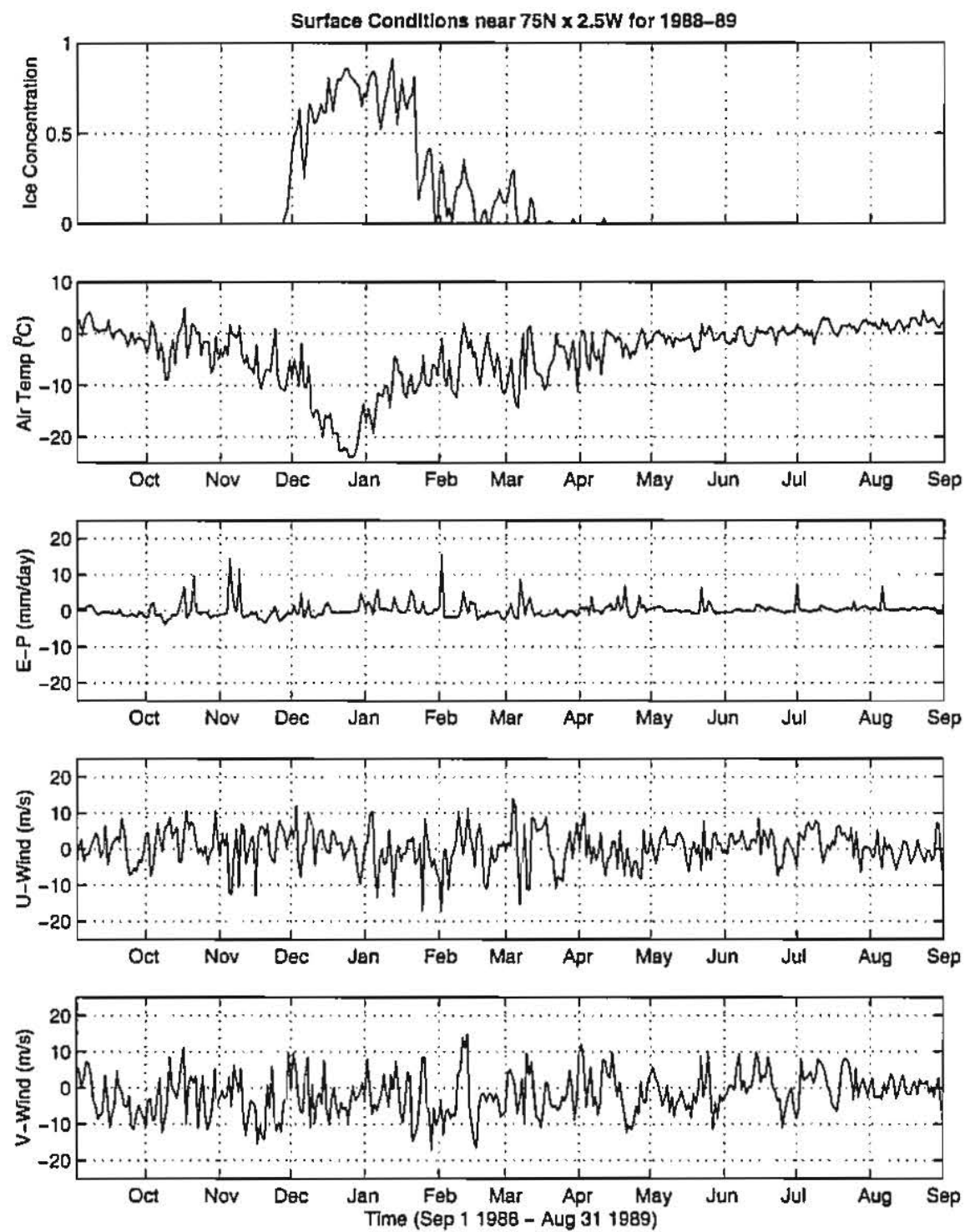

Figure C.10: Surface conditions in the central Greenland Sea gyre for 1988-89. 

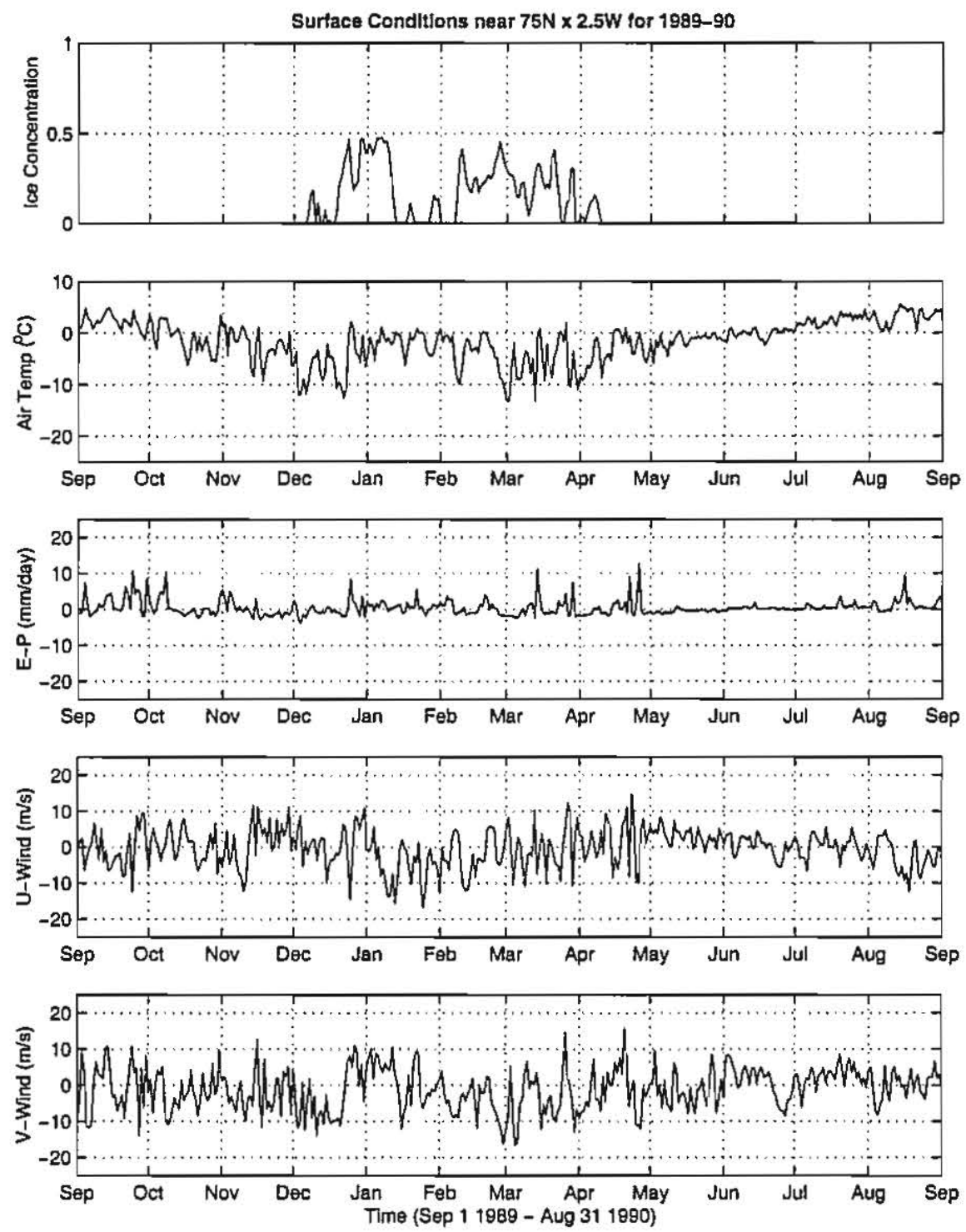

Figure C.11: Surface conditions in the central Greenland Sea gyre for 1989-90. 

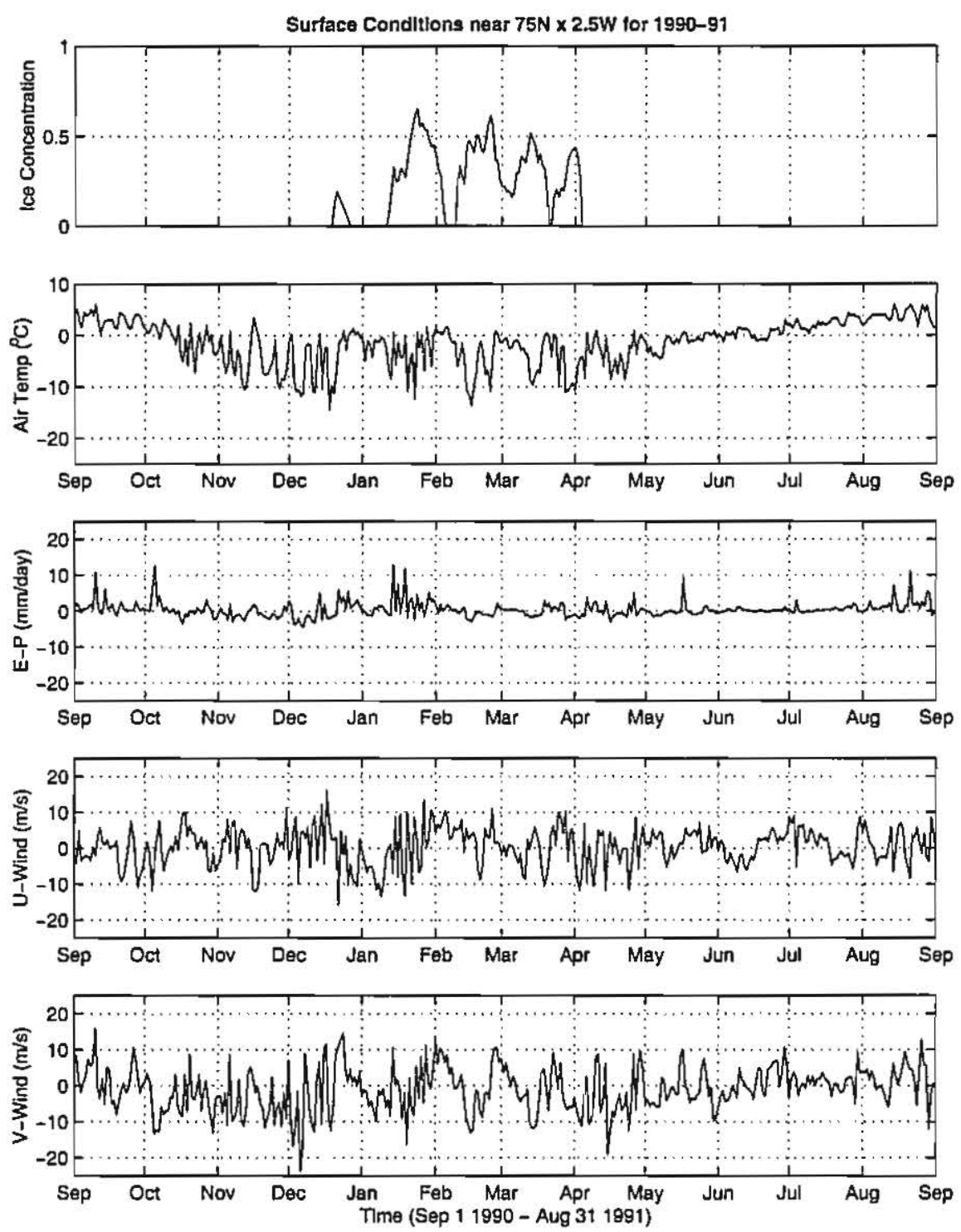

Figure C.12: Surface conditions in the central Greenland Sea gyre for 1990-91. 

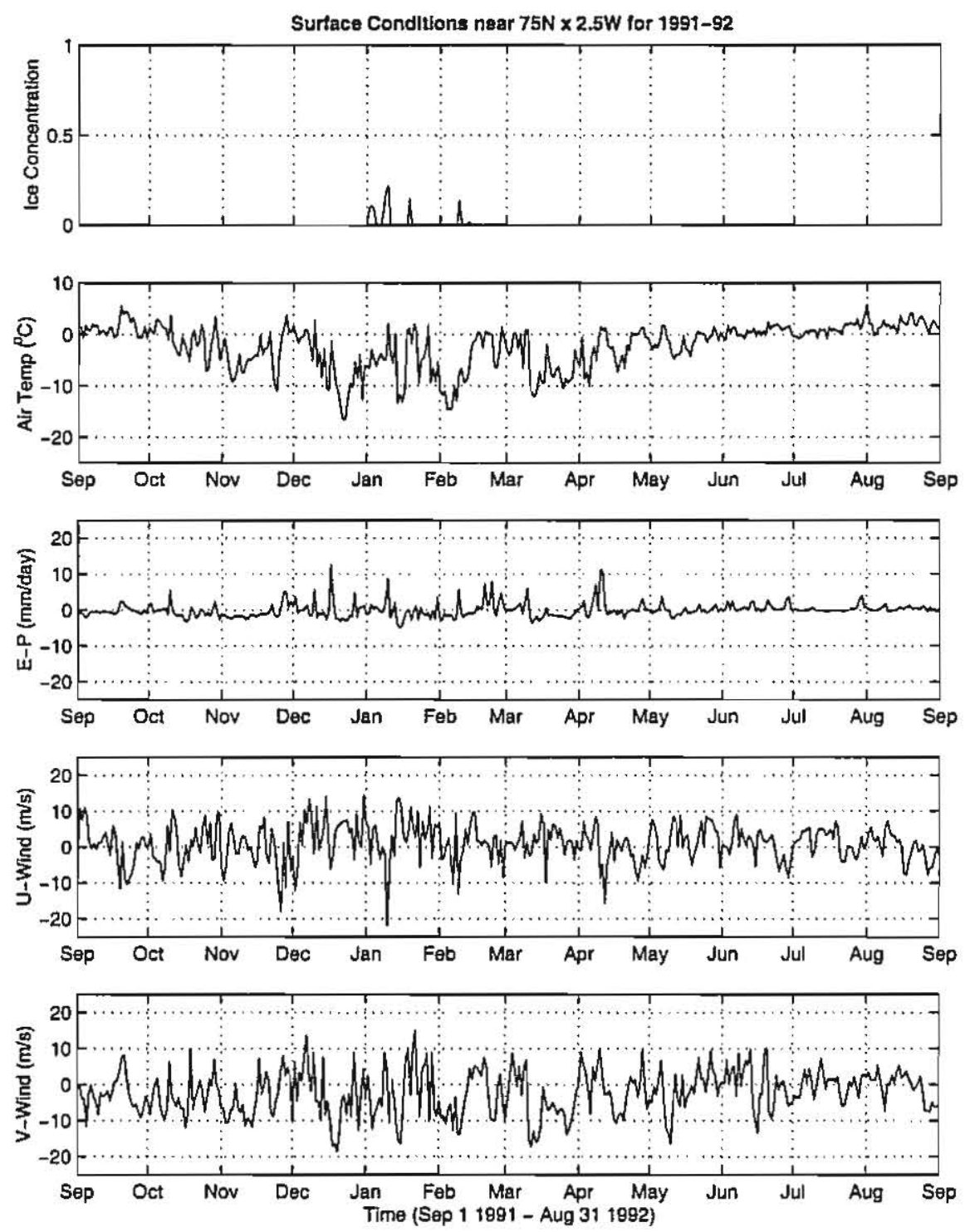

Figure C.13: Surface conditions in the central Greenland Sea gyre for 1991-92. 

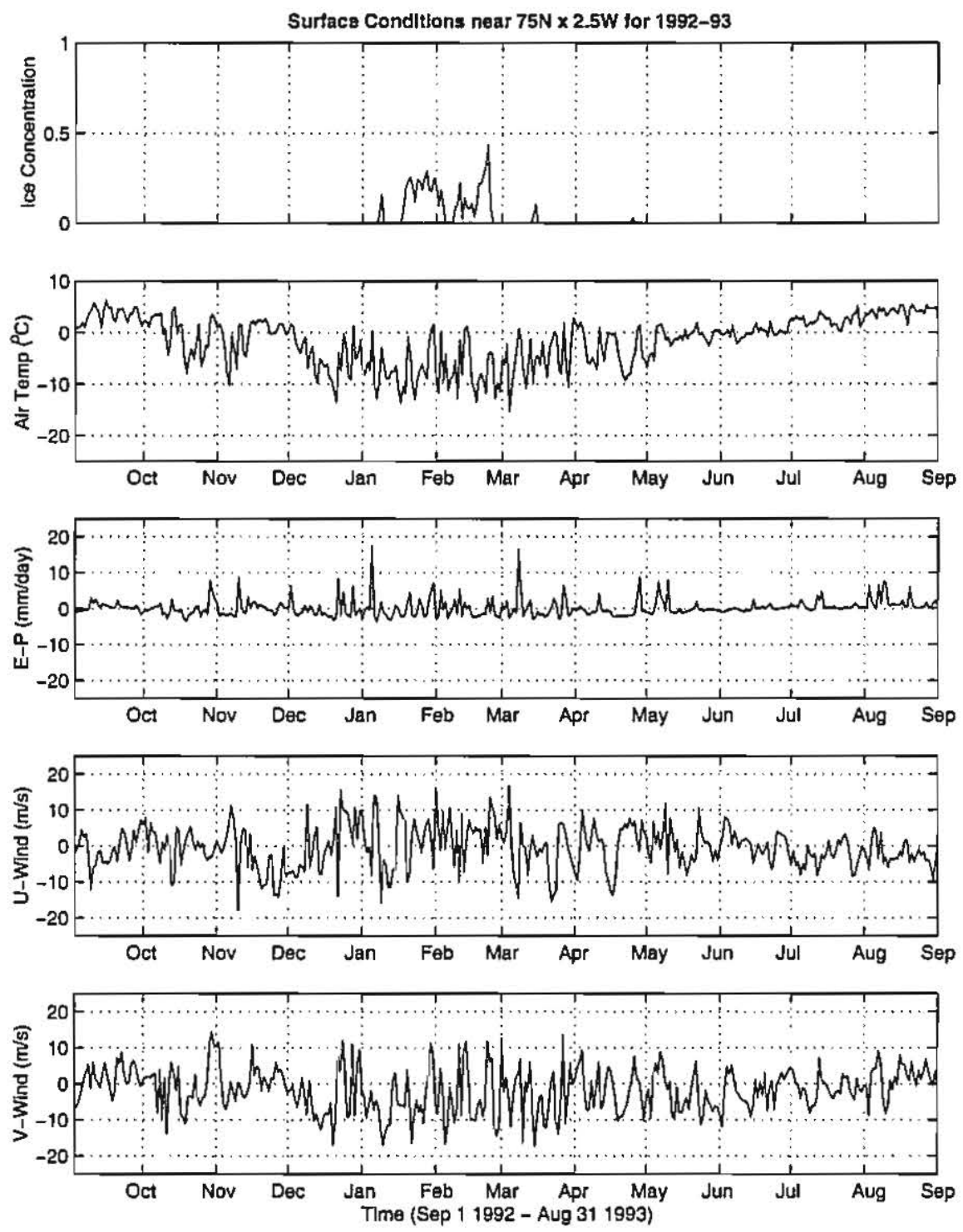

Figure C.14: Surface conditions in the central Greenland Sea gyre for 1992-93. 

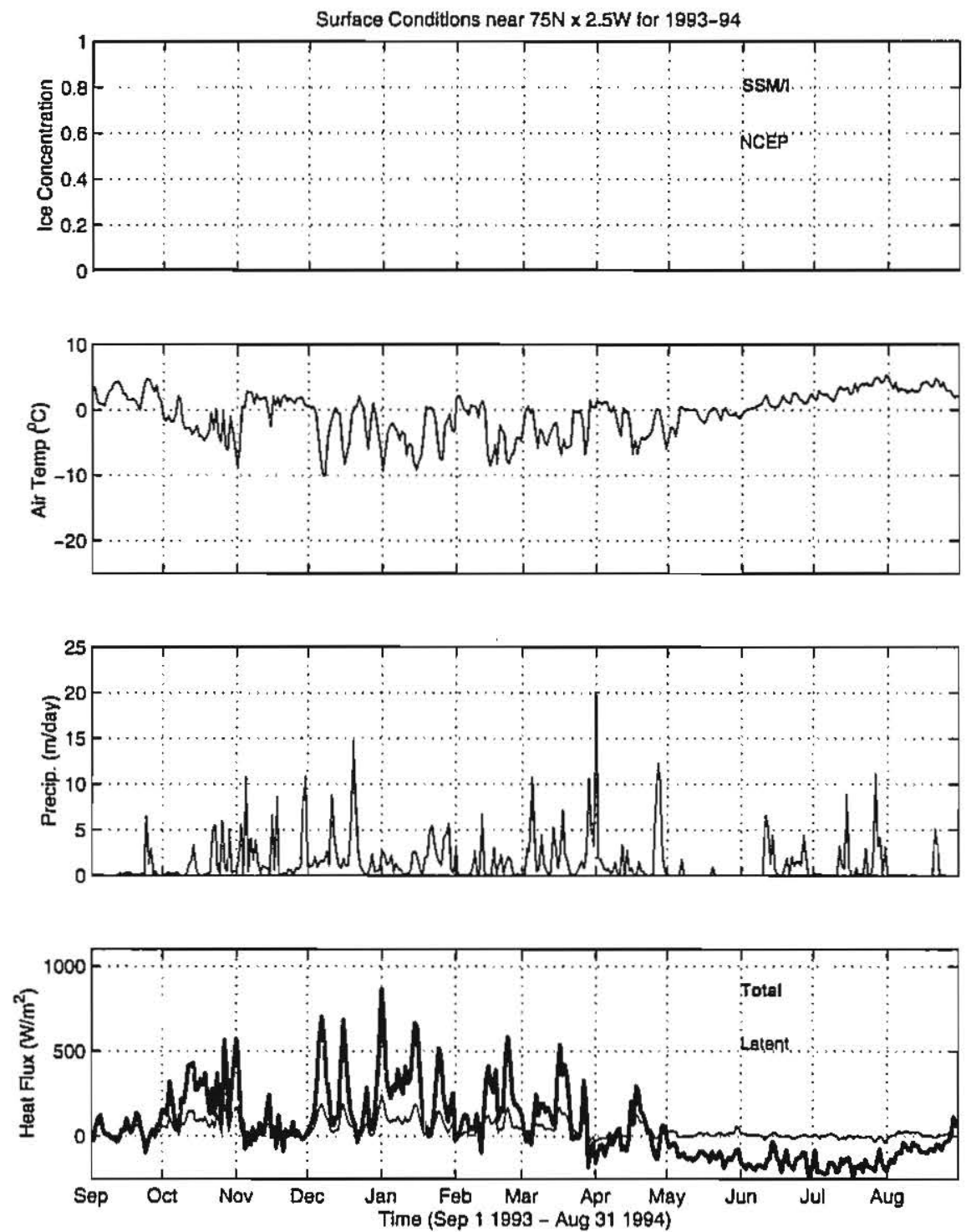

Figure C.15: Surface conditions in the central Greenland Sea gyre for 1993-94. 

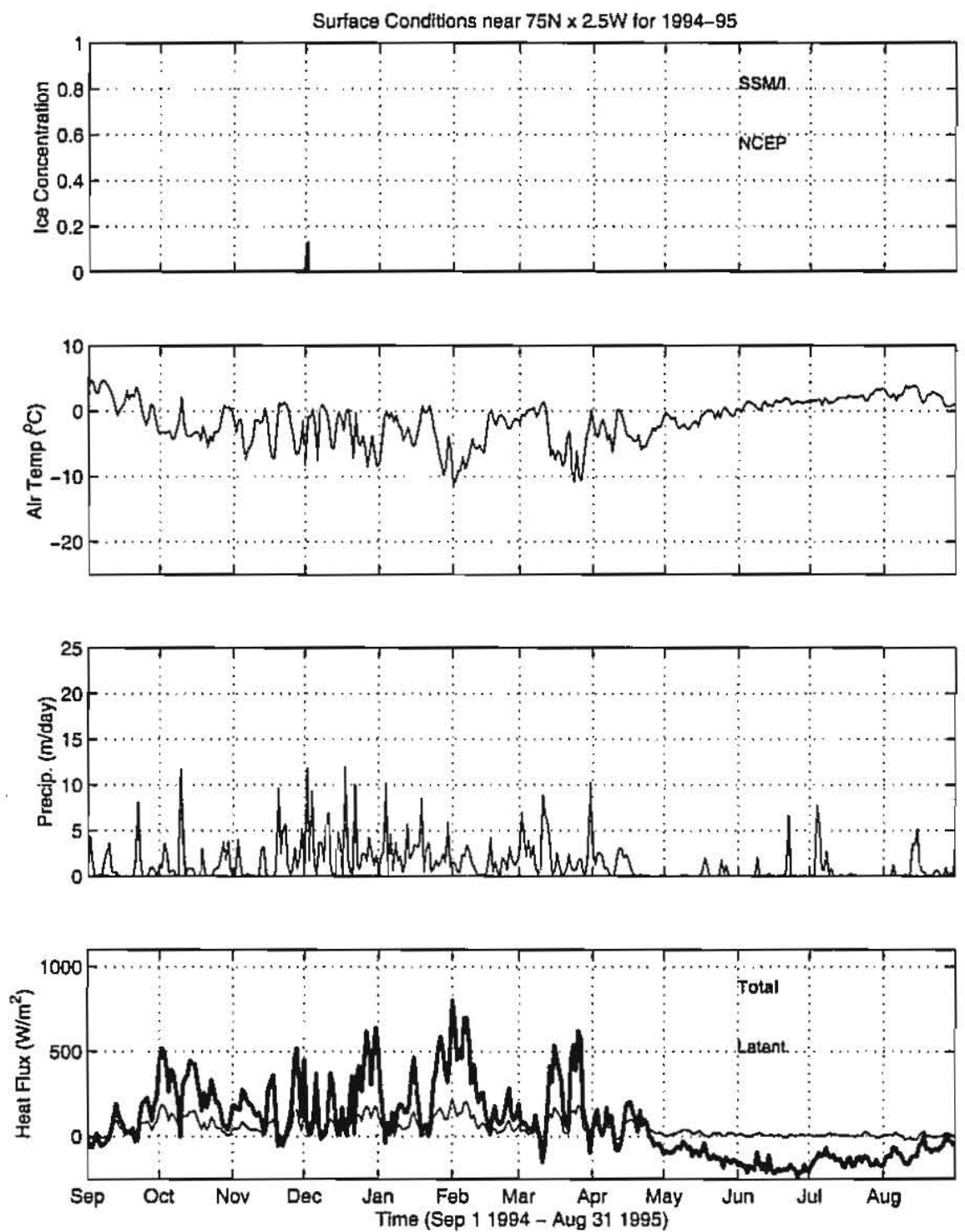

Figure C.16: Surface conditions in the central Greenland Sea gyre for 1994-95. 

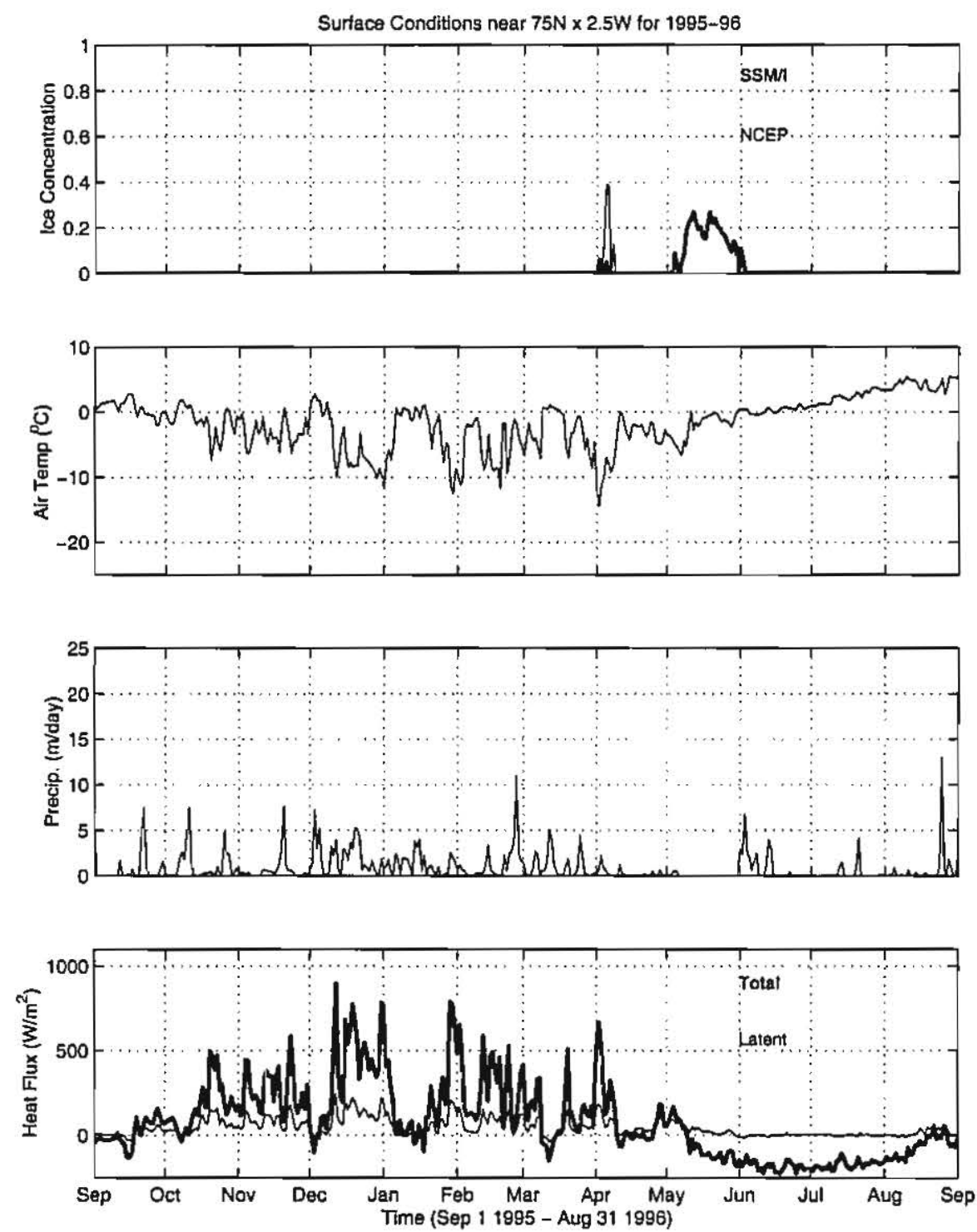

Figure C.17: Surface conditions in the central Greenland Sea gyre for 1995-96. 

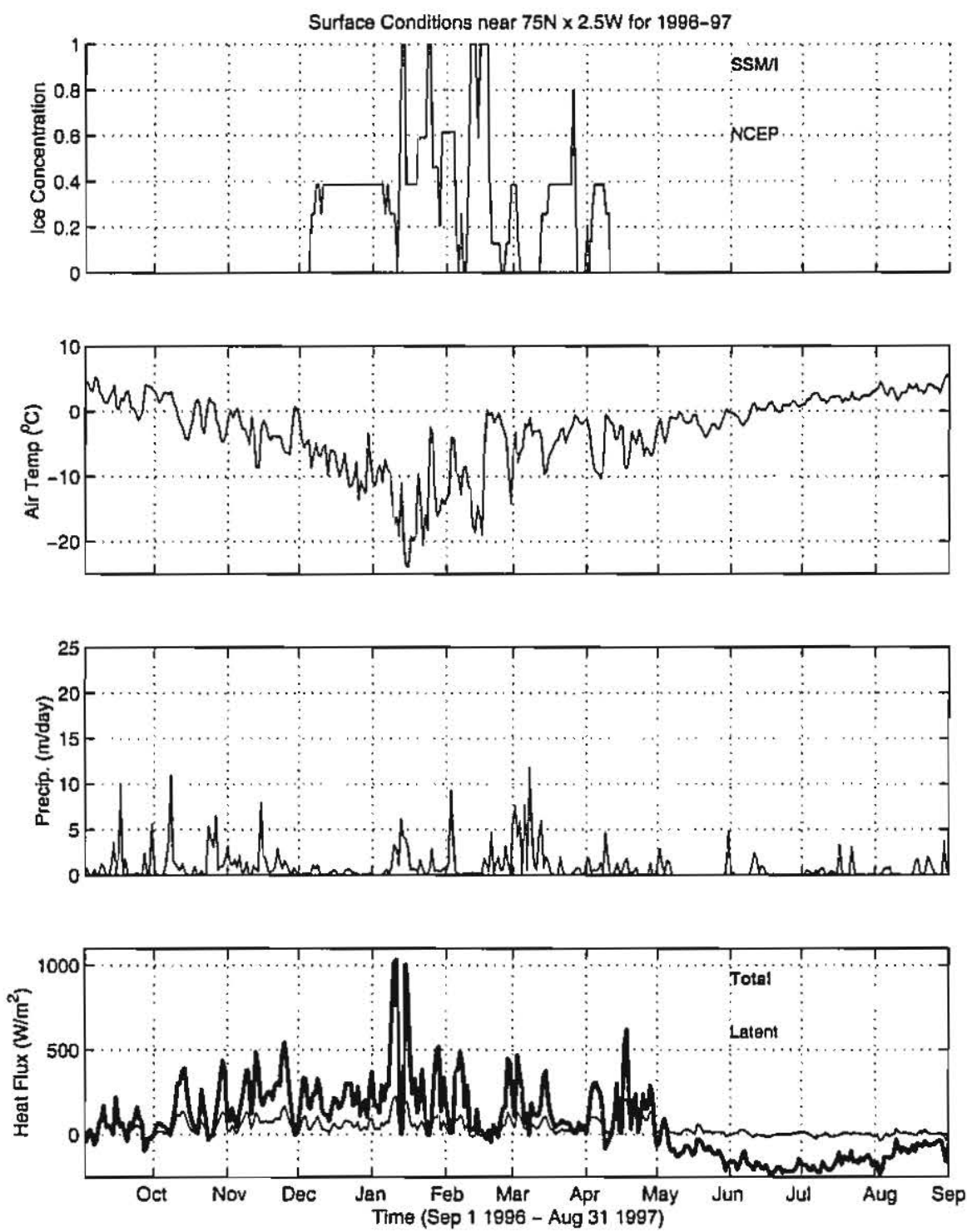

Figure C.18: Surface conditions in the central Greenland Sea gyre for 1996-97. 


\section{Appendix D}

\section{Optimization}

The adjoint method is being used to find best estimates of the strength of the restratification and of the initial temperature and salinity profiles which are consistent with both the model and the data. This procedure of finding an optimal state using the adjoint method is depicted as a flowchart in figure D.1.

Error estimates are available from the analysis of the tornographic data; however, these estimates were thought in some cases to be too small and so we apply a threshold of $0.01^{\circ} \mathrm{C}$. Furthermore, the tomographic temperature estimates during the ice-covered period are not very reliable (as discussed in chapter 2), and so these data are excluded.

The Tangent-Linear and Adjoint Model Compiler (TAMC), which was developed by Ralf Giering, is a FORTRAN pre-processor that creates code for the adjoint model from code for the forward model. Using the forward model and the corresponding adjoint model produced by the TAMC, the optimization was then carried out. The cost function which was minimized through this procedure is:

$$
\begin{aligned}
J & =\sum_{i=1}^{102} \sum_{j=1}^{L}\left\{\left(T_{j}(i)-T_{j}^{\text {obs }}(i)\right)^{2}+\right. \\
& \left.+\left(1-\exp \left[\frac{\left(T_{j}(i)-T_{F}\right)-\left|T_{j}(i)-T_{F}\right|}{a}\right]\right)\right\} .
\end{aligned}
$$

Note in particular the last term in the cost function, which has been inserted not to account for a misfit between model and data, but rather to impose a physical constraint into the optimization process. It prevents the optimization algorithm from moving towards a state 


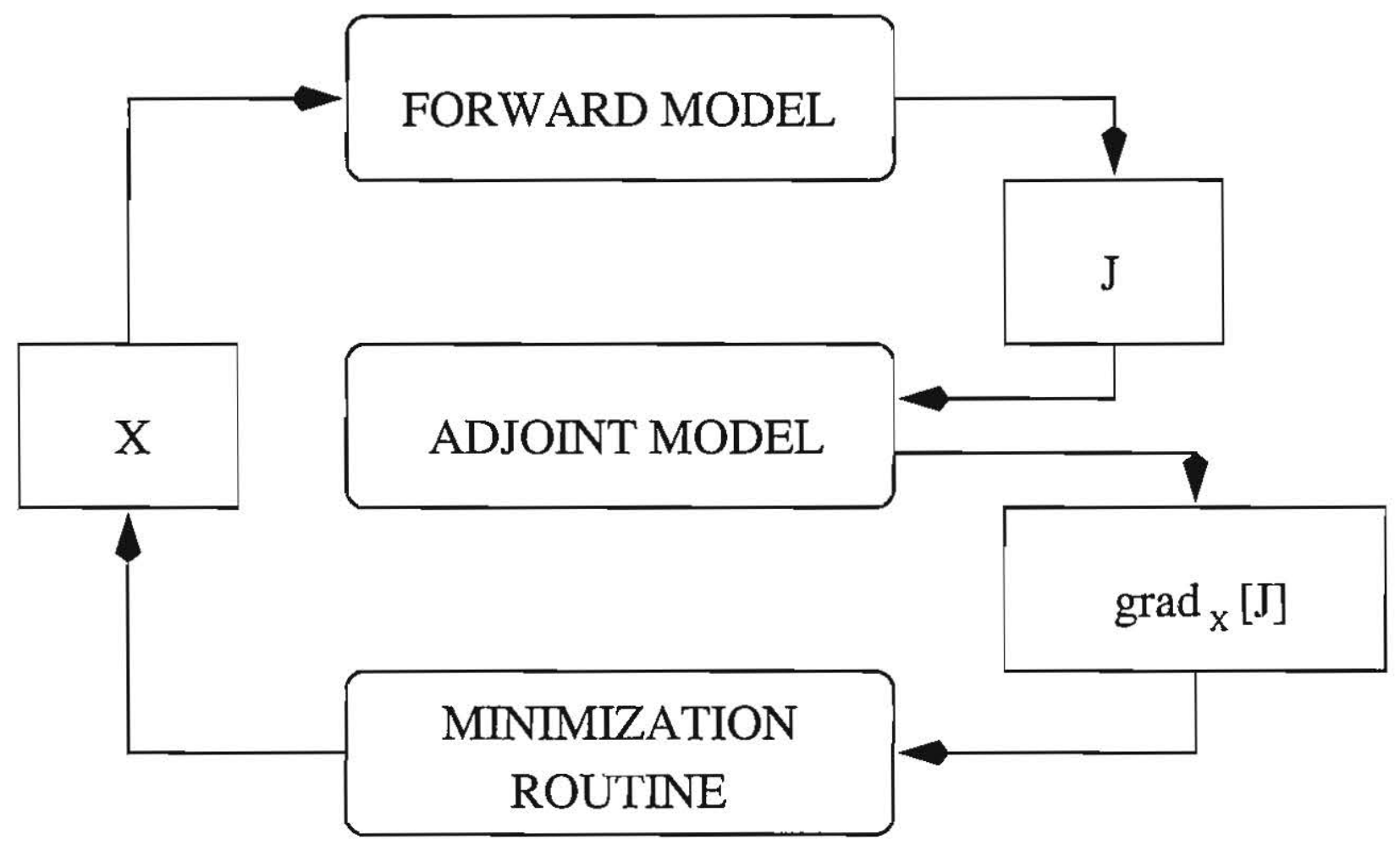

Figure D.1: A schematic diagram illustrating the optimization process. The vector of control variables $\mathrm{X}$ is passed to the forward model. The forward model computes the value of the cost function $\mathrm{J}$, which is passed to the adjoint model. The adjoint model computes the value of the gradient of the cost function with respect to the control variables. This information is passed to the minimization routine, which then tries to find a better estimate for the control variables which decreases the value of the cost function. 


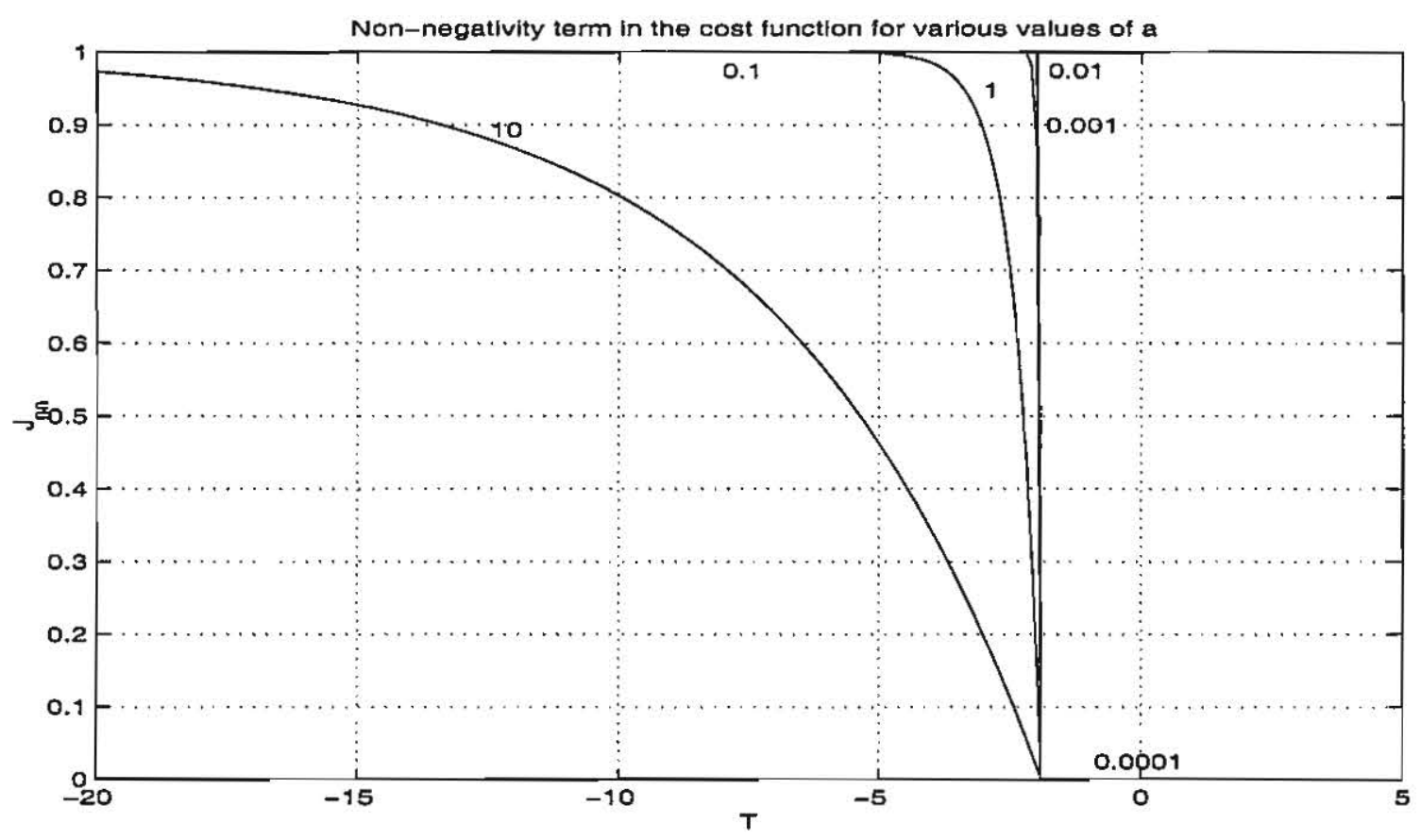

Figure D.2: The non-negativity term $J_{n n}$ in the cost function is used to prevent the water temperature from being artificially supercooled during the optimization process.

in which the water in supercooled (i.e. below freezing). There is no physical process in the model which would lead to such a state. However, it can still be artificially initialized to such a state since there is no physical constraint on the initial conditions. This nonnegativity term has no contribution to the cost function as long at the water temperature is above freezing, but increases exponentially as soon as it drops below freezing (see figure D.2). The constant parameter $a$ controls the rate of this exponential increase; for this study, a value of $a=100$ was used. One should further note that the function is piecewise differentiable and both the function and its derivative (figure D.3) are continuous. 


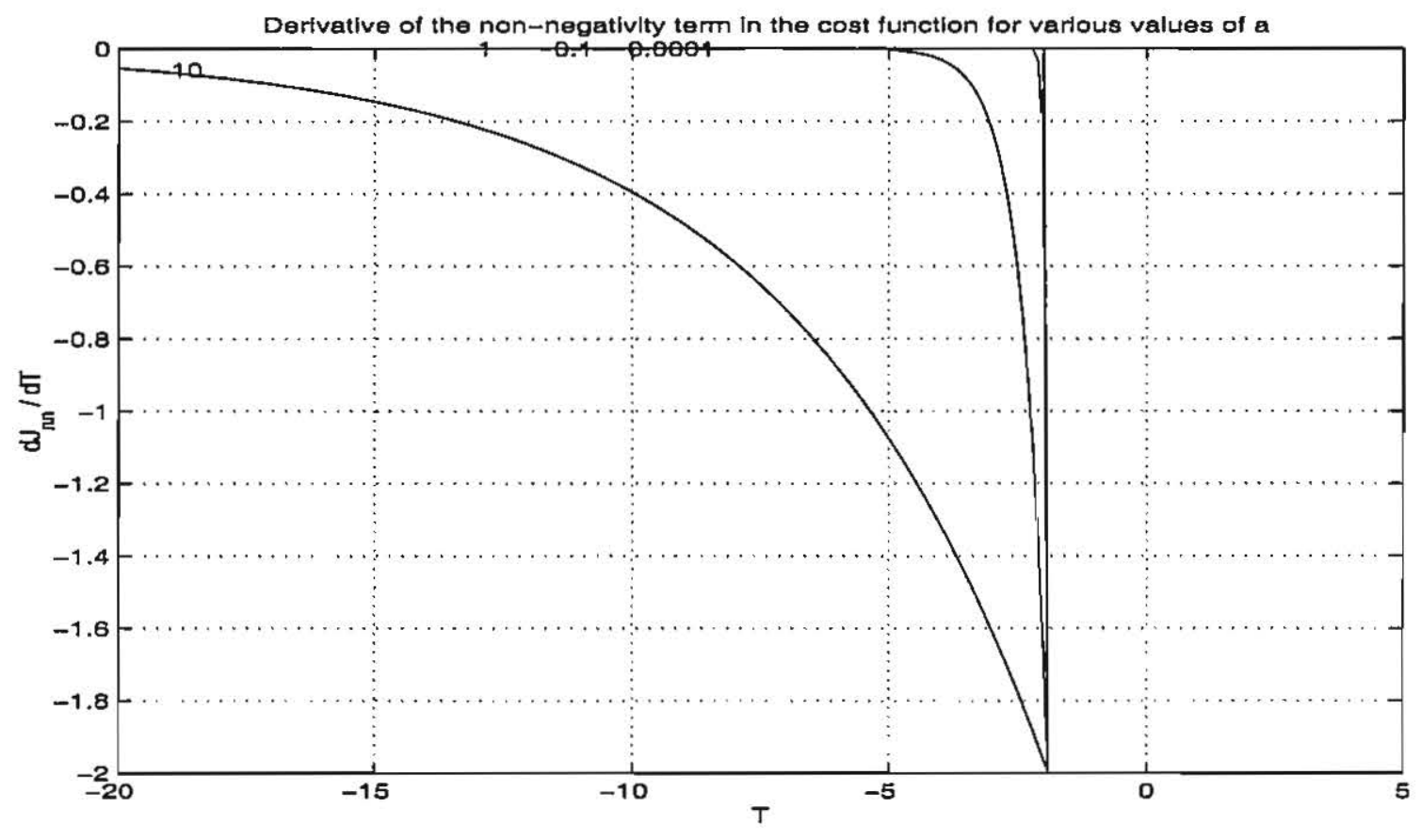

Figure D.3: The derivative of $J_{n n}$ is a well-behaved function. 


\section{Bibliography}

[1] Aagaard, K. and Carmack, E.C.; JGR, 94, 14485-14498, 1989. "The role of sea ice and other fresh water in the Arctic circulation"

[2] Anati, D.; Cah. Oceanogr., 22, 427-443, 1970. "On the mechanism of the deep mixed layer formation during MEDOC ' 69 '

[3] Barry, R.G.; Serreze, M.C.; Maslanik, J.A.; Preller, R.H.; Rev. Geophysics, 31, No. 4, 397-422, November 1993. "The Arctic Sea Ice - Climate System: Observations and Modeling"

[4] Bryan, F.; Nature, 323, 301-304, 1986. "High-latitude salinity and interhernispheric thermohaline circulation"

[5] Budeus, G.; Maul, A.; Krause, G.; JGR, 98, 9985-10000, 1993. "Variability in the Greenland Sea as revealed by a repeated high spatial resolution conductivitytemperature-depth survey"

[6] Carmack, E. and Aagaard, K.; DSR, 20, 687-715, 1973. "On the Deep Water of the Greenland Sea"

[7] Cavalieri; Parkinson, C.L.; Gloersen, P.; Zwally, H.J.; "Arctic and Antarctic sea ice concentrations from multichannel passive-microwave satellite data sets: October 1978 to September 1995, User's Guide", NASA Technical Memorandum 104647, 1997.

[8] Chapman, D.C. and Gawarkiewicz, G.; JPO, 27, 555-566, 1997. "Shallow Convection and Buoyancy Equilibration in an Idealized Coastal Polynya" 
[9] Clarke, R.A.; Swift, J.H.; Reid, J.L.; Koltermann, K.P.; DSR, Part A, 37, 13851424, 1990. "The formation of Greenland Sea deep water : double diffusion or deep convection?"

[10] Dickson, R.J.; Lazier, J.; Meinke, J.; Rhines, P.;Swift, J.; Prog. Oceanogr., 38, 241295, 1996. "Long-term coordinated changes in the convective activity of the North Atlantic"

[11] Esbensen, S.K. and Kushnir, Y.; "The heat budget of the global oceans: An atlas based on estimates from surface marine observations", Tech. Rep. 29, Climate Res. Inst., Oregon State Univ., Corvallis, 1981.

[12] Fong, D.; Ph.D. Thesis, M.I.T./ W.H.O.I. Joint Program in Oceanography, 1998. "Dynamics of freshwater plumes: observations and numerical modeling of the windforced response and alongshore freshwater transport"

[13] Gill, A.; Atmosphere-Ocean Dynamics, Academic Press, 1982.

[14] GSP Group; Eos, 71, 750-751, 754-755, 1990. "Greenland Sea Project: A venture toward improved understanding of the oceans' role in climate"

[15] Hakkinen, S.; JGR, 92, No. C5, 5031-5034, 1987. "Upwelling at the ice edge : A mechanism for deep water formation?"

[16] Hobbs, P.V.; Ice Physics, Clarendon Press, Oxford, 1974.

[17] Hogg, N.G.; DSR, 20, 449-459, 1973. "The preconditioning phase of MEDOC 1969-II. Topographic effects"

[18] Ivey, G.N.; Taylor, J.R.; Coates, M.J.; DSR, 42, NO. 3, 331-349, 1995. "Convectively driven mixed layer growth in a rotating, stratified fluid"

[19] Jones, $\mathrm{H}$ and Marshall, J.; JPO 27, No. 10, 2276-2287, 1997. "Restratification after deep convection"

[20] Killworth, P.D.; Rev. Geophys. and Space Phys., 21, No. 1, 1-26, 1983. "Deep Convection in the World Ocean"

[21] Killworth, P.D.; JPO, 9, 531-554, 1979. "On 'chimney' formations in the ocean" 
[22] Lascaratos, A.; Williams, R.G.; Tragou, E.; JGR, 98, No. C8, 14739-14749, 1993. "A Mixed-Layer Study of the Formation of Levantine Intermediate Water"

[23] Legg, S.; Jones, H.; Visbeck, M.; JPO, 26, No. 10, 2251-2266, 1996. "A Heton Perspective of Baroclinic Eddy Transfer in Localized Open Ocean Convection"

[24] Lemke, P.; JGR, 92, No. C12, 13164-13172, 1987. "A Coupled One-Dimensional Sea Ice-Ocean Model"

[25] Leppäranta, M.; Atmosphere-Ocean, 31, 123-138, 1993. "A Review of Analytical Models of Sea-Ice Growth"

[26] Macdonald, A. and Wunsch, C.; Nature, 382, 436-439, 1996. "A Global Estimate of the Ocean Circulation and Heat Fluxes"

[27] Macklin, S.; JGR, 88, 2845-2852, 1983. "Wind drag coefficient over first-year ice in the Bering Sea"

[28] Manabe, S. and Stouffer, R.J.; J. Clim., 1, 841-866, 1988. "Two stable equilibria of a coupled ocean-atmosphere model"

[29] Marotzke, J.; JPO, 27, No. 8, 1713-1728, 1997. "Boundary Mixing and the Dynamics of Three-Dimensional Thermohaline Circulations"

[30] Marotzke, J. and Willebrand, J.; JPO, 21, No. 9, 1372-1385, 1991. "Multiple Equilibria of the Global Thermohaline Circulation"

[31] Marotzke, J.; JPO, 21, No. 6, 903-907, 1991. "Influence of Convective Adjustment on the Stability of the Thermohaline Circulation"

[32] Marshall, J. and Schott, F.; to appear in Rev. Geophys., 1998. "Open-ocean convection: observations, theory and models"

[33] McDougall, T.; DSR, Part A, 30, 1109-1117, 1983. "Greenland Sea bottom water formation : A balance between advection and double-diffusion"

[34] McPhee, M.G.; JGR, 97, No. C4, 5365-5379, 1992. "Turbulent Heat Flux in the Upper Ocean Under Sea Ice" 
[35] McPhee, M.G.; Maykut, G.A.; Morison, J.H.; JGR, 92, No. C7, 7017-7031, 1987. "Dynamics and Thermodynamics of the Ice/Upper Ocean System in the Marginal Ice Zone of the Greenland Sea"

[36] MEDOC Group; Nature, 227, 1037-1040, 1970. "Observation of formation of deep water in the Mediterranean Sea"

[37] Meincke, J.; Jónnson, S.; Swift, J.H.; ICES Mar. Sci. Symp., 195, 32-39, 1992. "Variability of convective conditions in the Greenland Sea"

[38] Morawitz, W.M.L.; Sutton, P.J.; Worcester, P.F.; Cornuelle, B.D.; Lynch, J.F.; Pawlowicz; JPO, 26, 2316-2343, 1996. "Three-Dimensional Observations of a Deep Convective Chimney in the Greenland Sea during Winter 1988/89"

[39] Nagurny, A.P. and Popov, A.V.; Meteorol. Gidrol., 7, 70-75, 1985. "Intensive upwelling of deep and bottom waters and their formation at the surface in the region of the Greenland Hollow"

[40] Oort, A.H. and Vonder Haar, T.H.; JPO, 6, 781-800, 1976. "On the observed annual cycle in the ocean-atmosphere heat balance over the northern hemisphere"

[41] Parkinson, C.L. and Washington, W.M.; JGR, 84, No. C1, 311-337, 1979. "A LargeScale Numerical Model of Sea Ice"

[42] Pawlowicz, R.; JGR, 100, No. C3, 4715-4726, 1995. "A note on seasonal cycles of temperature and salinity in the upper waters of the Greenland Sea Gyre from historical data"

[43] Pawlowicz, R.; Lynch, J.F.; Owens, W.B.; Worcester, P.F.; Morawitz, W.M.L.; Sutton, P.J.; JGR, 100, No. C3, 4727-4750, 1995. "Thermal evolution of the Greenland Sea Gyre in 1988-1989"

[44] Pickard, G. and Emery, W.; Descriptive Physical Oceanography, Pergamon Press, 1990.

[45] Poulain, P.-M.; Warn-Varnas, A.; Niiler, P.P.; JGR, 101, No. C8, 18237-18258, 1996.

"Near-surface circulation of the Nordic seas as measured by Lagrangian drifters" 
[46] Price, J.F. and Yang, J.; unpublished manuscript, 1998. "Parameterization of Marginal Sea Overflows for Climate Simulations"

[47] Roach, A.T.; Aagaard, K.; Carsey, F.; Atmosphere-Ocean, 31, 1993, 319-337. "Coupled Ice-Ocean Variability in the Greenland Sea"

[48] Rossby, H.T.; DSR, 12, 9-16, 1965. "On thermal convection driven by non-uniform heating from below : an experimental study"

[49] Rudels, B.; JGR, 94, No. C3, 3223-3227, 1989. "Greenland Sea Convection in the Winter of 1987-1988"

[50] Rudels, B., DSR, 37 (9), 1491-1511, 1990. "Haline Convection in the Greenland Sea"

[51] Schlosser, P.G. et al.; Science, 251, 1054-1056, 1991. "Reduction of deepwater formation in the Greenland Sea during the 1980s: Evidence from tracer data"

[52] Schott, F.; Visbeck, M.; Fischer, J.; JGR, 98, No. C8, 14401-14421, 1993. "Observations of vertical currents and convection in the central Greenland Sea during the winter of 1988-1989"

[53] Schott, F.; Visbeck, M.; Send, U.; in Ocean Processes in Climate Dynamics: Global and Mediterranean Examples, edited by P. Malanotte-Rizzoli and A.R. Robinson, 203225, Kluwer Academic, 1994. "Open-ocean deep convection, Mediterranean and Greenland Seas"

[54] Stefan, J.; Ann. Phys., 3rd Ser. 42, 269-286, 1891. "Über die Theorie der Eisbildung, insbesondere über Eisbildung im Polarmeere"

[55] Stommel, H.; Tellus, 13, 224-230, 1961. "Thermohaline convection with two stable regimes of flow"

[56] Strass, V.H.; Fahrbach, E.; Schauer, U.; Sellmann, L.; JGR, 98, No. C4, 6907-6919, 1993. "Formation of Denmark Strait Overflow Water by Mixing in the East Greenland Current"

[57] Sutton, P.J.; Morawitz, W.M.L.; Worcester, P.F.; Cornuelle, B.D.; JGR, 102, No. C13, 27861-27874, 1997. "Temperature evolution of the upper ocean in the Greenland Sea January to March 1989" 
[58] Swift, J.H.; DSR, 31, No. 11, 1339-1355, 1984. "The circulation of the Denmark Strait and Iceland-Scotland overflow waters in the North Atlantic"

[59] Turner, J.S.; Buoyancy Effects in Fluids, 368 pp, Cambridge University Press, Cambridge, 1973.

[60] Toudal, L.; Low, D.; Valeur, H.; Wadhams, P.; Satellite observations of the Odden ice cover during the winter of 1995-1996, A scientific report to the Commission of the European Communities, DG XII, An additional work carried out under contract MAS2-CT93-0057, the European Subpolar Ocean Project, 1993-1996. (Internet document at the World Wide Web site: http://www.dcrs.dtu.dk/DCRS/projects/odden1996/page1.htm)

[61] Visbeck, M.; Fischer, J.; Schott, F.; JGR, 100, No. C9, 18489-18502, 1995. "Preconditioning the Greenland Sea for deep convection; Ice formation and ice drift"

[62] Visbeck, M.; Marshall, J.; Jones, H.; JPO, 26, No. 9, 1721-1734, 1996. “Dynamics of Isolated Convective Regions in the Ocean"

[63] Wadharns, P.; Comiso, J.C.; Prussen, E.; Wells, S.; Brandon, M., Aldworth, E.; Viehoff, T.; Allegrino, R.; Crane, D.R.; JGR, 101, No. C8, 18213-18235, 1996. "The development of the Odden ice tongue in the Greenland Sea during winter 1993 from remote sensing and field observations"

[64] Warren, B.A.; J. Mar. Res., 41, 327-347, 1983. "Why is no deep water formed in the North Pacific?"

[65] Warren, B.A.; in Evolution of Physical Oceanography, B.A. Warren and C. Wunsch, eds., The MIT Press, Cambridge, MA, 1981. "Deep Circulation of the World Ocean"

[66] Welander, P.; DAO, 1, 215-223, 1976. "Thermal oscillations in a fluid heated from below and cooled to freezing from above"

[67] Wettlaufer, J.S.; JGR, 96, No. C4, 7215-7236, 1991. "Heat Flux at the Ice-Ocean Interface"

[68] Yin, F.L. and Sarachik, E.S.; JPO, 24, 1425-1430, June 1994. "An Efficient Convective Adjustment Scheme for Ocean General Circulation Models" 
[69] Zhang, S.; Lin, C.A.; Greatbatch, R.J.; JMR, 53, 79-106, 1995. "A decadal oscillation due to the coupling between an ocean circulation model and a thermodynamic sea-ice model"

[70] Zhang, S. et. al.; JPO, 23, 287-299, 1993. "A Reexamination of the Polar Halocline Catastrophe and Implications for Coupled Ocean-Atmosphere Modeling" 